JORGE ALIOMAR TROCOLI ABDON DANTAS

MODELAGEM E VALIDAÇÃO DO ESCOAMENTO LAMINAR NÃO ISOTÉRMICO, REATIVO E DIFUSIVO, APLICADO AO PROCESSAMENTO TÉRMICO CONTÍNUO DE ALIMENTOS LÍQUIDOS EM TROCADORES BITUBULARES 
JORGE ALIOMAR TROCOLI ABDON DANTAS

MODELAGEM E VALIDAÇÃO DO ESCOAMENTO LAMINAR NÃO ISOTÉRMICO, REATIVO E DIFUSIVO, APLICADO AO PROCESSAMENTO TÉRMICO CONTÍNUO DE ALIMENTOS LÍQUIDOS EM TROCADORES BITUBULARES

Dissertação apresentada à Escola Politécnica da Universidade de São Paulo para obtenção do Título de Mestre em Engenharia. 
JORGE ALIOMAR TROCOLI ABDON DANTAS

\section{MODELAGEM E VALIDAÇÃO DO ESCOAMENTO LAMINAR NÃO ISOTÉRMICO, REATIVO E DIFUSIVO, APLICADO AO PROCESSAMENTO TÉRMICO CONTÍNUO DE ALIMENTOS LÍQUIDOS EM TROCADORES BITUBULARES}

Dissertação apresentada à Escola Politécnica da Universidade de São Paulo para obtenção do Título de Mestre em Engenharia.

Área de Concentração:

Engenharia Química

Orientador:

Prof. Dr. Jorge Andrey Wilhelms Gut

São Paulo

2012 
Este exemplar foi revisado e alterado em relação à versão original, sob responsabilidade única do autor e com a anuência de seu orientador.

São Paulo, de agosto de 2012.

Assinatura do autor

Assinatura do orientador

FICHA CATALOGRÁFICA

Dantas, Jorge Aliomar Trocolo Abdon

Modelagem e validação do escoamento laminar não isotérmico, reativo e difusivo, aplicado ao processamento térmico contínuo de alimentos líquidos em trocadores bitubulares / J.A.T.A. Dantas. -- ed.rev. -- São Paulo, 2012.

$167 \mathrm{p}$.

Dissertação (Mestrado) - Escola Politécnica da Universidade de São Paulo. Departamento de Engenharia Química.

1. Processamento de alimentos 2. Alimentos líquidos 3. Trocadores de calor 4 . Transferência de calor 5 . Modelos matemáticos I. Universidade de São Paulo. Escola Politécnica. Departamento de Engenharia Química II. t. 


\section{AGRADECIMENTOS}

A Deus pelos caminhos traçados e por ter me guiado para as melhores decisões.

Aos meus pais Jorge e Teresinha por todo tipo de apoio durante minha vida e pelo amor a mim dedicado.

À Ana Celina pelo companheirismo, dedicação, carinho e apoio durante estes últimos anos.

Ao Prof. Dr. Jorge Andrey Wilhelms Gut pela oportunidade concedida, orientação, conselhos, dedicação, apoio e excelência dos conhecimentos que foram fundamentais para todo o período de pesquisa.

À Profa. Dra. Carmen Cecília Tadini pela excelência dos conhecimentos repassados.

Aos colegas do Laboratório de Engenharia de Alimentos da Escola Politécnica da Universidade de São Paulo, Ana Cristina, Ana Maria, Arlet, Carola, Ewerton, Helena, Lina Maria, Luz, Otilia, Paula, Rafael e Viviane pela troca de conhecimentos e momentos de descontração.

Ao Departamento de Engenharia Química da Escola Politécnica da Universidade de São Paulo pelos excelentes professores.

À CAPES pela concessão da bolsa.

À FAPESP pelo auxílio financeiro (processo 2009/07934-3).

A todos que, direta ou indiretamente, contribuíram para a execução deste trabalho. 


\section{RESUMO}

O processamento térmico de alimentos visa garantir qualidade e inocuidade pela inativação de micro-organismos e enzimas. Geralmente ocorre sobreprocessamento, levando à perda de características nutricionais e sensoriais e à elevação de custos operacionais. Foi desenvolvida a modelagem matemática (modelos térmico, mássico, hidráulico e reativo) de um equipamento bitubular para o processamento térmico contínuo de um alimento líquido homogêneo em regime laminar difusivo, para determinação das distribuições de temperatura e letalidade. No modelo foram incorporados parâmetros para quantificar os efeitos das difusividades térmica e mássica efetivas na direção radial ao escoamento. $O$ modelo contempla três seções: aquecimento; tubo de retenção e resfriamento, em que as seções de aquecimento e resfriamento são trocadores de calor modulares. Foram considerados os seguintes volumes de controle: alimento, tubo interno, fluido de utilidade, tubo externo, isolamento térmico e ar ambiente. Balanços diferenciais de energia e massa foram aplicados para modelar as trocas térmicas e a distribuição de micro-organismos, enzimas ou nutrientes. Condições de contorno foram aplicadas para manter a continuidade entre as seções e módulos. O modelo foi resolvido através do método de diferenças finitas, discretizando as componentes axiais e radiais. No estudo de caso foram feitas simulações para o processamento térmico de suco de amora, quantificando os efeitos dos parâmetros difusivos e das variáveis de processo sobre os atributos de qualidade nutricional (antocianina) e qualidade microbiológica (levedura). $\mathrm{Na}$ validação dos modelos térmico e mássico os efeitos de mistura e difusão na direção radial foram quantificados através do ajuste da condutividade térmica efetiva e número de Peclet modificado. Utilizou-se um pasteurizador em escala laboratorial e os fluidos: mistura glicerina/água $80 \%$ (newtoniano) e solução de CMC 1\% (pseudoplástico) nas vazões de 10 a $50 \mathrm{~L} / \mathrm{h}$. Os resultados indicam que o modelo proposto representou satisfatoriamente as distribuições de temperaturas, letalidade e comportamento experimental com reduzida complexidade computacional.

Palavras-chave: Processamento térmico. Modelagem matemática. Fluido nãonewtoniano. Trocador de calor. Difusão. 


\begin{abstract}
The thermal processing ensures quality and safety by inactivation of micro-organisms and enzymes. Generally, over-processing occurs, resulting in sensorial and nutritional losses and operating costs increase. A mathematical model (thermal, mass, hydraulic and reactive) of a double-pipe pasteurizer has developed for the continuous thermal processing of a liquid food in laminar diffusive regime, to obtain the temperature and lethality distributions. Parameters to quantify the effects of thermal and mass effective diffusivities in the radial direction were incorporated in the model. The model comprises three zones: heating; holding tube and cooling, where the heating and cooling zones are modular double-pipe heat exchangers. The following control volumes were considered: food, inner tube, utility fluid, outer tube, thermal insulation and ambient air. Energy and mass differential balances were used for modeling the heat transfer and the destruction of micro-organisms, enzymes or nutrients. Boundary conditions were applied to maintain the continuity between zones and modules. The finite difference method was used to discretize the model in the axial and radial directions. A simulation study case for blueberry juice thermal processing was made, analyzing the effects of the diffusive parameters and processing variables of the thermal treatment in the nutritional quality (anthocyanin) and microbiological quality (yeasts) attributes. In the validations of the heat and mass models, the mixture and diffusive effects in the radial direction were quantified by adjusting the heat conductivity and the modified Peclet number. A laboratory scale pasteurizer was used with the following fluids: glycerin/water mixture $80 \%$ (newtonian) and CMC 1\% solution (pseudoplastic) in flows rates between 10 and 50 $\mathrm{L} / \mathrm{h}$. The obtained results indicate that the proposed model successfully represented the temperature and lethality distributions and experimental behavior with reduced computational complexity.
\end{abstract}

Keywords: Thermal processing. Mathematical modeling. Non-newtonian fluid. Heat exchanger. Diffusion. 


\section{LISTA DE FIGURAS}

Figura 3.1 - Gráfico de tensão de cisalhamento em função da taxa de cisalhamento para fluidos com diferentes reologias (Fonte: IBARZ; BARBOSACÁNOVAS, 2002)

Figura 4.1 - Pasteurizador bitubular do Laboratório de Engenharia de Alimentos da Universidade de São Paulo. Seção de aquecimento à direita, seção de resfriamento à esquerda e tubo de retenção no centro

Figura 4.2 - Representação esquemática do pasteurizador bitubular utilizado nos experimentos

Figura 4.3 - Tubo de retenção, em destaque, utilizado para os ensaios de DTR.....41

Figura 5.1 - Representação esquemática de um equipamento utilizado no tratamento térmico contínuo de alimentos

Figura 5.2 - Domínios axial e radial de um módulo k do trocador de calor.

Figura 5.3 - Domínios axial e radial do tubo de retenção

Figura 5.4 - Distribuição das temperaturas nos volumes de controle na seção de aquecimento/resfriamento e seus raios de referência

Figura 6.1 - Gráfico do valor de esterilização em função do tempo de simulação para discretizações axiais de 100 pontos (Axial_100), 120 pontos (Axial_120), 150 pontos (Axial_150) e 175 pontos (Axial_175)

Figura 6.2 - Perfis de temperaturas do tratamento térmico contínuo. Temperaturas da polpa de amora no centro do tubo interno (T1( $r=0)$ ); Temperatura da polpa de amora na parede interna do tubo interno (T1(r=R1)); Temperatura da polpa de amora média (T1_media); Temperatura dos fluidos utilidade (T2); Temperatura do isolante térmico (Tiso)....

Figura 6.3 - Perfis de concentração do atributo de qualidade microbiológica no tratamento térmico contínuo. Concentração do atributo no centro do tubo interno $(\mathrm{Ca}(\mathrm{r}=0))$; Concentração do atributo na parede interna do tubo interno (Ca(r=R1)); Concentração média do atributo (Ca_media) .........95

Figura 6.4 - Valor de esterilização do estudo de caso. .96

Figura 6.5 - Perfis do valor de esterilização para as difusividades térmicas efetivas na direção radial de 1 vez (1x), 5 vezes (5x), 10 vezes (10x), 15 vezes (15x) e 20 vezes (20x) maiores que a difusividade térmica para as difusividades mássicas de: a) $10^{-4} \mathrm{~m}^{2} . \mathrm{s}$; b) $10^{-5} \mathrm{~m}^{2} . \mathrm{s}$; c) $10^{-6} \mathrm{~m}^{2} . \mathrm{s}$; d) $10^{-7}$ $\mathrm{m}^{2} . \mathrm{s}$; e) $10^{-8} \mathrm{~m}^{2} . \mathrm{s}$; f) $10^{-9} \mathrm{~m}^{2} . \mathrm{s}$

Figura 6.6 - Perfis do valor de esterilização para as difusividades mássicas efetivas na direção radial de $10^{-4} \mathrm{~m}^{2} . \mathrm{s}(1 \mathrm{e}-4), 10^{-5} \mathrm{~m}^{2} . \mathrm{s}(1 \mathrm{e}-5), 10^{-6} \mathrm{~m}^{2} . \mathrm{s}(1 \mathrm{e}-6)$, $10^{-7} \mathrm{~m}^{2} . \mathrm{s}(1 \mathrm{e}-7), 10^{-8} \mathrm{~m}^{2} . \mathrm{s}(1 \mathrm{e}-8)$ e $10^{-9} \mathrm{~m}^{2} . \mathrm{s}(1 \mathrm{e}-9)$ para as difusividades térmicas efetivas maiores que as difusividades térmicas em: a) 1x; b) $5 x$; c) $10 x$; d) $15 x$; e) $20 x$ .99

Figura 6.7 - Superfície de resposta do atributo de qualidade microbiológica em função da temperatura de entrada da água quente e vazão volumétrica do produto.

Figura 6.8 - Superfície de resposta do atributo de qualidade nutricional em função da temperatura de entrada da água quente e vazão volumétrica do produto 
Figura 6.9 - Temperaturas experimentais e perfis de temperatura simulados para os dois ensaios com vazão de 10 L/h para a mistura glicerina/água $80 \%$ : a) Experimento 1; b) Experimento 6

Figura 6.10 - Temperaturas experimentais e perfis de temperatura simulados para os dois ensaios com vazão de $20 \mathrm{~L} / \mathrm{h}$ para a mistura glicerina/água $80 \%$ : a) Experimento 2; b) Experimento 7.

Figura 6.11 - Temperaturas experimentais e perfis de temperatura simulados para os dois ensaios com vazão de $30 \mathrm{~L} / \mathrm{h}$ para a mistura glicerina/água $80 \%$ : a) Experimento 3; b) Experimento 8.

Figura 6.12 - Temperaturas experimentais e perfis de temperatura simulados para os dois ensaios com vazão de $40 \mathrm{~L} / \mathrm{h}$ para a mistura glicerina/água $80 \%$ : a) Experimento 4; b) Experimento 9.

Figura 6.13 - Temperaturas experimentais e perfis de temperatura simulados para os dois ensaios com vazão de $50 \mathrm{~L} / \mathrm{h}$ para a mistura glicerina/água $80 \%$ : a) Experimento 5; b) Experimento 10

Figura 6.14 - Temperaturas experimentais e perfis de temperatura simulados para os dois ensaios com vazão de $10 \mathrm{~L} / \mathrm{h}$ para a solução de CMC 1\%: a)

Experimento 1 ; b) Experimento 6.

Figura 6.15 - Temperaturas experimentais e perfis de temperatura simulados para os dois ensaios com vazão de $20 \mathrm{~L} / \mathrm{h}$ para a solução de CMC 1\%: a)

Experimento 2; b) Experimento 7.

Figura 6.16 - Temperaturas experimentais e perfis de temperatura simulados para os dois ensaios com vazão de $30 \mathrm{~L} / \mathrm{h}$ para a solução de CMC 1\%: a) Experimento 3; b) Experimento 8.

Figura 6.17 - Temperaturas experimentais e perfis de temperatura simulados para os dois ensaios com vazão de $40 \mathrm{~L} / \mathrm{h}$ para a solução de CMC 1\%: a)

Experimento 4; b) Experimento 9.

Figura 6.18 - Temperaturas experimentais e perfis de temperatura simulados para os dois ensaios com vazão de $50 \mathrm{~L} / \mathrm{h}$ para a solução de CMC 1\%: a) Experimento 5; b) Experimento 10

Figura 6.19 - Curvas adimensionais de DTR obtidas pela simulação do modelo, considerando fluido Newtoniano $(\boldsymbol{n} r$ eo $=1,0)$ e número de Peclet modificado variável: a) Curvas obtidas para baixa difusividades $\left.\left(\log (\boldsymbol{P e r})^{\prime}\right) \geq 0,5\right)$; b) Curvas obtidas para alta difusividade $\left(\log \left(\boldsymbol{P e r}^{\prime}\right) \leq 0,5\right)$

Figura 6.20 - Curvas adimensionais de DTR obtidas pela simulação do modelo, considerando fluido pseudoplástico $($ nreo $=0,4)$ e número de Peclet modificado variável: a) Curvas obtidas para baixa difusividades $\left(\log (\boldsymbol{P e r})^{\prime} \geq 0,5\right)$; b) Curvas obtidas para alta difusividade $(\log (\boldsymbol{P e r}) \leq 0,5)$

Figura 6.21 - Exemplo de comparação entre uma DTR numérica e a DTR experimental de um ensaio

Figura 6.22 - Erros quadráticos obtidos pela comparação entre as DTR numéricas e

a DTR experimental em função do $\log \left(\boldsymbol{P e r}^{\prime}\right)$

Figura 6.23 - Valores de número de Peclet modificado para solução de CMC 1\% ajustados para os ensaios experimentais

Figura 6.24 - Valores de número de Peclet modificado para mistura glicerina/água $80 \%$ ajustados para os ensaios experimentais

Figura 6.25 - Valores da difusividade mássica efetiva da solução de CMC 1\% em função da vazão 
Figura 6.26 - Valores da difusividade mássica efetiva da mistura glicerina/água $80 \%$ em função da vazão

Figura A.0.1 - Casca cilíndrica (Adaptada de Incropera et al. (2008))...................140 


\section{LISTA DE TABELAS}

Tabela 3.1 - Casos especiais da equação constitutiva de Herschel-Buckley ............27

Tabela 4.1 - Parâmetros geométricos do pasteurizado e de suas seções utilizados nos experimentos

Tabela 4.2 - Posições efetivas dos termopares no pasteurizador bitubular utilizado nos experimentos.

Tabela 6.1 - Parâmetros do pasteurizador e de suas seções para o estudo de caso

Tabela 6.2 - Valores das constantes cinéticas de reação e energias de ativação nas temperaturas experimentais (SARKIS et al., 2011) e do parâmetro $\boldsymbol{Z} \boldsymbol{A}$ calculado pela equação (3.14)

Tabela 6.3 - Tempo computacional e valor de esterilização do atributo de qualidade microbiológica em função da quantidade de pontos axiais e radiais .....90

Tabela 6.4 - Propriedades termofísicas do fluido utilidade em cada módulo das seções de aquecimento e resfriamento (Unidades SI)

Tabela 6.5 - Propriedades termofísicas do fluido alimentício em cada módulo das seções de aquecimento, retenção e resfriamento (Unidades SI)

Tabela 6.6 - Efeitos das diferentes difusividades mássicas efetivas e condutividades térmicas efetivas no valor de esterilização do processo para o atributo de qualidade microbiológica.

Tabela 6.7 - Planejamento e os valores de esterilização para os atributos de qualidade microbiológica e qualidade nutricional

Tabela 6.8 - Efeitos lineares, quadráticos e cruzados da temperatura de entrada da água quente e da vazão do produto alimentício na degradação dos atributos de qualidade microbiológica e qualidade nutricional

Tabela 6.9 - Efeitos lineares, quadráticos e cruzados da temperatura de entrada da água quente e da vazão do produto alimentício na degradação dos atributos de qualidade microbiológica e qualidade nutricional, desconsiderando o efeito quadrático para a temperatura de entrada da água quente

Tabela 6.10 - Valores de temperatura de entrada da água quente e vazão do produto alimentício otimizados para valores de esterilização do atributo de qualidade microbiológica de 5 e 12, minimizando o valor de esterilização do atributo de qualidade nutricional

Tabela 6.11 - Temperaturas e vazões experimentais da mistura glicerina/água $80 \%$ utilizadas na validação do modelo térmico.

Tabela 6.12 - Temperaturas e vazões experimentais da solução de CMC 1\% utilizadas na validação do modelo térmico.

Tabela 6.13 - Valores das temperaturas experimentais para a mistura glicerina/água $80 \%$.

Tabela 6.14 - Valores das temperaturas experimentais para a solução de CMC 1\%

Tabela 6.15 - Parâmetros do pasteurizador e de suas seções 108

Tabela 6.16 - Condutividade térmica do isolante e fator de aumento da condutividade térmica efetiva radial do produto para os experimentos com a mistura glicerina/água $80 \%$ 
Tabela 6.17 - Condutividade térmica do isolante e fator de aumento da condutividade térmica efetiva radial do produto para os experimentos com solução de

CMC 1\%

Tabela 6.18 - Valores das Funções Objetivo para os perfis de temperaturas simulados obtidos através do ajuste do fator de aumento da condutividade térmica da mistura glicerina/água $80 \%$ e solução de CMC $1 \%$

Tabela 6.19 - Efeitos da temperatura de entrada da água quente e da vazão do produto no fator de aumento da condutividade térmica efetiva do produto 124

Tabela 6.20 - Valores do número de Peclet modificado para a mistura glicerina/água $80 \%$ e solução de CMC $1 \%$ nas vazões de estudo 129 


\section{LISTA DE ABREVIATURAS E SIGLAS}

$\begin{array}{ll}\text { ANOVA } & \text { Análise de Variância } \\ \text { BFDM } & \text { Backward Finite Differences Method } \\ \text { CFD } & \text { Computational Fluid Dynamics } \\ \text { CFDM } & \text { Centered Finite Difference Method } \\ \text { CMC } & \text { Carboximetilcelulose } \\ \text { CSTR } & \text { Continuous Stirred Tank Reactor } \\ \text { DTR } & \text { Distribuição do tempo de residência } \\ \text { EUA } & \text { Estados Unidos da América } \\ \text { FDA } & \text { United States Food and Drug Administration } \\ \text { FFDM } & \text { Forward Finite Differences Method } \\ \text { HTST } & \text { High Temperature Short Time } \\ \text { PFR } & \text { Plug Flow Reactor } \\ \text { UFC } & \text { Unidades Formadoras de Colônia } \\ \text { UHT } & \text { Ultra High Temperature }\end{array}$




\section{LISTA DE SÍMBOLOS}

$\% m_{\text {glic }} \quad$ Fração mássica de glicerina pura (kg de glicerina/kg de mistura).

A

Posição axial de entrada de um módulo que compõe uma seção $(\mathrm{m})$.

$A_{1}$ Área da seção perpendicular à direção axial do escoamento do fluido alimentício $\left(\mathrm{m}^{2}\right)$.

$A_{2} \quad$ Área da seção perpendicular à direção axial do escoamento do fluido utilidade $\left(\mathrm{m}^{2}\right)$.

$A_{4} \quad$ Área da parede interna do tubo externo $\left(\mathrm{m}^{2}\right)$.

$A_{5} \quad$ Área da parede externa do tubo externo $\left(\mathrm{m}^{2}\right)$.

$A_{6}$

$A_{7}$

Área da parede interna de isolamento térmico $\left(\mathrm{m}^{2}\right)$.

$A_{\text {ext-ti }}$

Área da parede externa de isolamento térmico $\left(\mathrm{m}^{2}\right)$.

$A_{\text {int-te }}$

Área da parede externa do tubo interno $\left(\mathrm{m}^{2}\right)$.

$B$

Área da parede interna do tubo externo $\left(\mathrm{m}^{2}\right)$.

$C^{\prime}$

Posição axial de saída de um módulo que compõe uma seção (m).

Concentração adimensional do traçador (adimensional).

$C_{A}$ Concentração volumétrica do atributo genérico "A" (UFC. $\mathrm{m}^{-3}$ ou kg. $\mathrm{m}^{-3}$ ).

$\overline{C_{A}}$ Concentração volumétrica média de mistura do atributo genérico " $A$ " (UFC. $\mathrm{m}^{-3}$ ou kg.m ${ }^{-3}$ ).

$C_{A 0}$

Concentração volumétrica do atributo genérico " $A$ " na entrada do pasteurizador (UFC. $\mathrm{m}^{-3}$ ou $\mathrm{kg} \cdot \mathrm{m}^{-3}$ ).

$C_{p} \quad$ Calor específico $\left(\mathrm{J} . \mathrm{kg}^{-1} \cdot \mathrm{K}^{-1}\right)$.

$C_{S S} \quad$ Concentração de sólidos totais ('Brix).

$C_{t} \quad$ Concentração volumétrica do traçador $\left(\mathrm{kg} \cdot \mathrm{m}^{-3}\right)$.

$C_{t i} \quad$ Concentração do traçador na alimentação $\left(\mathrm{kg} \cdot \mathrm{m}^{-3}\right)$.

D Diâmetro (m).

$D_{A} \quad$ Difusividade mássica do atributo genérico " $\mathrm{A}$ " $\left(\mathrm{m}^{2} \cdot \mathrm{s}^{-1}\right)$.

$D_{\text {dec } A} \quad$ Tempo de decaimento decimal do atributo genérico " $A$ " (s).

$D_{\text {mass_ef } A} \quad$ Difusividade mássica efetiva radial do atributo genérico " $\mathrm{A}$ " $\left(\mathrm{m}^{2} \cdot \mathrm{s}^{-1}\right)$.

$D_{\text {refa }} \quad$ Tempo de decaimento decimal do atributo genérico "A" na temperatura de referência $T_{\text {refa }}(\mathrm{s})$.

$D_{t} \quad$ Difusividade mássica do traçador $\left(\mathrm{m}^{2} \cdot \mathrm{s}^{-1}\right)$. 


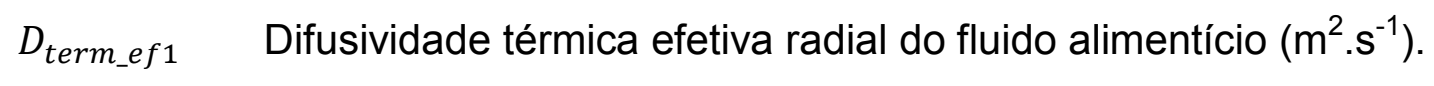

$e \quad$ Espessura $(\mathrm{m})$.

$E(t) \quad$ Função de distribuição do tempo de residência $\left(\mathrm{s}^{-1}\right)$.

$E_{\Phi}(\Phi) \quad$ Função de distribuição do tempo de residência adimensionalizada (adimensional).

$E_{a A} \quad$ Energia de ativação do atributo genérico "A" $\left(\mathrm{J} \cdot \mathrm{mol}^{-1}\right)$.

$F(t) \quad$ Função de distribuição cumulativa do tempo de residência (adimensional).

Fincr $1 \quad$ Fator de aumento da condutividade térmica do fluido alimentício na direção radial (adimensional).

Fincr 2 Fator de aumento da condutividade térmica do fluido utilidade na direção axial (adimensional).

$h \quad$ Coeficiente convectivo $\left(\mathrm{W} \cdot \mathrm{m}^{-2} \cdot \mathrm{K}^{-1}\right)$.

$h_{e f} \quad$ Coeficiente convectivo efetivo do ar ambiente sobre o tubo externo $\left(\mathrm{W} \cdot \mathrm{m}^{-2} \cdot \mathrm{K}^{-1}\right)$.

$i \quad$ Contador (adimensional).

$j \quad$ Contador (adimensional).

$k \quad$ Condutividade térmica $\left(\mathrm{W} \cdot \mathrm{m}^{-1} \cdot \mathrm{K}^{-1}\right)$.

$k_{e f 1} \quad$ Condutividade térmica radial efetiva do fluido alimentício $\left(\mathrm{W} \cdot \mathrm{m}^{-1} \cdot \mathrm{K}^{-1}\right)$.

$k_{e f 2} \quad$ Condutividade térmica axial efetiva do fluido utilidade $\left(\mathrm{W} \cdot \mathrm{m}^{-1} \cdot \mathrm{K}^{-1}\right)$.

$k_{r} \quad$ Constante cinética de destruição térmica para uma reação de $1^{\mathrm{a}}$ ordem $\left(s^{-1}\right)$.

$K_{\text {reo }} \quad$ Índice de consistência $\left(P a . s^{\text {nreo }}\right)$.

$L \quad$ Comprimento do tubo $(\mathrm{m})$.

$L_{I} \quad$ Comprimento efetivo de um módulo que compõe a seção de aquecimento $(m)$.

$L_{I I} \quad$ Comprimento do tubo de retenção $(\mathrm{m})$.

$L_{I I I} \quad$ Comprimento efetivo de um módulo que compõe a seção de resfriamento $(m)$.

$n \quad$ Número de módulos que compõe determinada seção (adimensional).

$n_{\text {reo }} \quad$ Índice de comportamento (adimensional).

$\mathrm{Nu} \quad$ Número de Nusselt (adimensional).

$P_{\text {mol }} \quad$ Perímetro molhado do ânulo (m). 


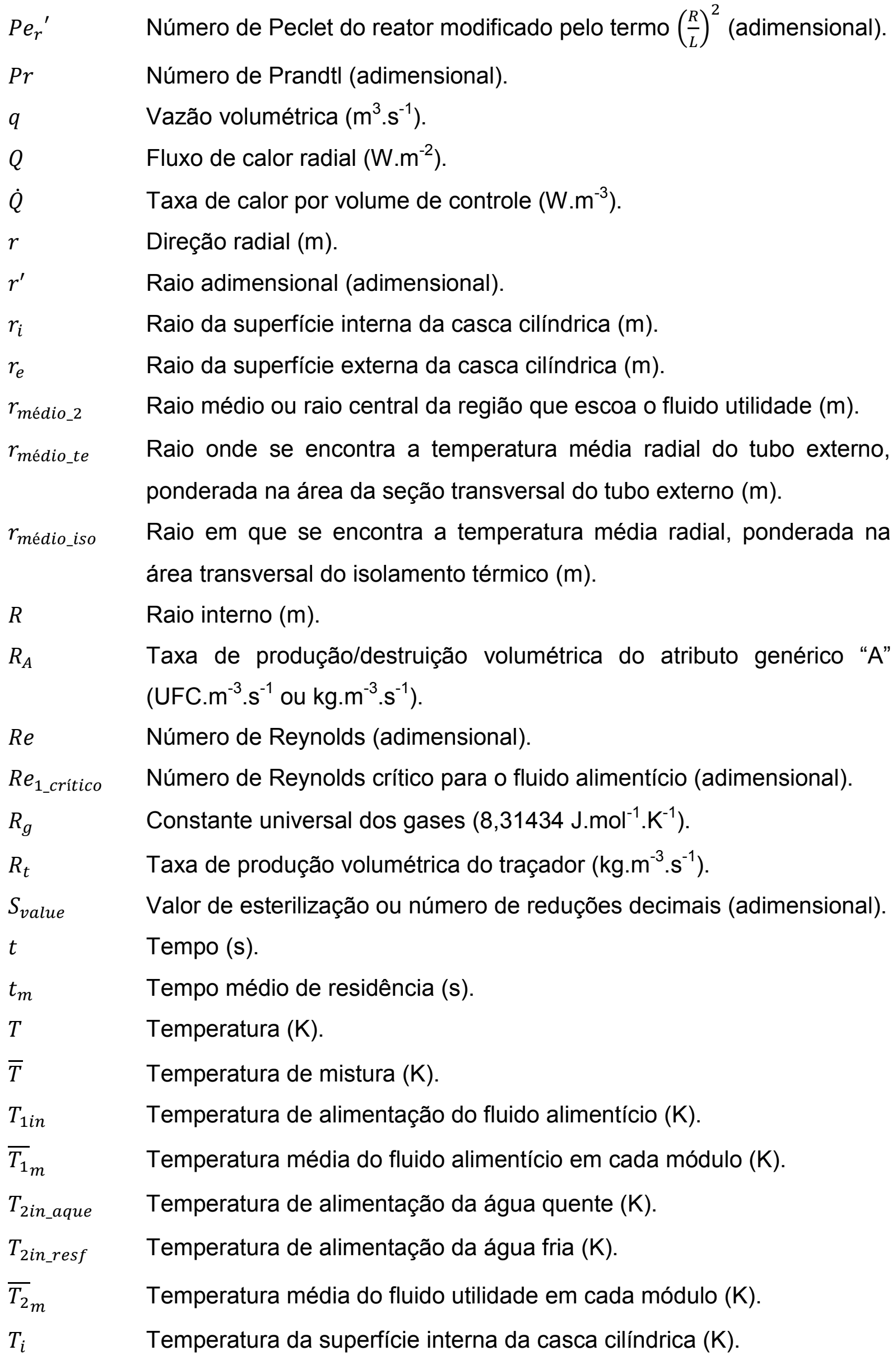


$T_{e} \quad$ Temperatura da superfície externa da casca cilíndrica (K).

$\overline{T_{l s o}} \quad$ Temperatura média radial do isolamento térmico, ponderada na área da seção transversal do isolamento térmico $(K)$.

$T_{\text {refA }} \quad$ Temperatura de referência para $D_{\text {refA }}(\mathrm{K})$.

$\overline{T_{t e}}$ Temperatura média radial do tubo externo, ponderada na área da seção transversal $(K)$.

$U \quad$ Coeficiente de troca térmica $\left(\mathrm{W} \cdot \mathrm{m}^{-2} \cdot \mathrm{K}^{-1}\right)$.

$\vec{v} \quad$ Vetor velocidade $\left(\mathrm{m} . \mathrm{s}^{-1}\right)$.

$v_{\theta} \quad$ Velocidade na direção angular $\left(\operatorname{rad} . \mathrm{s}^{-1}\right)$.

$v_{r} \quad$ Velocidade na direção radial $\left(\mathrm{m} . \mathrm{s}^{-1}\right)$.

$v_{z} \quad$ Velocidade na direção axial $\left(\mathrm{m} \mathrm{s}^{-1}\right)$.

$\overline{v_{z}} \quad$ Velocidade axial média ou "bulk" $\left(\mathrm{m} \cdot \mathrm{s}^{-1}\right)$.

$V \quad$ Volume $\left(\mathrm{m}^{3}\right)$.

$x_{\text {des }} \quad$ Comprimento necessário para desenvolvimento da camada limite hidrodinâmica $(m)$.

$z \quad$ Direção axial $(\mathrm{m})$.

$z^{\prime} \quad$ Comprimento adimensional (adimensional).

$Z_{A} \quad$ Variação de temperatura necessária para promover uma variação de 10 vezes no valor de $D_{d e c A}(\mathrm{~K})$. 


\section{LETRAS GREGAS}

$\begin{array}{ll}\dot{\gamma} & \text { Taxa de cisalhamento }\left(\mathrm{s}^{-1}\right) . \\ \theta & \text { Direção angular (radiano). } \\ \Phi & \text { Tempo adimensional (adimensional). } \\ \mu & \text { Viscosidade dinâmica ou absoluta }\left(\mathrm{m}^{2} \cdot \mathrm{s}^{-1}\right) . \\ \pi & \text { Constante pi ( } \pi=3,1416) . \\ \rho & \text { Massa específica média }\left(\mathrm{kg} \cdot \mathrm{m}^{-3}\right) . \\ \tau & \text { Tensão de cisalhamento }\left(\mathrm{N} \cdot \mathrm{m}^{-2}\right) . \\ \tau_{\mathrm{m}} & \text { Tempo espacial (s). } \\ \overrightarrow{\varphi_{\theta}} & \text { Vetor unitário na direção angular (adimensional). } \\ \overrightarrow{\varphi_{\mathrm{r}}} & \text { Vetor unitário na direção radial (adimensional). } \\ \overrightarrow{\varphi_{\mathrm{z}}} & \text { Vetor unitário na direção axial (adimensional). }\end{array}$




\section{SUBSCRITOS}

1

2

$2-$ te

$2-\mathrm{ti}$

$\mathrm{amb}$

aque

ar

glic

$\mathrm{h}$

iso

iso - sup

Fluido alimentício.

Fluido utilidade (água quente/fria).

Do centro do fluido utilidade para o raio médio do tubo externo.

Do centro do fluido utilidade para a parede externa do tubo interno.

Ambiente.

Seção de aquecimento.

Ar ambiente.

Glicerina pura.

Hidráulico.

Isolamento térmico.

Da posição radial média do isolamento térmico para a superfície externa do isolamento térmico.

QM Qualidade microbiológica.

QN Qualidade nutricional.

resf Seção de resfriamento.

ret Tubo de retenção.

sup Superfície.

sup - amb Da superfície do equipamento para ambiente.

t Traçador.

te Tubo externo.

te -2 Da posição radial média do tubo externo para o centro do fluido utilidade.

te - sup Da posição radial média do tubo externo para a superfície externa do tubo externo.

ti Tubo interno.

ti - iso Da superfície externa do tubo interno para o raio médio do isolamento térmico.

W

Água pura. 


\section{SUMÁRIO}

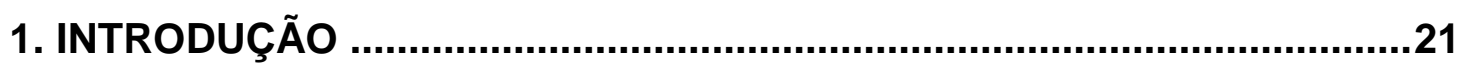

2. OBJETIVOS

3. REVISÃO BIBLIOGRÁFICA

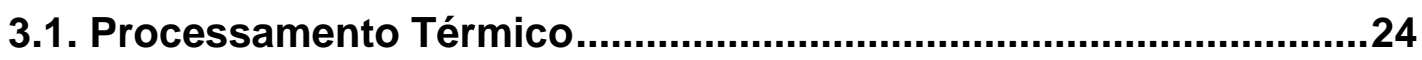

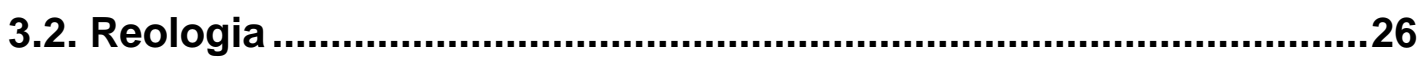

3.3. Distribuição do tempo de residência (DTR) ...................................28

3.4. Cinética de destruição térmica ..........................................................31

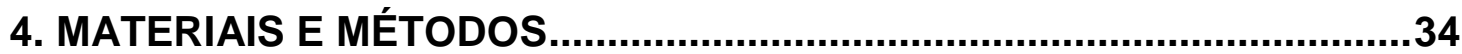

4.1. Validação do modelo térmico.........................................................35

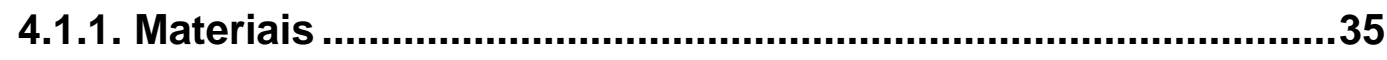

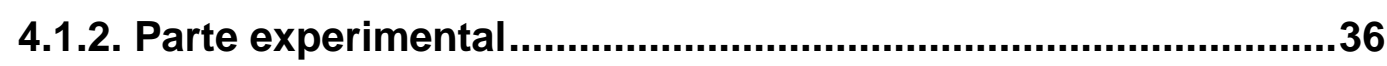

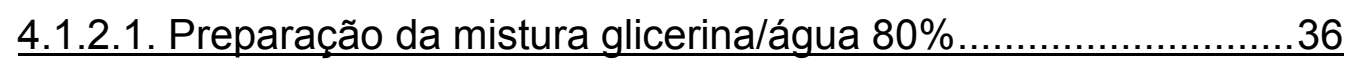

4.1.2.2. Preparação da solução de CMC 1\% ……….........................36

4.1.2.3. Experimentos …….......................................................

4.1.3. Ajuste do parâmetro do modelo térmico ...................................39

4.2. Validação do modelo mássico ..........................................................40

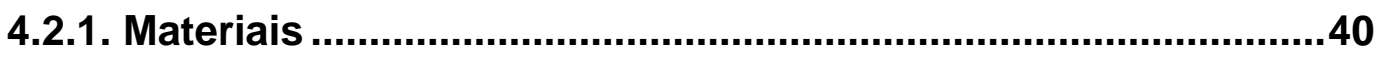

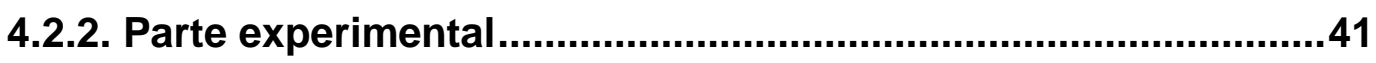

4.2.2.1. Preparação da mistura glicerina/água $80 \%$............................41

4.2.2.2. Preparação da solução de CMC 1\% ....................................41

4.2.2.3. Experimentos ……........................................................... 41

4.2.3. Ajuste do parâmetro do modelo mássico .................................42

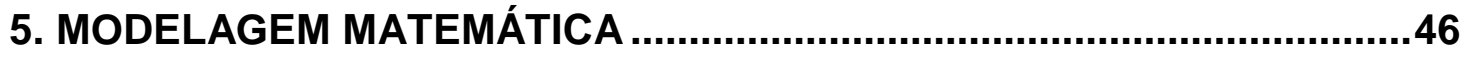

5.1. Modelagem dos módulos de aquecimento/resfriamento ...............48

5.1.1. Fluido escoando no tubo interno ...........................................49

5.1.1.1. Modelagem de escoamento ...............................................49

5.1.1.2. Balanço de energia ..........................................................51

5.1.1.3. Conservação de atributos de qualidade microbiológica ou

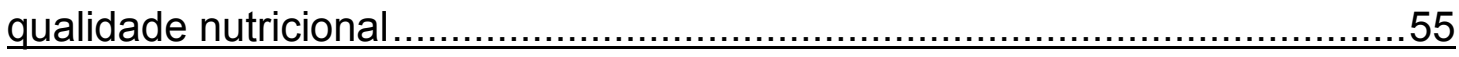

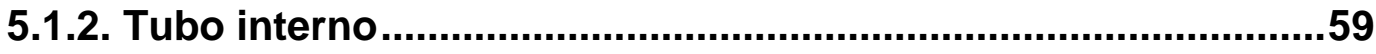


5.1.2.1. Balanço de energia ….....................................................59

5.1.3. Fluido utilidade escoando na região anular ............................63

5.1.3.1. Balanço de energia ............................................................ 63

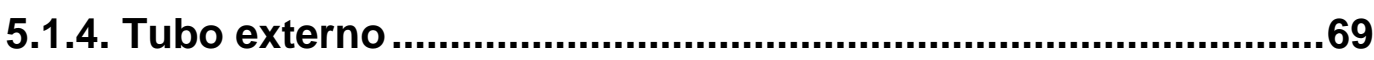

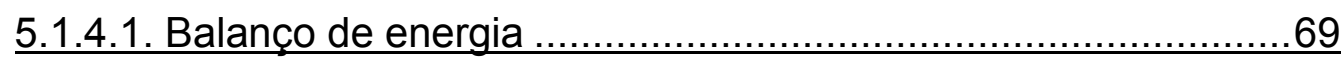

5.1.4.2. Determinação do raio em que se encontra a temperatura média radial do tubo externo (rmédio te) ..........................................................74

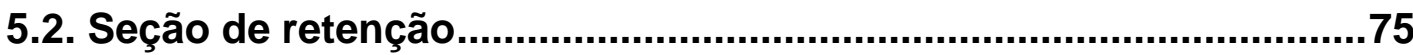

5.2.1. Fluido escoando dentro do tubo interno .................................76

5.2.1.1. Balanço de energia ............................................................ 76

5.2.1.2. Conservação de atributos de qualidade microbiológica ou

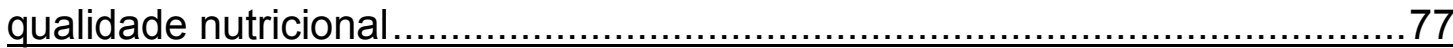

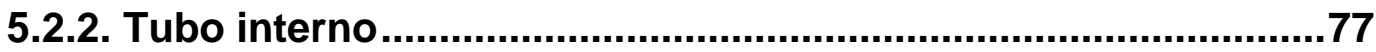

5.2.2.1. Balanço de energia …................................................... 77

5.2.3. Isolamento térmico .................................................................

5.2.3.1. Balanço de energia …………............................................. 79

5.3. Distribuição de temperaturas nos trocadores ................................. 81

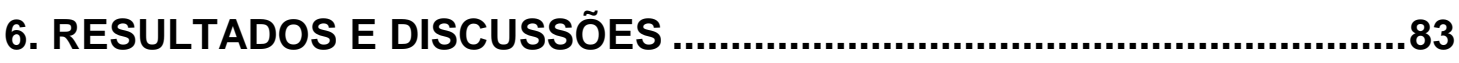

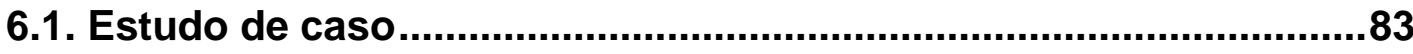

6.1.1. Estudo 1: Sensibilidade do modelo ao número de pontos de discretização

6.1.2. Estudo 2: Efeitos das difusividades efetivas térmica e mássica .96

6.1.3. Estudo 3: Influência da temperatura de entrada da água quente e da vazão do produto no valor de esterilização.........................................100

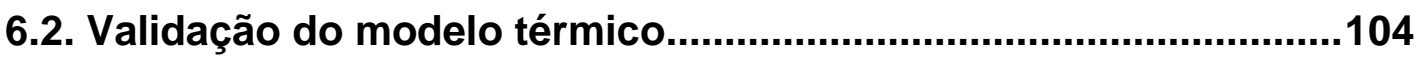

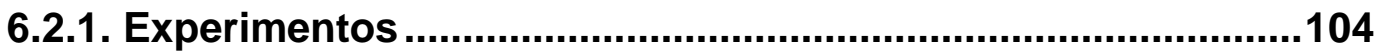

6.2.2. Ajuste do parâmetro do modelo térmico .................................107

6.3. Validação do modelo mássico .....................................................125

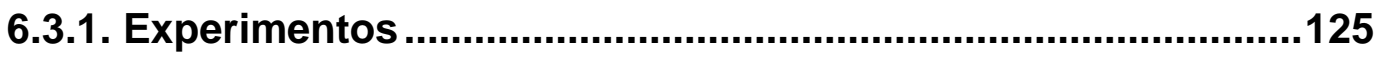

6.3.2. Ajuste do parâmetro do modelo mássico ...............................125

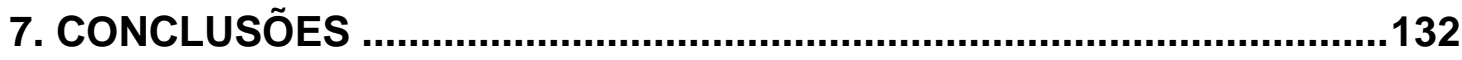

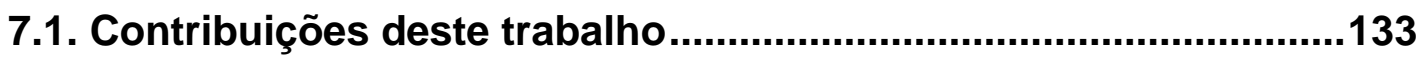

7.2. Perspectivas para trabalhos futuros ............................................134 
8. REFERÊNCIAS BIBLIOGRÁFICAS .135 APÊNDICE A - PERFIL DE TEMPERATURA EM UMA CASCA CILÍNDRICA

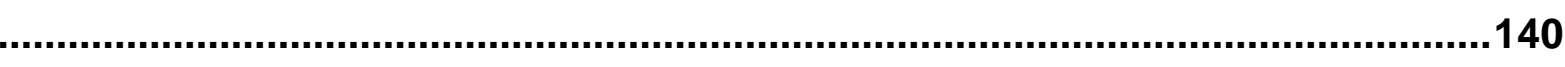
APÊNDICE B - ARQUIVO FONTE DO GPROMS...................................142 


\section{INTRODUÇÃO}

Uma das grandes tendências para os próximos anos é a necessidade de maior oferta de alimentos para consumo. É cada vez mais sabido que a população busca alimentos com melhores qualidades, principalmente as nutricionais. Ao longo dos anos, a indústria de alimentos vem tentando se adequar às necessidades e padrões de qualidade impostos pelos consumidores, melhorando seus processos, projetos e estudos em diversas áreas.

Dentre os principais processos na indústria de alimentos tem-se o processamento ou tratamento térmico, cujo principal objetivo é a destruição de micro-organismos patogênicos, deterioradores e enzimas, pela ação da alta temperatura, garantindo sua inocuidade alimentar e aumentando sua vida de prateleira. Neste tratamento, o produto é submetido a um aquecimento até que se alcance a temperatura de tratamento térmico, seguido de um tempo necessário para garantir o nível de esterilização (retenção), e posteriormente resfriamento para cessar todo tipo de reação térmica. No entanto, durante todo o tratamento térmico existe uma perda indesejável de qualidade do produto, tanto nutricional (como degradação de vitaminas) quanto sensorial (mudanças de características como cor, aroma, sabor, textura). Criado o binômio: qualidade versus segurança tem-se um problema de otimização que consiste em tornar o alimento mais inócuo e duradouro com as características mais próximas de sua origem natural.

O tratamento térmico contínuo é um dos tipos de processamento térmico, que é geralmente conduzido em trocadores de calor e aplicados a líquidos como leite, suco de frutas e alimentos pastosos (GUT e PINTO, 2005). Dos quais, os trocadores de calor a placas são utilizados para líquidos com baixa viscosidade aparente, enquanto os trocadores tubulares ou de superfície raspadas são aplicáveis para os que possuem alta viscosidade aparente.

No tratamento térmico contínuo, de modo geral, ocorre sobreprocesso do produto devido ao super-dimensionamento do processo, este devido à adoção de hipóteses que simplificam a modelagem do problema como: 1) Efeitos da esterilização no aquecimento e resfriamento desprezados, considerando somente a destruição térmica na etapa de retenção; 2) Velocidade do escoamento considerada como sendo a velocidade máxima do produto; 3) Sem perdas de calor para o 
ambiente. Estas hipóteses conservadoras simplificam muito o dimensionamento e garantem a inocuidade alimentar, porém acarretam em custos energéticos e operacionais adicionais e perdas nutricionais e sensoriais, pois o produto é mantido por um tempo maior que o necessário em alta temperatura.

Segundo Grijspeerdt, Hazarika, e Vucinic (2003) uma modelagem rigorosa do processo é necessária para eu se possa simular e otimizar o tratamento térmico que ocorre no pasteurizador, visando determinar condições ótimas de operação, para minimizar os efeitos indesejáveis do aquecimento, garantir a qualidade microbiológica do alimento e reduzir os custos operacionais. Para a correta modelagem, são fundamentais modelos térmico e hidráulico do equipamento, dados confiáveis de cinética de inativação térmica e de propriedades termofísicas, além de propriedades reológicas e estudos de determinação da distribuição do tempo de residência (DTR).

Tendo em vista o cenário acima, o presente trabalho visa desenvolver e validar um modelo matemático, baseado em reatores químicos, para simular o processamento térmico contínuo de alimentos líquidos viscosos em escoamento laminar não isotérmico, reativo e difusivo, em trocadores bitubulares. A modelagem envolve equações diferenciais dos modelos térmico e mássico, equações algébricas para o modelo hidráulico, considerações como: 1) perfil de velocidade laminar; 2) contribuição das seções de aquecimento, retenção e resfriamento para a inativação/destruição do atributo de qualidade microbiológica ou qualidade nutricional; 3) difusões mássica e térmica efetivas na direção radial decorrente de acessórios e imperfeições da tubulação, tubos corrugados e variações de densidades; 4) dependência das propriedades reológicas e termofísicas com a temperatura. Tendo como principais resultados a diminuição do sobreprocessamento do tratamento térmico e, a acentuação da qualidade do alimento.

O presente trabalho, no entanto, não tem como objetivo desenvolver um modelo baseado totalmente em CFD (Computational Fluid Dynamics), que requer uma grande complexidade e sofisticação de informações (equipamentos, domínios, formulação e computacional). A menor complexidade do modelo desenvolvido possibilita um pequeno tempo computacional na resolução das equações e consequentemente a possibilidade de otimização do modelo. 


\section{OBJETIVOS}

Os objetivos do presente trabalho são:

a) Desenvolver a modelagem matemática (modelos térmico, mássico, hidráulico e reativo) de um pasteurizador bitubular, incorporando a cinética de destruição térmica, para processamento térmico contínuo não isotérmico em regime laminar, determinando as distribuições de temperatura, de concentração e de letalidade.

b) Estudar os efeitos das difusividades efetivas térmica e mássica na direção radial, no processamento térmico contínuo de alimentos, em pasteurizador bitubular.

c) Validar experimentalmente o modelo térmico e mássico, ajustando o modelo matemático, para que se possa reproduzir o comportamento real do processo.

d) Determinar as condições ideais para processamento térmico e de escoamento, encontrando o melhor ponto de operação do sistema. 


\section{REVISÃO BIBLIOGRÁFICA}

\subsection{Processamento Térmico}

O tratamento térmico de alimentos é uma das técnicas mais utilizadas no processamento de alimentos. Essa técnica consiste na aplicação de calor ao alimento, objetivando a inativação ou destruição de micro-organismos patogênicos e deterioradores, além de enzimas dando ao alimento a inocuidade adequada e aumentando sua vida de prateleira. $O$ efeito preservativo do processamento com calor é devido à desnaturação de proteínas que atuam na atividade enzimática e metabólica dos micro-organismos (FELLOWS, 2000).

O processo de tratamento térmico ocorre em três etapas: 1) aquecimento do produto até a temperatura de interesse; 2) retenção do produto em um tempo determinado para atingir o grau de inativação desejado; 3) resfriamento até a temperatura de envase.

Um importante problema do tratamento térmico em alimentos é o viés nutricional (destruição de vitaminas e proteínas) e sensorial (mudança no sabor, cor e textura). Diferentemente do que ocorre em processos ideais, em processos reais o alimento passa normalmente um tempo de tratamento maior que o necessário, no intuito de garantir uma maior segurança ao alimento. Como uma das consequências disto, tem-se o aumentando das perdas nutricional e sensorial. Estas perdas indesejáveis de qualidade nutricional do produto estão ligadas ao dimensionamento conservativo dos equipamentos de troca térmica devido à adoção de hipóteses que simplificam a modelagem do problema.

Dentre as hipóteses que são utilizadas usualmente no projeto $\mathrm{e}$ processamento contínuo de alimentos, Jung e Fryer (1999) citam: i) escoamento laminar completamente desenvolvido; ii) velocidade máxima duas vezes maior que a velocidade média (fluido newtoniano); iii) comprimento do tubo de retenção suficientemente longo para garantir toda a letalidade do processo; iv) aquecimento e resfriamento instantâneos, ou seja, a destruição dos micro-organismos só ocorre na retenção. Os autores também expõem que tais hipóteses garantem a inocuidade 
alimentar, no entanto, tornam o produto pobre em qualidade e com um processo mais custoso. Em seu trabalho, Ditchfield (2004) dimensionou um pasteurizador bitubular com as hipóteses descritas acima, para estudar a pasteurização contínua do purê de banana objetivando encontrar as melhores condições de tempo e temperatura que aumentassem a qualidade nutricional do produto (cor e sabor). Mais tarde, Pegoraro (2012) estudou, neste pasteurizador, a letalidade do processo caso fosse processado um fluido com comportamentos semelhantes aos da mistura glicerina/água $80 \%$ (em massa de glicerina) e solução de CMC $1 \%$ (carboximetilcelulose). A autora verificou que para o trocador em estudo tem-se uma letalidade de 8 a 16 vezes maior que a letalidade ideal para a solução de CMC 1\%, e de 13 a 31 vezes maior para a mistura glicerina/água $80 \%$. Ou seja, o tempo que os fluidos passam no trocador de calor seriam de 8 a 31 vezes maior que os tempos de processamento ideais.

Segundo Grijspeerdt et al. (2003) uma modelagem rigorosa do processo é necessária para que se possa simular e otimizar o tratamento térmico que ocorre no pasteurizador, visando determinar condições ótimas de operação, para minimizar os efeitos indesejáveis do aquecimento, garantir a qualidade microbiológica do alimento e reduzir os custos operacionais.

Em sua revisão, Ramaswamy, Awuah e Economides (2007) discutiram os efeitos do processamento térmico na qualidade dos alimentos processados, discutindo a importância de parâmetros do tratamento térmico, técnicas de tratamento térmico como o HTST (High Temperature Short Time) e UHT (Ultra High Temperature) e algumas abordagens de projeto e otimização da qualidade.

Para a correta modelagem, são fundamentais modelos térmico e hidráulico do equipamento, dados confiáveis de cinética de inativação térmica e de propriedades termofísicas. Welti-Chanes, Vergara-Balderas e Bermúdez-Aguirre (2005) revisam conceitos fundamentais de fenômenos de transporte (equações de conservação de massa, energia e quantidade de movimento), propriedades reológicas e técnicas numéricas aplicadas em alimentos, associados a uma extensa revisão bibliográfica.

Já Kiziltas, Erdogdu e Palazoglu (2010) estudaram a transferência de calor em alimentos sólido-líquido enlatados, fazendo a modelagem e validando seu modelo nas condições de pasteurização. Os autores consideraram a transferência de calor nas direções axial e radial por condução e convecção simultaneamente. Foi 
utilizada a técnica de CFD para determinar a distribuição de temperatura do alimento.

Jung e Fryer (1999) simularam a esterilização de alimentos líquidos nãonewtonianos em trocadores de calor bitubulares modelando o perfil de velocidade no tubo interno. Em seus resultados, eles observaram que, devido à grande parte da inativação térmica ocorrer fora do tubo de retenção, ocorre uma significativa perda de qualidade nutricional do alimento devido ao sobreprocessamento.

\subsection{Reologia}

Reologia é o estudo da deformação e fluxo da matéria. Entende-se por deformação as modificações sofridas por materiais sólidos, e fluxo de matéria as deformações sofridas por fluidos através da imposição de uma tensão. Em geral, os alimentos são classificados como viscoelásticos, ou seja, possuem um comportamento intermediário entre sólidos (elásticos) e líquidos (inelásticos).

Dentre os materiais inelásticos, pode-se dividir em newtonianos (ideais) e não-newtonianos, e estes como dependentes e independentes do tempo de cisalhamento (STEFFE, 1996; IBARZ; BARBOSA-CÁNOVAS, 2002).

Os alimentos com comportamento newtoniano são caracterizados por uma relação diretamente proporcional entre a tensão e a taxa de cisalhamento, consequentemente, possuindo viscosidade constante para uma dada temperatura. $A$ equação constitutiva destes fluidos é (STEFFE, 1996):

$$
\tau=\mu \cdot \dot{\gamma}
$$

em que $\tau$ é a tensão de cisalhamento $\left(\mathrm{N} \cdot \mathrm{m}^{-2}\right), \mu$ é a viscosidade dinâmica ou absoluta (Pa.s) e $\dot{\gamma}$ é a taxa de cisalhamento $\left(\mathrm{s}^{-1}\right)$.

Já para os fluidos não-newtonianos, as tensões e as taxas não são linearmente relacionadas, ocorrendo ou não a presença de uma tensão residual, que é definida como a mínima tensão requerida para se iniciar o escoamento do fluido. Os materiais de comportamento não-newtoniano podem ser classificados como pseudoplásticos (diminuição da viscosidade aparente com aumento da tensão de cisalhamento) ou dilatantes (aumento da viscosidade aparente com aumento da 
tensão de cisalhamento). A equação constitutiva dos fluidos não-newtonianos é representada pela equação de Herschel-Buckley (STEFFE, 1996):

$$
\tau=K_{\text {reo }} \cdot \dot{\gamma}^{n_{\text {reo }}}+\tau_{0}
$$

em que $\tau_{0}$ é a tensão de cisalhamento residual $\left(\mathrm{N} \cdot \mathrm{m}^{-2}\right), K_{\text {reo }}$ é o índice de consistência ( $\mathrm{Pa} . \mathrm{s}^{n_{\text {roo }}}$ ) e $n_{\text {reo }}$ é o índice de comportamento (adimensional).

A equação (3.2) descreve bem o comportamento da maioria dos fluidos alimentícios (STEFFE, 1996; GUERRERO; ALZAMORA, 1998; IBARZ; BARBOSACÁNOVAS, 2002).

Segundo Ibarz e Barbosa-Cánovas (2002) e Steffe (1996), uma tensão abaixo a tensão de tensão residual o fluido apresenta características de um sólido, fazendo com que este efeito seja importante no projeto e controle de qualidade no processamento de iogurte, requeijão e margarina.

A Tabela 3.1 e a Figura 3.1 mostram alguns casos especiais da equação de Herschel-Buckley e o comportamento gráfico da tensão de cisalhamento com a variação da taxa de cisalhamento.

Tabela 3.1 - Casos especiais da equação constitutiva de Herschel-Buckley

\begin{tabular}{cccc}
\hline Modelo & $\boldsymbol{K}_{\text {reo }}$ & $\boldsymbol{n}_{\text {reo }}$ & $\boldsymbol{\tau}_{\mathbf{0}}$ \\
\hline Lei de Potência & $>0$ & $\neq 1$ & $=0$ \\
Fluido de Bingham & $>0$ & $=1$ & $\neq 0$ \\
Fluidos dilatantes & $>0$ & $>1$ & $=0$ \\
Fluidos pseudoplásticos & $>0$ & $<1$ & $=0$ \\
\hline
\end{tabular}

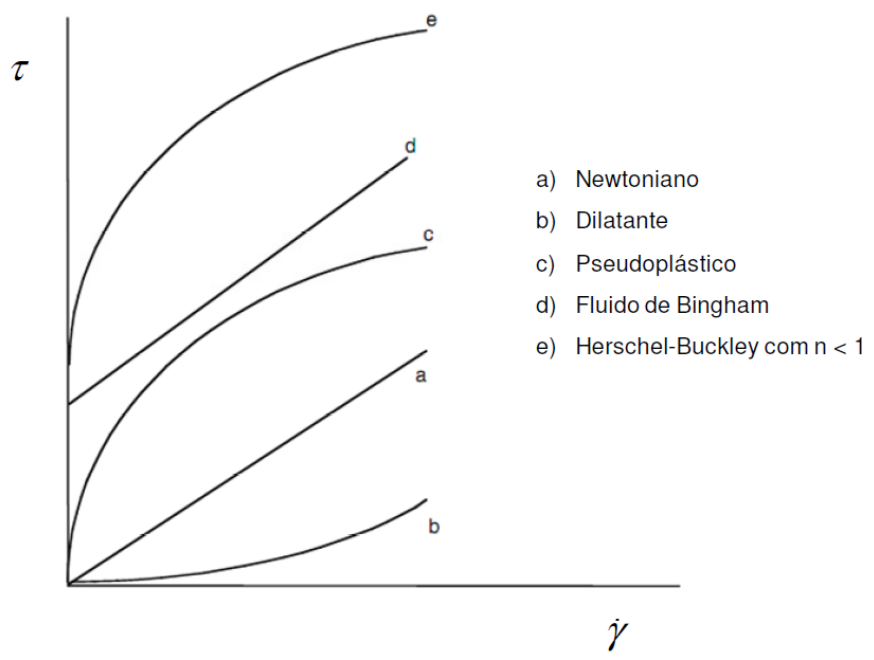

Figura 3.1 - Gráfico de tensão de cisalhamento em função da taxa de cisalhamento para fluidos com diferentes reologias (Fonte: IBARZ; BARBOSA-CÁNOVAS, 2002) 
Ditchfield (2004) utilizou o modelo de Herschel-Buckley para representar a reologia do purê de banana em seus estudos sobre processamento térmico. Já Berto et al. (2003) estudaram as propriedades reológicas de solução aquosa de 65\% de açúcar e $0,1 \%$ de CMC em diferentes temperaturas, chegando à conclusão que o melhor modelo que representa a solução é de Lei de Potência. Gratão, Silveira Jr. e Telis-Romero (2007) determinaram as propriedades reológicas do suco de graviola, considerado como fluido pseudoplástico.

Gratão, Silveira Jr. e Telis-Romero (2006) estudaram escoamento forçado de fluidos com comportamento pseudoplástico em ânulos e tubos circulares, obtendo os coeficientes convectivos e números de Nusselt para suco de laranja em regime laminar. Eles obtiveram também propriedades termofísicas (calor específico e densidade), apresentando corelações empíricas. Os mesmos autores estudaram os coeficientes de atrito em tubos anulares.

Silva (2008) estudou o comportamento reológico da polpa de jenipapo em diferentes concentrações e para diferentes modelos reológicos, tendo como melhores resultados de parâmetros ajustados os modelos de Bingham e HerschelBuckley.

Seguindo a linha de fluidos não-newtonianos, Min et al. (1997) estudaram a transferência de calor de fluidos de Bingham em tubos circulares, determinando os perfis de temperatura e de velocidade, através de métodos numéricos.

\subsection{Distribuição do tempo de residência (DTR)}

Um equipamento tubular de processamento térmico contínuo é antes de tudo um reator tubular em que, ao longo de seu comprimento, a concentração dos atributos varia ao longo do volume, sobre a ação da temperatura.

Um importante estudo para caracterizar equipamentos que transportam fluidos é saber como o fluido escoa dentro do dispositivo e qual o grau de mistura.

Idealmente existem dois tipos de reatores, o CSTR (Continuous Stirred Tank Reactor), ou reator tanque contínuo de agitação perfeita e o PFR (Plug Flow Reactor), ou reator de escoamento pistonado (FOGLER, 2006). Nos reatores CSTR, as moléculas do fluido são misturadas idealmente, fazendo com que exista uma 
composição homogênea no volume de todo reator. Já no PFR o escoamento é considerado pistonado e segregado, fazendo com que as moléculas do fluido fiquem alinhadas, atravessando todo o reator com a mesma velocidade. Neste tipo de reator não existe dispersão axial nem radial.

No entanto, observa-se que existem desvios dos dois modelos de reatores ideias, que podem ocorre devido a alguns fenômenos como: i) escoamento preferencial; ii) zonas mortas; iii) reciclo e iv) curto-circuito. No escoamento preferencial existe uma diferença de tempo de escoamento entre elementos do fluido, fazendo com que uns escoam mais rápido que outros. A presença de zonas mortas faz com que nesta região não ocorra mistura do fluido e pouca interação com as regiões ativas. Reciclo e curto-circuito ocorrem quando o fluido é recirculado para o interior do equipamento e quando elementos do fluido escoam diretamente para a saída sem percorrer todo o interior do equipamento, respectivamente (FOGLER, 2006).

Esses desvios, no entanto, podem ser observados experimentalmente pela análise de curvas de distribuição do tempo de residência (DTR) e pela comparação da mesma curva para reatores ideais.

Para caracterizar um reator não-ideal é preciso ter conhecimento: i) da função de distribuição do tempo de residência; ii) tempo médio de residência; iii) função de distribuição cumulativa e iv) variância da distribuição (FOGLER, 2006).

A distribuição do tempo de residência do fluido escoando pode ser diretamente determinada pelo método de investigação muito utilizada, o método experimental estímulo-resposta (LEVENSPIEL, 2000). A técnica consiste de injetar de forma controlada um traçador na entrada do sistema que se deseja analisar e acompanhar a concentração de traçador na saída do sistema. As injeções de traçadores podem ser feitas de diferentes formas, tais como: degrau e pulso. Para uma injeção do tipo pulso é injetada em um pequeno espaço de tempo determinada quantidade de traçador, enquanto na injeção degrau, o traçador é injetado continuamente durante todo o experimento. O traçador utilizado no sistema deve ser uma espécie não reativa, facilmente detectável e ter propriedades físicas semelhantes à do material em estudo além de ser completamente solúvel no mesmo (FOGLER, 2006).

A função de distribuição do tempo de residência é dada por (LEVENSPIEL, 1999; FOGLER, 2006): 


$$
E(t)=\frac{C_{t}(t)}{\int_{0}^{\infty} C_{t}(t) d t}
$$

em que $C_{t}(t)$ é a concentração de saída do traçador no tempo t $\left(\mathrm{kg} \cdot \mathrm{m}^{-3}\right)$.

A função de distribuição cumulativa do tempo de residência é dada por (LEVENSPIEL, 1999; FOGLER, 2006):

$$
F(t)=\int_{0}^{t} E(t) d t
$$

O tempo médio de residência é dado por (LEVENSPIEL, 1999; FOGLER, 2006):

$$
t_{m}=\frac{\int_{0}^{\infty} t C_{t}(t) d t}{\int_{0}^{\infty} C_{t}(t) d t}=\int_{0}^{\infty} t E(t) d t
$$

A variância, que representa o quadrado do espalhamento da distribuição à medida que esta passa através do vaso é definida como (LEVENSPIEL, 1999; FOGLER, 2006):

$$
\sigma^{2}=\frac{\int_{0}^{\infty}\left(t-t_{m}\right)^{2} C_{t}(t) d t}{\int_{0}^{\infty} C_{t}(t) d t}
$$

Quanto maior o valor desta variância, maior será o espalhamento da distribuição.

No entanto, é comumente utilizada as funções de distribuição adimensionalizadas, pois as características do escoamento dentro de reatores de tamanhos diferentes podem ser comparadas diretamente (FOGLER, 2006). Para tanto o tempo adimensional é relativo ao tempo de residência médio. As equações (3.7) e (3.8) mostram como é calculado o tempo de residência adimensional e a função adimensional $E_{\Phi}(\Phi)$ :

$$
\begin{gathered}
\Phi=\frac{t}{t_{m}} \\
E_{\Phi}(\Phi)=t_{m} E(t)
\end{gathered}
$$

Para descrever o comportamento do escoamento do fluido utilizam-se alguns modelos matemáticos como: modelo de dispersão axial, modelo de tanques em série, modelo laminar modificado e modelo compartimentado, que envolve a associação de reatores ideias PFR e CSTR (LEVENSPIEL, 1999; FOGLER, 2006). 


\subsection{Cinética de destruição térmica}

A inativação térmica lida com a destruição de enzimas e microrganismos pela alta temperatura envolvidos na deterioração de alimentos e na proteção da saúde pública. Os mesmos princípios são aplicados ao efeito do processamento térmico sobre a qualidade nutricional e sensorial de alimentos processados.

A inativação térmica de atributos leva em consideração a cinética de inativação dos mesmos em alta temperatura. Geralmente, a cinética de inativação é representada por uma lei de reação de primeira ordem. Ou seja, a taxa de reação é diretamente proporcional à concentração do atributo (TOLEDO, 2007).

Em seu trabalho, Slongo e Aragão (2008), mostraram que para temperaturas acima de $85{ }^{\circ} \mathrm{C}$ alguns fungos e leveduras possuem uma taxa de destruição seguindo a cinética de $1^{\text {a }}$ ordem. No entanto, verificaram que para temperaturas inferiores a cinética de destruição não tem comportamento linear.

Já Sarkis et al. (2011) estudaram e compararam a cinética de destruição de antocianinas, em suco de amora, para tratamento convencional e ôhmico. Os autores determinaram a energia de ativação e a constante de reação, além de, chegar à conclusão que a cinética de ambos os tratamentos são de $1^{\text {a }}$ ordem e que a variação de um tratamento para outro influencia muito pouco em parâmetros cinéticos.

Por sua vez, Lavarda et al. (2011) estudaram a cinética de destruição da vitamina C em suco de acerola, concluindo que o modelo de Weibull (modelo de estimação não linear) foi o que teve melhor ajuste em relação aos dados experimentais, tanto em tratamentos convencionais quanto ôhmicos. No entanto, observou-se que o modelo de $1^{\mathrm{a}}$ ordem representa bem os dados experimentais.

Para um reator batelada de mistura prefeita que possui um atributo obedecendo a uma cinética de primeira ordem tem-se:

$$
R_{A}=\frac{d C_{A}}{d t}=-k_{r} \cdot C_{A}
$$

em que:

$C_{A}=$ concentração volumétrica do atributo genérico "A" (UFC. $\mathrm{m}^{-3}$ ou kg. $\left.\mathrm{m}^{-3}\right)$;

$k_{r}=$ constante cinética de destruição térmica $\left(\mathrm{s}^{-1}\right)$;

$t=$ tempo (s). 
Integrando-se a equação (3.9) e reescrevendo na forma de logaritmo na base 10, tem-se:

$$
\log \left(\frac{C_{A}}{C_{A 0}}\right)=-k_{r} \cdot \log \mathrm{e} \cdot t
$$

em que $C_{A 0}$ é a concentração volumétrica inicial do atributo "A", ou seja, a concentração em $\mathrm{t}=0 \mathrm{~s}$.

Definindo o parâmetro $D_{d e c A}$ como o tempo necessário para que ocorra uma redução de $90 \%$ da concentração do atributo inicial, ou uma redução logarítmica decimal, tem-se que a equação (3.10) pode ser escrita como:

$$
\log \left(\frac{0,1 C_{A 0}}{C_{A 0}}\right)=-\frac{k_{r}}{\ln 10} \cdot D_{\text {dec } A}
$$

Obtendo a relação da constante de reação com o tempo de redução decimal:

$$
k_{r}=\frac{\ln 10}{D_{\operatorname{dec} A}}
$$

No entanto, assim como a equação de Arrhenius, que relaciona a constante de reação com a temperatura, propõe-se uma expressão semelhante, relacionando o tempo de redução decimal com a temperatura (TOLEDO, 2007):

$$
D_{\text {decA }}=D_{\text {refA }} \cdot 10^{\left(\frac{T_{r e f A}-T}{Z_{A}}\right)}
$$

em que:

$D_{\text {refA }}=$ tempo de redução decimal do atributo "A" na temperatura de referência $T_{\text {refA }}(\mathrm{s})$;

$T_{\text {refA }}=$ temperatura de referência para $D_{\text {refA }}(\mathrm{K})$;

$Z_{A} \quad=$ variação de temperatura necessária para promover uma variação de 10 vezes no valor de $D_{\operatorname{dec} A}(\mathrm{~K})$.

A variável $Z_{A}$ é relacionada com a energia de ativação e pode ser calculada conforme a equação (VAN LOEY, 2005):

$$
Z_{A}=\frac{\ln 10 \cdot R_{g} \cdot T_{r e f A} \cdot T}{E_{a A}}
$$

em que $R_{g}$ é a constante universal dos gases $\left(8,31434 \mathrm{~J} \cdot \mathrm{mol}^{-1} \cdot \mathrm{K}^{-1}\right)$ e $E_{a A}$ é a energia de ativação do atributo genérico "A" $\left(\mathrm{J} \cdot \mathrm{mol}^{-1}\right)$.

Da equação (3.10), defini-se que o valor de esterilização do tratamento térmico no fluido alimentício, que é expresso através do número de reduções decimais (TOLEDO, 2007): 


$$
S_{\text {value }}=\log _{10}\left(\frac{C_{A 0}}{C_{A}}\right)
$$

Por valor de esterilização entende-se em quantos ciclos decimais houve a redução do atributo pela ação do tratamento térmico. Por exemplo, para um valor de esterilização igual a 5, tem-se que a concentração final de atributo de 0,01, para uma concentração inicial de 1000. 


\section{MATERIAIS E MÉTODOS}

Com o objetivo de validar a modelagem proposta, neste trabalho (capítulo 5), realizaram-se ensaios experimentais de troca térmica e de distribuição do tempo de residência, em um pasteurizador. Este equipamento é compostos por seções de aquecimento e resfriamento, sendo estes trocadores de calor bitubulares. Nos experimentos foram obtidos valores das temperaturas dos fluidos utilizados, além de parâmetros de escoamento, que foram posteriormente utilizados para ajustar parâmetros térmico e mássico do modelo proposto. Com o objetivo de simular um alimento em processamento, utilizou-se mistura glicerina/água $80 \%$ (fluido newtoniano) e solução de CMC 1\% (fluido não-newtoniano). Para o fluido utilidade utilizou-se a água.

O modelo proposto para o processamento térmico contínuo de um alimento, resumidamente, é composto por três seções: 1) Aquecimento; 2) Retenção e 3) Resfriamento, em que as seções de aquecimento e resfriamento são trocadores de calor bitubulares de tubos concêntricos modulares e a seção de retenção um tubo metálico com camada de isolamento térmico. O fluido alimentício escoa pelo tubo interno em contracorrente com os fluidos de utilidade, que por sua vez escoam na região anular. Os trocadores de calor de aquecimento e de resfriamento, assim como o tubo de retenção, foram modelados considerando os volumes de controle: alimento, tubo interno, fluido de utilidade, tubo externo, isolamento térmico e ar ambiente. Balanços de energia foram aplicados aos trechos do equipamento para modelar a troca térmica e balanços materiais foram aplicados ao alimento para modelar a distribuição axial e radial dos atributos de qualidade microbiológica e qualidade nutricional. Em ambos os balanços considerou-se o efeito da difusão radial mássica e térmica no processo. Os parâmetros que representam estes efeitos serão ajustados pela comparação com dados experimentais, validando o modelo.

Todas as simulações do modelo matemático proposto e das validações dos modelos térmico e mássico foram realizadas no software de simulação gPROMS (PSE) e em um computador com processador Intel Core 2 Quad $(2.66 \mathrm{GHz})$ e $4 \mathrm{~Gb}$ de memória RAM. 


\subsection{Validação do modelo térmico}

\subsubsection{Materiais}

Pasteurizador em escala laboratorial em aço inox AISI 304 do Laboratório de Engenharia de Alimentos da Escola Politécnica da Universidade de São Paulo. Constituído por 2 trocadores bitubulares e tubo de retenção (Figura 4.1).

Gerador de água gelada modelo MAS-5-RI-220/C (Mecalor,Brasil): para resfriar a água utilizada no trocador de calor utilizado na seção de resfriamento;

Rotâmetro modelo 440 (Contech, Brasil): para medir a vazão volumétrica de circulação de água fria, utilizada na seção de resfriamento.

Gerador de vapor modelo RO430 (Clayton, Brasil) e injetor de vapor modelo 6X7-1 (Pick Heaters Inc, EUA): para gerar vapor e misturar o mesmo com água da rede urbana, gerando água quente utilizada no trocador de calor utilizado na seção de aquecimento.

Bomba centrífuga modelo 32-16A (KSB, Brasil): para bombear a água aquecida pelo trocador de calor utilizado na seção de aquecimento;

Medidor de vazão magnético modelo 47005-010PFACA-E (FoxBoro, Dinamarca): utilizado para medir a vazão volumétrica de circulação de água quente, utilizada na seção de aquecimento.

Bomba de deslocamento positivo modelo 3NE10A (Netzsch, Brasil): para bombear o fluido alimentício ao longo do processo.

Variador de frequência modelo VLT- Micro (DanFoss, Dinamarca): para controlar a vazão do fluido alimentício.

Tanque em aço inox AISI 304: para armazenar o fluido alimentício não processado.

10 termopares tipo T (IOPE, Brasil) e 1 tipo J: para medir as temperaturas do fluido alimentício em diversas posições do pasteurizador.

4 termoresistências $(\mathrm{H}$. Cidade, Brasil): para medir as temperaturas de entrada e saída dos fluidos de utilidade. 
Sistema de aquisição de dados Compact-DAQ (National Instruments, EUA) e software LabView 8.6 (National Instruments, EUA): para aquisição das temperaturas durante os experimentos.

\subsubsection{Parte experimental}

\subsubsection{Preparação da mistura glicerina/água $80 \%$}

A mistura glicerina/água $80 \%$ em base mássica foi preparada pela mistura de $80 \%$ de glicerina P.A. (Casa Americana, Brasil) e 20\% de água destilada, em base mássica. Posteriormente, a mistura sofreu agitação - agitador de bancada modelo 715 (Fisatom, Brasil) - por 10 minutos para homogeneização.

\subsubsection{Preparação da solução de CMC 1\%}

A solução de CMC 1\% em base mássica foi preparada pela mistura de 1,00\% de CMC (Sal Sódico U.S.P, Labsynth, Brasil) para 99\% de água destilada, em base mássica. O CMC foi adicionado lentamente à água destilada sob agitação constante, permanecendo por agitação por mais 1 hora após completa adição do CMC. Após 24 horas em repouso, a mistura sofreu mais 10 minutos de agitação, para completa homogeneização.

\subsubsection{Experimentos}

Os experimentos foram realizados no pasteurizador bitubular do Laboratório de Engenharia de Alimentos da Escola Politécnica da Universidade de São Paulo (Figura 4.1) e também serviram de base para o trabalho de Ferrão (2012). 


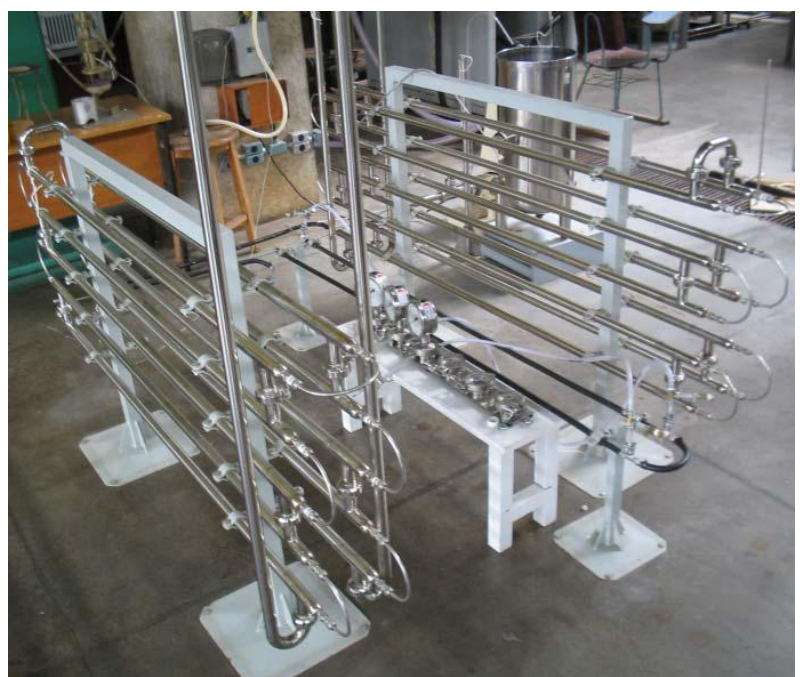

Figura 4.1 - Pasteurizador bitubular do Laboratório de Engenharia de Alimentos da Universidade de São Paulo. Seção de aquecimento à direita, seção de resfriamento à esquerda e tubo de retenção no centro

Este pasteurizador é composto de uma seção de aquecimento contendo 10 módulos bitubulares, um tubo de retenção e uma seção de resfriamento composta também por 10 módulos. Nos experimentos realizados para validação do modelo térmico foram utilizados apenas 4 módulos nas seções de aquecimento e resfriamento. Os parâmetros geométricos do pasteurizador estão mostrados na Tabela 4.1.

Tabela 4.1 - Parâmetros geométricos do pasteurizado e de suas seções utilizados nos experimentos

\begin{tabular}{|c|c|c|c|c|c|}
\hline & \multirow[b]{2}{*}{ Símbolo } & \multirow[b]{2}{*}{ Unidade } & \multicolumn{3}{|c|}{ PASTEURIZADOR } \\
\hline & & & Aquec. & Reten. & Resfr. \\
\hline Número de módulos & $n$ & $a d m$ & 4 & 1 & 4 \\
\hline $\begin{array}{l}\text { Comprimento efetivo do } \\
\text { módulo }\end{array}$ & $L$ & $\mathrm{~m}$ & 1,675 & 5 & 1,675 \\
\hline $\begin{array}{l}\text { Comprimento total } \\
\text { efetivo da seção }\end{array}$ & & $\mathrm{m}$ & 6,70 & 5 & 6,70 \\
\hline $\begin{array}{l}\text { Raio interno do tubo } \\
\text { interno }\end{array}$ & $R_{t i}$ & $\mathrm{~m}$ & $2,25 \times 10^{-3}$ & $2,25 \times 10^{-3}$ & $2,25 \times 10^{-3}$ \\
\hline $\begin{array}{l}\text { Espessura do tubo } \\
\text { interno }\end{array}$ & $e_{t i}$ & $\mathrm{~m}$ & $1,5 \times 10^{-3}$ & $1,5 \times 10^{-3}$ & $1,5 \times 10^{-3}$ \\
\hline $\begin{array}{c}\text { Raio interno do tubo } \\
\text { externo }\end{array}$ & $R_{t e}$ & $\mathrm{~m}$ & $1,27 \times 10^{-2}$ & & $1,27 \times 10^{-2}$ \\
\hline $\begin{array}{c}\text { Espessura do tubo } \\
\text { externo }\end{array}$ & $e_{t e}$ & $\mathrm{~m}$ & $2,20 \times 10^{-3}$ & & $2,20 \times 10^{-3}$ \\
\hline Espessura do isolamento & $e_{i s o}$ & $\mathrm{~m}$ & & $9,00 \times 10^{-3}$ & \\
\hline
\end{tabular}

Os comprimentos efetivos dos módulos e do tubo de retenção são os comprimentos que ocorrem as trocas térmicas. Nestes comprimentos não são levados em consideração as curvas que interligam um módulo a outro. 
Para a realização dos experimentos procedeu-se como descrito abaixo:

Mediu-se a temperatura do ar com auxílio de um termômetro.

Ligou-se o gerador de água gelada com o objetivo de estabilizar a temperatura de entrada e a vazão pré-determinada da água gelada que passava por toda a região anular de toda seção de resfriamento. Ajustou-se a vazão da água gelada e mediu-se a temperatura de entrada da mesma.

Ligou-se a o gerador de vapor com o objetivo de estabilizar a pressão na linha de vapor e eliminar o condensado da mesma. A pressão na saída da caldeira era de $8 \mathrm{kgf} . \mathrm{cm}^{-2}$, reduzindo a mesma para $4 \mathrm{~kg} . \mathrm{cm}^{-2}$ após a passagem por uma válvula redutora.

Ligou-se a água da rede urbana, posteriormente a bomba centrífuga, deixando a água da rede circular por toda a região anular da seção de aquecimento.

Armazenou-se a mistura glicerina/água $80 \%$ ou a solução de CMC $1 \%$ no tanque de aço inox. Ligou-se a bomba de deslocamento positivo e deixou-se que o fluido do tanque expurgasse toda a água contida no tubo interno. O fluido que passava nesse momento inicial era descartado.

Com a pressão do vapor estabilizada, fez-se com que vapor e água passassem pelo injetor, aquecendo a água, e a mesma fosse enviada a região anular da seção de aquecimento. Ajustou-se a vazão da água quente. A temperatura de entrada da água quente foi ajustada e medida conforme cada experimento abrindo ou fechando, manualmente, a válvula pneumática que pertencia ao sistema de injeção.

Ajustou-se a vazão do fluido produto através do variador de frequência. As vazões utilizadas para os experimentos foram de 10, 20, 30, 40 e $50 \mathrm{~L} / \mathrm{h}$, para ambos os fluidos em estudo.

A aquisição das temperaturas foi feita por meio dos termopares conectados à tubulação, o sistema de aquisição de dados Compact-DAQ (National Instruments, EUA) e o software LabView 8.6 (National Instruments, EUA). Os valores das temperaturas experimentais foram obtidos, de modo que, após verificado o regime permanente do sistema, coletaram-se as temperaturas do sistema em um intervalo de $30 \mathrm{~s}$. Posteriormente, os valores médios das temperaturas para cada termopar foram calculados.

A Figura 4.2 mostra, esquematicamente, o pasteurizador utilizado nos experimentos. 


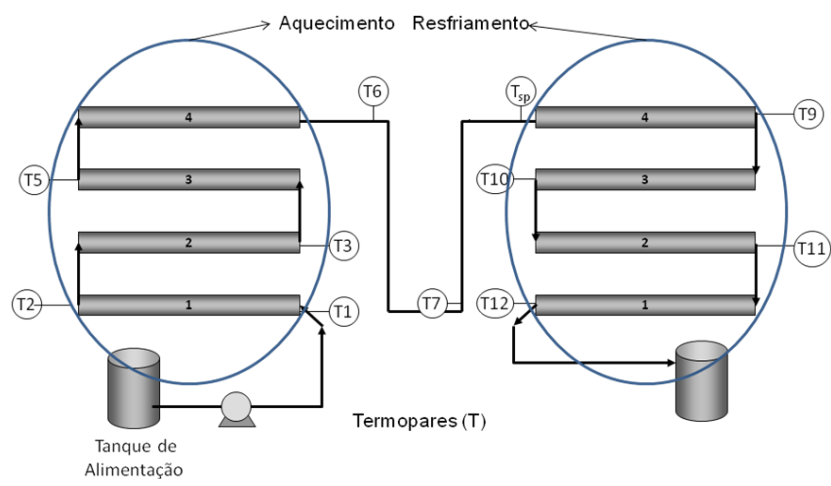

Figura 4.2 - Representação esquemática do pasteurizador bitubular utilizado nos experimentos

As posições efetivas (sem levar em consideração as curvas de ligação entre um módulo e outro) dos termopares estão mostradas na Tabela 4.2.

Tabela 4.2 - Posições efetivas dos termopares no pasteurizador bitubular utilizado nos experimentos

\begin{tabular}{ccc}
\hline Seção & Termopar & Posição efetiva $(\mathrm{m})$ \\
\hline \multirow{3}{*}{ Aquecimento } & T1 & 0 \\
& T2 & 1,675 \\
& T3 & 3,655 \\
Retenção & T5 & 5,635 \\
& T6 & 7,875 \\
& T7 & 9,845 \\
\multirow{2}{*}{ Resfriamento } & Tsp & 12,335 \\
& T9 & 14,01 \\
& T10 & 15,99 \\
& T11 & 17,97 \\
& T12 & 19,95 \\
\hline
\end{tabular}

\subsubsection{Ajuste do parâmetro do modelo térmico}

Para a validação do modelo proposto, forneceram-se as temperaturas experimentais obtidas no módulo de estimação de parâmetros do software de simulação gPROMS (PSE). Neste módulo, o usuário digita os valores dos ensaios realizados, seleciona o(s) parâmetro(s) do modelo que deseja ajustar e o software realiza a regressão dos dados experimentais comparando com as repostas do modelo proposto e ajustando o parâmetro desejado do modelo através da minimização do erro quadrático.

O modelo foi resolvido pelo método número das diferenças finitas para trás (BFDM) - fluido alimentício, tubo interno, tubo externo, ar ambiente - ou para frente 
(FFDM) - fluido utilidade - para a direção axial, e para a direção radial, utilizou-se o método das diferenças finitas centradas (CFDM). Os domínios axiais foram discretizados em 100 pontos, e os radiais em 20 pontos para o fluido alimentício e 5 pontos para o tubo interno. Escolheu-se esta discretização, pois em testes preliminares observou-se que para malhas mais refinadas o tempo de resolução do problema era muito elevado (mais de 30 minutos), além da, não resolução do modelo por limitações de memória do computador. Detalhes sobre métodos numéricos podem ser encontrados em Lapidus e Pinder (1982).

\subsection{Validação do modelo mássico}

Para a validação do modelo mássico utilizou-se a metodologia e dados experimentais de Pegoraro (2012). Nas próximas seções são descritos os materiais e procedimentos utilizados pela autora.

\subsubsection{Materiais}

Pasteurizador em escala laboratorial em aço inox AISI 304 do Laboratório de Engenharia de Alimentos da Escola Politécnica da Universidade de São Paulo. Constituído por 2 trocadores bitubulares e tubo de retenção (Figura 4.1);

Tanque em aço inox AISI 304: para armazenar os fluidos teste.

Bomba de deslocamento positivo modelo 3NE10A (Netzsch, Brasil): para bombear os fluidos teste do tanque em aço para o pasteurizador.

Variador de frequência modelo VLT- Micro (DanFoss, Dinamarca): para controlar as vazões dos fluidos em estudos.

Azul de metileno (Labsynth, Brasil): para ser o traçador nas determinações das distribuições dos tempos de residência. Utilizou-se este traçador, pois o mesmo é muito miscível em água.

Seringa de $10 \mathrm{~mL}$ : para injetar a solução de azul de metileno durante os experimentos.

Espectrofotômetro modelo 700 Plus (FEMTO, Brasil). 


\subsubsection{Parte experimental}

\subsubsection{Preparação da mistura glicerina/água $80 \%$}

Realiza de forma igual à descrita na seção 4.1.2.1.

\subsubsection{Preparação da solução de CMC $1 \%$}

Realiza de forma igual à descrita na seção 4.1.2.2.

\subsubsection{Experimentos}

Os experimentos foram realizados no pasteurizador descrito na seção 4.1.2.3. No entanto, utilizou-se somente o tubo de retenção do referido pasteurizador, pois o tamanho do mesmo é equivalente ao tamanho de 1 grampo do pasteurizador, além de, se ter melhor acesso e representar satisfatoriamente o escoamento em todo o trocador. O tubo de retenção se encontra destacado na Figura 4.3.

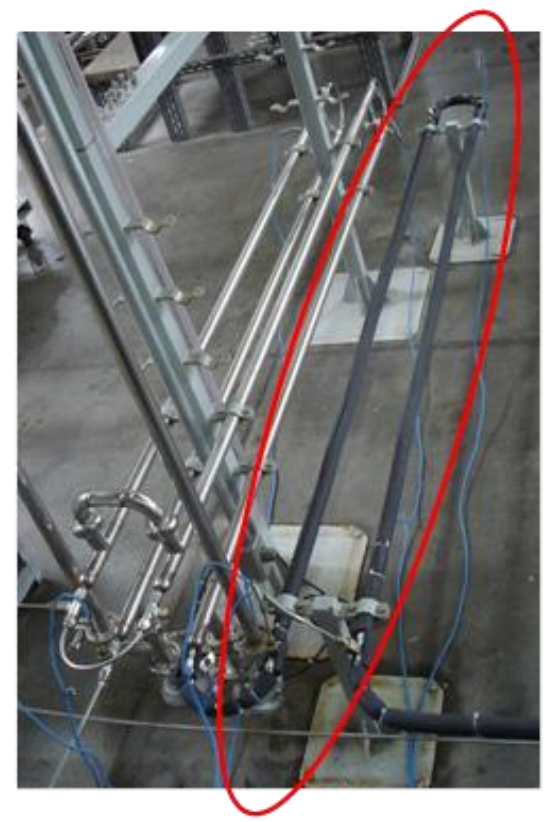

Figura 4.3 - Tubo de retenção, em destaque, utilizado para os ensaios de DTR 
Os experimentos consistiram em determinar as DTR's do trocador pela técnica colorimétrica. Vazões volumétricas de 10, 20, 30, 40 e $50 \mathrm{~L} / \mathrm{h}$ foram utilizadas, mantendo-as constante durante a realização dos ensaios. Os ensaios consistiram na injeção do azul de metileno na entrada do sistema, que passava a mistura glicerina/água $80 \%$ ou a solução de CMC 1\%, para posterior análise em um espectrofotômetro. Segundo a autora, a vantagem da técnica está no fato do mesmo fornecer de maneira simples a determinação de quantidades reduzidas de substâncias.

Inicialmente, a autora preparou as soluções com os traçadores pela adição direta de água destilada, para tanto, a mesma realizou testes para determinar a concentração ideal do traçador azul de metileno em solução, encontrando-se um valor de 160 ppm, que foi utilizado nos experimentos.

Com os fluidos testes passando pelo equipamento, injetou-se um volume de 0,35 $\mathrm{mL}$ de solução com corante, através de uma tampa de silicone na entrada do sistema usando uma seringa de $10 \mathrm{~mL}$.

Coletou-se, manualmente e de forma contínua, em intervalos de 1 s (vazões de 20, 30, 40 e 50 L/h) e 2 s (vazão de 10 L/h), na saída do sistema amostras dos fluidos que posteriormente foram homogeneizadas $e$ analisadas no espectrofotômetro.

Repetiu-se cinco vezes cada experimento. Sendo que todos estes foram realizados a temperatura ambiente $\left(20\right.$ a $\left.22^{\circ} \mathrm{C}\right)$.

Nas análises feitas no espectrofotômetro, inicialmente, homogeneizou-se as amostras, transferindo-as para cubetas de quartzo com caminho ótico de $10 \mathrm{~mm}$ analisando- as para um comprimento de onda de $665 \mathrm{~nm}$.

Posteriormente, os ensaios foram analisados pela autora.

\subsubsection{Ajuste do parâmetro do modelo mássico}

Como o modelo do pasteurizador tubular proposto é baseado na operação em regime permanente, é necessário desenvolver um modelo transiente paralelo que considera a passagem de um traçador pelo tubo do produto em condições 
isotérmicas. Do balanço diferencial de massa do traçador em um volume de controle tem-se a expressão dada por Bird, Stewart e Lightfoot (2002):

$$
\frac{\partial C_{t}}{\partial t}+\vec{v}_{t} \cdot \nabla C_{t}=\nabla \cdot\left(D_{t} \nabla C_{t}\right)+R_{t}
$$

em que:

$C_{t}=$ concentração volumétrica do traçador $\left(\mathrm{kg} \cdot \mathrm{m}^{-3}\right)$;

$D_{t}=$ difusividade mássica do traçador $\left(\mathrm{m}^{2} \cdot \mathrm{s}^{-1}\right)$;

$R_{t}=$ taxa de produção/destruição volumétrica do traçador $\left(\mathrm{kg} \cdot \mathrm{m}^{-3} \cdot \mathrm{s}^{-1}\right)$.

Considerando:

- Tubo cilíndrico e reto com simetria angular:

$$
v_{\theta t}=\frac{\partial C_{t}}{\partial \theta}=0 \rightarrow\left(\vec{v}_{t} \cdot \nabla C_{t}\right)=v_{r t} \frac{\partial C_{t}}{\partial r}+v_{z t} \frac{\partial C_{t}}{\partial z} ;
$$

- Escoamento desenvolvido:

$$
v_{r t}=0 \rightarrow\left(\vec{v}_{t} \cdot \nabla C_{t}\right)=v_{z t} \frac{\partial C_{t}}{\partial z}
$$

- Contribuição da transferência de massa associada ao escoamento na direção axial muito maior que a contribuição do transporte difusivo na direção axial:

$$
v_{z \mathrm{t}} \frac{\partial C_{t}}{\partial z} \gg D_{t} \frac{\partial^{2} C_{t}}{\partial z^{2}} \rightarrow D_{t} \frac{\partial^{2} C_{t}}{\partial z^{2}} \text { é desprezível; }
$$

- Sem geração ou consumo interno do traçador:

$$
R_{t}=0 \text {; }
$$

- Escoamento laminar com difusão efetiva: considera-se a existência de difusividade mássica efetiva radial $\left(D_{\text {mass_eft }}\right)$, decorrente da interação e mistura entre as lâminas do fluido, devido a vibrações mecânicas, imperfeições na tubulação, acessórios de tubulação, uso de tubos corrugados, variações de densidades e flutuação das vazões. Este efeito de mistura aumenta a difusividade mássica:

$$
D_{t} \rightarrow D_{\text {mass_eft }}
$$

- Perfil de velocidade no tubo obedecendo à Lei de Potência, admitindo escoamento desenvolvido:

$$
v_{z t}(r)=\bar{v}_{z t} \cdot\left(\frac{3 \cdot n_{\text {reo }}+1}{n_{\text {reo }}+1}\right) \cdot\left(1-\left(\frac{r}{R}\right)^{\left(\frac{n_{r e o}+1}{n_{\text {reo }}}\right)}\right)
$$


Reescrevendo a equação (4.1), levando as considerações mencionadas acima:

$$
\frac{\partial C_{t}}{\partial t}+\bar{v}_{z t} \cdot\left(\frac{3 \cdot n_{\text {reo }}+1}{n_{\text {reo }}+1}\right) \cdot\left(1-\left(\frac{r}{R}\right)^{\left(\frac{n_{\text {reo }}+1}{n_{\text {reo }}}\right)}\right) \frac{\partial C_{t}}{\partial z}=D_{\text {mass_eft }}\left[\frac{1}{r} \frac{\partial}{\partial r}\left(r \frac{\partial C_{t}}{\partial r}\right)\right]
$$

A equação (4.2) pode ser a pode ser adimensionalizada usando as seguintes variáveis:

$$
\begin{gathered}
C^{\prime}=\frac{C_{t}}{C_{t i}} \quad C^{\prime} \geq 0 \\
\Phi=\frac{t}{t_{m}}=t \frac{\bar{v}_{z t}}{L} \quad \Phi \geq 0 \\
r^{\prime}=\frac{r}{R} \quad 0 \leq r^{\prime} \leq 1 \\
z^{\prime}=\frac{z}{L} \quad 0 \leq z^{\prime} \leq 1 \\
P e_{r}{ }^{\prime}=\frac{\bar{v}_{z t} \cdot L}{D_{\text {mass_eft }}}\left(\frac{R}{L}\right)^{2}
\end{gathered}
$$

em que:

$C^{\prime}=$ concentração adimensional do traçador (adimensional);

$C_{t i}=$ concentração do traçador na alimentação $\left(\mathrm{kg} \cdot \mathrm{m}^{-3}\right)$;

$\Phi=$ tempo adimensional (adimensional);

$t_{m}=$ tempo médio de residência (s);

$L=$ comprimento do tubo $(\mathrm{m})$;

$r^{\prime}=$ raio adimensional (adimensional);

$z^{\prime}=$ comprimento adimensional (adimensional);

$P e_{r}{ }^{\prime}=$ número de Peclet do reator, modificado pelo termo $\left(\frac{R}{L}\right)^{2}$ (adimensional).

Para chegar à equação (4.4), adotou-se a hipótese que o tempo médio de residência é igual ao tempo espacial. Ou seja:

$$
t_{m}=\tau_{\mathrm{m}}=\frac{\text { Volume }}{\text { Vazão }}=\frac{L}{\overline{v_{z t}}}
$$

Reescrevendo a equação (4.2), em formato adimensional:

$$
\frac{\partial C^{\prime}}{\partial \Phi}+\left(\frac{3 \cdot n_{r e o}+1}{n_{\text {reo }}+1}\right) \cdot\left(1-\left(r^{\prime}\right)^{\left(\frac{n_{r e o}+1}{n_{r e o}}\right)}\right) \frac{\partial C^{\prime}}{\partial z^{\prime}}=\frac{1}{P e_{r}{ }^{\prime}}\left[\frac{1}{r^{\prime}} \frac{\partial}{\partial r^{\prime}}\left(r^{\prime} \frac{\partial C^{\prime}}{\partial r^{\prime}}\right)\right]
$$

Sendo que os dois parâmetros livres nesta equação são o número de Peclet modificado $\left(P e_{r}{ }^{\prime}\right)$ e o índice de comportamento $\left(n_{\text {reo }}\right)$. 
Para resolver a equação (4.8) são necessárias três condições de contorno, sendo uma na direção axial, e duas na direção radial. É também requerida uma condição inicial.

a) Inicialmente o tubo está livre de traçador:

$$
\Phi=0 \rightarrow C^{\prime}=0
$$

b) Injeção do tipo degrau do traçador na entrada do tubo:

$$
C^{\prime}=\left.1\right|_{z^{\prime}=0}
$$

c) Não variação da concentração devido à simetria de eixo em $r^{\prime}=0$ :

$$
\left.\left(\frac{\partial C^{\prime}}{\partial r^{\prime}}\right)\right|_{r \prime=0}=0
$$

d) Não variação da concentração devido à impermeabilidade da parede interna do tubo em $r^{\prime}=1$ :

$$
\left.\left(\frac{\partial C^{\prime}}{\partial r^{\prime}}\right)\right|_{r=1}=0
$$

O modelo foi resolvido pelo método número das diferenças finitas sendo centrado de segunda ordem para o raio e para trás para o comprimento. O domínio axial foi discretizado em 1000 pontos e os radial em 300. O tempo adimensional avançou até $\Phi=10$, sendo o intervalo de registro de 0,01 .

A média de mistura da concentração adimensional do traçador foi calculada em função do tempo na saída do tubo por meio da equação (4.13). O gráfico de $C^{\prime}$ em função de $\Phi$ é a conhecida curva $F_{\Phi}$ de DTR (distribuição cumulativa adimensional) (LEVENSPIEL, 1984). A curva $E_{\Phi}$ da DTR foi obtida por derivação numérica da curva $\mathrm{F}_{\Phi}$ usando o método de diferenças finitas para trás.

$$
\bar{C}_{\text {saída }}^{\prime}=F_{\Phi}=\int_{0}^{1}\left(\frac{3 \cdot n_{r e o}+1}{n_{r e o}+1}\right) \cdot\left(1-\left(r^{\prime}\right)^{\left(\frac{n_{r e o}+1}{n_{r e o}}\right)}\right) C_{s a i ́ d a}^{\prime} \cdot 2 r^{\prime} d r^{\prime}
$$

O $\log \left(P e_{r}{ }^{\prime}\right)$ foi avaliado entre -1,5 e 2,5 para explorar seu efeito sobre a DTR numérica para dado $n_{\text {reo }}$, obtendo para cada caso uma curva teórica Cada curva experimental foi comparada com os conjuntos de curvas teóricas para ajuste do $P e_{r}{ }^{\prime}$. Para cada comparação gerou-se um valor de erro quadrático. Este erro foi usado para identificar, por interpolação polinomial, em qual valor de $\log \left(P e_{r}{ }^{\prime}\right)$ encontrava-se o mínimo erro. 


\section{MODELAGEM MATEMÁTICA}

A modelagem proposta neste trabalho é baseada nos trabalhos de está baseado nos trabalhos de Crivellari (2010) e Kechichian (2011).

Para o desenvolvimento da modelagem matemática considerou-se, no tratamento térmico contínuo de alimentos líquidos, um equipamento composto por três seções: 1) Aquecimento: cuja função é aquecer o alimento até a temperatura de tratamento térmico; 2) Retenção: seção onde ocorre o tratamento térmico propriamente dito, e que a temperatura de tratamento térmico deve permanecer durante todo o seu comprimento; 3) Resfriamento: seção responsável pelo resfriamento do alimento, cujo objetivo é cessar rapidamente os efeitos do aquecimento após o correto tratamento térmico. As seções de aquecimento e resfriamento são trocadores de calor bitubulares de tubos concêntricos, compostas por $n_{\text {aque }}$ e $n_{\text {resf }}$ número de módulos lineares, respectivamente. A retenção, por sua vez, é um tubo metálico com camada de isolamento térmico (opcional).

Tanto no aquecimento quanto no resfriamento, o fluido alimentício deve ser rapidamente aquecido e resfriado, com intuito de minimizar os efeitos da temperatura sobre a qualidade do produto final. Tendo em vista isto, no aquecimento (considerando a seção com um todo e/ou em cada módulo) tem-se o alimento escoando em contracorrente com o fluido utilidade. Já no resfriamento, se for utilizado escoamento em contracorrente na seção como um todo (fluido utilidade entrando no final da seção), haverá um resfriamento mais lento na entrada do alimento e consequentemente uma demora no tempo de cessão das reações de destruição térmica. Se considerarmos, no entanto, em cada módulo da seção, escoamento contracorrente entre os fluidos e em paralelo em relação à seção inteira (fluido utilidade entrando no final do primeiro módulo da seção de resfriamento), consegue-se um resfriamento mais rápido na entrada do produto. A Figura 5.1 mostra uma representação esquemática do equipamento e da sua configuração.

Para o desenvolvimento da modelagem, modelou-se cada módulo separadamente. A continuidade entre eles, assim como a continuidade entre as seções, foi representada através de condições de contorno pertinentes. Para o modelo proposto, no entanto, a modelagem e os efeitos das curvas de ligação entre 
os módulos foram desconsiderados, assumindo que os fluidos entrem e saiam instantaneamente nos módulos. Considerou-se para hipóteses do modelo:

- Estado estacionário;

- Escoamento desenvolvido;

- Tubos cilíndricos e retos;

- Fluidos incompressíveis;

- Propriedades dos fluidos constantes nos módulos;

- Isotropia dos materiais;

- Efeitos das curvas que ligam os módulos desconsiderados.

Para cada módulo o produto alimentício escoa dentro do tubo interno e o fluido de aquecimento ou resfriamento (fluido utilidade) escoa na região anular, em contracorrente com o alimento. As propriedades dos fluidos são constantes e calculadas na temperatura média aritmética entre a entrada e a saída do módulo através de correlações preditivas adequadas.

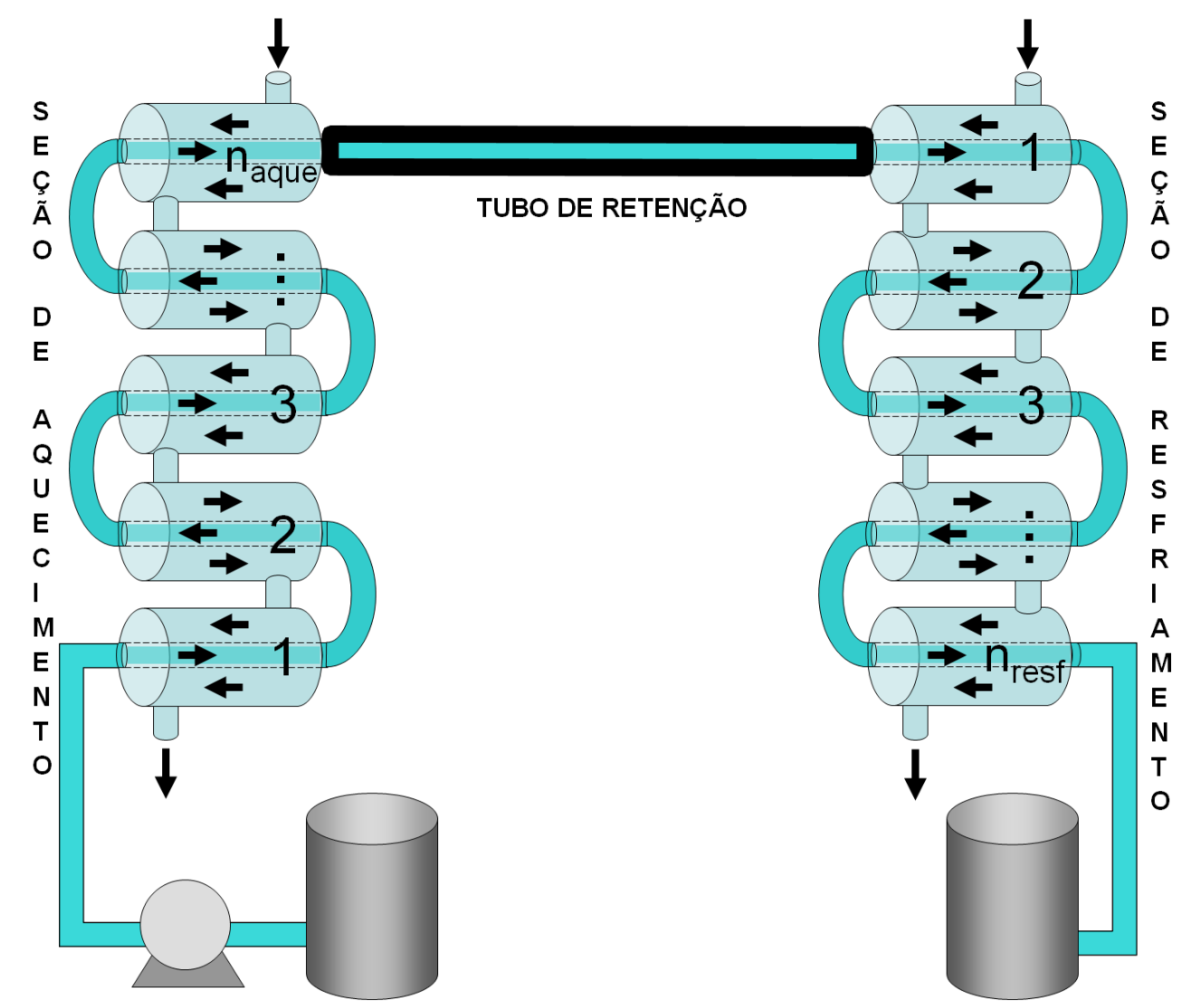

Figura 5.1 - Representação esquemática de um equipamento utilizado no tratamento térmico contínuo de alimentos 


\subsection{Modelagem dos módulos de aquecimento/resfriamento}

Os módulos que compõem as seções de aquecimento e de resfriamento do pasteurizador são trocadores de calor tubulares semelhantes. Devido a isto, estes módulos foram modelados de forma igual, mudando somente as condições de contorno aplicadas. Cada módulo estudado foi dividido em cinco volumes de controle:

- Fluido escoando dentro do tubo interno (produto alimentício);

- Tubo interno;

- Fluido escoando na região anular (fluido utilidades);

- Tubo externo;

- $\operatorname{Ar}$ ambiente;

Para cada volume de controle foram realizados os balanços de massa e/ou de energia, e aplicadas as condições de contorno pertinentes.

O domínio axial de cada módulo $i\left(i=1,2,3, \ldots, n_{\text {aque }}\right)$ que compõe a seção de aquecimento é limitado por:

$$
\begin{gathered}
A_{\text {aque }}{ }^{(i)} \leq z \leq B_{\text {aque }}{ }^{(i)} \\
A_{\text {aque }}{ }^{(i)}=(i-1) \cdot L_{I} \\
B_{\text {aque }}{ }^{(i)}=i \cdot L_{I}
\end{gathered}
$$

em que $A_{a q u e}{ }^{(i)}$ e $B_{a q u e}{ }^{(i)}$ são as posições axiais de entrada e saída $(\mathrm{m})$ do módulo e $L_{I}$ é o comprimento efetivo de um módulo que compõe a seção de aquecimento (m).

O domínio axial de cada módulo $j\left(j=1,2,3, \ldots, n_{\text {resf }}\right)$ que compõe a seção de resfriamento é limitado por:

$$
\begin{gathered}
A_{\text {resf }}{ }^{(j)} \leq z \leq B_{\text {resf }}{ }^{(j)} \\
A_{\text {resf }}{ }^{(j)}=n_{\text {aque }} \cdot L_{I}+L_{I I}+(j-1) \cdot L_{I I I} \\
B_{\text {resf }}{ }^{(j)}=n_{\text {aque }} \cdot L_{I}+L_{I I}+j \cdot L_{I I I}
\end{gathered}
$$

sendo $A_{\text {resf }}{ }^{(j)}$ e $B_{\text {resf }}{ }^{(j)}$ as posições axiais de entrada e saída (m) do módulo, $L_{I I}$ o comprimento do tubo de retenção $(\mathrm{m})$ e $L_{I I I}$ o comprimento efetivo de um módulo que compõe a seção de resfriamento $(\mathrm{m})$.

O domínio radial é dividido em: 
$0 \leq r \leq R_{t i}$ (fluido alimentício escoando dentro do tubo interno)

$R_{t i} \leq r \leq R_{t i}+e_{t i}$ (tubo interno)

$R_{t i}+e_{t i} \leq r \leq R_{t e}$ (fluido utilidade escoando na região anular)

$R_{t e} \leq r \leq R_{t e}+e_{t e}$ (tubo externo)

$R_{t e}+e_{t e} \leq r \leq \infty($ ar ambiente $)$

sendo $R_{t i}$ o raio interno do tubo interno $(\mathrm{m}), e_{t i}$ a espessura do tubo interno $(\mathrm{m}), R_{t e}$ o raio interno do tubo externo $(\mathrm{m})$ e $e_{t e}$ a espessura do tubo externo $(\mathrm{m})$.

A Figura 5.2 mostra os domínios para um módulo genérico $k$ de aquecimento ou resfriamento.

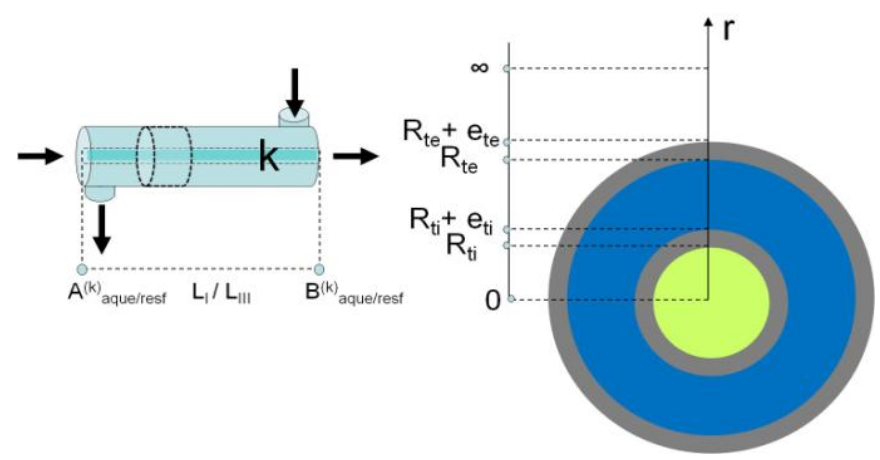

Figura 5.2 - Domínios axial e radial de um módulo $k$ do trocador de calor

\subsubsection{Fluido escoando no tubo interno}

\subsubsection{Modelagem de escoamento}

Para a modelagem do escoamento do produto alimentício (fluido que passa dentro do tubo interno), considera-se um fluido de comportamento não-newtoniano representado pela Lei de Potência. A reologia de tal fluido é representada por:

$$
\tau=K_{\text {reo }} \cdot \dot{\gamma}^{n_{\text {reo }}}
$$

em que:

$$
\begin{array}{ll}
\tau & =\text { tensão de cisalhamento }\left(\mathrm{N} \cdot \mathrm{m}^{-2}\right) ; \\
K_{\text {reo }} & =\text { índice de consistência }\left(\mathrm{Pa} \cdot \mathrm{s}^{\left.n_{\text {reo }}\right)} ;\right. \\
n_{\text {reo }} & =\text { índice de comportamento (adimensional); } \\
\dot{\gamma} & =\text { taxa de cisalhamento }\left(\mathrm{s}^{-1}\right) .
\end{array}
$$


Considerando, também, escoamento em regime do tipo laminar desenvolvido isotérmico em tubo cilíndrico, tem-se que o perfil de velocidade na direção axial dado por Bird, Stewart e Lightfoot (2002):

$$
v_{z 1}(r)=\overline{v_{z 1}} \cdot\left(\frac{3 \cdot n_{\text {reo }}+1}{n_{\text {reo }}+1}\right) \cdot\left(1-\left(\frac{r}{R_{t i}}\right)^{\left(\frac{n_{r e o}+1}{n_{\text {reo }}}\right)}\right)
$$

Em que $\overline{\mathrm{v}_{\mathrm{z} 1}}$ é calculado por:

$$
\overline{v_{z 1}}=\frac{q_{1}}{A_{1}}=\frac{q_{1}}{\pi R_{t i}^{2}}
$$

sendo:

$$
\begin{aligned}
& v_{z 1}(r)=\text { velocidade do fluido alimentício na direção axial }\left(\mathrm{m} . \mathrm{s}^{-1}\right) ; \\
& \overline{v_{z 1}} \quad=\text { velocidade média }\left(\text { bulk) do fluido alimentício }\left(\mathrm{m} \cdot \mathrm{s}^{-1}\right) ;\right. \\
& q_{1} \quad=\text { vazão volumétrica do fluido alimentício }\left(\mathrm{m}^{3} \cdot \mathrm{s}^{-1}\right) ; \\
& A_{1} \quad=\text { área da seção perpendicular à direção axial do escoamento do fluido }
\end{aligned}
$$
alimentício $\left(\mathrm{m}^{2}\right)$.

O perfil de velocidade obtido na equação (5.2(5.2) leva-se em consideração regime laminar desenvolvido. O comprimento necessário para que ocorra o desenvolvimento completo da camada limite hidrodinâmica do escoamento laminar é dado por Incropera et al. (2008) por:

$$
\frac{x_{d e s}}{D_{t i}} \approx 0,05 \cdot R e_{1}
$$

A validade da hipótese de escoamento laminar desenvolvido é testada no estudo da seção 6.1.1.

Como se trata de um alimento com comportamento reológico que segue Lei de Potência, o número de Reynolds para escoamento laminar em tubo circular de diâmetro interno $D_{t i}$ é calculado, segundo Steffe e Singh (1997), por:

$$
R e_{1}=\frac{D_{t i}^{n_{\text {reo }} \cdot \rho_{1} \cdot \overline{v_{z 1}}\left(2-n_{\text {reo }}\right)}}{8^{\left(n_{\text {reo }}-1\right) \cdot K_{\text {reo }}}}\left(\frac{4 \cdot n_{\text {reo }}}{3 \cdot n_{\text {reo }}+1}\right)^{n_{\text {reo }}}
$$

Para um fluido newtoniano $\left(n_{\text {reo }}=1\right.$ e $\left.K_{\text {reo }}=\mu\right)$, a equação (5.5) reduz-se ao número de Reynolds para escoamento em dutos:

$$
R e=\frac{D_{t i} \cdot \rho_{1} \cdot \overline{v_{z 1}}}{\mu}
$$

O número de Reynolds é utilizado, principalmente, para caracterizar o regime de escoamento (laminar ou turbulento) dos fluidos. O valor ou faixa de valores, limites entre os dois regimes é determinado pelo número de Reynolds crítico. Para 
fluidos com comportamento não-newtoniano e seguindo a Lei de Potências, segundo Grovier e Aziz (1972), tem-se que o número de Reynolds crítico é dado por:

$$
R e_{1_{-} \text {critico }}=\frac{6464 \cdot n_{\text {reo }}}{\left(3 \cdot n_{\text {reo }}+1\right)^{2} \cdot\left[\frac{1}{2+n_{\text {reo }}}\right]^{\left(\frac{2+n_{\text {reo }}}{1+n_{\text {reo }}}\right)}}
$$

Sendo que para garantir escoamento laminar: $R e_{1}<R e_{1_{-} c r i ́ t i c o}$.

\subsubsection{Balanço de energia}

Aplicando o balanço diferencial de energia ao volume de controle cilíndrico do fluido alimentício no módulo $k$, tem-se a seguinte expressão de acordo com Bird, Stewart e Lightfoot (2002):

$$
\rho_{1}{ }^{(k)} C_{p 1}{ }^{(k)}\left(\frac{\partial T_{1}{ }^{(k)}}{\partial t}+\vec{v}_{1} \cdot \nabla T_{1}{ }^{(k)}\right)=\nabla\left(k_{1}{ }^{(k)} \cdot \nabla T_{1}{ }^{(k)}\right)+{\dot{Q_{1}}}^{\left({ }^{k}\right)}
$$

Os termos do lado esquerdo da equação (5.7) representam o acúmulo de energia e transporte de energia por advecção, e os do lado direito, transporte de energia por difusão e geração volumétrica de energia térmica. Nesta equação:

$(k)=\left\{\begin{array}{l}i=1,2,3, \ldots, n_{\text {aque }}, \text { se módulo da seção de aquecimento; } \\ j=1,2,3, \ldots, n_{\text {resf }}, \text { se módulo da seção de resfriamento; }\end{array}\right.$

$\rho_{1} \quad=$ massa específica média do fluido alimentício $\left(\mathrm{kg} \cdot \mathrm{m}^{-3}\right) ;$

$C_{p 1}=$ calor específico médio do fluido alimentício $\left(\mathrm{J} \cdot \mathrm{kg}^{-1} \cdot \mathrm{K}^{-1}\right)$;

$k_{1}=$ condutividade térmica média do fluido alimentício $\left(\mathrm{W} \cdot \mathrm{m}^{-1} \cdot \mathrm{K}^{-1}\right)$;

$\vec{v}_{1} \quad=$ vetor velocidade do fluido alimentício $\left(\mathrm{m} . \mathrm{s}^{-1}\right)$;

$\dot{Q}_{1} \quad=$ taxa de geração volumétrica de energia térmica no fluido alimentício $\left(\mathrm{W} . \mathrm{m}^{-3}\right)$;

$T_{1}(z, r)=$ temperatura do fluido alimentício $(\mathrm{K})$.

Considera-se:

- Estado estacionário:

$$
\left(\frac{\partial T_{1}^{(k)}}{\partial t}\right)=0
$$


- Tubo cilíndrico e reto com simetria angular:

$$
v_{\theta 1}=\frac{\partial T_{1}{ }^{(k)}}{\partial \theta}=0 \rightarrow\left(\vec{v}_{1} \cdot \nabla T_{1}{ }^{(k)}\right)=v_{r 1} \frac{\partial T_{1}^{(k)}}{\partial r}+v_{z 1} \frac{\partial T_{1}^{(k)}}{\partial z} ;
$$

- Escoamento desenvolvido:

$$
v_{r 1}=0 \rightarrow\left(\vec{v}_{1} \cdot \nabla T_{1}^{(k)}\right)=v_{z 1} \frac{\partial T_{1}^{(k)}}{\partial z} ;
$$

- Contribuição da transferência de energia associada ao escoamento na direção axial muito maior que a contribuição do transporte difusivo na direção axial. Portanto, contribuição do transporte difusivo na direção axial desprezível:

$v_{z 1} \frac{\partial T_{1}{ }^{(k)}}{\partial z} \gg k_{1}{ }^{(k)}\left(\frac{\partial^{2} T_{1}{ }^{(k)}}{\partial z^{2}}\right) \rightarrow k_{1}{ }^{(k)}\left(\frac{\partial^{2} T_{1}{ }^{(k)}}{\partial z^{2}}\right)$ é desprezível;

- Sem geração ou consumo interno de energia térmica:

$$
\dot{Q}_{1}^{(k)}=0 \text {; }
$$

- Escoamento laminar com difusão radial efetiva: no escoamento laminar ideal não existe uma mistura entre as lâminas do fluido, ocorrendo somente transporte de energia por condução entre elas. No entanto, devido a vibrações mecânicas, imperfeições na tubulação, acessórios de tubulação (curvas, tes, válvulas), uso de tubos corrugados, variações de densidades e flutuação das vazões, há um aumento da turbulência e consequentemente uma mistura entre as camadas de fluido durante o escoamento, aumentando a condutividade térmica do fluido. Para quantificar estes efeitos de mistura, e consequentemente um escoamento real, considera-se que existe uma condutividade térmica efetiva radial $\left(k_{e f 1}{ }^{(k)}\right)$ e esta possui um valor superior a condutividade térmica do fluido $\left(k_{1}{ }^{(k)}\right)$ :

$$
k_{1}{ }^{(k)} \rightarrow k_{e f 1}{ }^{(k)}
$$

Em que $k_{e f 1}{ }^{(k)}$ é calculado como:

$$
k_{e f 1}{ }^{(k)}=F_{\text {incr } 1}{ }^{(k)} \cdot{k_{1}}^{(k)}
$$

sendo $F_{\text {incr } 1}{ }^{(k)}$ definido como o fator de aumento da condutividade térmica do fluido alimentício na direção radial (adimensional).

Reescrevendo a equação (5.7), levando as considerações mencionadas: 


$$
\rho_{1}{ }^{(k)} C_{p 1}{ }^{(k)}\left(v_{z 1} \frac{\partial T_{1}{ }^{(k)}}{\partial z}\right)=k_{e f 1}{ }^{(k)}\left(\frac{1}{r} \frac{\partial}{\partial r}\left(r \frac{\partial T_{1}^{(k)}}{\partial r}\right)\right)
$$

Em termos de difusividade térmica efetiva, a equação (5.9) pode ser escrita como:

$$
\left(v_{z 1} \frac{\partial T_{1}^{(k)}}{\partial z}\right)=D_{t e r m \_e f 1}{ }^{(k)}\left(\frac{1}{r} \frac{\partial}{\partial r}\left(r \frac{\partial T_{1}^{(k)}}{\partial r}\right)\right)
$$

em que, $D_{\text {term_ef } 1}{ }^{(k)}$ é a difusividade térmica efetiva radial do fluido alimentício $\left(\mathrm{m}^{2} \cdot \mathrm{s}^{-1}\right)$ e seu valor é calculado por:

$$
D_{\text {term_ef } 1}{ }^{(k)}=\frac{k_{e f 1}{ }^{(k)}}{\rho_{1}{ }^{(k)} C_{p 1}{ }^{(k)}}
$$

Para resolver a equação (5.9) são necessárias três condições de contorno, sendo uma na direção axial, decorrente da derivada parcial de primeira ordem, e duas na direção radial, devido à derivada parcial de segunda ordem.

As condições de contorno para o balanço diferencial de energia nos módulos da seção de aquecimento são:

a) No módulo 1 da seção de aquecimento, a temperatura de entrada do fluido alimentício é igual a um parâmetro $T_{1 \text { in }}$ (temperatura de alimentação), e para os demais módulos, a temperatura de entrada é igual à temperatura de saída do fluido no módulo anterior. Esta condição é válida ao longo de $0 \leq r \leq R_{t i}$.

$$
\begin{aligned}
& \text { Para } z=A_{\text {aque }}{ }^{(i)} \text { e } 0 \leq r \leq R_{t i}: \\
& \left.T_{1}{ }^{(i)}\right|_{z=A_{\text {aque }}{ }^{(i)}}=\left\{\begin{array}{cl}
T_{1 \text { in }}, & i=1 \\
\left.T_{1}{ }^{(i-1)}\right|_{z=B_{\text {aque }}{ }^{(i-1)},} & i=2,3, \ldots, n_{\text {aque }}
\end{array}\right.
\end{aligned}
$$

b) Devido à hipótese de simetria de eixo, não existirá gradiente de temperatura em $r=0$. Ou seja, em $r=0$ e para qualquer posição axial, exceto a posição de entrada dos módulos (pois já há uma condição de contorno nesta posição), o fluxo de calor será igual à zero.

$$
\begin{aligned}
& \text { Para } r=0 \text { e } A_{\text {aque }}{ }^{(i)}<z \leq B_{\text {aque }}{ }^{(i)} \text { : } \\
& \left.\quad k_{e f 1}{ }^{(i)}\left(\frac{\partial T_{1}{ }^{(i)}}{\partial r}\right)\right|_{r=0}=0, \quad i=1,2,3, \ldots, n_{\text {aque }}
\end{aligned}
$$


c) O fluxo de calor (W.m ${ }^{-2}$ ) transferido para o fluido alimentício em $r=R_{t i}$ é igual ao fluxo de calor transferido pela parede do tubo interno em contato com o fluido alimentício.

$$
\begin{aligned}
& \text { Para } r=R_{t i} \text { e } A_{\text {aque }}{ }^{(i)}<z \leq B_{\text {aque }}{ }^{(i)}: \\
& \left.k_{\text {ef } 1}{ }^{(i)}\left(\frac{\partial T_{1}{ }^{(i)}}{\partial r}\right)\right|_{r=R_{t i}}=\left.k_{t i}\left(\frac{\partial T_{t i}{ }^{(i)}}{\partial r}\right)\right|_{r=R_{t i}}, \quad i=1,2,3, \ldots, n_{\text {aque }}
\end{aligned}
$$

em que $k_{t i}$ é a condutividade térmica do tubo interno $\left(\mathrm{W} \cdot \mathrm{m}^{-1} \cdot \mathrm{K}^{-1}\right)$ e $T_{t i}$ é a temperatura do tubo interno $(\mathrm{K})$.

Os domínios das condições de contorno das equações (5.13) e (5.14) são abertos na posição axial $\mathrm{A}$, pois nas posições $\left(A_{\text {aque }}, 0\right)$ e $\left(A_{\text {aque }}, R_{t i}\right)$ já está estabelecida a condição dada na equação (5.12).

De forma análoga, as condições de contorno para o balanço diferencial de energia nos módulos da seção de resfriamento são:

a) No módulo 1 da seção de resfriamento, a temperatura de entrada do fluido é igual à temperatura de saída do mesmo no tubo de retenção, e para os demais módulos a temperatura de entrada é igual à temperatura de saída do fluido no módulo anterior. Esta condição é válida ao longo de $0 \leq r \leq R_{t i}$.

$$
\begin{aligned}
& \text { Para } z=A_{\text {resf }}^{(j)} \text { e } 0 \leq r \leq R_{t i}: \\
& \left.T_{1}^{(j)}\right|_{z=A_{\text {resf }}{ }^{(j)}}=\left\{\begin{aligned}
\left.T_{1}\right|_{z=B_{r e t}}, & j=1 \\
\left.T_{1}^{(j-1)}\right|_{z=B_{\text {resf }}{ }^{(j-1)},} & j=2,3, \ldots, n_{\text {resf }}
\end{aligned}\right.
\end{aligned}
$$

b) Analogamente à condição de contorno mostrada na equação (5.13).

$$
\begin{aligned}
& \text { Para } r=0 \text { e } A_{\text {resf }}{ }^{(j)}<z \leq B_{\text {resf }}{ }^{(j)}: \\
&\left.k_{e f 1}{ }^{(j)}\left(\frac{\partial T_{1}^{(j)}}{\partial r}\right)\right|_{r=0}=0, \quad j=1,2,3, \ldots, n_{\text {resf }}
\end{aligned}
$$

c) Analogamente à condição de contorno mostrada na equação (5.14).

$$
\begin{aligned}
& \text { Para } r=R_{t i} \text { e } A_{\text {resf }}{ }^{(j)}<z \leq B_{\text {resf }}{ }^{(j)}: \\
& \left.k_{e f 1}{ }^{(j)}\left(\frac{\partial T_{1}^{(j)}}{\partial r}\right)\right|_{r=R_{t i}}=\left.k_{t i}\left(\frac{\partial T_{t i}^{(j)}}{\partial r}\right)\right|_{r=R_{t i}}, \quad j=1,2,3, \ldots, n_{r e s f}
\end{aligned}
$$


Calculam-se as propriedades termo-físicas médias, de cada módulo, na temperatura que é a média aritmética entre as temperaturas de mistura na entrada e na saída do respectivo módulo. A temperatura média de mistura é dada por Incropera et al. (2008) como:

$$
\begin{gathered}
\overline{T_{1}{ }^{(k)}}(z)=\frac{\int_{0}^{R_{1}} v_{z 1}(r) \cdot T_{1}{ }^{(k)}(z, r) \cdot d A_{1}}{\overline{v_{z 1}} \cdot A_{1}} \\
\overline{T_{1}{ }^{(k)}}(z)=\frac{\int_{0}^{R_{1}} v_{z 1}(r) \cdot T_{1}{ }^{(k)}(z, r) \cdot 2 \pi r d r}{\overline{v_{z 1}} \cdot \pi R_{1}{ }^{2}} \\
\overline{T_{1}{ }^{(k)}}(z)=\frac{2}{\overline{v_{z 1}} \cdot R_{t i}{ }^{2}} \int_{0}^{R_{t i}} v_{z 1}(r) \cdot T_{1}{ }^{(k)}(z, r) \cdot r d r
\end{gathered}
$$

Calcula-se a temperatura média de cada módulo $k$ como:

$$
\overline{T_{1}{ }^{(k)}}{ }_{m}=\frac{\left.\overline{T_{1}^{(k)}}\right|_{z=A^{(k)}}+\left.\overline{T_{1}^{(k)}}\right|_{z=B^{(k)}}}{2}
$$

\subsubsection{Conservação de atributos de qualidade microbiológica ou qualidade}

nutricional

Os atributos de qualidade microbiológica ou qualidade nutricional são componentes do alimento no qual se deseja acompanhar no tratamento térmico com o objetivo de torná-lo mais adequado para consumo. Dentre os atributos de qualidade microbiológica, têm-se os micro-organismos patogênicos ou deterioradores (células vegetativas ou esporos) ou enzimas. E como atributos de qualidade nutricional têm-se, por exemplo, as vitaminas e a cor.

Aplicando, ao fluido alimentício em um módulo $k$, o balanço diferencial de um atributo genérico "A", tem-se a seguinte expressão de acordo com Bird, Stewart e Lightfoot (2002):

$$
\frac{\partial C_{A}{ }^{(k)}}{\partial t}+\vec{v}_{1} \cdot \nabla C_{A}{ }^{(k)}=\nabla \cdot\left(D_{A} \nabla C_{A}{ }^{(k)}\right)+R_{A}{ }^{(k)}
$$

Os termos do lado esquerdo da equação (5.20) representam o acúmulo e o transporte por advecção, e os do lado direito, transporte por difusão e termo de produção/consumo volumétrico, sendo: 
$(k)=\left\{\begin{array}{l}i=1,2,3, \ldots, n_{\text {aque }}, \text { se módulo da seção de aquecimento; } \\ j=1,2,3, \ldots, n_{\text {resf }}, \text { se módulo da seção de resfriamento; }\end{array}\right.$

$C_{A}=$ concentração volumétrica do atributo genérico "A" (UFC. $\mathrm{m}^{-3}$ ou kg. $\mathrm{m}^{-3}$ );

$D_{A}=$ difusividade mássica do atributo genérico " $\mathrm{A}$ " $\left(\mathrm{m}^{2} . \mathrm{s}^{-1}\right)$;

$R_{A}=$ taxa de produção/destruição volumétrica do atributo genérico "A" (UFC. $\mathrm{m}^{-3} \cdot \mathrm{s}^{-1}$ ou $\mathrm{kg} \cdot \mathrm{m}^{-3} \cdot \mathrm{s}^{-1}$ ).

Considerando:

- Estado estacionário:

$$
\left(\frac{\partial C_{A}{ }^{(k)}}{\partial t}\right)=0
$$

- Tubo cilíndrico e reto com simetria angular:

$$
v_{\theta 1}=\frac{\partial C_{A}{ }^{(k)}}{\partial \theta}=0 \rightarrow\left(\vec{v}_{1} \cdot \nabla C_{A}{ }^{(k)}\right)=v_{r 1} \frac{\partial C_{A}{ }^{(k)}}{\partial r}+v_{z 1} \frac{\partial C_{A}{ }^{(k)}}{\partial z} ;
$$

- Escoamento desenvolvido:

$$
v_{r 1}=0 \rightarrow\left(\vec{v}_{1} \cdot \nabla C_{A}^{(k)}\right)=v_{z 1} \frac{\partial C_{A}^{(k)}}{\partial z} ;
$$

- Contribuição da transferência de massa associada ao escoamento na direção axial muito maior que a contribuição do transporte difusivo na direção axial:

$$
v_{z 1} \frac{\partial C_{A}{ }^{(k)}}{\partial z} \gg D_{A} \frac{\partial^{2} C_{A}^{(k)}}{\partial z^{2}} \rightarrow D_{A} \frac{\partial^{2} C_{A}^{(k)}}{\partial z^{2}} \text { é desprezível; }
$$

- Taxa de destruição volumétrica obedecendo a uma cinética de primeira ordem:

$$
R_{A}{ }^{(k)}=-k_{r}{ }^{(k)} C_{A}{ }^{(k)}=-\frac{\ln 10}{D_{\operatorname{dec} A}{ }^{(k)}} C_{A}{ }^{(k)}
$$

em que $k_{r}{ }^{(k)}$ e $D_{\text {dec }}{ }^{(k)}$ são, respectivamente, constante cinética de destruição térmica $\left(\mathrm{s}^{-1}\right)$ e tempo de decaimento decimal do atributo genérico " $A$ " (s), e seus valores são calculados pelas equações (3.12) e (3.13).

- Escoamento laminar com difusão radial efetiva: leva-se em consideração a existência de uma difusividade mássica efetiva radial $\left(D_{\text {mass_ef } A}\right)$, decorrendo da interação entre as lâminas do fluido, devido a vibrações mecânicas, imperfeições na tubulação, acessórios de tubulação (curvas, tes, válvulas), uso de tubos corrugados, variações 
de densidade e flutuação das vazões ocorrendo mistura entre as camadas. Este efeito de mistura aumenta a difusividade mássica:

$$
D_{A} \rightarrow D_{\text {mass_ef } A}
$$

Reescrevendo a equação (5.20), levando as considerações mencionadas:

$$
v_{z 1} \frac{\partial C_{A}{ }^{(k)}}{\partial z}=D_{\text {mass_ef } A}\left[\frac{1}{r} \frac{\partial}{\partial r}\left(r \frac{\partial C_{A}{ }^{(k)}}{\partial r}\right)\right]-\frac{\ln 10}{D_{\text {decA }}{ }^{(k)}} C_{A}{ }^{(k)}
$$

Substituindo a equação (3.13) em (5.21) tem-se:

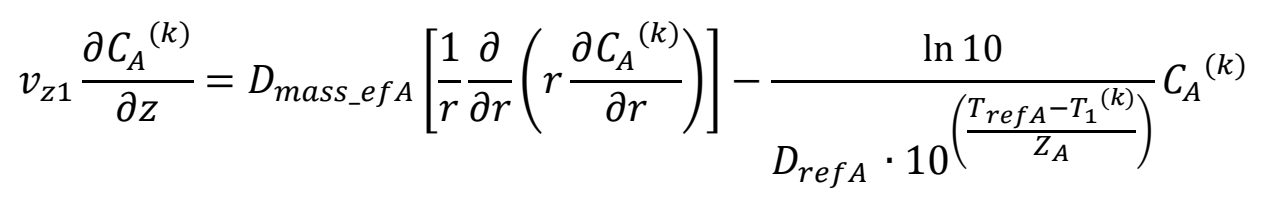

O valor da difusividade mássica efetiva foi considerado igual em todos os módulos, por ser um parâmetro de difícil determinação.

Para resolver a equação (5.22) são necessárias três condições de contorno, sendo uma na direção axial, decorrente da derivada parcial de primeira ordem em $z$, e duas na direção radial, devido à derivada parcial de segunda ordem em $r$.

As condições de contorno para o balanço diferencial do atributo nos módulos da seção de aquecimento são:

a) Concentração do atributo "A" na entrada do pasteurizador $\left(C_{A 0}\right)$ é conhecida (entrada do módulo 1), e para os demais módulos o perfil de concentração do atributo na entrada é igual ao perfil de concentração na saída do módulo anterior. Válido para $0 \leq r \leq R_{1}$.

$$
\begin{aligned}
& \text { Para } z=A_{\text {aque }}{ }^{(i)} \text { e } 0 \leq r \leq R_{t i}: \\
& \left.C_{A}{ }^{(i)}\right|_{z=A_{\text {aque }}{ }^{(i)}}= \begin{cases}C_{A 0}, & i=1 \\
\left.C_{A}{ }^{(i-1)}\right|_{z=B_{\text {aque }}{ }^{(i-1)},} & i=2,3, \ldots, n_{\text {aque }}\end{cases}
\end{aligned}
$$

b) Não variação da concentração devido à simetria de eixo. Válido para $A_{\text {aque }}{ }^{(i)}<z \leq B_{\text {aque }}{ }^{(i)}$, pois na posição $A_{\text {aque }}{ }^{(i)}$ tem-se uma condição de contorno.

$$
\begin{aligned}
& \text { Para } r=0 \text { e } A_{\text {aque }}{ }^{(i)}<z \leq B_{\text {aque }}{ }^{(i)}: \\
& \qquad\left.\left(\frac{\partial C_{A}{ }^{(i)}}{\partial r}\right)\right|_{r=0}=0, \quad i=1,2,3, \ldots, n_{\text {aque }}
\end{aligned}
$$


c) Não variação da concentração devido à impermeabilidade da parede interna do tubo interno. Válido para $A_{\text {aque }}{ }^{(i)}<z \leq B_{a q u e}{ }^{(i)}$, pois na posição $A_{a q u e}{ }^{(i)}$ tem-se uma condição de contorno.

$$
\begin{aligned}
\text { Para } r= & R_{t i} \text { e } A_{\text {aque }}{ }^{(i)}<z \leq B_{\text {aque }}{ }^{(i)}: \\
& \left.\left(\frac{\partial C_{A}{ }^{(i)}}{\partial r}\right)\right|_{r=R_{t i}}=0, \quad i=1,2,3, \ldots, n_{\text {aque }}
\end{aligned}
$$

Analogamente, as condições de contorno para o balanço diferencial do atributo genérico "A" nos módulos da seção de resfriamento são:

a) No módulo 1 da seção de resfriamento, o perfil radial de concentração de entrada do atributo "A" é igual ao da saída do mesmo proveniente do tubo de retenção, e para os demais módulos o perfil da concentração de entrada é igual ao de saída no módulo anterior.

$$
\begin{aligned}
& \text { Para } z=A_{\text {resf }}{ }^{(j)} \text { e } 0 \leq r \leq R_{t i}: \\
& \left.C_{A}{ }^{(j)}\right|_{z=A_{\text {resf }}(j)}=\left\{\begin{aligned}
\left.C_{A}\right|_{z=B_{r e t}}, & j=1 \\
\left.C_{A}{ }^{(j-1)}\right|_{z=B_{\text {resf }}} ^{(j-1)}, & j=2,3, \ldots, n_{\text {resf }}
\end{aligned}\right.
\end{aligned}
$$

b) Analogamente à condição de contorno mostrada na equação (5.24).

$$
\begin{aligned}
& \text { Para } r=0 \text { e } A_{\text {resf }}^{(j)}<z \leq B_{\text {resf }}^{(j)} \text { : } \\
& \qquad\left.\left(\frac{\partial C_{A}^{(j)}}{\partial r}\right)\right|_{r=0}=0, \quad j=1,2,3, \ldots, n_{\text {resf }}
\end{aligned}
$$

c) Analogamente à condição de contorno mostrada na equação (5.25).

$$
\begin{aligned}
& \text { Para } r=R_{t i} \text { e } A_{\text {resf }}^{(j)}<z \leq B_{\text {resf }}^{(j)}: \\
& \qquad\left.\left(\frac{\partial C_{A}^{(j)}}{\partial r}\right)\right|_{r=R_{t i}}=0, \quad j=1,2,3, \ldots, n_{\text {resf }}
\end{aligned}
$$

Para avaliação da destruição do atributo de qualidade microbiológica ou qualidade nutricional utiliza-se o valor de esterilização. Este valor quantifica o número de reduções decimais que o atributo sofreu. Por exemplo, se o valor de esterilização for igual a 5, quer dizer que 99,999\% do atributo sofreu inativação ou foi destruído no final do processo. Na modelagem, esta variável é calculada através da concentração média de mistura. A concentração média de mistura é calculada pela equação (5.29) e sua dedução é análoga à da equação (5.18). 


$$
\overline{C_{A}{ }^{(k)}}(z)=\frac{2}{\overline{v_{z 1}} \cdot R_{t i}^{2}} \int_{0}^{R_{t i}} v_{z 1}(r) \cdot C_{A}{ }^{(k)}(z, r) \cdot r d r
$$

O valor de esterilização do tratamento térmico no fluido alimentício, expresso a partir da equação (3.15) como o número de reduções decimais, é:

$$
S_{\text {value }}^{(k)}(z)=\log _{10}\left(\frac{C_{A 0}}{\overline{C_{A}^{(k)}(z)}}\right)
$$

\subsubsection{Tubo interno}

\subsubsection{Balanço de energia}

Aplicando o balanço diferencial de energia ao volume de controle do tubo interno tem-se a seguinte expressão de acordo com Bird, Stewart e Lightfoot (2002):

$$
\rho_{t i}{ }^{(k)} C_{p t i}{ }^{(k)}\left(\frac{\partial T_{t i}{ }^{(k)}}{\partial t}+\vec{v}_{t i} \cdot \nabla T_{t i}{ }^{(k)}\right)=\nabla\left(k_{t i} \cdot \nabla T_{t i}{ }^{(k)}\right)+\dot{Q}_{t i}{ }^{(k)}
$$

Os termos do lado esquerdo da equação (5.31) representam o acúmulo de energia e o transporte de energia por advecção, e os do lado direito, transporte por difusão e geração volumétrica de energia térmica, sendo:

$(k)=\left\{\begin{array}{l}i=1,2,3, \ldots, n_{\text {aque }}, \text { se módulo da seção de aquecimento; } \\ j=1,2,3, \ldots, n_{\text {resf }}, \text { se módulo da seção de resfriamento; }\end{array}\right.$

$\rho_{t i} \quad=$ massa específica do tubo interno $\left(\mathrm{kg} \cdot \mathrm{m}^{-3}\right)$;

$C_{p t i}=$ calor específico do tubo interno $\left(\mathrm{J} \cdot \mathrm{kg}^{-1} \cdot \mathrm{K}^{-1}\right)$;

$k_{t i}=$ condutividade térmica do tubo interno $\left(\mathrm{W} \cdot \mathrm{m}^{-1} \cdot \mathrm{K}^{-1}\right)$;

$\dot{Q}_{t i} \quad=$ geração volumétrica de energia térmica no tubo interno (W. $\left.\mathrm{m}^{-3}\right)$;

$T_{t i}(z, r)=$ temperatura do tubo interno $(\mathrm{K})$.

Considerando:

- Estado estacionário:

$$
\left(\frac{\partial T_{t i}^{(k)}}{\partial t}\right)=0
$$


- Tubo cilíndrico e reto com simetria angular:

$$
\frac{\partial T_{t i}{ }^{(k)}}{\partial \theta}=0 ;
$$

- Sem advecção em material sólido:

$$
\left(\vec{v}_{t i} \cdot \nabla T_{t i}^{(k)}\right)=0 ;
$$

- Sem geração interna de energia térmica:

$$
\dot{Q}_{t i}{ }^{(k)}=0 \text {; }
$$

- Material isotrópico.

Reescrevendo a equação (5.31), levando as considerações mencionadas acima:

$$
0=k_{t i}\left[\frac{1}{r} \frac{\partial}{\partial r}\left(r \frac{\partial T_{t i}{ }^{(k)}}{\partial r}\right)+\frac{\partial}{\partial z}\left(\frac{\partial T_{t i}{ }^{(k)}}{\partial z}\right)\right]
$$

Para a resolução da equação (5.32) são necessárias quatro condições de contorno. Duas para a direção axial e duas para a direção radial, pois em ambas as direções têm-se derivadas parciais de segunda ordem.

As condições de contorno para o balanço de energia do tubo interno, nos módulos da seção de aquecimento são:

a) No início do módulo 1, considera-se a parede lateral adiabática. Nos demais módulos existe a continuidade de temperatura entre final e início de módulos consecutivos. A condição é válida para o intervalo radial $R_{t i} \leq r \leq R_{t i}+e_{t i}$

$$
\begin{aligned}
& \text { Para } z=A_{\text {aque }}{ }^{(i)} \text { e } R_{t i} \leq r \leq R_{t i}+e_{t i} \text { : } \\
& \left\{\begin{aligned}
\left.k_{t i}\left(\frac{\partial T_{t i}{ }^{(i)}}{\partial z}\right)\right|_{z=A_{\text {aque }}{ }^{(i)}}=0, & i=1 \\
\left.T_{t i}{ }^{(i)}\right|_{z=A_{\text {aque }}(i)}=\left.T_{t i}^{(i-1)}\right|_{z=B_{\text {aque }}}{ }^{(i-1)}, & i=2,3, \ldots, n_{\text {aque }}
\end{aligned}\right.
\end{aligned}
$$

b) A temperatura da parede lateral, no final do último módulo da seção de aquecimento, é igual à temperatura no início do tubo de retenção. Nos outros módulos da seção de aquecimento, tem-se que o fluxo de calor axial, no final de determinado módulo é igual ao fluxo de calor no início do módulo posterior. Ao longo de $R_{t i} \leq r \leq R_{t i}+e_{t i}$.

$$
\text { Para } z=B_{\text {aque }}{ }^{(i)} \text { e } R_{t i} \leq r \leq R_{t i}+e_{t i} \text { : }
$$




$$
\begin{gathered}
\left.T_{t i}{ }^{(i)}\right|_{z=B_{\text {aque }}(i)}=\left.T_{t i}\right|_{z=A_{\text {ret }}}, \quad i=n_{\text {aque }} \\
\left.k_{t i}\left(\frac{\partial T_{t i}{ }^{(i)}}{\partial z}\right)\right|_{z=B_{\text {aque }}(i)}=\left.k_{t i}\left(\frac{\partial T_{t i}{ }^{(i+1)}}{\partial z}\right)\right|_{z=A_{\text {aque }}{ }^{(i+1)}}, \quad i=1,2,3, \ldots,\left(n_{\text {aque }}-1\right)
\end{gathered}
$$

Observa-se que na equação (5.34) foi utilizada uma igualdade de fluxos de calor entre o início de um módulo e final do outro. Isto se deve ao fato de que, caso houvesse uma igualdade de temperatura, como na condição (5.33), ter-se-ia uma mesma condição de contorno, aplicada em duas posições distintas, nos módulos intermediários, fazendo com que existisse um sistema de uma equação para duas variáveis.

c) Igualdade de temperatura na interface parede interna do tubo interno e fluido alimentício. Ela é válida para o intervalo $A_{\text {aque }}{ }^{(i)}<z<B_{a q u e}{ }^{(i)}$, pois as extremidades de cada módulo são representadas pelas condições de contorno (5.33) e (5.34).

$$
\begin{aligned}
& \text { Para } r=R_{t i} \text { e } A_{\text {aque }}{ }^{(i)}<z<B_{\text {aque }}{ }^{(i)}: \\
& \left.T_{t i}{ }^{(i)}\right|_{r=R_{t i}}=\left.T_{1}{ }^{(i)}\right|_{r=R_{t i}}, \quad i=1,2,3, \ldots, n_{\text {aque }}
\end{aligned}
$$

d) Definição do fluxo de calor radialmente trocado entre a parede externa do tubo interno e o centro do fluido que passa pelo ânulo. Ela é válida para o intervalo $A_{\text {aque }}{ }^{(i)}<z<B_{\text {aque }}{ }^{(i)}$, pois as extremidades de cada módulo são representadas por condições de contorno.

$$
\begin{gathered}
\text { Para } r=R_{t i}+e_{t i} \text { e } A_{a q u e}{ }^{(i)}<z<B_{a q u e}{ }^{(i)}: \\
-\left.k_{t i}\left(\frac{\partial T_{t i}{ }^{(i)}}{\partial z}\right)\right|_{r=R_{t i}+e_{t i}}=Q_{2-t i}{ }^{(i)} \\
-\left.k_{t i}\left(\frac{\partial T_{t i}{ }^{(i)}}{\partial z}\right)\right|_{r=R_{t i}+e_{t i}}=U_{2-t i}{ }^{(i)}\left(\left.T_{t i}{ }^{(i)}\right|_{r=R_{t i}+e_{t i}}-T_{2}{ }^{(i)}\right), \quad i=1,2,3, \ldots, n_{\text {aque }}
\end{gathered}
$$

em que $T_{2}{ }^{(i)}(z)$ é a temperatura do centro do fluido utilidade (média radial) $(\mathrm{K}) \mathrm{e}$ $U_{2-t i}{ }^{(k)}$ é coeficiente de troca térmica entre o centro do fluido utilidade e a parede externa do tubo interno $\left(\mathrm{W} \cdot \mathrm{m}^{-2} \cdot \mathrm{K}^{-1}\right)$, e é determinado posteriormente pela equação (5.52). Ambas as variáveis são melhores compreendidas na seção 5.1.3.

As condições de contorno para o balanço de energia do tubo interno, nos módulos da seção de resfriamento são: 
a) A temperatura na entrada da seção de resfriamento (módulo 1) é igual à temperatura de saída do tubo de retenção para o fluido. Para os demais módulos, a temperatura na posição de entrada é igual à temperatura na posição de saída do módulo anterior. A condição é válida para o intervalo de $R_{t i} \leq r \leq R_{t i}+e_{t i}$.

$$
\begin{aligned}
& \text { Para } z=A_{\text {resf }}{ }^{(j)} \text { e } R_{t i} \leq r \leq R_{t i}+e_{t i}: \\
& \left.T_{t i}{ }^{(j)}\right|_{z=A_{\text {resf }}{ }^{(j)}}=\left\{\begin{aligned}
\left.T_{t i}\right|_{z=B_{r e t}}, & j=1 \\
\left.T_{t i}{ }^{(j-1)}\right|_{z=B_{\text {resf }}{ }^{(j-1)},}, & j=2,3, \ldots, n_{\text {resf }}
\end{aligned}\right.
\end{aligned}
$$

b) No final da seção de resfriamento (módulo $n_{\text {resf }}$ ) considera-se a parede lateral adiabática. Nos demais módulos, iguala-se o fluxo de calor na posição de saída de um módulo com o fluxo de calor na posição de entrada do módulo sucessor. A condição é válida para o intervalo radial $R_{t i} \leq r \leq R_{t i}+e_{t i}$

Para $z=B_{\text {resf }}^{(j)}$ e $R_{t i} \leq r \leq R_{t i}+e_{t i}$ :

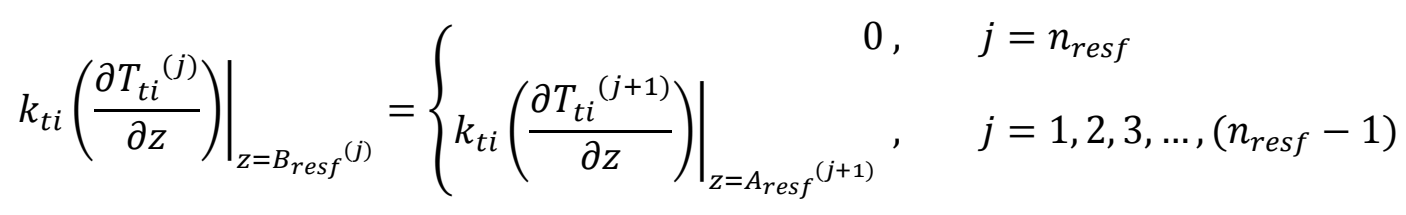

c) Condição análoga à explicitada nas equações em (5.35).

$$
\begin{aligned}
\text { Para } r & =R_{t i} \text { e } A_{\text {resf }}{ }^{(j)}<z<B_{\text {resf }}{ }^{(j)} \text { : } \\
& \left.T_{t i}{ }^{(j)}\right|_{r=R_{t i}}=\left.T_{1}^{(j)}\right|_{r=R_{t i}}, \quad j=1,2,3, \ldots, n_{\text {resf }}
\end{aligned}
$$

d) Condição análoga à explicitada nas equações em (5.36).

$$
\begin{gathered}
\text { Para } r=R_{t i}+e_{t i} \text { e } A_{r e s f}^{(j)}<z<B_{r e s f}{ }^{(j)}: \\
-\left.k_{t i}\left(\frac{\partial T_{t i}^{(j)}}{\partial z}\right)\right|_{r=R_{t i}+e_{t i}}=Q_{2-t i}{ }^{(j)} \\
-\left.k_{t i}\left(\frac{\partial T_{t i}^{(j)}}{\partial z}\right)\right|_{r=R_{t i}+e_{t i}}=U_{2-t i}^{(j)}\left(\left.T_{t i}^{(j)}\right|_{r=R_{t i}+e_{t i}}-T_{2}^{(j)}\right), \quad j=1,2,3, \ldots, n_{r e s f}
\end{gathered}
$$




\subsubsection{Fluido utilidade escoando na região anular}

\subsubsection{Balanço de energia}

Aplicando o balanço diferencial de energia ao volume de controle anular do fluido utilidade, tem-se a expressão dada por Bird, Stewart e Lightfoot (2002):

$$
\rho_{2}{ }^{(k)} C_{p 2}{ }^{(k)}\left(\frac{\partial T_{2}{ }^{(k)}}{\partial t}+\vec{v}_{2} \cdot \nabla T_{2}{ }^{(k)}\right)=\nabla\left(k_{2} \cdot \nabla T_{2}{ }^{(k)}\right)+\dot{Q}_{2}{ }^{(k)}
$$

em que:

$(k)=\left\{\begin{array}{l}i=1,2,3, \ldots, n_{\text {aque }}, \text { se módulo da seção de aquecimento; } \\ j=1,2,3, \ldots, n_{\text {resf }}, \text { se módulo da seção de resfriamento; }\end{array}\right.$

$\rho_{2} \quad=$ massa específica média do fluido utilidade $\left(\mathrm{kg} \cdot \mathrm{m}^{-3}\right)$;

$C_{p 2} \quad=$ calor específico médio do fluido utilidade $\left(\mathrm{J} \cdot \mathrm{kg}^{-1} \cdot \mathrm{K}^{-1}\right)$;

$k_{2}=$ condutividade térmica média do fluido utilidade $\left(\mathrm{W} \cdot \mathrm{m}^{-1} \cdot \mathrm{K}^{-1}\right)$;

$\vec{v}_{2} \quad=$ vetor velocidade do fluido utilidade $\left(\mathrm{m} . \mathrm{s}^{-1}\right)$;

$\dot{Q_{2}}=$ geração volumétrica de energia térmica no fluido utilidade $\left(\mathrm{W} \cdot \mathrm{m}^{-3}\right)$;

$T_{2}(z, r)=$ temperatura do fluido utilidade $(\mathrm{K})$.

Considerando:

- Estado estacionário:

$$
\left(\frac{\partial T_{2}^{(k)}}{\partial t}\right)=0
$$

- Escoamento turbulento em contracorrente com o fluido alimentício:

$$
\begin{gathered}
\vec{v}_{2}=-v_{z 2} \cdot \overrightarrow{\varphi_{z}}+v_{r 2} \cdot \overrightarrow{\varphi_{r}}+v_{\theta 2} \cdot \overrightarrow{\varphi_{\theta}} ; \\
\left(\vec{v}_{2} \cdot \nabla T_{2}{ }^{(k)}\right)=-v_{z 2} \frac{\partial T_{2}{ }^{(k)}}{\partial z}+v_{r 2} \frac{\partial T_{2}{ }^{(k)}}{\partial r}+\frac{v_{\theta 2}}{r} \frac{\partial T_{2}{ }^{(k)}}{\partial \theta}
\end{gathered}
$$

- Perfil de velocidade axial pistonado e devido aos efeitos de mistura da turbulência considera-se que a temperatura, ao longo do raio, será uniforme, consequentemente o gradiente de temperatura em relação à direção radial será igual à zero.

$$
\frac{\partial T_{2}{ }^{(k)}}{\partial r}=0 \rightarrow\left(\vec{v}_{2} \cdot \nabla T_{2}^{(k)}\right)=-v_{z 2} \frac{\partial T_{2}^{(k)}}{\partial z}+\frac{v_{\theta 2}}{r} \frac{\partial T_{2}^{(k)}}{\partial \theta} ;
$$


- Tubo cilíndrico e reto com simetria angular:

$$
\frac{\partial T_{2}{ }^{(k)}}{\partial \theta}=0 \rightarrow\left(\vec{v}_{2} \cdot \nabla T_{2}{ }^{(k)}\right)=-v_{z 2} \frac{\partial T_{2}{ }^{(k)}}{\partial z} ;
$$

- Devido a efeitos da turbulência, a velocidade na direção axial será considerada constante e seu valor será o valor da velocidade média do fluido:

$$
\begin{gathered}
v_{z 2}=\overline{v_{z 2}} \rightarrow\left(\vec{v}_{2} \cdot \nabla T_{2}{ }^{(k)}\right)=-\overline{v_{z 2}} \frac{\partial T_{2}{ }^{(k)}}{\partial z} ; \\
\overline{v_{z 2}}=\frac{q_{2}}{A_{2}}=\frac{q_{2}}{\pi \cdot\left(R_{t e}{ }^{2}-\left(R_{t i}+e_{t i}\right)^{2}\right)}
\end{gathered}
$$

em que $q_{2}$ é a vazão volumétrica do fluido utilidade $\left(\mathrm{m}^{3} . \mathrm{s}^{-1}\right)$ e $A_{2}$ é a área da seção perpendicular à direção axial do escoamento do fluido utilidade $\left(\mathrm{m}^{2}\right)$;

- Condutividade térmica axial efetiva, ao invés de condutividade térmica, devido aos efeitos de mistura axial proporcionados pela turbulência:

$$
k_{2}{ }^{(k)} \rightarrow k_{e f 2}{ }^{(k)}
$$

Em que $k_{e f 2}{ }^{(k)}$ é calculado como:

$$
k_{\text {ef } 2}{ }^{(k)}=F_{\text {incr } 2}{ }^{(k)} \cdot k_{2}{ }^{(k)}
$$

sendo $F_{\text {incr } 2}{ }^{(k)}$ definido como o fator de aumento da condutividade térmica do fluido utilidade na direção axial (adimensional).

- Sem geração interna de energia. Contempla-se, no entanto, o calor trocado radialmente como geração volumétrica de energia térmica, já que o gradiente radial de temperatura foi desprezado. No volume de controle em estudo, a taxa de calor trocado pelo fluido da região anular por volume de fluido utilidade, é a soma da taxa de calor trocado do centro do fluido utilidade com o tubo interno mais a taxa de calor trocado do centro do fluido utilidade com o tubo externo, por unidade de volume de fluido utilidade:

$$
{\dot{Q_{2}}}^{(k)}=\dot{Q}_{2-t i}{ }^{(k)}+\dot{Q}_{2-t e}{ }^{(k)} \text {; }
$$

Reescrevendo a equação (5.41), levando as considerações mencionadas mais o acréscimo dos termos de calor radialmente transportado do fluido para sua vizinhança, tem-se:

$$
\rho_{2}{ }^{(k)} C_{p 2}{ }^{(k)}\left(-\overline{v_{z 2}} \frac{\partial T_{2}{ }^{(k)}}{\partial z}\right)=k_{e f 2}\left(\frac{\partial^{2} T_{2}{ }^{(k)}}{\partial z^{2}}\right)+\dot{Q}_{2-t i}{ }^{(k)}+\dot{Q}_{2-t e}{ }^{(k)}
$$


em que:

$k_{e f 2}=$ condutividade térmica axial efetiva do fluido utilidade $\left(\mathrm{W} \cdot \mathrm{m}^{-1} \cdot \mathrm{K}^{-1}\right)$;

$\overline{v_{z 2}} \quad=$ velocidade média (bulk) do fluido utilidade $\left(\mathrm{m} . \mathrm{s}^{-1}\right)$;

$T_{2}(z)=$ temperatura do centro do fluido utilidade (média radial) (K);

$\dot{Q}_{2-t i}=$ taxa de calor trocado radialmente entre o centro do fluido utilidade e a parede externa do tubo interno, por unidade de volume de fluido utilidade $\left(\mathrm{W} . \mathrm{m}^{-3}\right)$;

$\dot{Q}_{2-t e}=$ taxa de calor trocado radialmente entre o centro do fluido utilidade e o raio médio do tubo externo (raio em que se encontra a temperatura média do tubo externo), por unidade de volume de fluido utilidade (W. $\mathrm{m}^{-3}$ ).

O primeiro termo do lado direito da equação (5.44) é o gradiente da temperatura do fluido utilidade na direção axial devido ao efeito da difusão. Este termo pode ser utilizado a depender do grau de informação que se tenha e se queira obter. A contribuição deste termo será muito pequena frente ao termo convectivo (lado esquerdo). No entanto, para efeitos desta modelagem este efeito não será desprezado.

Como se considerou não existência de gradiente da temperatura do fluido utilidade na direção radial, ou seja, temperatura do fluido é igual para qualquer posição radial entre $R_{t i}+e_{t i} \leq r \leq R_{t e}$. Para a modelagem adotou-se um raio de referência e este é o raio médio ou central da região que escoa o fluido. Seu valor é dado por:

$$
r_{\text {médio_2 }}=\frac{R_{t i}+e_{t i}+R_{t e}}{2}
$$

Para resolução da equação (5.44) são necessárias duas condições de contorno na direção axial.

As condições de contorno para o balanço de energia do fluido utilidade, nos módulos da seção de aquecimento são:

a) No início do módulo 1 (saída do fluido utilidade da seção de aquecimento) não existe gradiente de temperatura do fluido (fluxo de calor na direção axial desprezível ao fluxo de calor na direção radial) enquanto nos demais módulos existe a continuidade de temperatura entre final e início de módulos consecutivos. A condição é aplicada em $r=r_{\text {médio_2 }}$. 


$$
\begin{aligned}
& \text { Para } z=A_{\text {aque }}{ }^{(i)} \text { e } r=r_{\text {médio_ } 2}: \\
& \left\{\begin{array}{c}
\left.k_{\text {ef2 }}\left(\frac{\partial T_{2}{ }^{(i)}}{\partial z}\right)\right|_{z=A_{\text {aque }}{ }^{(i)}}=0, \quad i=1 \\
\left.T_{2}{ }^{(i)}\right|_{z=A_{\text {aque }}{ }^{(i)}}=\left.T_{2}{ }^{(i-1)}\right|_{z=B_{\text {aque }}{ }^{(i-1)},}, i=2,3, \ldots, n_{\text {aque }}
\end{array}\right.
\end{aligned}
$$

b) A temperatura do fluido, no final do último módulo da seção de aquecimento (entrada do fluido) é igual a um parâmetro $T_{2 i n \_a q u e}$ (temperatura de alimentação da água quente). Enquanto, nos outros módulos da seção de aquecimento, tem-se que o fluxo de calor axial, no final de determinado módulo é igual ao fluxo de calor axial no início do módulo posterior. Válido para $r=r_{\text {médio_2 }}$.

$$
\begin{gathered}
\text { Para } z=B_{\text {aque }}{ }^{(i)} \text { e } r=r_{\text {médio_2 }}: \\
\left.T_{2}{ }^{(i)}\right|_{z=B_{\text {aque }}{ }^{(i)}}=T_{2 \text { 2in_aque }}, \quad i=n_{\text {aque }} \\
\left.k_{\text {ef } 2}\left(\frac{\partial T_{2}{ }^{(i)}}{\partial z}\right)\right|_{z=B_{\text {aque }}{ }^{(i)}}=\left.k_{e f 2}\left(\frac{\partial T_{2}{ }^{(i+1)}}{\partial z}\right)\right|_{z=A_{\text {aque }}{ }^{(i+1)}}, \quad i=1,2,3, \ldots,\left(n_{\text {aque }}-1\right)
\end{gathered}
$$

Com base na configuração do escoamento da seção de resfriamento (fluido utilidade escoando em contracorrente com o fluido alimentício nos módulos, e em paralelo em relação à seção como um todo), tem-se que as condições de contorno para o balanço de energia do fluido utilidade, nos módulos da seção de resfriamento são:

a) Na posição inicial do módulo $n_{\text {resf }}$ (saída do fluido utilidade na seção de resfriamento) não existe gradiente de temperatura do fluido (fluxo de calor na direção axial desprezível ao fluxo de calor na direção radial) enquanto nos demais módulos existe uma continuidade de fluxos de calor entre o início de cada módulo e o final do módulo posterior. A condição é válida para $r=r_{m e ́ d i o \_2}$.

$$
\begin{aligned}
& \text { Para } z=A_{\text {resf }}{ }^{(j)} \text { e } r=r_{\text {médio_2 }}: \\
& \left.k_{\text {ef } 2}\left(\frac{\partial T_{2}^{(j)}}{\partial z}\right)\right|_{z=A_{\text {resf }}(j)}=0, \quad j=n_{\text {resf }} \\
& =\left\{\begin{aligned}
\left.k_{e f 2}\left(\frac{\partial T_{2}^{(j+1)}}{\partial z}\right)\right|_{z=B_{\text {resf }}(j+1)}, j=1,2,3, \ldots,\left(n_{\text {resf }}-1\right)
\end{aligned}\right.
\end{aligned}
$$


b) A temperatura do fluido, no final do módulo 1 da seção de resfriamento (entrada do fluido utilidade), é igual a um parâmetro $T_{2 i n \_r e s f}$ (temperatura de alimentação da água fria). Enquanto, nos outros módulos, da seção de resfriamento, tem-se que a temperatura no final de determinado módulo é igual à temperatura no início do módulo anterior, (vide Figura 5.1). Exemplificando, a temperatura no final do módulo $2\left(B_{\text {resf }}{ }^{(2)}\right)$ é igual à temperatura na entrada do módulo 1 $\left(A_{\text {resf }}{ }^{(1)}\right)$. Válido para $r=r_{\text {médio_2. }}$.

$$
\begin{aligned}
& \text { Para } z=B_{\text {resf }}{ }^{(j)} r=r_{\text {médio__ }}: \\
& \left.T_{2}^{(j)}\right|_{z=B_{\text {resf }}(j)}=\left\{\begin{aligned}
T_{\text {2in_resf }}, & j=1 \\
\left.T_{2}{ }^{(j-1)}\right|_{z=A_{\text {resf }}(j-1)}, & j=2,3, \ldots, n_{\text {resf }}
\end{aligned}\right.
\end{aligned}
$$

Calculam-se as taxas de calor, trocado radialmente pelo fluido utilidade, pelo conjunto de equações (5.50) a (5.56):

$$
\begin{gathered}
\dot{Q}_{2-t i}{ }^{(k)}=U_{2-t i}{ }^{(k)} \frac{d A_{\text {ext_ti }}}{d V_{2}}\left(\left.T_{t i}\right|_{r=R_{1}+e_{1}}{ }^{(k)}-T_{2}{ }^{(k)}\right) \\
\dot{Q}_{2-t e}{ }^{(k)}=U_{2-t e}{ }^{(k)} \frac{d A_{\text {int_te }}}{d V_{2}}\left(T_{a m b}-\overline{T_{t e}{ }^{(k)}}\right) \\
\frac{1}{U_{2-t i}{ }^{(k)}}=\frac{1}{h_{2}{ }^{(k)}} \\
\frac{1}{U_{2-t e}{ }^{(k)}}=\frac{1}{h_{2}{ }^{(k)}}+\frac{R_{t e}}{k_{t e}} \ln \left(\frac{r_{\text {médio_te }}}{R_{t e}}\right) \\
d A_{\text {ext_ti }}=2 \pi\left(R_{t i}+e_{t i}\right) d z \\
d A_{\text {int_te }}=2 \pi R_{t e} d z \\
d V_{2}=\left(\pi\left(R_{t e}\right)^{2}-\pi\left(R_{t i}+e_{t i}\right)^{2}\right) d z
\end{gathered}
$$

em que:

$U_{2-t i}=$ coeficiente de troca térmica entre o centro do fluido utilidade e a parede externa do tubo interno, por área externa de tubo interno $\left(\mathrm{W} \cdot \mathrm{m}^{-2} \cdot \mathrm{K}^{-1}\right)$;

$U_{2-t e}=$ coeficiente de troca térmica entre o centro do fluido utilidade e o raio onde se encontra a temperatura média do tubo externo, por área interna de tubo externo $\left(\mathrm{W} \cdot \mathrm{m}^{-2} \cdot \mathrm{K}^{-1}\right)$;

$h_{2} \quad=$ coeficiente convectivo do fluido utilidade $\left(\mathrm{W} \cdot \mathrm{m}^{-2} \cdot \mathrm{K}^{-1}\right)$; 
$T_{a m b}=$ temperatura ambiente $(\mathrm{K})$;

$d A_{\text {ext } t i t}=$ área infinitesimal da parede externa do tubo interno $\left(\mathrm{m}^{2}\right)$;

$d A_{\text {int_te }}=$ área infinitesimal da parede interna do tubo externo $\left(\mathrm{m}^{2}\right)$;

$d V_{2} \quad=$ volume infinitesimal de fluido utilidade $\left(\mathrm{m}^{3}\right)$;

$k_{t e} \quad=$ condutividade térmica do tubo externo $\left(\mathrm{W} \cdot \mathrm{m}^{-1} \cdot \mathrm{K}^{-1}\right)$;

$\overline{T_{t e}}=$ temperatura média do tubo externo, ponderada na área da seção transversal $(\mathrm{K})$;

$r_{\text {médio_te }}=$ raio onde se encontra $\overline{T_{t e}}(\mathrm{~m})$.

As variáveis $r_{\text {médio_te }}$ e $\overline{T_{t e}}$ são esclarecidas na seção 5.1.4.

O valor de $h_{2}{ }^{(k)}$ pode ser determinado pelo conjunto das equações (5.57) (5.60), sendo que a equação (5.59) representa uma correlação empírica.

$$
\begin{gathered}
\operatorname{Re}_{2}{ }^{(k)}=\frac{D_{h} \cdot \rho_{2}{ }^{(k)} \cdot \overline{v_{z 2}}}{\mu_{2}{ }^{(k)}} \\
D_{h}=\frac{4 \cdot A_{2}}{P_{m o l}}=\frac{4 \cdot \pi \cdot\left(R_{t e}{ }^{2}-\left(R_{t i}+e_{t i}\right)^{2}\right)}{2 \cdot \pi \cdot\left(R_{t e}+\left(R_{t i}+e_{t i}\right)\right)}=2 \cdot\left(R_{t e}-\left(R_{t i}+e_{t i}\right)\right) \\
\operatorname{Pr}_{2}{ }^{(k)}=\frac{C p_{2}{ }^{(k)} \cdot \mu_{2}{ }^{(k)}}{k_{2}{ }^{(k)}} \\
N u_{2}{ }^{(k)}=\frac{h_{2}{ }^{(k)} \cdot D_{h}}{k_{2}{ }^{(k)}}=f(\operatorname{Re}, \operatorname{Pr})
\end{gathered}
$$

sendo:

$$
\begin{aligned}
& R e_{2}=\text { Número de Reynolds do fluido utilidade (adimensional); } \\
& \operatorname{Pr}_{2} \quad=\text { Número de Prandtl do fluido utilidade (adimensional); } \\
& N u_{2} \quad=\text { Número de Nusselt do fluido utilidade (adimensional); } \\
& \mu_{2} \quad=\text { viscosidade absoluta do fluido utilidade }\left(\mathrm{m}^{2} \cdot \mathrm{s}^{-1}\right) ; \\
& P_{m o l} \quad=\text { perímetro molhado do ânulo }(\mathrm{m}) ; \\
& D_{h} \quad=\text { diâmetro hidráulico do ânulo }(\mathrm{m}) .
\end{aligned}
$$

Utilizando, como exemplo, a equação de Colburn, apresentada por Incropera et al. (2008), que é válida para $0,7 \leq \operatorname{Pr} \leq 160, \operatorname{Re} \geq 10000$ e $\frac{L}{D}>10$, tem-se a equação (5.60) como:

$$
N u_{2}=0,023 \cdot R e_{2}{ }^{\frac{4}{5}} \cdot \operatorname{Pr}_{2}{ }^{\frac{1}{3}}
$$

Assim como no fluido alimentício, as propriedades do fluido utilidade são calculadas a partir da temperatura média deste fluido em cada módulo. Tem-se, portanto, que a temperatura média do fluido utilidade em cada módulo $k$ é: 


$$
{\overline{T_{2}^{(k)}}}_{m}=\frac{\left.T_{2}^{(k)}\right|_{z=A^{(k)}}+\left.T_{2}^{(k)}\right|_{z=B^{(k)}}}{2}
$$

\subsubsection{Tubo externo}

\subsubsection{Balanço de energia}

Aplicando o balanço diferencial de energia ao volume de controle do tubo externo, tem-se a seguinte expressão de acordo com Bird, Stewart e Lightfoot (2002):

$$
\rho_{t e}{ }^{(k)} C_{p t e}{ }^{(k)}\left(\frac{\partial T_{t e}{ }^{(k)}}{\partial t}+\vec{v}_{t e} \cdot \nabla T_{t e}{ }^{(k)}\right)=\nabla\left(k_{t e} \cdot \nabla T_{t e}{ }^{(k)}\right)+\dot{Q}_{t e}{ }^{(k)}
$$

Os termos do lado esquerdo da equação (5.63) representam o acúmulo de energia e o transporte de energia por advecção, e os do lado direito, a energia transportada por difusão e a energia térmica gerada no volume de controle, sendo:

$(k)=\left\{\begin{array}{l}i=1,2,3, \ldots, n_{a q u e}, \text { se módulo da seção de aquecimento; } \\ j=1,2,3, \ldots, n_{\text {resf }}, \text { se módulo da seção de resfriamento; }\end{array}\right.$

$\rho_{t e} \quad=$ massa específica do tubo externo $\left(\mathrm{kg} \cdot \mathrm{m}^{-3}\right)$;

$C_{p t e}=$ calor específico do tubo externo $\left(\mathrm{J} \mathrm{kg}^{-1} \cdot \mathrm{K}^{-1}\right)$;

$k_{t e}=$ condutividade térmica do tubo externo $\left(\mathrm{W} \cdot \mathrm{m}^{-1} \cdot \mathrm{K}^{-1}\right)$;

$\dot{Q}_{t e}=$ geração volumétrica de energia térmica do tubo externo (W.m $\left.{ }^{-3}\right)$;

$T_{t e}(z, r)=$ temperatura do tubo externo $(\mathrm{K})$.

Considerando:

- Estado estacionário:

$$
\left(\frac{\partial T_{t e}^{(k)}}{\partial t}\right)=0
$$

- Tubo cilíndrico e reto com simetria angular:

$$
\frac{\partial T_{t e}{ }^{(k)}}{\partial \theta}=0
$$

- Sem advecção em material sólido:

$$
\left(\vec{v}_{t e} \cdot \nabla T_{t e}{ }^{(k)}\right)=0 ;
$$


- Sem geração interna de energia térmica:

$$
\dot{Q}_{t e}{ }^{(k)}=0 \text {; }
$$

- Material isotrópico;

Reescrevendo a equação (5.63), levando as considerações mencionadas acima:

$$
0=k_{t e}\left[\frac{1}{r} \frac{\partial}{\partial r}\left(r \frac{\partial T_{t e}{ }^{(k)}}{\partial r}\right)+\frac{\partial}{\partial z}\left(\frac{\partial T_{t e}{ }^{(k)}}{\partial z}\right)\right]
$$

Para solucionar a equação (5.64) são necessárias quatro condições de contorno. Sendo duas delas na direção axial e as outras duas na direção radial. A modelagem o tubo externo não é tão importante quanto a do tubo interno (contato direto com o fluido alimentício e o fluido utilidade), desta forma, foi desprezado o gradiente de temperatura na direção radial do tubo externo. Vale salientar também que o objetivo é desenvolver uma modelagem não tão pesada quanto o CFD.

Apesar da consideração de gradiente de temperatura na direção radial desprezível, tem-se que calor é trocado radialmente pelo tubo externo e sua vizinhança. Para quantificar este calor trocado radialmente, é necessário escolher uma posição radial de referência entre $R_{t e} \leq r \leq R_{t e}+e_{t e}$, e a partir daí determinar as taxas de calores trocados, por unidade de volume, daquela posição até o centro do fluido utilidade e até a superfície externa do tubo externo. A posição radial considerada será o raio em que se encontra a temperatura média do tubo externo, ponderada na área, em determinada posição axial (raio médio do tubo externo $r_{\text {médio_te }}$ ), definido na seção 5.1.4.2.

Reescrevendo a equação (5.64) em função de uma temperatura média radial do tubo externo e acrescentando os termos de taxas de calor radialmente transportado, por unidade de volume de tubo externo, da posição radial onde se encontra a temperatura média para o fluido utilidade e também para a superfície externa do tubo, tem-se:

$$
0=k_{t e}\left(\frac{\partial}{\partial z}\left(\frac{\partial{\overline{T_{t e}}}^{(k)}}{\partial z}\right)\right)+\dot{Q}_{t e-2}{ }^{(k)}+\dot{Q}_{t e-s u p}^{(k)}
$$

em que:

$\overline{T_{t e}}(z)=$ temperatura média radial do tubo externo, ponderada na área da seção transversal $(\mathrm{K})$; 
$\dot{Q}_{t e-2}=$ taxa de calor trocado radialmente entre o raio médio do tubo externo e o centro do fluido utilidade, por unidade de volume de tubo externo (W. $\left.\mathrm{m}^{-3}\right)$;

$\dot{Q}_{t e-s u p}=$ taxa de calor trocado radialmente entre o raio médio do tubo externo e a superfície externa do tubo externo, por unidade de volume de tubo externo (W.m $\left.{ }^{3}\right)$.

Para a resolução da equação (5.65) são necessárias duas condições de contorno na direção axial.

As condições de contorno para o balanço de energia do tubo externo, nos módulos da seção de aquecimento são:

a) Parede adiabática no início da seção de aquecimento. Nos demais módulos estabelece-se uma igualdade de temperatura na entrada do módulo com a saída do módulo anterior. A condição é válida para $r=r_{\text {médio_te }}$.

Para $z=A_{\text {aque }}{ }^{(i)}$ e $r=r_{\text {médio_te: }}$ :

$$
\left\{\begin{array}{cl}
\left.k_{t e}\left(\frac{\partial{\overline{T_{t e}}}^{(i)}}{\partial z}\right)\right|_{z=A_{\text {aque }}(i)}=0, & i=1 \\
\left.{\overline{T_{t e}}}^{(i)}\right|_{z=A_{\text {aque }}{ }^{(i)}}=\left.{\overline{T_{t e}}}^{(i-1)}\right|_{z=B_{\text {aque }}} ^{(i-1)}, \quad i=2,3, \ldots, n_{\text {aque }}
\end{array}\right.
$$

b) Parede adiabática no final da seção de aquecimento. Nos demais módulos estabelece-se uma igualdade do fluxo de calor axial na saída do módulo com a entrada do módulo posterior. A condição é válida para $r=r_{\text {médio_te }}$.

$$
\begin{aligned}
& \text { Para } z=B_{\text {aque }}{ }^{(i)} \text { e } r=r_{\text {médio_te }}: \\
&\left.k_{t e}\left(\frac{\partial{\overline{T_{t e}}}^{(i)}}{\partial z}\right)\right|_{z=B_{\text {aque }}{ }^{(i)}} 0, \quad i=n_{\text {aque }} \\
&=\left\{\begin{aligned}
\left.k_{t e}\left(\frac{\partial{\overline{T_{t e}}}^{(i+1)}}{\partial z}\right)\right|_{z=A_{\text {aque }}{ }^{(i+1)}}, & i=1,2,3, \ldots,\left(n_{\text {aque }}-1\right)
\end{aligned}\right.
\end{aligned}
$$

As condições de contorno para o balanço de energia do tubo externo, nos módulos da seção de resfriamento, levando em consideração a configuração do escoamento do fluido utilidade na Figura 5.1, são: 
a) Parede adiabática na posição inicial do último módulo da seção de resfriamento, e nos demais módulos estabelece-se uma igualdade do fluxo de calor axial na entrada do módulo com a saída do módulo posterior. A condição é válida para $r=r_{\text {médio_te }}$.

$$
\begin{aligned}
& \text { Para } z=A_{\text {resf }}{ }^{(j)} \text { e } r=r_{\text {médio_te }}: \\
&\left.k_{t e}\left(\frac{\partial \overline{T_{t e}}(j)}{\partial z}\right)\right|_{z=A_{\text {resf }}(j)} 0, \quad j=n_{\text {resf }} \\
&=\left\{\begin{aligned}
\left.k_{t e}\left(\frac{\partial{\overline{T_{t e}}}^{(j+1)}}{\partial z}\right)\right|_{z=B_{\text {resf }}(j+1)}, j=1,2,3, \ldots,\left(n_{\text {resf }}-1\right)
\end{aligned}\right.
\end{aligned}
$$

b) Parede adiabática na posição de saída do primeiro módulo da seção de resfriamento, e nos demais módulos estabelece-se uma igualdade do fluxo de calor axial na entrada do módulo com a saída do módulo posterior. A condição é válida para $r=r_{\text {médio_te. }}$ A condição é válida para $r=r_{\text {médio_te }}$.

$$
\begin{aligned}
& \text { Para } z=B_{\text {resf }}{ }^{(j)} \text { e } r=r_{\text {médio_te }}: \\
& \left\{\begin{array}{c}
\left.k_{t e}\left(\frac{\partial{\overline{T_{t e}}}^{(j)}}{\partial z}\right)\right|_{z=B_{\text {resf }}(j)}=0, \quad j=1 \\
\left.{\overline{T_{t e}}}^{(j)}\right|_{z=B_{\text {resf }}(j)}=\left.\bar{T}_{t e}^{(j-1)}\right|_{z=A_{\text {resf }}} ^{(j-1)}, \quad j=2,3, \ldots, n_{\text {resf }}
\end{array}\right.
\end{aligned}
$$

Calculam-se as taxas de calor trocado radialmente pelo tubo externo pelo conjunto de equações (5.70) a (5.75), e (5.53):

$$
\begin{gathered}
\dot{Q}_{t e-2}{ }^{(k)}=U_{t e-2}{ }^{(k)} \frac{d A_{4}}{d V_{t e}}\left(T_{2}{ }^{(k)}-\left.{\overline{T_{t e}}}^{(k)}\right|_{r=r_{\text {médio_te }}}\right) \\
\dot{Q}_{t e-s u p}{ }^{(k)}=U_{t e-s u p} \frac{d A_{5}}{d V_{t e}}\left(T_{\text {sup }}{ }^{(k)}-\left.{\overline{T_{t e}}}^{(k)}\right|_{\left.r=r_{\text {médio_te }}\right)}\right) \\
\frac{1}{U_{t e-2}{ }^{(k)}}=\frac{1}{U_{2-t e}{ }^{(k)}}=\frac{1}{h_{2}{ }^{(k)}}+\frac{R_{t e}}{k_{t e}} \ln \left(\frac{r_{\text {médio_te }}}{R_{t e}}\right) \\
\frac{1}{U_{t e-s u p}}=\frac{R_{t e}+e_{t e}}{k_{t e}} \ln \left(\frac{R_{t e}+e_{t e}}{r_{\text {médio_te }}}\right) \\
d A_{4}=2 \pi R_{t e} d z \\
d A_{5}=2 \pi\left(R_{t e}+e_{t e}\right) d z
\end{gathered}
$$




$$
d V_{t e}=\left(\pi\left(R_{t e}+e_{t e}\right)^{2}-\pi\left(R_{t e}\right)^{2}\right) d z
$$

em que:

$U_{t e-2}=$ coeficiente de troca térmica entre o raio médio do tubo externo e o centro do fluido utilidade, por área interna de tubo externo $\left(\mathrm{W} . \mathrm{m}^{-2} \cdot \mathrm{K}^{-1}\right)$;

$U_{t e-s u p}=$ coeficiente de troca térmica entre o raio médio do tubo externo e a superfície externa do tubo externo, por área externa de tubo externo $\left(\mathrm{W} \cdot \mathrm{m}^{-2} \cdot \mathrm{K}^{-1}\right)$;

$r_{\text {médio_t }}=$ raio onde se encontra a temperatura média radial do tubo externo, ponderada na área da seção transversal do tubo externo $(\mathrm{m})$;

$d A_{4} \quad=$ área infinitesimal da parede interna do tubo externo $\left(\mathrm{m}^{2}\right) ;$

$d A_{5} \quad=$ área infinitesimal da parede externa do tubo externo $\left(\mathrm{m}^{2}\right)$;

$d V_{t e}=$ volume infinitesimal do tubo externo $\left(\mathrm{m}^{3}\right)$;

$k_{t e}=$ condutividade térmica do tubo externo $\left(\mathrm{W} \cdot \mathrm{m}^{-1} \cdot \mathrm{K}^{-1}\right)$;

$T_{\text {sup }}(z)=$ temperatura da superfície externa do tubo externo $(\mathrm{K})$.

No entanto, a taxa de calor trocado radialmente entre o raio médio do tubo externo e a superfície externa do tubo externo é igual à taxa de calor trocado pela superfície externa do tubo com o ar ambiente. Sabendo disto relaciona-se a temperatura de superfície com a temperatura média radial do tubo externo e a temperatura ambiente:

$$
\begin{aligned}
& \dot{Q}_{\text {te-sup }}{ }^{(k)}=\dot{Q}_{\text {sup-amb }}{ }^{(k)} \\
& U_{\text {te-sup }} \frac{d A_{5}}{d V_{\text {te }}}\left(T_{\text {sup }}{ }^{(k)}-\left.{\overline{T_{t e}}}^{(k)}\right|_{r=r_{\text {médio_te }}}\right)=U_{\text {sup }-a m b} \frac{d A_{5}}{d V_{t e}}\left(T_{a m b}-T_{\text {sup }}{ }^{(k)}\right) \\
& U_{\text {te-sup }}\left(T_{\text {sup }}{ }^{(k)}-\left.{\overline{T_{t e}}}^{(k)}\right|_{r=r_{\text {médio_te }}}\right)=U_{\text {sup-amb }}\left(T_{a m b}-T_{\text {sup }}{ }^{(k)}\right) \\
& \frac{1}{U_{\text {sup-amb }}}=\frac{1}{h_{e f}}
\end{aligned}
$$

sendo:

$U_{\text {sup-amb }}=$ coeficiente de troca térmica entre a superfície externa do tubo externo e o ar ambiente, por área externa de tubo externo $\left(\mathrm{W} \cdot \mathrm{m}^{-2} \cdot \mathrm{K}^{-1}\right)$;

$h_{e f}=$ coeficiente convectivo efetivo do ar ambiente sobre o tubo externo (W. $\left.\mathrm{m}^{-2} \cdot \mathrm{K}^{-1}\right)$; 
5.1.4.2. Determinação do raio em que se encontra a temperatura média radial do tubo externo $\left(r_{\text {médio_te }}\right)$

Segundo Incropera et al. (2008), para uma casca cilíndrica, com gradiente da temperatura somente na direção radial; com suas superfícies interna e externa com temperaturas uniformes; em regime estacionário e sem geração interna de calor, tem-se o seguinte perfil de temperatura $T(r)$ (APÊNDICE A):

$$
T(r)=T_{e}-\frac{T_{i}-T_{e}}{\ln \left({ }^{r_{i}} / r_{e}\right)} \ln \left(r_{e}\right)+\frac{T_{i}-T_{e}}{\ln \left({ }^{r_{i}} / r_{e}\right)} \cdot \ln (r)
$$

em que:

$T_{e} \quad=$ temperatura da superfície externa da casca cilíndrica $(\mathrm{K})$;

$T_{i} \quad=$ temperatura da superfície interna da casca cilíndrica (K);

$r_{e} \quad=$ raio externo da casca cilíndrica $(\mathrm{m})$;

$r_{i} \quad=$ raio interno da casca cilíndrica $(\mathrm{m})$.

Considerando(5.76) que a temperatura do tubo externo tenha um perfil de temperatura logarítmico igual a equação (5.78), tem-se:

$$
T_{t e}(z, r)^{(k)}=\beta+\alpha \cdot \ln (r)
$$

Calculando-se a temperatura média radial do tubo externo em relação à área da seção transversal do tubo externo, nesta mesma posição axial, tem-se:

$$
\begin{gathered}
\overline{T_{t e}}(z)^{(k)}=\frac{1}{A_{t e}} \int_{R_{t e}}^{R_{t e}+e_{t e}} T_{t e}(z, r)^{(k)} \cdot d A_{t e} \\
\overline{T_{t e}}(z)^{(k)}=\frac{1}{\pi\left(R_{t e}+e_{t e}\right)^{2}-\pi\left(R_{t e}\right)^{2}} \int_{R_{t e}}^{R_{t e}+e_{t e}} T_{t e}(z, r)^{(k)} \cdot 2 \pi \cdot r d r \\
\overline{T_{t e}}(z)^{(k)}=\left(\beta-\frac{\alpha}{2}\right)+\alpha\left[\frac{\left(R_{t e}+e_{t e}\right)^{2} \ln \left(R_{t e}+e_{t e}\right)-\left(R_{t e}\right)^{2} \ln \left(R_{t e}\right)}{\left(R_{t e}+e_{t e}\right)^{2}-\left(R_{t e}\right)^{2}}\right]
\end{gathered}
$$

Encontra-se o raio médio do tubo externo, substituindo a equação (5.80) na equação (5.79) e isolando-se o termo radial.

$$
\begin{gathered}
\overline{T_{t e}}(z)^{(k)}=\alpha+\beta \ln \left(r_{\text {médio_te }}\right) \\
\left(\beta-\frac{\alpha}{2}\right)+\alpha\left[\frac{\left(R_{t e}+e_{t e}\right)^{2} \ln \left(R_{t e}+e_{t e}\right)-\left(R_{t e}\right)^{2} \ln \left(R_{t e}\right)}{\left(R_{t e}+e_{t e}\right)^{2}-\left(R_{t e}\right)^{2}}\right]=\beta+\alpha \cdot \ln \left(r_{\text {médio_te }}\right) \\
r_{\text {médio_te }}=\exp \left[\frac{\left(R_{t e}+e_{t e}\right)^{2} \ln \left(R_{t e}+e_{t e}\right)-\left(R_{t e}\right)^{2} \ln \left(R_{t e}\right)}{\left(R_{t e}+e_{t e}\right)^{2}-\left(R_{t e}\right)^{2}}-\frac{1}{2}\right]
\end{gathered}
$$


Pela equação (5.81), observa-se que o raio onde se encontra a temperatura média da parede do tubo externo é uma constante e só depende dos raios interno e externo da parede do tubo.

\subsection{Seção de retenção}

O tubo de retenção é a seção do pasteurizador em que o fluido alimentício passa uma determinada quantidade de tempo, na temperatura de tratamento térmico, para garantir a inocuidade desejada. Na modelagem será assumido somente um módulo com os seguintes volumes de controle:

- Fluido escoando dentro do tubo interno (produto alimentício);

- Tubo interno;

- Isolamento térmico

- Ar ambiente;

A modelagem destes volumes de controle são análogas às descritas na seção 5.1 de modelagem dos módulos de aquecimento/resfriamento, mudando somente o domínio na direção axial e, consequentemente, as condições de contorno. O volume de controle do isolamento térmico foi deduzido e as condições de controle pertinentes são aplicadas.

O domínio axial da seção em estudo é:

$$
\begin{gathered}
A_{\text {ret }}{ }^{(i)} \leq z \leq B_{\text {ret }}{ }^{(i)} \\
A_{\text {ret }}{ }^{(i)}=n_{\text {aque }} \cdot L_{I} \\
B_{\text {ret }}{ }^{(i)}=n_{\text {aque }} \cdot L_{I}+L_{I I}
\end{gathered}
$$

O domínio radial é dividido em:

$0 \leq r \leq R_{t i}$ (fluido escoando dentro do tubo interno)

$R_{t i} \leq r \leq R_{t i}+e_{t i}$ (tubo interno)

$R_{\text {iso }} \leq r \leq R_{\text {iso }}+e_{\text {iso }}$ (isolamento térmico)

$R_{\text {iso }}+e_{\text {iso }} \leq r \leq \infty$ (ar ambiente)

Sendo, $R_{\text {iso }}$ o raio interno do isolamento térmico $(\mathrm{m})$ e $e_{i s o}$ a espessura do isolamento térmico $(\mathrm{m})$. Vale salientar, que o isolamento térmico do tubo de retenção é um volume de controle opcional, pois nem sempre é utilizado na prática. 
A Figura 5.3 mostra os domínios para o tubo de retenção.
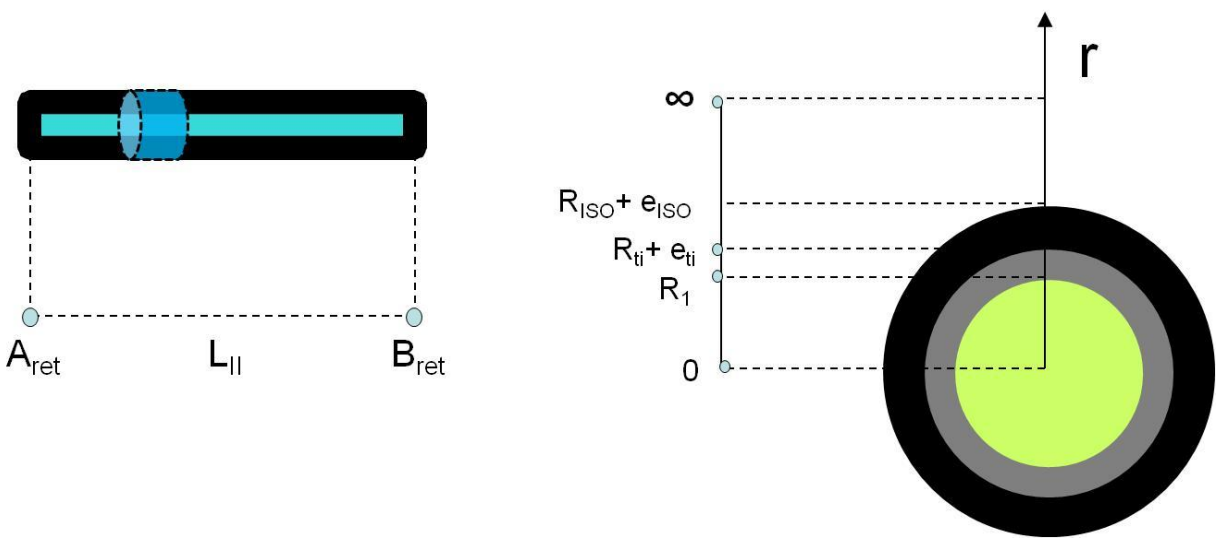

Figura 5.3 - Domínios axial e radial do tubo de retenção

\subsubsection{Fluido escoando dentro do tubo interno}

\subsubsection{Balanço de energia}

As condições de contorno para o balanço diferencial de energia dado pela equação (5.9), no tubo de retenção, são:

a) A temperatura do fluido alimentício na entrada do tubo de retenção é igual à temperatura de saída do fluido no último módulo da seção de aquecimento. A condição é válida para o intervalo radial de $0 \leq r \leq R_{t i}$.

Para $z=A_{\text {ret }}{ }^{(k)}$ e $0 \leq r \leq R_{t i}$ :

$$
\left.T_{1}{ }^{(k)}\right|_{z=A_{\text {ret }}(k)}=\left.T_{1}{ }^{\left(n_{\text {aque }}\right)}\right|_{z=B_{\text {aque }}\left(n_{\text {aque }}\right)}, \quad k=1
$$

b) Análoga à condição mostrada na equação (5.13).

$$
\begin{aligned}
& \text { Para } r=0 \text { e } A_{r e t}{ }^{(k)}<z \leq B_{\text {ret }}{ }^{(k)}: \\
& \qquad\left.k_{e f 1}{ }^{(k)}\left(\frac{\partial T_{1}^{(k)}}{\partial r}\right)\right|_{r=0}=0, \quad k=1
\end{aligned}
$$

c) Análoga à condição mostrada na equação (5.14).

$$
\begin{aligned}
& \text { Para } r=R_{t i} \text { e } A_{r e t}{ }^{(k)}<z \leq B_{r e t}{ }^{(k)}: \\
& \left.\quad k_{e f 1}{ }^{(k)}\left(\frac{\partial T_{1}{ }^{(k)}}{\partial r}\right)\right|_{r=R_{t i}}=\left.k_{t i}\left(\frac{\partial T_{t i}{ }^{(k)}}{\partial r}\right)\right|_{r=R_{t i}}, \quad k=1
\end{aligned}
$$


5.2.1.2. Conservação de atributos de qualidade microbiológica ou qualidade nutricional

As condições de contorno para o balanço diferencial do atributo dada pela equação (5.21), no tubo de retenção, são:

a) O perfil de concentração do atributo "A" na entrada do tubo de retenção é igual ao perfil de concentração na saída do último módulo da seção de aquecimento. A condição é válida para $0 \leq r \leq R_{1}$.

$$
\begin{aligned}
& \text { Para } z=A_{\text {ret }}{ }^{(k)} \text { e } 0 \leq r \leq R_{t i} \text { : } \\
& \qquad\left.C_{A}{ }^{(k)}\right|_{z=A_{\text {ret }}{ }^{(k)}}=\left.C_{A}{ }^{\left(n_{\text {aque }}\right)}\right|_{z=B_{\text {aque }}{ }^{\left(n_{\text {aque }}\right)}, \quad k=1} \\
& \text { b) Condição análoga à mostrada na equação (5.24). }
\end{aligned}
$$

$$
\begin{aligned}
& \text { Para } r=0 \text { e } A_{r e t}{ }^{(k)}<z \leq B_{r e t}{ }^{(k)} \text { : } \\
& \qquad\left.\left(\frac{\partial C_{A}{ }^{(k)}}{\partial r}\right)\right|_{r=0}=0, \quad k=1
\end{aligned}
$$

C) Condição análoga à mostrada na equação (5.25).

$$
\begin{aligned}
& \text { Para } r=R_{t i} \text { e } A_{r e t}{ }^{(i)}<z \leq B_{r e t}{ }^{(i)} \text { : } \\
& \qquad\left.\left(\frac{\partial C_{A}{ }^{(k)}}{\partial r}\right)\right|_{r=R_{t i}}=0, \quad k=1
\end{aligned}
$$

\subsubsection{Tubo interno}

\subsubsection{Balanço de energia}

As condições de contorno para o balanço diferencial de energia dada pela equação (5.32), no tubo de retenção, são: 
a) Fluxo de calor axial no início do tubo de retenção é igual ao fluxo de calor axial no final da seção de aquecimento para o intervalo $R_{t i} \leq r \leq$ $R_{t i}+e_{t i}$

Para $z=A_{\text {ret }}{ }^{(k)}$ e $R_{t i} \leq r \leq R_{t i}+e_{t i}$ :

$\left.k_{t i}\left(\frac{\partial T_{t i}{ }^{(k)}}{\partial z}\right)\right|_{z=A_{r e t}{ }^{(k)}}=\left.k_{t i}\left(\frac{\partial T_{t i}{ }^{\left(n_{a q u e}\right)}}{\partial z}\right)\right|_{z=B_{a q u e}\left(n_{a q u e}\right)}, \quad k=1$

b) Fluxo de calor axial no final do tubo de retenção é igual ao fluxo de calor axial no início da seção de resfriamento para o intervalo $R_{t i} \leq r \leq$ $R_{t i}+e_{t i}$

Para $z=B_{\text {ret }}{ }^{(k)}$ e $R_{t i} \leq r \leq R_{t i}+e_{t i}$ :

$\left.k_{t i}\left(\frac{\partial T_{t i}^{(k)}}{\partial z}\right)\right|_{z=B_{r e t}(k)}=\left.k_{t i}\left(\frac{\partial T_{t i}^{(1)}}{\partial z}\right)\right|_{z=A_{r e s f}{ }^{(1)}}, \quad k=1$

c) Condição análoga à explicitada nas equações em (5.35).

$$
\begin{aligned}
\text { Para } r=R_{t i} & \text { e } A_{r e t}{ }^{(k)}<z<B_{r e t}{ }^{(k)}: \\
\left.T_{t i}{ }^{(k)}\right|_{r=R_{t i}} & =\left.T_{1}{ }^{(k)}\right|_{r=R_{t i}}, \quad k=1
\end{aligned}
$$

d) Condição análoga à explicitada nas equações em (5.36).

$$
\begin{gathered}
\text { Para } r=R_{t i}+e_{t i} \text { e } A_{r e t}{ }^{(k)}<z<B_{r e t}{ }^{(k)}: \\
-\left.k_{t i}\left(\frac{\partial T_{t i}{ }^{(k)}}{\partial z}\right)\right|_{r=R_{t i}+e_{t i}}=Q_{t i-i s o}{ }^{(k)} \\
-\left.k_{t i}\left(\frac{\partial T_{t i}{ }^{(k)}}{\partial z}\right)\right|_{r=R_{t i}+e_{t i}}=U_{t i-i s o}\left(\left.T_{t i}{ }^{(k)}\right|_{r=R_{t i}+e_{t i}}-\left.\overline{T_{l s o}}(k)\right|_{r=r_{\text {médio } i s o}}\right), \quad k=1
\end{gathered}
$$

em que $\bar{T}_{l s o}{ }^{k}$ é a temperatura média radial do isolamento térmico, ponderada na área da seção transversal $(\mathrm{K})$ e $U_{t i-i s o}$ é coeficiente de troca térmica entre o raio médio do isolamento térmico e a parede externa do tubo interno $\left(\mathrm{W} \cdot \mathrm{m}^{-2} \cdot \mathrm{K}^{-1}\right)$, e é determinado pela equação (5.97). Ambas as variáveis são mais bem compreendidas na seção 5.2.3. 


\subsubsection{Isolamento térmico}

\subsubsection{Balanço de energia}

A modelagem do isolamento térmico é semelhante à modelagem feita para o tubo externo de um módulo do trocador de calor. Todas as considerações e suposições são válidas. Exceto o fato de o isolamento térmico ser um mal condutor de calor (baixa condutividade térmica), diferentemente do aço do tubo.

Escrevendo uma equação análoga à equação (5.65) do tubo externo para o isolamento obtém-se:

$$
0=k_{i s o}\left(\frac{\partial}{\partial z}\left(\frac{\partial{\overline{T_{l s o}}}^{(k)}}{\partial z}\right)\right)+\dot{Q}_{t i-i s o}^{(k)}+\dot{Q}_{i s o-s u p}^{(k)}
$$

em que:

$\overline{T_{l s o}}(z)=$ temperatura média radial do isolamento térmico, ponderada na área da seção transversal do isolamento térmico $(\mathrm{K})$;

$\dot{Q}_{t i-i s o}=$ taxa de calor trocado radialmente entre a superfície externa do tubo interno e o raio médio do isolamento térmico, por unidade de volume de isolamento térmico $\left(\mathrm{W} . \mathrm{m}^{-3}\right)$;

$\dot{Q}_{\text {iso-sup }}=$ taxa de calor trocado radialmente entre o raio médio do isolamento térmico e a superfície externa do isolamento térmico, por unidade de volume de isolamento térmico $\left(\mathrm{W} . \mathrm{m}^{-3}\right)$;

$k_{\text {iso }}=$ condutividade térmica do material do isolamento $\left(\mathrm{W} \cdot \mathrm{m}^{-1} \cdot \mathrm{K}^{-1}\right)$.

A soma das taxas $\dot{Q}_{t i-i s o}$ e $\dot{Q}_{i s o-s u p}$ corresponde à taxa total de calor trocado, por volume, do isolamento térmico.

Para a resolução da equação (5.92) são necessárias duas condições de contorno na direção axial. As condições de contorno para o balanço de energia do isolamento térmico, no tubo de retenção, são:

a) Parede adiabática no início do tubo de retenção. A condição é válida

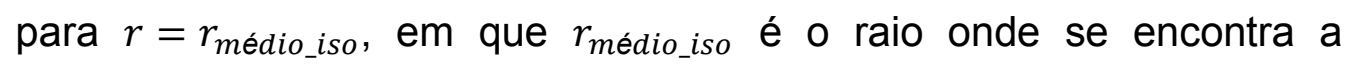
temperatura média radial, ponderada na área da seção transversal do isolamento térmico, do isolamento térmico $(\mathrm{m})$. 
Para $z=A_{\text {ret }}{ }^{(k)}$ e $r=r_{\text {médio_iso: }}$ :

$$
\left.k_{\text {iso }}\left(\frac{\partial \overline{T_{\text {lso }}}(k)}{\partial z}\right)\right|_{z=A_{\text {ret }}(k)}=0, \quad k=1
$$

b) Parede adiabática no final do tubo de retenção. A condição é válida para $r=r_{\text {médio_iso. }}$

$$
\begin{array}{r}
\text { Para } z=B_{\text {ret }}{ }^{(k)} \text { e } R_{\text {iso }} \leq r \leq R_{\text {iso }}+e_{\text {iso }}: \\
\left.k_{\text {iso }}\left(\frac{\partial \overline{T_{\text {lso }}}}{\partial z}\right)\right|_{z=B_{\text {ret }}{ }^{(k)}}=0, \quad k=1
\end{array}
$$

Calculam-se as taxas de calor trocado pelo conjunto de equações (5.95) a (5.101):

$$
\begin{gathered}
\dot{Q}_{t i-i s o}{ }^{(k)}=U_{\text {ti-iso }} \frac{d A_{6}}{d V_{\text {iso }}}\left(\left.T_{t i}{ }^{(k)}\right|_{r=R_{1}+e_{1}}-\left.\overline{T_{\text {lso }}}{ }^{(k)}\right|_{r=r_{\text {médio_iso }}}\right) \\
\dot{Q}_{\text {iso-sup }}{ }^{(k)}=U_{\text {iso-sup }} \frac{d A_{7}}{d V_{\text {iso }}}\left(T_{\text {sup }}{ }^{(k)}-\left.{\overline{T_{\text {lso }}}}^{(k)}\right|_{r=r_{\text {médio_iso }}}\right) \\
\frac{1}{U_{t i-i s o}}=\frac{R_{\text {iso }}}{k_{\text {iso }}} \ln \left(\frac{r_{\text {médio_iso }}}{R_{\text {iso }}}\right) \\
\frac{1}{U_{\text {iso-sup }}}=\frac{R_{\text {iso }}+e_{\text {iso }}}{k_{\text {iso }}} \ln \left(\frac{R_{\text {iso }}+e_{\text {iso }}}{r_{\text {médio_iso }}}\right) \\
d A_{6}=2 \pi R_{\text {iso }} d z \\
d A_{7}=2 \pi\left(R_{\text {iso }}+e_{\text {iso }}\right) d z \\
d V_{\text {iso }}=\left(\pi\left(R_{\text {iso }}+e_{\text {iso }}\right)^{2}-\pi\left(R_{\text {iso }}\right)^{2}\right) d z
\end{gathered}
$$

em que:

$U_{t i-i s o}=$ coeficiente de troca térmica entre a superfície externa do tubo interno e o raio onde se encontra a temperatura média do isolamento térmico, por área interna de isolamento térmico $\left(\mathrm{W} . \mathrm{m}^{-2} \cdot \mathrm{K}^{-1}\right)$;

$U_{\text {iso-sup }}=$ coeficiente de troca térmica entre o raio onde se encontra a temperatura média do isolamento térmico e a superfície externa do isolamento térmico, por área externa de isolamento térmico $\left(\mathrm{W} \cdot \mathrm{m}^{-2} \cdot \mathrm{K}^{-1}\right)$;

$d A_{6} \quad=$ área infinitesimal da parede interna de isolamento térmico $\left(\mathrm{m}^{2}\right)$;

$d A_{7} \quad=$ área infinitesimal da parede externa de isolamento térmico $\left(\mathrm{m}^{2}\right)$;

$d V_{\text {iso }}=$ volume infinitesimal de isolamento térmico $\left(\mathrm{m}^{3}\right)$; 
$\overline{T_{\text {lso }}} \quad=$ temperatura média radial do isolamento térmico, ponderada na área da seção transversal do isolamento térmico $(\mathrm{K})$;

$T_{\text {sup }} \quad=$ temperatura da superfície externa do isolamento térmico (K);

$r_{\text {médio_iso }}=$ raio onde se encontra $\overline{T_{l s o}}(\mathrm{~m})$.

No entanto, a taxa de calor trocado radialmente entre o raio médio do isolamento e sua superfície externa é igual à taxa de calor trocado pela superfície externa do isolamento com o ambiente. Sabendo disto, relaciona-se a temperatura de superfície com a temperatura média radial do isolamento térmico e a temperatura ambiente.

$$
\begin{gathered}
\dot{Q}_{\text {iso-sup }}{ }^{(k)}=\dot{Q}_{\text {sup-amb }}{ }^{(k)} \\
U_{\text {iso-sup }} \frac{d A_{7}}{d V_{\text {iso }}}\left(T_{\text {sup }}{ }^{(k)}-\left.{\overline{T_{\text {lso }}}}^{(k)}\right|_{r=r_{\text {médio_iso }}}\right)=U_{\text {sup }-a m b} \frac{d A_{7}}{d V_{\text {iso }}}\left(T_{a m b}-T_{\text {sup }}{ }^{(k)}\right) \\
U_{\text {iso-sup }}\left(T_{\text {sup }}{ }^{(k)}-\left.{\overline{T_{\text {lso }}}}^{(k)}\right|_{r=r_{\text {médio_iso }}}\right)=U_{\text {sup-amb }}\left(T_{a m b}-T_{\text {sup }}{ }^{(k)}\right) \\
\frac{1}{U_{\text {sup-amb }}}=\frac{1}{h_{e f}}
\end{gathered}
$$

em que:

$U_{\text {sup-amb }}=$ coeficiente de troca térmica entre a superfície externa do isolamento térmico e o ar ambiente $\left(\mathrm{W} \cdot \mathrm{m}^{-2} \cdot \mathrm{K}^{-1}\right)$;

De forma semelhante ao tubo externo (equação (5.81)) encontra-se o raio médio do isolamento térmico (APÊNDICE A). Seu valor é calculado por:

$$
r_{\text {médio_iso }}=\exp \left[\frac{\left(R_{\text {iso }}+e_{\text {iso }}\right)^{2} \ln \left(R_{\text {iso }}+e_{\text {iso }}\right)-\left(R_{\text {iso }}\right)^{2} \ln \left(R_{\text {iso }}\right)}{\left(R_{\text {iso }}+e_{\text {iso }}\right)^{2}-\left(R_{\text {iso }}\right)^{2}}-\frac{1}{2}\right]
$$

\subsection{Distribuição de temperaturas nos trocadores}

A Figura 5.4 mostra, para melhor entendimento, as distribuições de temperatura nos módulos das seções de aquecimento/resfriamento e no tubo de retenção e em qual posição radial elas são avaliadas. 


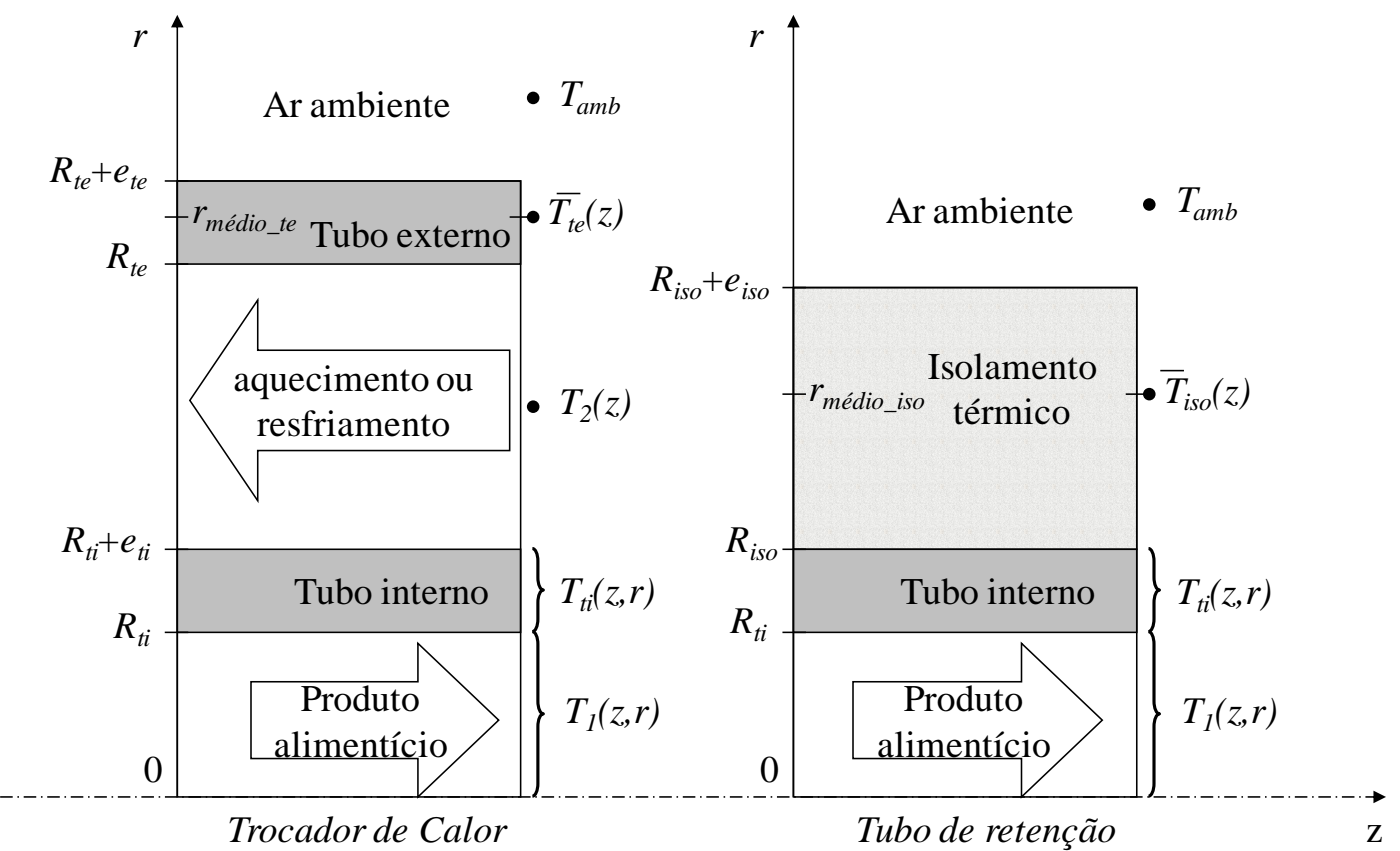

Figura 5.4 - Distribuição das temperaturas nos volumes de controle na seção de aquecimento/resfriamento e seus raios de referência

As temperaturas do fluido alimentício $\left(T_{1}(z, r)\right)$ e do tubo interno $\left(T_{t i}(z, r)\right)$ são avaliadas nas direções axial e radial. Já as temperaturas $T_{2}(z), \overline{T_{t e}}(z)$ e $\overline{T_{l s o}}(z)$ são avaliadas somente na direção axial, sendo que as duas últimas temperaturas são temperaturas médias radiais, ponderadas na área da seção transversal dos respectivos volumes de controle e estão localizadas nos raios médios $r_{\text {médio_te }} \mathrm{e}$ $r_{\text {médio_iso }}$, obtidos nas seções 5.1.4.2 e 5.2.3.1. 


\section{RESULTADOS E DISCUSSÕES}

\subsection{Estudo de caso}

Um estudo de caso foi analisado com objetivo de testar a consistência do modelo proposto. Foram feitas simulações para o processamento térmico contínuo de polpa de suco de amora, quantificando os efeitos do tratamento térmico em um atributo de qualidade nutricional e um de qualidade microbiológica. Para o estudo de caso proposto, utilizou-se como fluidos de utilidade água quente e fria nas seções de aquecimento e resfriamento, respectivamente. Por sua vez, a escolha da polpa do suco de amora como produto alimentício ocorreu pela disponibilidade das correlações e dados utilizados, trazendo o estudo de caso para o mais próximo da realidade de um tratamento térmico, além de ser um estudo de caso não encontrado na literatura. A Tabela 6.1 mostra, para cada seção, os valores dos parâmetros que são considerados nas simulações. Os conteúdos da Tabela 6.1 são apresentados ao longo desta seção.

Tabela 6.1 - Parâmetros do pasteurizador e de suas seções para o estudo de caso

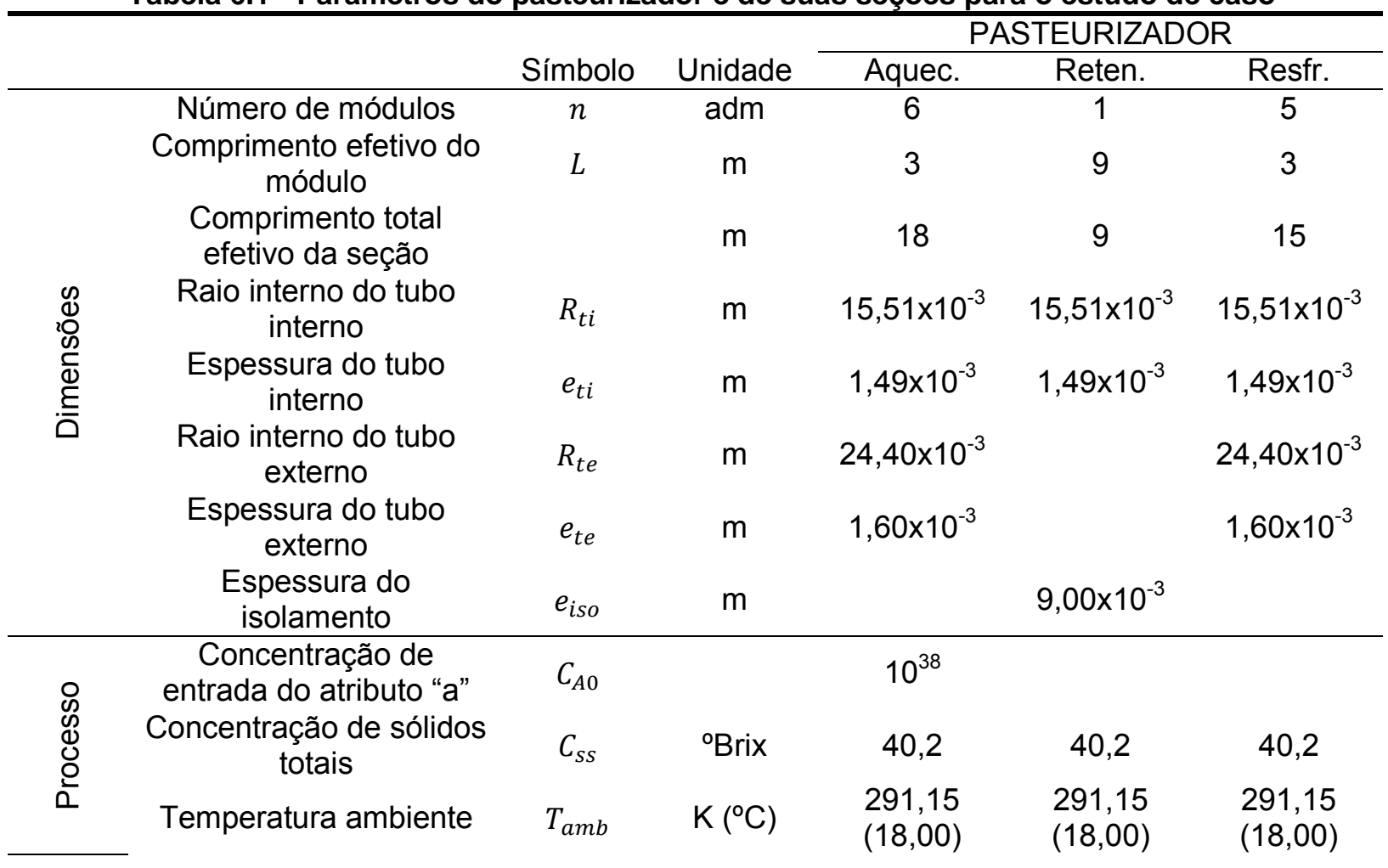




\begin{tabular}{|c|c|c|c|c|c|c|}
\hline & $\begin{array}{c}\text { Temperatura de entrada } \\
\text { do produto alimentício }\end{array}$ & $T_{1 \text { in }}$ & $\mathrm{K}\left({ }^{\circ} \mathrm{C}\right)$ & $\begin{array}{l}291,15 \\
(18,00)\end{array}$ & \multirow{4}{*}{$\begin{array}{l}2,22 \times 10^{-4} \\
(800)\end{array}$} & \multirow{4}{*}{$\begin{array}{c}281,15 \\
(8,00) \\
2,22 \times 10^{-4} \\
(800) \\
2,22 \times 10^{-3} \\
(8000)\end{array}$} \\
\hline & $\begin{array}{l}\text { Temperatura de entrada } \\
\text { do fluido utilidade }\end{array}$ & $T_{2 i n}$ & $\mathrm{~K}\left({ }^{\circ} \mathrm{C}\right)$ & $\begin{array}{l}359,15 \\
(86,00)\end{array}$ & & \\
\hline & $\begin{array}{l}\text { Vazão volumétrica do } \\
\text { produto alimentício }\end{array}$ & $q_{1}$ & $\begin{array}{l}\mathrm{m}^{3} \cdot \mathrm{s}^{-1} \\
(\mathrm{~L} / \mathrm{h})\end{array}$ & $\begin{array}{l}2,22 \times 10^{-4} \\
(800)\end{array}$ & & \\
\hline & $\begin{array}{l}\text { Vazão volumétrica do } \\
\text { fluido utilidade }\end{array}$ & $q_{2}$ & $\begin{array}{l}\mathrm{m}^{3} \cdot \mathrm{s}^{-1} \\
(\mathrm{~L} / \mathrm{h})\end{array}$ & $\begin{array}{c}2,22 \times 10^{-3} \\
(8000)\end{array}$ & & \\
\hline \multirow{3}{*}{ 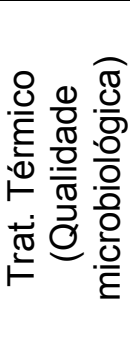 } & $\begin{array}{l}\text { Temperatura de } \\
\text { referência para o } \\
\text { tratamento térmico }\end{array}$ & $T_{\text {refA }}$ & $\mathrm{K}\left({ }^{\circ} \mathrm{C}\right)$ & $\begin{array}{l}355,35 \\
(82,20)\end{array}$ & $\begin{array}{l}355,35 \\
(82,20)\end{array}$ & $\begin{array}{l}355,35 \\
(82,20)\end{array}$ \\
\hline & $\begin{array}{c}\text { Tempo de redução } \\
\text { decimal na temperatura } \\
\text { de referência }\end{array}$ & $D_{\text {refA }}$ & $s$ & 0,57 & 0,57 & 0,57 \\
\hline & $\begin{array}{l}\text { Constante de tempo de } \\
\text { destruição térmica }\end{array}$ & $Z_{A}$ & $\mathrm{~K} /{ }^{\circ} \mathrm{C}$ & 7 & 7 & 7 \\
\hline \multirow{10}{*}{ 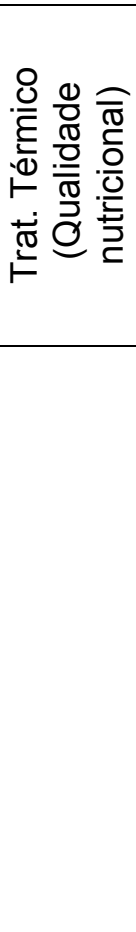 } & $\begin{array}{l}\text { Temperatura de } \\
\text { referência para o } \\
\text { tratamento térmico }\end{array}$ & $T_{\text {refA }}$ & $\mathrm{K}\left({ }^{\circ} \mathrm{C}\right)$ & $\begin{array}{l}355,35 \\
(82,20)\end{array}$ & $\begin{array}{l}355,35 \\
(82,20)\end{array}$ & $\begin{array}{l}355,35 \\
(82,20)\end{array}$ \\
\hline & $\begin{array}{c}\text { Tempo de redução } \\
\text { decimal na temperatura }\end{array}$ & $D_{\text {refA }}$ & $\mathrm{s}$ & 669 & 669 & 669 \\
\hline & de referência & $D$ ref A & 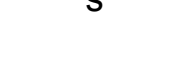 & 005 & 000 & 005 \\
\hline & $\begin{array}{l}\text { Constante de tempo de } \\
\text { destruição térmica }\end{array}$ & $Z_{A}$ & $\mathrm{~K}$ & 35 & 35 & 35 \\
\hline & $\begin{array}{c}\text { Condutividade térmica } \\
\text { do tubo }\end{array}$ & $k_{t i}$ & $\mathrm{~W} \cdot \mathrm{m}^{-1} \cdot \mathrm{K}^{-1}$ & 14,9 & 14,9 & 14,9 \\
\hline & $\begin{array}{l}\text { Condutividade térmica } \\
\text { do isolamento }\end{array}$ & $k_{\text {iso }}$ & $W \cdot m^{-1} \cdot K^{-1}$ & & 0,039 & \\
\hline & $\begin{array}{l}\text { Coeficiente convectivo } \\
\text { do ar ambiente }\end{array}$ & $h_{e f}$ & $W \cdot m^{-2} \cdot K^{-1}$ & 45 & 45 & 70 \\
\hline & $\begin{array}{c}\text { Difusividade mássica } \\
\text { efetiva }\end{array}$ & $D_{\text {mass_efA }}$ & $m^{2} \cdot s^{-1}$ & $10^{-5}$ & $10^{-5}$ & $10^{-5}$ \\
\hline & $\begin{array}{l}\text { Fator de aumento da } \\
\text { condutividade térmica do } \\
\text { fluido alimentício (radial) }\end{array}$ & $F_{\text {incr } 1}$ & $\mathrm{adm}$ & 15 & 15 & 15 \\
\hline & $\begin{array}{l}\text { Fator de aumento da } \\
\text { condutividade térmica do } \\
\text { fluido utilidade (axial) }\end{array}$ & $F_{\text {incr } 2}$ & $\mathrm{adm}$ & 1 & & 1 \\
\hline
\end{tabular}

Os comprimentos efetivos dos módulos e do tubo de retenção são os comprimentos que ocorrem as trocas térmicas. Nestes comprimentos não são levados em consideração as curvas que interligam um módulo a outro

Para o estudo de caso proposto utilizou-se como referência, para os cálculos das propriedades reológicas e termofísicas da polpa do suco de amora, os dados experimentais e relações apresentadas por Cabral et al. (2007). Tais relações foram propostas como funções de temperatura e concentração de sólidos totais.

As propriedades termofísicas e reológicas foram calculadas através da temperatura média de cada módulo. Para a polpa do suco de amora, têm-se as seguintes relações: 
- Massa específica:

$\rho_{1}{ }^{(k)}=955,4-0,513 \cdot\left({\overline{T_{1}{ }^{(k)}}}_{m}-273,15\right)+5,725 \cdot C_{s S}$

- Calor específico:

$C_{p 1}{ }^{(k)}=4210+4,54 \cdot\left({\overline{T_{1}}}^{(k)}{ }_{m}-273,15\right)-33,4 \cdot C_{s s}$

- Condutividade térmica:

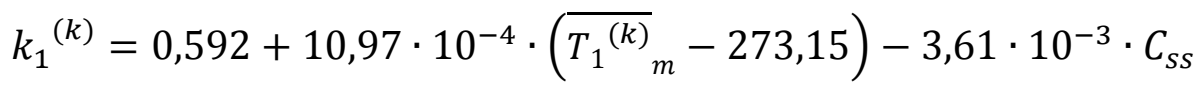

- Condutividade térmica efetiva:

$$
k_{e f 1}{ }^{(k)}=F_{\text {incr } 1} \cdot k_{1}{ }^{(k)}
$$

- Índice de consistência:

$$
K_{\text {reo }}{ }^{(k)}=\exp \left(-5,08-0,0683 \cdot\left(\overline{T_{1}{ }^{(k)}}{ }_{m}-273,15\right)+0,171 \cdot C_{s S}\right)
$$

- Índice de comportamento:

$$
n_{\text {reo }}{ }^{(k)}=10,97 \cdot 10^{-1} \cdot \exp \left(-7,89 \cdot 10^{-4} \cdot C_{s s}\right) \cdot \exp \left(\frac{-630,9}{8,315 \cdot \overline{T_{1}{ }^{(k)}}{ }_{m}}\right)
$$

em que $C_{s s}$ é a concentração de sólidos totais ( ${ }^{\circ} \mathrm{Brix}$ ).

As unidades de medida das variáveis mostradas nas equações (6.1) à (6.5) e (5.8) estão no Sistema Internacional (SI).

As relações mostradas das equações (6.1), (6.3) e (6.5) foram obtidas diretamente de Cabral et al. (2007) com os coeficientes de correlação $\left(R^{2}\right)$ 0,966; 0,993 e 0,935 , respectivamente. No entanto, as equações (6.2) e (6.4), foram determinadas através da regressão linear sobre os dados publicados, através do software Statistica 7.0 (StatSoft, EUA), e os valores de $R^{2}$ foram de 0,991 e 0,998, respectivamente.

De forma análoga ao suco de amora, as propriedades da água quente e fria foram calculadas a partir das temperaturas médias de cada módulo que compõe a seção de aquecimento e resfriamento. Utilizaram-se as seguintes relações:

- Massa específica:

$$
\rho_{2}{ }^{(k)}=997,18+3,1439 \mathrm{e}^{-3} \cdot\left(\overline{T_{2}\left({ }_{m}\right)}-273,15\right)-3,7574 \mathrm{e}^{-3} \cdot\left(\overline{T_{2}{ }^{(k)}}{ }_{m}-273,15\right)^{2}
$$

- Calor específico:

$$
C_{p 2}{ }^{(k)}=4176,2-9,0864 \mathrm{e}^{-2} \cdot\left(\overline{T_{2}{ }^{(k)}}{ }_{m}-273,15\right)+5,4731 \mathrm{e}^{-3} \cdot\left(\overline{T_{2}{ }_{m}^{(k)}}-273,15\right)^{2}
$$

- Condutividade térmica: 


$$
k_{2}{ }^{(k)}=0,571+17,6 \mathrm{e}^{-3} \cdot\left(\overline{T_{2}^{(k)}}{ }_{m}-273,15\right)-6,70 \mathrm{e}^{-6} \cdot\left(\overline{T_{2}^{(k)}}{ }_{m}-273,15\right)^{2}
$$

- Condutividade térmica efetiva:

$$
k_{e f 2}{ }^{(k)}=F_{\text {incr } 2} \cdot k_{2}{ }^{(k)}
$$

- Viscosidade newtoniana:

$$
\begin{aligned}
\frac{1}{\mu_{2}{ }^{(k)}}=21,481 & \left\{\left[\left({\overline{T_{2}{ }^{(k)}}}_{m}-273,15\right)-8,435\right]\right. \\
& \left.+\sqrt{8078,4+\left[\left(\overline{T_{2}^{(k)}}{ }_{m}-273,15\right)-8,435\right]^{2}}\right\}-1200
\end{aligned}
$$

As equações (6.6) a (6.8) foram obtidas de Choi e Okos (1986), e a (6.9) de Gut e Pinto (2003).

As unidades de medida das variáveis mostradas nas equações (6.6) à (6.9) e (5.43) estão no Sistema Internacional (SI).

O coeficiente convectivo do fluido utilidade foi obtido pela relação de Colburn (equação (5.61)), juntamente com as equações (5.57), (5.59) e (5.60).

Para o estudo de caso proposto, adotaram-se alguns critérios para escolha dos valores dos parâmetros mostrados na Tabela 6.1. São eles:

- Dimensões do pasteurizador: o número de módulos foi escolhido arbitrariamente. As dimensões dos tubos estão de acordo com o modelo ViscoLine Monotube fabricado pela empresa de trocadores de calor ALFA LAVAL (ALFA LAVAL, 2011). A espessura do isolamento foi a correspondente a espuma elastomérica AF/F18 (ARMAFLEX, 2011).

- Parâmetros de processo: concentração inicial do atributo "A" elevada, com o objetivo de evitar eventuais erros numéricos na simulação. Salienta-se que a alta concentração inicial tem somente significado numérico e não compromete o resultado final, pois a relação de interesse é $\frac{C_{A 0}}{C_{A}}$. Temperatura ambiente e de entrada do produto alimentício foram escolhidas arbitrariamente. A vazão volumétrica do produto alimentício foi escolhida de modo que obtivesse um número de Reynolds correspondente a um escoamento laminar. A vazão volumétrica do fluido utilidade foi dez vezes maior que a de produto alimentício, para que a variação da temperatura da utilidade fosse 
pequena ao longo das seções de aquecimento e resfriamento. temperatura de entrada do fluido utilidade escolhida arbitrariamente.

- Parâmetros de tratamento térmico para 0 atributo de qualidade microbiológica: escolheu-se as leveduras como atributo de qualidade microbiológica, pois Cabral et al. (2007), determinaram um pH para a polpa do suco de amora de 2,94. Neste $\mathrm{pH}$, segundo Ibarz e BarbosaCánovas (2002) e Teixeira (2007), os micro-organismos alvos são as leveduras. Os parâmetros $T_{\text {refA }}, D_{\text {refA }}$ e $Z_{A}$ foram obtidos de Toledo (2007) e seus valores são genéricos. Ou seja, não são valores para uma espécie específica de levedura.

- Parâmetros de tratamento térmico para 0 atributo de qualidade nutricional: escolheu-se a antocianina como o atributo de qualidade nutricional, pois além de ser o pigmento predominante no suco de amora, a cor é um dos critérios perceptíveis pelo consumidor e é uma substância importante à saúde, pois pode prevenir o câncer. Os parâmetros $D_{\text {ref } A}$ e $Z_{A}$ foram calculados através dos dados publicados por Sarkis et al. (2011). Os autores determinaram a constante cinética de destruição térmica para uma reação de primeira ordem $\left(k_{r}\right)$ e a energia de ativação da antocianina $\left(E_{a A}\right)$. Na Tabela 6.2 encontra-se os valores obtidos por Sarkis et al. (2011) em seus experimentos.

Tabela 6.2 - Valores das constantes cinéticas de reação e energias de ativação nas temperaturas experimentais (SARKIS et al., 2011) e do parâmetro $Z_{A}$ calculado pela equação (3.14)

\begin{tabular}{|c|c|c|c|}
\hline Temperatura $\left({ }^{\circ} \mathrm{C}\right)$ & $k_{r}\left(\min ^{-1}\right)$ & $E_{a A}\left(\mathrm{~kJ} \mathrm{~mol}^{-1}\right)$ & $Z_{A}(\mathrm{~K})$ \\
\hline 70 & 0,002 & \multirow{4}{*}{68,309} & 34,2 \\
\hline 75 & 0,002 & & 34,7 \\
\hline 80 & 0,003 & & 35,2 \\
\hline \multirow[t]{2}{*}{90} & 0,005 & & 36,2 \\
\hline & & Média= & 35,0 \\
\hline
\end{tabular}

Como se tem uma temperatura de referência para o tratamento térmico de $82,2{ }^{\circ} \mathrm{C}$ determinou-se o tempo de redução decimal da antocianina na temperatura de referência $\left(D_{r e f A}\right)$, encontrando o valor da constante cinética pela interpolação linear das constantes nas temperaturas de 80 e $90{ }^{\circ} \mathrm{C}$, e substituindo o valor encontrado na equação (3.12). Para a 
determinação de $Z_{A}$, calculou-se, com auxílio da equação (3.14), os valores para cada temperatura experimental e a média aritmética foi adotada (ver Tabela 6.2).

- A condutividade térmica do tubo foi considerada constante ao longo de todo o pasteurizador e seu valor, assumindo tubo de aço inoxidável AISI 304, foi obtido de Incropera et al. (2008).

- Considerou-se para o isolamento térmico (espuma elastomérica AF/F18) uma condutividade térmica constante, e o valor da mesma foi obtido através da brochura do produto no site da empresa (ARMAFLEX, 2011).

- Os coeficientes convectivos do ar ambiente sobre um pasteurizador tubular foram obtidos por Ferrão, Funcia e Gut (2011) e o maior valor na seção de resfriamento corresponde aos efeitos da condensação da umidade do ar.

- Pelas especificações do fabricante ALFA LAVAL, o modelo da unidade de troca térmica (Viscoline Monotube) é um modelo de tubos corrugados, o que promove mistura, durante o escoamento. Este efeito foi levado em consideração na condutividade térmica efetiva e difusividade mássica. Para efeitos de simulação a condutividade térmica efetiva foi arbitrariamente escolhida 15 vezes maior que a condutividade térmica para o fluido produto. Ou seja, fator de aumento da condutividade térmica do fluido alimentício na direção radial igual a 15. Tem-se também uma difusividade mássica arbitraria de $10^{-5} \mathrm{~m}^{2} \cdot \mathrm{s}^{-1}$ (10000 vezes maior), se considerarmos um valor de difusividade de referência, para sistemas liquído-liquído, de $10^{-9} \mathrm{~m}^{2} . \mathrm{s}$ (BIRD; STEWART; LIGHTFOOT, 2002; FOSTER; CUSSLER, 1986).

- Fator de aumento da condutividade térmica do fluido utilidade na direção axial, escolhido arbitrariamente, igual a 1.

O método numérico empregado para discretização na direção axial na resolução do modelo foi o das diferenças finitas para trás (BFDM) para fluido alimentício, tubo interno, tubo externo, ar ambiente e para frente (FFDM) para fluido utilidade. Para a direção radial, utilizou-se o método das diferenças finitas centradas (CFDM) no fluido alimentício e no tubo interno. 


\subsubsection{Estudo 1: Sensibilidade do modelo ao número de pontos de discretização}

Com o objetivo de estudar a sensibilidade do modelo ao número de pontos de discretização na direção axial e radial, realizou-se, inicialmente, um estudo que busca identificar uma discretização que alcance um resultado aceitável e ao mesmo tempo, com um tempo de simulação computacional não muito elevado.

Para este estudo, utilizou-se a variável valor de esterilização $\left(S_{\text {value }}\right)$ na saída do processo térmico (posição final da última seção de resfriamento) como a variável analisada, pois é uma variável importante do processamento (representa o quanto do atributo foi destruído ou degradado), além de ser uma variável que apresenta grande sensibilidade ao número de pontos (dependência na forma de potência da temperatura, conforme equação (3.15)).

De acordo com o modelo proposto (Figura 5.4) as temperaturas do fluido alimentício e a do tubo interno são distribuídas nas direções axial e radial. No entanto, pela Tabela 6.1 tem-se que a espessura do tubo interna é cerca de 10 vezes menor que o raio interno do mesmo. Devido a isto, as discretizações axiais do fluido alimentício e do tubo interno terão a mesma quantidade de pontos, enquanto a discretização radial do fluido alimentício terá seu efeito estudado, mantendo uma discretização radial para o tubo interno de 10 pontos em todas as simulações.

A Tabela 6.3 mostra a quantidade de pontos axiais e radiais por módulo, os valores de esterilização ao final do resfriamento para o atributo de qualidade microbiológica e o tempo computacional necessário para realizar a solução do modelo. Já na Figura 6.1 plotou-se o gráfico do valor de esterilização em função do tempo computacional. Escolheu-se o atributo de qualidade microbiológica, pois este atributo é mais sensível à temperatura que $\mathrm{o}$ atributo de qualidade nutricional (valores menores de $D_{\text {refA }}$ e $Z_{A}$ ). Ou seja, para ocorrer uma redução decimal das leveduras são necessários $0,57 \mathrm{~s}$ e uma variação de temperatura de $7 \mathrm{~K}$ em relação à temperatura de referência, enquanto para a antocianina, é necessário um tempo de 40161 s e uma variação de $35 \mathrm{~K}$. 
Tabela 6.3 - Tempo computacional e valor de esterilização do atributo de qualidade microbiológica em função da quantidade de pontos axiais e radiais

\begin{tabular}{ccccc}
\hline Simul. & $\begin{array}{c}\text { Quant. Pontos } \\
\text { Axiais }\end{array}$ & $\begin{array}{c}\text { Quant. Pontos } \\
\text { Radiais }\end{array}$ & $\begin{array}{c}\text { Tempo } \\
\text { simulação (s) }\end{array}$ & $\begin{array}{c}S_{\text {value }} \\
\text { (Saída Resfriamento) }\end{array}$ \\
\hline 1 & 100 & 30 & 143 & 7,85 \\
2 & 100 & 35 & 157 & 7,90 \\
3 & 100 & 40 & 257 & 7,94 \\
4 & 100 & 45 & 298 & 7,96 \\
5 & 100 & 50 & 348 & 7,98 \\
6 & 100 & 60 & 383 & 8,01 \\
7 & 120 & 30 & 242 & 7,88 \\
8 & 120 & 35 & 274 & 7,93 \\
9 & 120 & 40 & 275 & 7,97 \\
10 & 120 & 45 & 292 & 7,99 \\
11 & 120 & 50 & 444 & 8,01 \\
12 & 120 & 60 & 661 & 8,04 \\
13 & 150 & 30 & 284 & 7,90 \\
14 & 150 & 35 & 318 & 7,96 \\
15 & 150 & 40 & 450 & 8,00 \\
16 & 150 & 45 & 462 & 8,02 \\
17 & 150 & 50 & 570 & 8,04 \\
18 & 150 & 60 & 816 & 8,07 \\
19 & 175 & 30 & 316 & 7,92 \\
20 & 175 & 35 & 357 & 7,97 \\
21 & 175 & 40 & 487 & 8,01 \\
22 & 175 & 45 & 650 & 8,04 \\
23 & 175 & 50 & 948 & 8,06 \\
24 & 175 & 60 & 1204 & 8,09 \\
\hline
\end{tabular}

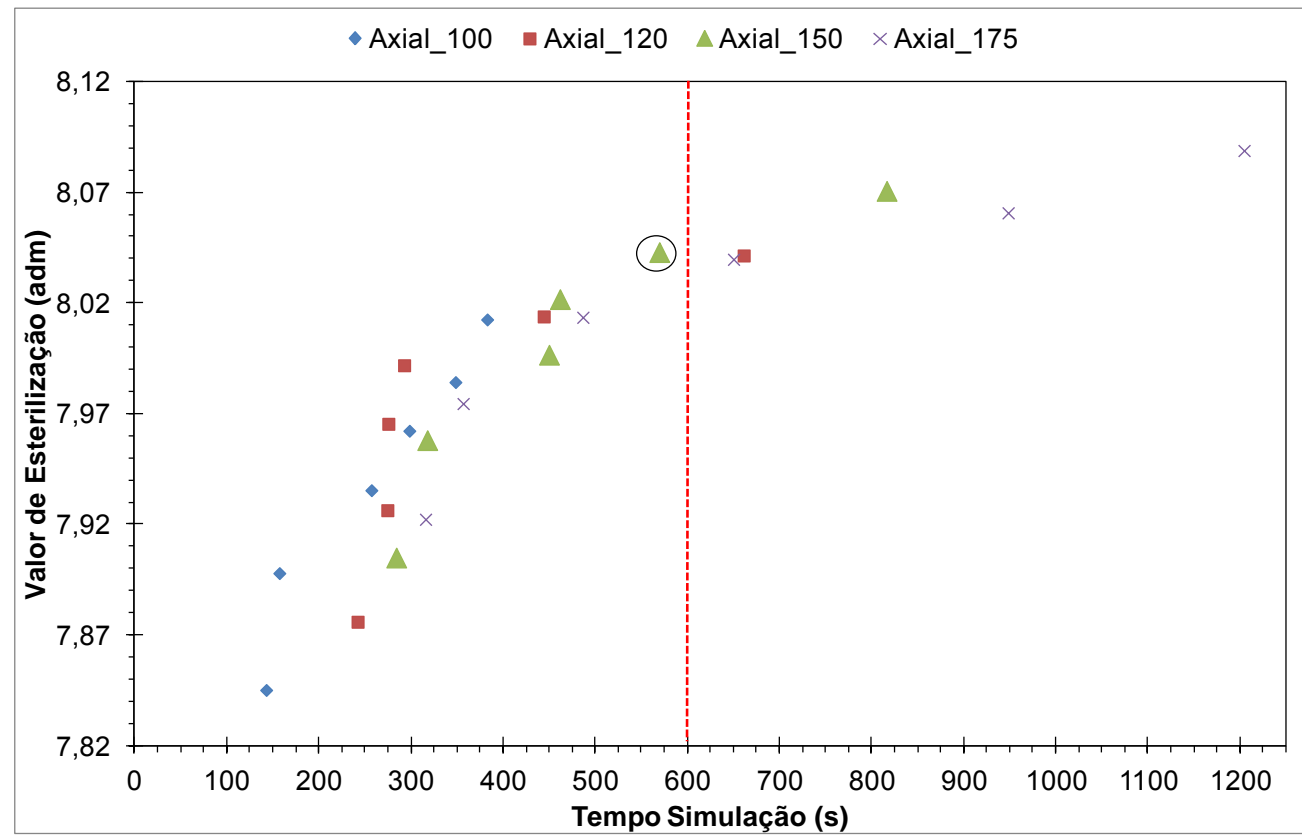

Figura 6.1 - Gráfico do valor de esterilização em função do tempo de simulação para discretizações axiais de 100 pontos (Axial_100), 120 pontos (Axial_120), 150 pontos (Axial_150) e 175 pontos (Axial_175) 
Para um dado número de pontos axial, o aumento em pontos radiais provoca um aumento no valor de esterilização. Nota-se na Figura $6.1 \mathrm{com}$ o aumento de pontos axiais e radiais o valor de $S_{\text {value }}$ tende a um valor assintótico.

Como critérios de seleção para a discretização mais conveniente para este trabalho, considerou-se inicialmente que um tempo computacional aceitável seria de 600 segundos, desconsiderando todas as simulações acima deste valor (linha vermelha na Figura 6.1). Posteriormente, dentre os dados restantes, escolheu-se aquele que tivesse maior valor de esterilização. Seguindo estes critérios, escolheuse a simulação de número 17 (150 pontos axiais e 50 pontos radiais).

Observa-se também que a variação entre do valor de esterilização da discretização escolhida e os eliminados com tempo acima de $600 \mathrm{~s}$ é pequena (variação máxima de 0,05 ). Portanto, uma malha mais refinada traz pequenas melhoras e acarreta em tempos de simulações maiores.

Com o valor da discretização escolhido, realizou-se uma simulação com o intuído de analisar as respostas obtidas pelo modelo proposto. A Figura 6.2 mostra os perfis de temperatura do suco de amora no centro e na parede do tubo interno, assim como, a temperatura média do suco e as temperaturas médias dos fluidos utilidades e do isolante térmico.

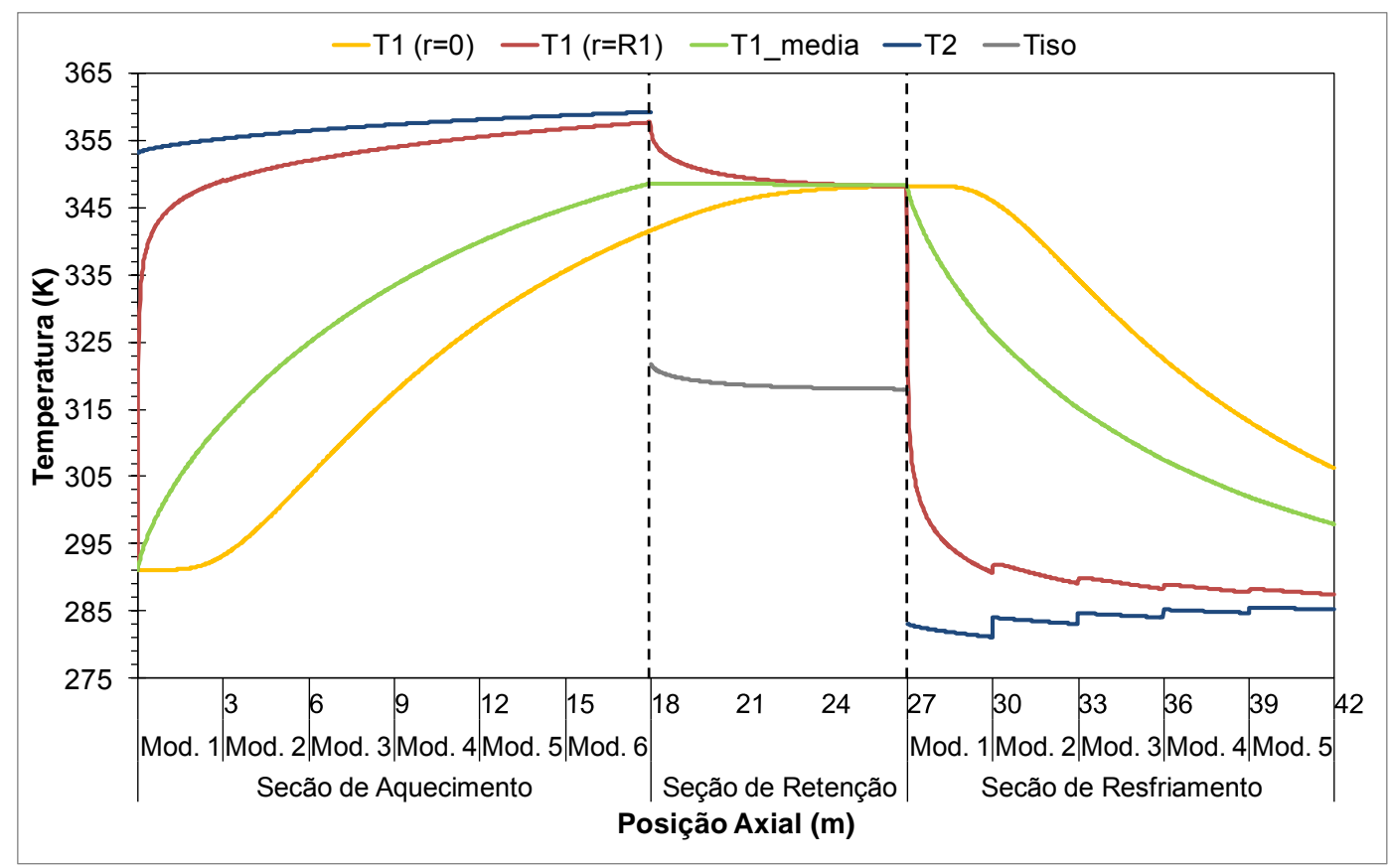

Figura 6.2 - Perfis de temperaturas do tratamento térmico contínuo. Temperaturas da polpa de amora no centro do tubo interno $(\mathrm{T} 1(\mathrm{r}=0))$; Temperatura da polpa de amora na parede interna do tubo interno ( 1 1 $(r=R 1))$; Temperatura da polpa de amora média (T1_media); Temperatura dos fluidos utilidade (T2); Temperatura do isolante térmico (Tiso) 
Analisando a Figura 6.2, observa-se uma diferença entre a temperatura de entrada e saída do fluido utilidade nas seções de aquecimento e resfriamento são menores que $6{ }^{\circ} \mathrm{C}$. Isto se deve ao fato da vazão e das capacidades caloríficas (vazão x calor específico) dos fluidos utilidade serem muito maiores (maior ou igual a 10 vezes) que as do fluido alimentício. Percebe-se também que na seção de resfriamento o fluido utilidade apresenta um perfil em forma de "escada", em decorrência da forma de escoamento "misto" na seção, conforme Figura 5.1. Ou seja, escoamento em contracorrente nos módulos, e paralelo na seção como um todo.

As propriedades termofísicas do fluido utilidade em cada módulo das seções de resfriamento e aquecimento, assim como, a temperatura média do módulo, estão mostradas na Tabela 6.4 .

Tabela 6.4 - Propriedades termofísicas do fluido utilidade em cada módulo das seções de aquecimento e resfriamento (Unidades $\mathrm{SI}$ )

\begin{tabular}{|c|c|c|c|c|c|c|c|c|}
\hline & Mod. & $\overline{T_{2}}$ & $C_{p 2}$ & $\rho_{2}$ & $\mu_{2}$ & $k_{2}$ & $\boldsymbol{k}_{e f 2}$ & $R e_{2}$ \\
\hline \multirow{6}{*}{$\begin{array}{l}\frac{0}{1} \\
\frac{1}{d} \\
\frac{E}{0} \\
\frac{\Phi}{2} \\
\frac{0}{4}\end{array}$} & 1 & 354,2 & 4204 & 972,8 & $3,519 \times 10^{-4}$ & 0,670 & 0,670 & $9,446 \times 10^{7}$ \\
\hline & 2 & 355,8 & 4206 & 971,8 & $3,451 \times 10^{-4}$ & 0,671 & 0,671 & $9,624 \times 10^{7}$ \\
\hline & 3 & 356,8 & 4206 & 971,1 & $3,407 \times 10^{-4}$ & 0,671 & 0,671 & $9,740 \times 10^{7}$ \\
\hline & 4 & 357,7 & 4207 & 970,6 & $3,374 \times 10^{-4}$ & 0,672 & 0,672 & $9,832 \times 10^{7}$ \\
\hline & 5 & 358,3 & 4208 & 970,2 & $3,347 \times 10^{-4}$ & 0,672 & 0,672 & $9,906 \times 10^{7}$ \\
\hline & 6 & 358,9 & 4208 & 969,8 & $3,325 \times 10^{-4}$ & 0,673 & 0,673 & $9,968 \times 10^{7}$ \\
\hline \multirow{5}{*}{ 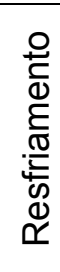 } & 1 & 282,1 & 4175 & 996,9 & $1,347 \times 10^{-3}$ & 0,586 & 0,586 & $2,529 \times 10^{7}$ \\
\hline & 2 & 283,6 & 4175 & 996,8 & $1,292 \times 10^{-3}$ & 0,589 & 0,589 & $2,637 \times 10^{7}$ \\
\hline & 3 & 284,4 & 4175 & 996,7 & $1,262 \times 10^{-3}$ & 0,590 & 0,590 & $2,698 \times 10^{7}$ \\
\hline & 4 & 285,0 & 4175 & 996,7 & $1,242 \times 10^{-3}$ & 0,591 & 0,591 & $2,742 \times 10^{7}$ \\
\hline & 5 & 285,4 & 4175 & 996,7 & $1,228 \times 10^{-3}$ & 0,592 & 0,592 & $2,774 \times 10^{7}$ \\
\hline
\end{tabular}

Analisando a Tabela 6.4 observa-se a que a diferença das temperaturas médias do primeiro e último módulo das seções de aquecimento e resfriamento é menores que $5^{\circ} \mathrm{C}$ e $3^{\circ} \mathrm{C}$, respectivamente. Isso reflete na pequena variação das propriedades termofísicas. Tem-se também que o escoamento do fluido utilidade no ânulo é altamente turbulento, pois este é quase 30000 vezes maior que o número de Reynolds Crítico (3000).

Para o suco de amora, observa-se que a diferença entre a temperatura no centro e na parede varia de aproximadamente $53^{\circ} \mathrm{C}$ no primeiro módulo da seção de aquecimento e $13^{\circ} \mathrm{C}$ no final do último módulo da seção. Isso se deve ao fato do 
fluido ser viscoso e estar escoando em regime laminar, fazendo com que as lâminas que compõem o fluido não conseguirem se misturar mais efetivamente. Pode-se diminuir esta diferença de temperaturas, fazendo com que o fluido sofra mais misturas (aumentando o número de acessórios de tubulação ao longo do pasteurizador e corrugação do tubo).

Vale salientar, que para a simulação considerou-se uma difusividade mássica efetiva radial de $10^{-5} \mathrm{~m}^{2}$.s. Este valor, comparado com um valor de difusividade de referência, para sistemas liquído-liquído, de $10^{-9} \mathrm{~m}^{2} . \mathrm{s}$ (BIRD; STEWART; LIGHTFOOT, 2002; FOSTER; CUSSLER, 1986) aumentou em 10000 vezes. Com isto, a difusão de matéria ficou mais facilitada gerando maior movimentação entre as camadas de fluido.

Tem-se também que a condutividade térmica efetiva radial foi 15 vezes maior que a condutividade térmica. Ou seja, a penetração de calor na direção radial aumentou 15 vezes, facilitando a mistura entre as camadas do fluido.

Observa-se, pela Figura 6.2, que o fluido alimentício que escoa no centro do tubo interno possui um "atraso" em seu aquecimento e resfriamento. A polpa do suco de amora só começa a aquecer praticamente no final do primeiro módulo, e continua seu aquecimento até os seis metros do tubo de retenção, quando a temperatura se mantém praticamente constante até o começo do resfriamento no final do primeiro módulo de resfriamento. Este fato pode ser explicado pela alta concentração de sólidos (40,2 ºRIX), que aumenta o índice de consistência (viscosidade aparente), que por sua vez dificulta penetração do calor da parede para o centro, fazendo com que ocorra o atraso da variação de temperatura na região central.

Ainda na Figura 6.2, a temperatura do isolamento térmico se mantém quase que constante, sendo uma temperatura intermediária entre a temperatura do ar ambiente e a temperatura média da polpa de amora.

As propriedades termofísicas do fluido alimentício em cada módulo das seções de aquecimento, retenção e resfriamento, assim como, a temperatura média do módulo, e os números de Reynolds e Reynolds crítico (equações (5.5) e (5.6)) estão mostrados na Tabela 6.5. 
Tabela 6.5 - Propriedades termofísicas do fluido alimentício em cada módulo das seções de aquecimento, retenção e resfriamento (Unidades $\mathrm{SI}$ )

\begin{tabular}{|c|c|c|c|c|c|c|c|c|c|c|}
\hline & Mod. & $\bar{T}_{1_{m}}$ & $C_{p 1}$ & $\rho_{1}$ & $K_{\text {reo }}$ & $n_{\text {reo }}$ & $k_{1}$ & $k_{e f 1}$ & $R e_{1}$ & $\boldsymbol{R e}_{1 \_c r i ́ t i c o}$ \\
\hline \multirow{6}{*}{ 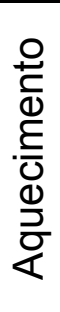 } & 1 & 302,2 & 2999 & 1171 & 0,829 & 0,636 & 0,479 & 7,18 & 57,15 & 2317 \\
\hline & 2 & 319,0 & 3075 & 1162 & 0,263 & 0,645 & 0,497 & 7,46 & 173,0 & 2313 \\
\hline & 3 & 329,1 & 3121 & 1157 & 0,132 & 0,649 & 0,508 & 7,62 & 337,1 & 2310 \\
\hline & 4 & 336,6 & 3155 & 1153 & 0,079 & 0,653 & 0,517 & 7,75 & 553,2 & 2308 \\
\hline & 5 & 342,3 & 3181 & 1150 & 0,053 & 0,655 & 0,523 & 7,84 & 806,7 & 2307 \\
\hline & 6 & 346,7 & 3201 & 1148 & 0,040 & 0,657 & 0,528 & 7,91 & 1076 & 2306 \\
\hline \multicolumn{2}{|c|}{ Retenção } & 348,3 & 3208 & 1147 & 0,036 & 0,658 & 0,529 & 7,94 & 1196 & 2305 \\
\hline \multirow{5}{*}{ 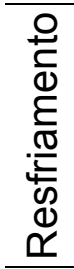 } & 1 & 337,1 & 3157 & 1153 & 0,077 & 0,653 & 0,517 & 7,75 & 569,3 & 2308 \\
\hline & 2 & 320,6 & 3082 & 1161 & 0,235 & 0,645 & 0,499 & 7,48 & 192,6 & 2312 \\
\hline & 3 & 311,3 & 3040 & 1166 & 0,445 & 0,641 & 0,489 & 7,33 & 104,1 & 2315 \\
\hline & 4 & 304,7 & 3010 & 1169 & 0,697 & 0,637 & 0,481 & 7,22 & 67,56 & 2317 \\
\hline & 5 & 299,9 & 2988 & 1172 & 0,966 & 0,635 & 0,476 & 7,14 & 49,35 & 2318 \\
\hline
\end{tabular}

Pela Tabela 6.5 tem-se que a variação dos calores e massas específicas são menores que $7 \%$ para as seções em estudo. Já para a condutividade térmica, temse uma variação de aproximadamente $10 \%$, entre os primeiros e últimos módulos de cada seção, observando-se também um aumento do valor da propriedade com o aumento da temperatura ao longo do processamento térmico. Em relação às propriedades reológicas, a viscosidade aparente apresenta uma grande diminuição de seu valor na seção de aquecimento, passando de 829 cP no primeiro módulo para aproximadamente $40 \mathrm{cP}$ no sexto módulo. Opostamente, no resfriamento, temse um aumento da mesma, passando de $77 \mathrm{cP}$ para $966 \mathrm{cP}$. Para o índice de comportamento, como esperado, tem-se pequena variação. Já os números de Reynolds e Reynolds crítico, aumentam e diminuem no aquecimento, influenciados principalmente pela diminuição da viscosidade aparente, chegando a seu valor máximo no tubo de retenção, mostrando que ao longo do tubo o fluido alimentício ainda sofre um pequeno aquecimento proveniente dos efeitos de difusão e mistura.

Ainda pela Tabela 6.5 tem-se que o número de Reynolds no primeiro módulo da seção de aquecimento (entrada do alimento no processo) é 57,1. Para este número tem-se que o comprimento necessário para desenvolvimento da camada limite hidrodinâmica em regime laminar, calculada a partir da equação (5.4), é de aproximadamente $9 \mathrm{~cm}$. Com isso, conclui-se que a adoção da hipótese de escoamento desenvolvido é válida para o processo em questão, pois o comprimento necessário para desenvolvimento da camada é 34 vezes menor que o comprimento de um único módulo. 
A Figura 6.3 mostra os perfis de concentração do atributo de qualidade microbiológica no centro, na parede interna do tubo e o valor da concentração média em cada módulo.

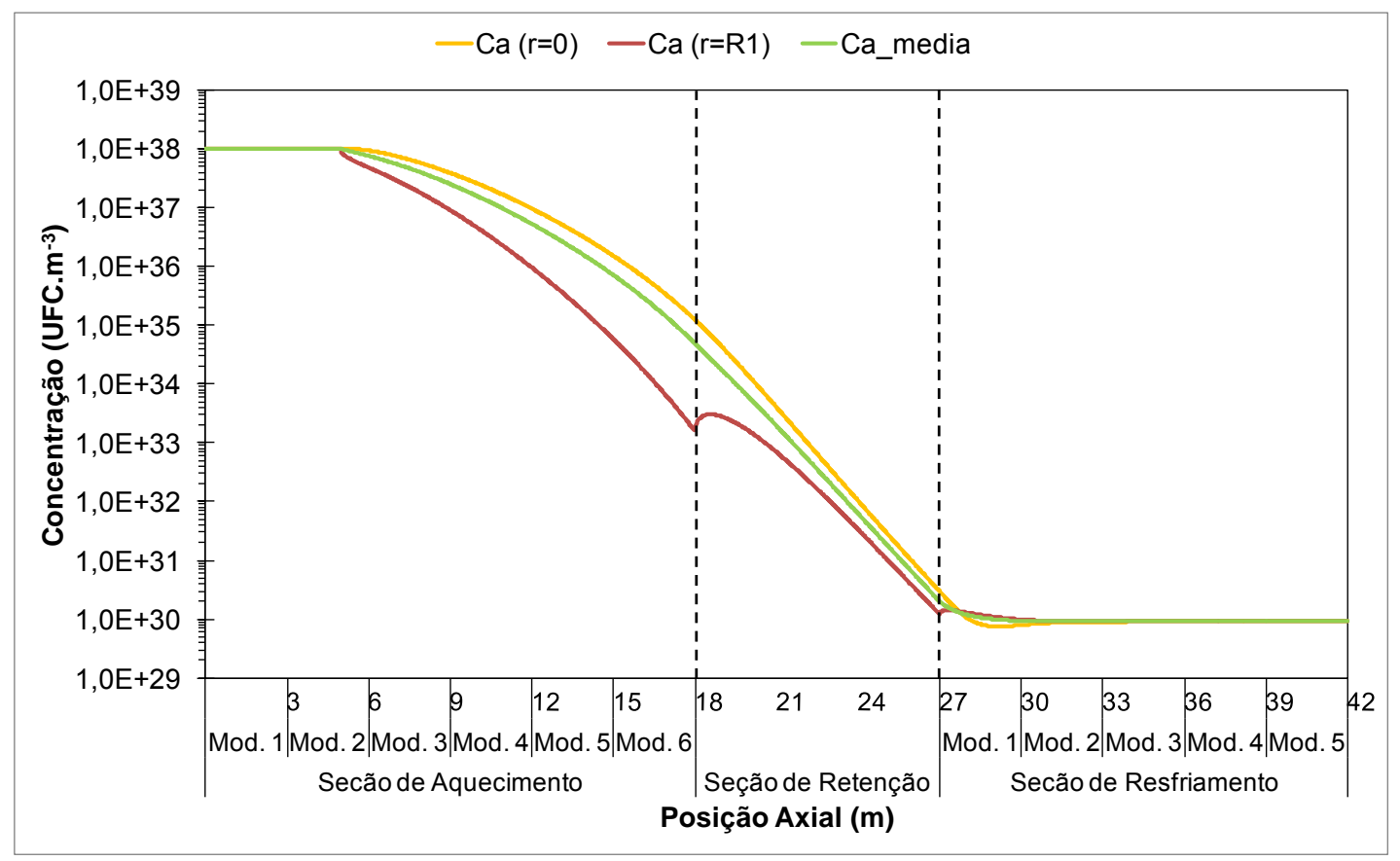

Figura 6.3 - Perfis de concentração do atributo de qualidade microbiológica no tratamento térmico contínuo. Concentração do atributo no centro do tubo interno $(\mathrm{Ca}(\mathrm{r}=0))$; Concentração do atributo na parede interna do tubo interno ( $\mathrm{Ca}(\mathrm{r}=\mathrm{R} 1))$; Concentração média do atributo (Ca_media)

Observa-se que na parede do tubo tem-se um decaimento rápido da concentração em relação ao centro do tubo, pois a temperatura na parede é maior que a temperatura do centro no aquecimento. Observa-se também que ao final do aquecimento que no centro e na parede do tubo a concentração do micro-organismo diminui em, aproximadamente 3 e 5 reduções decimais.

Observa-se também, pela Figura 6.3, que na interface aquecimento-retenção, na parede do tubo, existe uma inflexão que é decorrente da descontinuidade do fluido utilidade. Esse efeito pode ser explicado pelo fato da parede não estar mais sobre influência de um aquecimento, fazendo com que haja uniformização da temperatura e consequentemente diminuição da temperatura da parede e aumento da concentração, devido aos efeitos de mistura e da difusão mássica do centro para a parede, da mesma.

No resfriamento, ocorre basicamente a cessão da reação de destruição térmica, fazendo com que a concentração mantenha-se constante. No entanto, 
como discutido anteriormente, como existe um atraso no resfriamento no centro do tubo existe uma pequena inativação de micro-organismos.

Em análises convencionais, o aquecimento e o resfriamento são considerados instantâneos, ou seja, seus efeitos para a destruição dos micro-organismos são desprezíveis. Para o estudo de caso, tem-se que a concentração do microorganismo sofre uma redução total de aproximadamente 8 ciclos decimais. Se levarmos em conta a concentração média na saída do aquecimento, temos que quase $44 \%$ deste valor são referentes à seção de aquecimento e resfriamento.

A Figura 6.4 mostra o valor de esterilização ao longo de todo o processamento térmico, este valor representa o número de ciclos de reduções decimais que o atributo sofre. Observa-se que grande parte da destruição térmica se dá na retenção (maior inclinação do gráfico) e chega ao seu valor final no resfriamento.

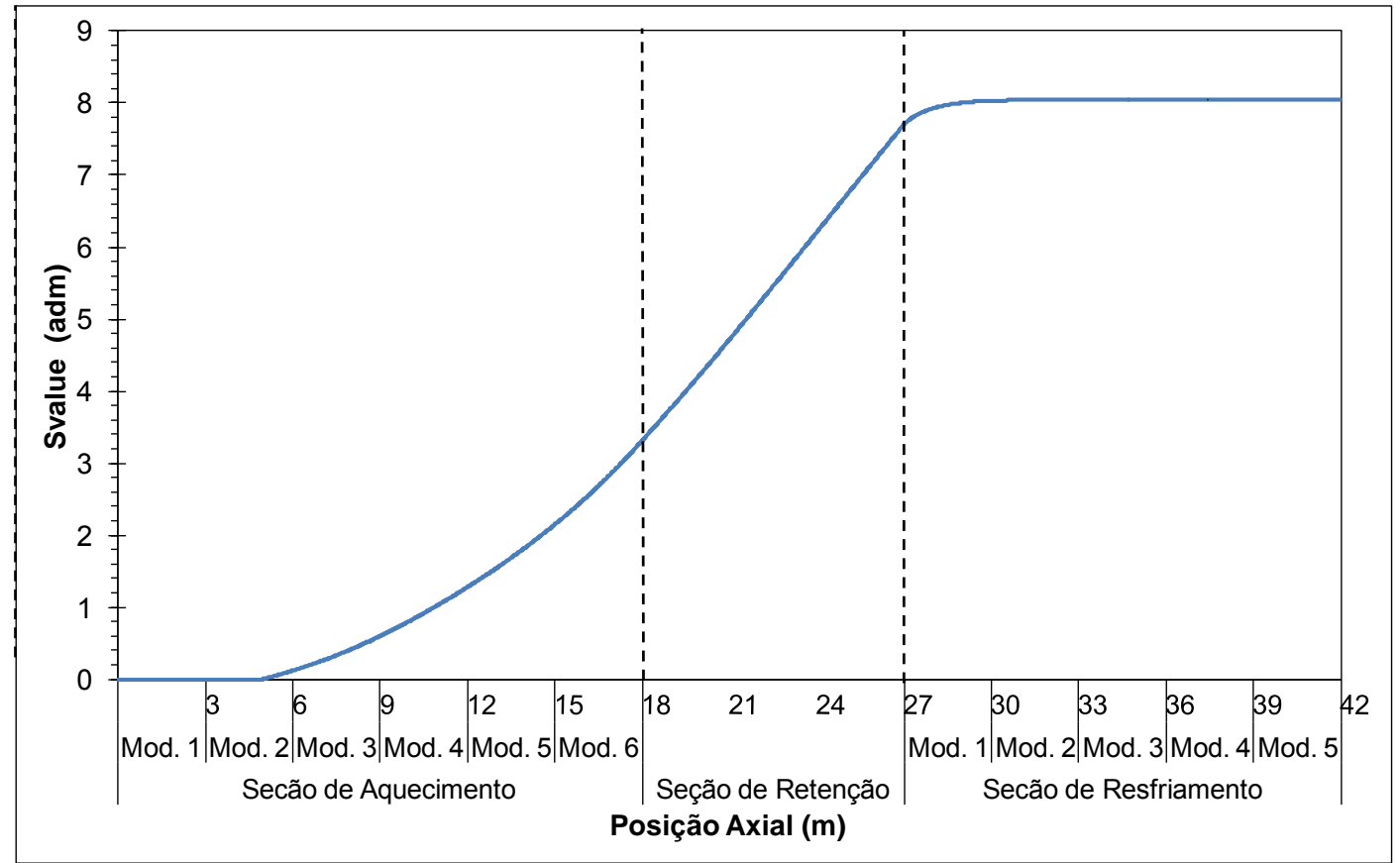

Figura 6.4 - Valor de esterilização do estudo de caso

\subsubsection{Estudo 2: Efeitos das difusividades efetivas térmica e mássica}

Nesta seção objetiva-se verificar quais são os efeitos da variação da difusividade térmica efetiva radial e da difusividade mássica efetiva radial, no valor de esterilização do processo. Para tanto, utilizou-se o estudo de caso proposto e 
realizaram-se simulações com valores diferentes de fatores de aumento da condutividade térmica do fluido alimentício para diferentes difusividades mássicas efetivas e vice-versa. Vale salientar, que o fator de aumento é aplicado a todo o equipamento e é um multiplicador da condutividade térmica do alimento.

A Tabela 6.6 mostra os valores das difusividades mássicas efetivas e condutividade térmica efetivas (proporcional à difusividade térmica efetiva) usadas para as simulações, assim como, os valores de esterilização na saída da seção de resfriamento das simulações realizadas.

Tabela 6.6 - Efeitos das diferentes difusividades mássicas efetivas e condutividades térmicas efetivas no valor de esterilização do processo para o atributo de qualidade microbiológica

\begin{tabular}{ccccccc}
\hline & \multicolumn{5}{c}{ Difusividade mássica efetiva radial $\left(\mathrm{m}^{2} \cdot \mathrm{s}\right)$} \\
\cline { 2 - 6 }$k_{\text {ef } 1}\left(\mathrm{~W} \cdot \mathrm{m}^{-1} \cdot \mathrm{K}^{-1}\right)$ & $10^{-4}$ & $10^{-5}$ & $10^{-6}$ & $10^{-7}$ & $10^{-8}$ & $10^{-9}$ \\
\cline { 2 - 6 } $1 \mathrm{x} k_{1}$ & 4,42 & 2,19 & 0,45 & 0,10 & 0,04 & 0,03 \\
$5 \mathrm{x} k_{1}$ & 6,53 & 2,67 & 0,54 & 0,18 & 0,13 & 0,12 \\
$10 \times k_{1}$ & 9,23 & 3,71 & 1,03 & 0,62 & 0,59 & 0,58 \\
$15 \mathrm{x} k_{1}$ & 17,19 & 8,04 & 3,94 & 3,54 & 3,54 & 3,54 \\
$20 \mathrm{x} k_{1}$ & 33,09 & 18,06 & 12,56 & 12,18 & 12,15 & 12,14 \\
\hline
\end{tabular}

Pela Tabela 6.6, observa-se que quanto maior for a condutividade térmica efetiva e difusividade mássica efetiva maiores são os valores de esterilização, pois ocorre o efeito das mistura das lâminas pela penetração do calor (tornando o fluido menos viscoso) e pelo transporte difusivo de massa. Observa-se também, que para o valor da condutividade térmica efetiva igual ao da condutividade térmica do alimento, para uma difusividade mássica efetiva de $10^{-9} \mathrm{~m}^{2} . \mathrm{s}$, não existe, praticamente, troca térmica e mássica por efeitos de difusão entre todas as lâminas na direção radial, ocorrendo consequentemente um tratamento térmico ineficiente, para o equipamento estudado.

A Figura 6.5 mostra os perfis do valor de esterilização para as difusividades mássicas efetivas estudas variando os valores das condutividades térmicas efetivas.

Já a Figura 6.6 mostra os perfis dos valores de esterilização para diversos valores de condutividade térmica mudando a difusividade mássica. 

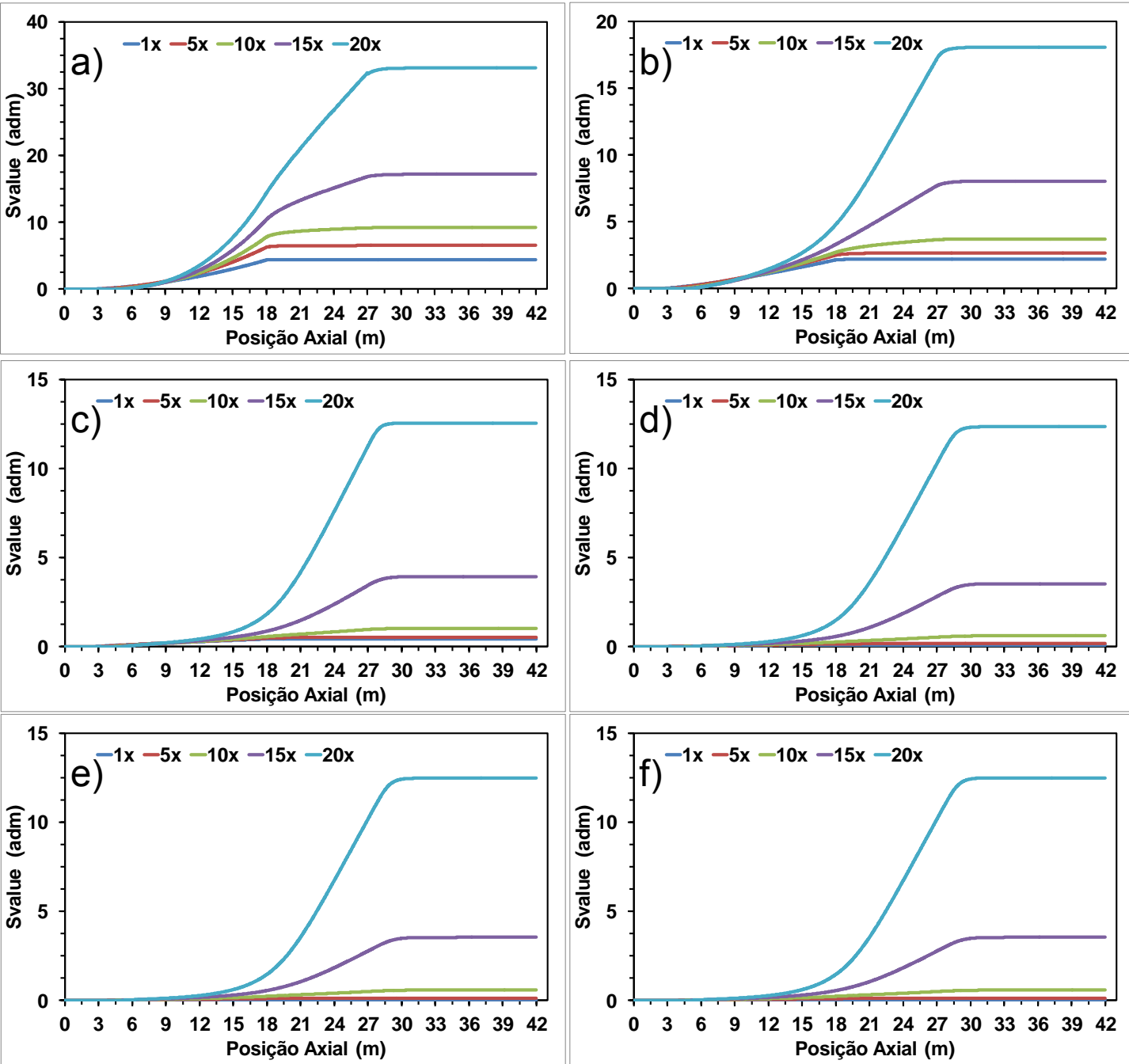

Figura 6.5 - Perfis do valor de esterilização para as difusividades térmicas efetivas na direção radial de 1 vez (1x), 5 vezes (5x), 10 vezes (10x), 15 vezes (15x) e 20 vezes (20x) maiores que a difusividade térmica para as difusividades mássicas de: a) $10^{-4} \mathrm{~m}^{2} . \mathrm{s}$; b) $10^{-5} \mathrm{~m}^{2} . \mathrm{s}$; c) $10^{-6} \mathrm{~m}^{2} . \mathrm{s}$; d) $10^{-7} \mathrm{~m}^{2} . \mathrm{s}$; e) $10^{-8} \mathrm{~m}^{2} . \mathrm{s}$; f) $10^{-9} \mathrm{~m}^{2} . \mathrm{s}$ 

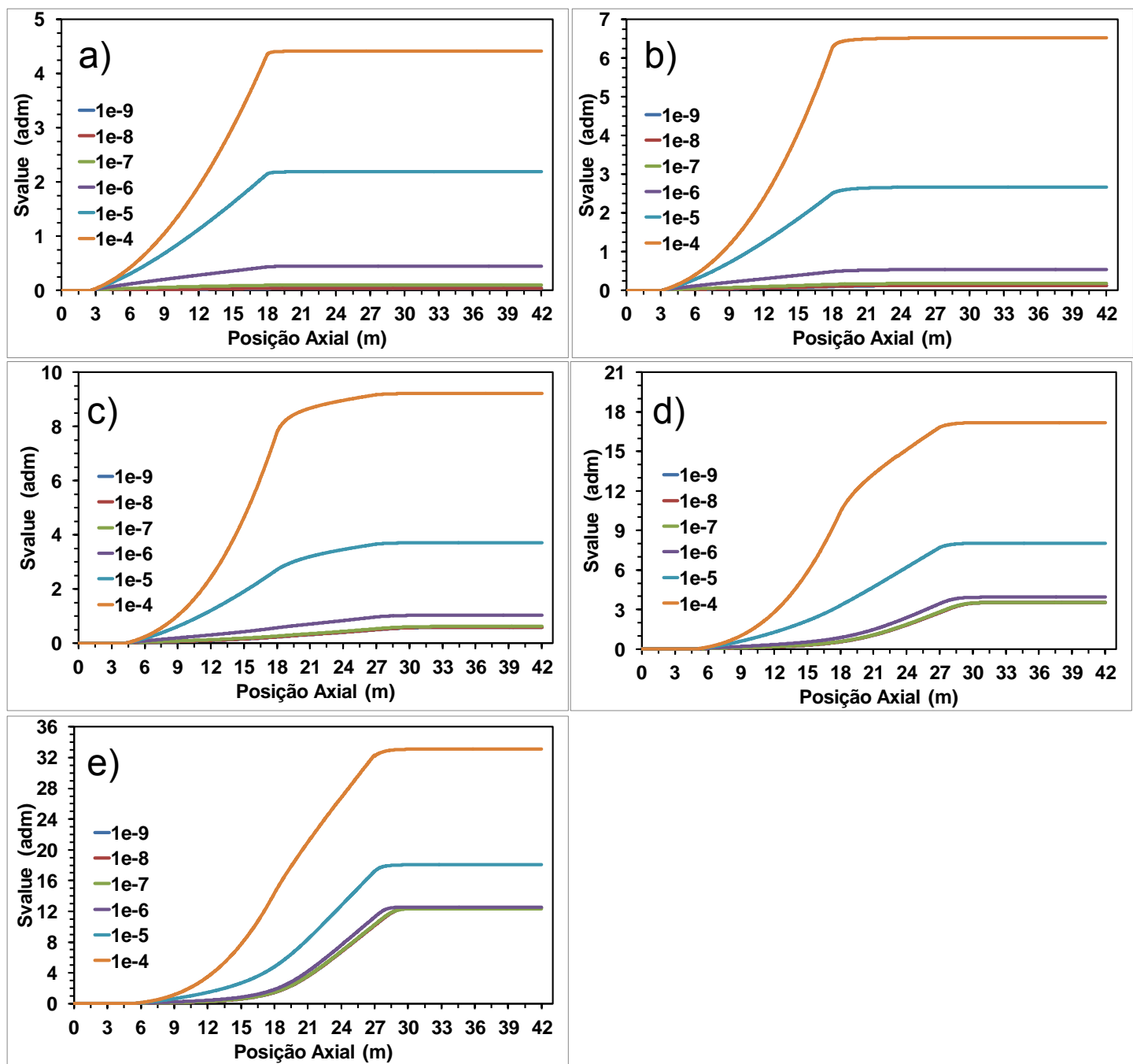

Figura 6.6 - Perfis do valor de esterilização para as difusividades mássicas efetivas na direção radial de $10^{-4} \mathrm{~m}^{2} . \mathrm{s}(1 \mathrm{e}-4), 10^{-5} \mathrm{~m}^{2} . \mathrm{s}(1 \mathrm{e}-5), 10^{-6} \mathrm{~m}^{2} . \mathrm{s}(1 \mathrm{e}-6), 10^{-7} \mathrm{~m}^{2} . \mathrm{s}$ (1e-7), $10^{-8} \mathrm{~m}^{2} . \mathrm{s}(1 \mathrm{e}-8)$ e $10^{-9} \mathrm{~m}^{2} . \mathrm{s}(1 \mathrm{e}-9)$ para as difusividades térmicas efetivas maiores que as difusividades térmicas em: a) $1 \mathrm{x}$; b) $5 \mathrm{x}$; c) $10 \mathrm{x}$; d) 15x; e) 20x

Observa-se pela Figura 6.5 e pela Figura 6.6, que quanto maiores às condutividades térmicas efetivas e difusividades mássicas efetivas maior a letalidade do processo, pois calor é mais facilmente trocado e distribuído no fluido, além de ocorrer mais mistura radial, inativando, consequentemente, mais micro-organismos.

Apesar das duas difusividades serem estudas separadamente, tem-se que as mesmas não são independentes na prática. Ou seja, uma difusividade tem influência sobre a outra e consequentemente na letalidade do processo. 


\subsubsection{Estudo 3: Influência da temperatura de entrada da água quente e da vazão do produto no valor de esterilização}

Com o objetivo de verificar a influência dos parâmetros de processo no valor de esterilização ao final do tratamento térmico, estudou-se a influência da variação da temperatura de entrada da água quente $\left(T_{\text {2in_aque }}\right)$ juntamente com a vazão volumétrica do suco de amora $\left(q_{1}\right)$. Escolheram-se estes parâmetros, pois ambos são facilmente controlados, além de, o primeiro estar relacionado ao grau de tratamento desejado, enquanto o segundo ao tempo que o alimento está sobre a ação da alta temperatura. Os valores de esterilização ao final do processo foram quantificados para os atributos de qualidade microbiológica e de qualidade nutricional.

Inicialmente, montou-se um planejamento $3^{2}$ ( 3 níveis de valores para cada uma das 2 variáveis), totalizando 9 simulações. Posteriormente, com os parâmetros mostrados na Tabela 6.1 , realizou-se as simulações, determinando os valores de esterilização dos atributos de qualidade microbiológica e qualidade nutricional na saída do processo.

Os valores dos níveis estudados e os valores de esterilização determinados são mostrados na Tabela 6.7

Tabela 6.7 - Planejamento e os valores de esterilização para os atributos de qualidade microbiológica e qualidade nutricional

\begin{tabular}{cccc}
\hline$T_{\text {2in_aque }}\left({ }^{\circ} \mathrm{C}\right)$ & $q_{1}(\mathrm{~L} / \mathrm{h})$ & $S_{\text {value_QM }}$ & $S_{\text {value } Q N}$ \\
\hline $86(-1)$ & $800(-1)$ & 8,04 & 0,0757 \\
$88(0)$ & $800(-1)$ & 11,22 & 0,0842 \\
$90(1)$ & $800(-1)$ & 15,62 & 0,0938 \\
$86(-1)$ & $1000(0)$ & 3,70 & 0,0515 \\
$88(0)$ & $1000(0)$ & 4,86 & 0,0570 \\
$90(1)$ & $1000(0)$ & 6,29 & 0,0632 \\
$86(-1)$ & $1200(1)$ & 2,21 & 0,0376 \\
$88(0)$ & $1200(1)$ & 2,88 & 0,0415 \\
$90(1)$ & $1200(1)$ & 3,60 & 0,0458 \\
\hline
\end{tabular}

Observando a Tabela 6.7, observa-se, como esperado, um aumento do valor da destruição dos atributos de qualidade microbiológica e qualidade nutricional para temperaturas maiores e vazões menores. Isto se deve ao fato de ter o fluido sobre uma maior temperatura por um tempo maior (menor vazão). 
Comprova-se, como dito na seção 6.1.1, que o atributo de qualidade nutricional é menos sensível que o de qualidade microbiológica. Devido a isso, podese dizer que o atributo de qualidade nutricional cor (destruição do pigmento antocianina) não sofre efeitos de alterações significativos durante o tratamento térmico proposto, podendo ter outro atributo, como as vitaminas, mais crítico no quesito qualidade nutricional.

Realizou-se a Análise de Variância, com o software Statistica 7.0 (StatSoft, EUA), para cada atributo separadamente, com um intervalo de confiança de 95\% para quantificar os efeitos lineares, quadráticos e cruzados das variáveis no valor de esterilização. A Tabela 6.8 mostra os valores dos efeitos da temperatura da água quente e da vazão do alimento, para os atributos de qualidade microbiológica e qualidade nutricional.

Tabela 6.8 - Efeitos lineares, quadráticos e cruzados da temperatura de entrada da água quente e da vazão do produto alimentício na degradação dos atributos de qualidade microbiológica e qualidade nutricional

Atributo de Qualidade Atributo de Qualidade microbiológica nutricional

\begin{tabular}{ccccccc}
\cline { 2 - 6 } Fonte & Efeito & $\begin{array}{c}\text { Erro } \\
\text { Padrão }\end{array}$ & Valor $\mathrm{p}$ & Efeito & $\begin{array}{c}\text { Erro } \\
\text { Padrão }\end{array}$ & Valor $\mathrm{p}$ \\
\hline Interseção & 6,493 & 0,222 & 0,000 & 0,0611 & 0,0002 & 0,0000 \\
$T_{2 \text { in_aque }}$ (Linear) & 3,855 & 0,543 & 0,006 & 0,0127 & 0,0004 & 0,0001 \\
$T_{2 \text { in_aque }(\text { Quadrático) }}$ & $-0,256$ & 0,471 & 0,624 & $-0,0003$ & 0,0004 & 0,4042 \\
$q_{1}$ (Linear) & $-8,734$ & 0,543 & 0,001 & $-0,0429$ & 0,0004 & 0,0000 \\
$q_{1}$ (Quadrático) & $-2,308$ & 0,471 & 0,016 & $-0,0059$ & 0,0004 & 0,0005 \\
$T_{2 \text { in_aque (Linear) } x}$ & $-3,094$ & 0,666 & 0,019 & $-0,0050$ & 0,0005 & 0,0021 \\
$q_{1}$ (Linear) & & & & &
\end{tabular}

Tem-se que o efeito quadrático da temperatura de entrada da água quente não é relevante (valor $p>0,05$ ) para ambos os atributos. Devido a isto este efeito foi desconsiderado. Salienta-se que estatisticamente quando menor o valor $p$ mais significativo é o efeito no valor da resposta. Portanto, os efeitos linear e quadrático da vazão do produto possuem maior e menor significância, respectivamente. A Tabela 6.9 mostra os efeitos recalculados, não levando em conta os efeitos quadráticos da temperatura de entrada da água quente. 
Tabela 6.9 - Efeitos lineares, quadráticos e cruzados da temperatura de entrada da água quente e da vazão do produto alimentício na degradação dos atributos de qualidade microbiológica e qualidade nutricional, desconsiderando o efeito quadrático para a temperatura de entrada da água quente

\begin{tabular}{|c|c|c|c|c|c|c|}
\hline \multirow[b]{2}{*}{ Fonte } & \multicolumn{3}{|c|}{$\begin{array}{c}\text { Atributo de Qualidade } \\
\text { microbiológica }\end{array}$} & \multicolumn{3}{|c|}{$\begin{array}{c}\text { Atributo de Qualidade } \\
\text { nutricional }\end{array}$} \\
\hline & Efeito & $\begin{array}{c}\text { Erro } \\
\text { Padrão }\end{array}$ & Valor $p$ & Efeito & $\begin{array}{c}\text { Erro } \\
\text { Padrão }\end{array}$ & Valor $p$ \\
\hline Interseção & 6,493 & 0,201 & 0,000 & 0,0612 & 0,0002 & 0,0000 \\
\hline$T_{2 \text { in_aque }}($ Linear) & 3,855 & 0,493 & 0,001 & 0,0127 & 0,0004 & 0,0000 \\
\hline$q_{1}$ (Linear) & $-8,734$ & 0,493 & 0,000 & $-0,0429$ & 0,0004 & 0,0000 \\
\hline$q_{1}$ (Quadrático) & $-2,308$ & 0,427 & 0,006 & $-0,0059$ & 0,0004 & 0,0001 \\
\hline $\begin{array}{c}T_{2 \text { in_aque }}(\text { Linear }) \mathrm{X} \\
q_{1}(\text { Linear })\end{array}$ & $-3,094$ & 0,604 & 0,007 & $-0,0050$ & 0,0005 & 0,0005 \\
\hline
\end{tabular}

Por regressão tem-se algebricamente que o valor de esterilização para o atributo de qualidade microbiológica e qualidade nutricional como função da temperatura de entrada da água quente e vazão do produto alimentício são dados, juntamente com coeficiente de correlação, pelas equações (6.10) e (6.11):

$$
\begin{gathered}
S_{\text {value_QM }}=-340,687+4,832 \cdot T_{2 \text { in_aque }}+0,203 \cdot q_{1}+5,770 \mathrm{e}^{-5} \cdot q_{1}{ }^{2} \\
-3,868 \mathrm{e}^{-3} \cdot T_{2 \text { in_aque }} \cdot q_{1} \quad\left(R^{2}=0,9816\right) \\
S_{\text {value_QN }}=-5,156 \mathrm{e}^{-1}+9,391 \mathrm{e}^{-3} \cdot T_{2 \text { in_aque }}+1,481 \mathrm{e}^{-4} \cdot q_{1}+1,463 \mathrm{e}^{-7} \cdot q_{1}{ }^{2} \\
-6,228 \mathrm{e}^{-6} \cdot T_{2 \text { in_aque }} \cdot q_{1} \quad\left(R^{2}=0,9997\right)
\end{gathered}
$$

As superfícies de resposta obtidas através das equações (6.10) e (6.11) são mostradas na Figura 6.7 e na Figura 6.8.

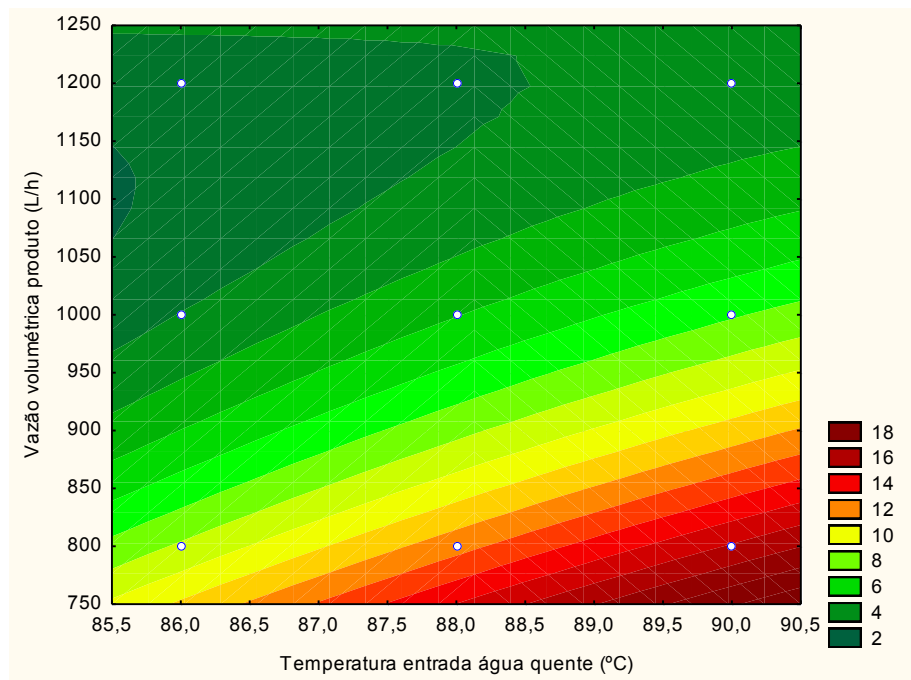

Figura 6.7 - Superfície de resposta do atributo de qualidade microbiológica em função da temperatura de entrada da água quente e vazão volumétrica do produto 


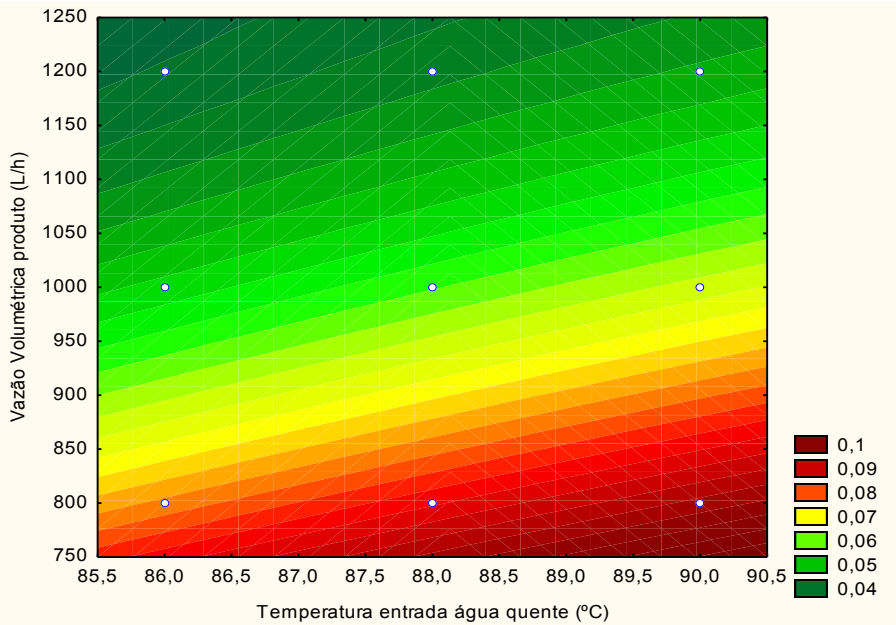

Figura 6.8 - Superfície de resposta do atributo de qualidade nutricional em função da temperatura de entrada da água quente e vazão volumétrica do produto

Observando a Figura 6.7 tem-se que o ponto de máxima esterilização é encontrado "caminhando" pela superfície no sentido de temperaturas maiores e vazões menores. De maneira oposta, pela Figura 6.8 consegue-se minimizar a destruição do atributo de qualidade nutricional pelo aumento da vazão e diminuição de temperatura.

As equações (6.10) e (6.11) podem auxiliar em um processo posterior de otimização do processamento térmico do alimento (garantir a inocuidade minimizando as perdas de qualidade nutricional).

De acordo com Toledo (2007) as principais agências reguladoras e a indústria de alimentos adotam, para uma esterilização comercial, 5 e 12 reduções decimais para micro-organismos deterioradores e patogênicos, respectivamente, para garantir a inocuidade microbiológica do alimento caso se tenha determinada concentração inicial dos mesmos. A Tabela 6.10 mostra os valores da temperatura da água quente e da vazão do produto alimentício ótimos, caso desejasse um valor de esterilização do atributo de qualidade microbiológica de 5 ou de 12, minimizando os efeitos da destruição do atributo de qualidade nutricional.

Tabela 6.10 - Valores de temperatura de entrada da água quente e vazão do produto alimentício otimizados para valores de esterilização do atributo de qualidade microbiológica de 5 e 12, minimizando o valor de esterilização do atributo de qualidade nutricional

\begin{tabular}{cccc}
\hline$T_{2 \text { in_aque }}\left({ }^{\circ} \mathrm{C}\right)$ & $q_{1}(\mathrm{~L} / \mathrm{h})$ & $S_{\text {value_QM }}$ & $S_{\text {value_QN }}$ \\
\hline 91,0 & 1098 & 5 & 0,0557 \\
94,2 & 976 & 12 & 0,0805 \\
\hline
\end{tabular}


Os valores da tabela acima foram encontrados utilizando a ferramenta Solver do software Excel 2007 (Microsoft, EUA). Observa-se que os valores de temperatura encontrados são valores extrapolados aos que foram simulados (observar superfície de resposta na Figura 6.7).

Vale salientar que o tratamento térmico é realizado para inativar/destruir o "micro-organismo alvo", que dependendo das condições de processo (temperatura, tempo de processamento, concentração inicial do micro-organismo) pode mudar. Ou seja, para um mesmo processo, em determinadas condições, pode-se ter como micro-organismo alvo um patogênico, e ao serem mudadas estas condições ter-se como alvo agora os deteriorantes, mudando também o nível de esterilização exigido sem afetar a qualidade microbiológica do alimento.

Conclui-se também que apesar dos valores e relações até aqui obtidos serem específicos para o processamento proposto, a metodologia é aplicável a casos análogos.

\subsection{Validação do modelo térmico}

\subsubsection{Experimentos}

De acordo com o procedimento experimental descrito na seção 4.1 , foram realizados ensaios com o objetivo de obter temperaturas dos fluidos produto $\mathrm{e}$ utilidade em diversos pontos do pasteurizador laboratorial, para posterior utilização na validação do modelo térmico proposto pelo ajuste do parâmetro térmico.

Foram utilizados como fluido produto mistura glicerina/água $80 \%$ e solução de CMC 1\% nas vazões de 10, 20, 30, 40 e $50 \mathrm{~L} / \mathrm{h}$. E para os fluidos de utilidade água quente (seção de aquecimento) e água gelada (seção de resfriamento).

A temperatura do ar ambiente medida foi de $299,1 \mathrm{~K}\left(25,9^{\circ} \mathrm{C}\right)$.

As vazões das águas quente e gelada, para todos os experimentos, foram de $1500 \mathrm{~L} / \mathrm{h}$. 
A Tabela 6.11 e a Tabela 6.12 mostram as vazões da mistura glicerina/água $80 \%$ e solução de CMC 1\%, além das temperaturas ambientes, e de entrada dos fluidos produto, e das águas quente e fria, para cada experimento realizado.

Tabela 6.11 - Temperaturas e vazões experimentais da mistura glicerina/água $80 \%$ utilizadas na validação do modelo térmico

\begin{tabular}{cccccc}
\hline \multirow{2}{*}{ Exp. } & \multirow{2}{*}{$T_{a m b}(\mathrm{~K})$} & \multicolumn{5}{c}{ Mistura glicerina/água 80\% } \\
\cline { 3 - 6 } 1 & 299,1 & $T_{1 \text { in }}(\mathrm{K})$ & $q_{1}(\mathrm{~L} / \mathrm{h})$ & $T_{\text {2in_aque }}(\mathrm{K})$ & $T_{\text {2in_resf }}(\mathrm{K})$ \\
\cline { 3 - 6 } 2 & $291,40 \pm 0,03$ & 10 & 374,3 & 278,7 \\
3 & 299,1 & $302,39 \pm 0,04$ & 20 & 378,7 & 278,7 \\
4 & 299,1 & $303,56 \pm 0,02$ & 30 & 375,6 & 278,6 \\
5 & 299,1 & $301,08 \pm 0,04$ & 40 & 376,9 & 278,8 \\
6 & 299,1 & $299,56 \pm 0,02$ & 50 & 374,9 & 279,5 \\
7 & 299,1 & $298,36 \pm 0,04$ & 20 & 359,7 & 279,0 \\
8 & 299,1 & $298,56 \pm 0,05$ & 30 & 368,2 & 279,5 \\
9 & 299,1 & $299,28 \pm 0,04$ & 40 & 367,6 & 279,1 \\
10 & 299,1 & $301,10 \pm 0,02$ & 50 & 365,3 & 279,0 \\
\hline
\end{tabular}

Tabela 6.12 - Temperaturas e vazões experimentais da solução de CMC $1 \%$ utilizadas na validação do modelo térmico

\begin{tabular}{cccccc}
\hline \multirow{2}{*}{ Exp. } & \multirow{2}{*}{$T_{a m b}(\mathrm{~K})$} & $T_{1 \text { in }}(\mathrm{K})$ & $q_{1}(\mathrm{~L} / \mathrm{h})$ & $T_{2 \text { in_aque }}(\mathrm{K})$ & $T_{\text {2in_resf }}(\mathrm{K})$ \\
\cline { 3 - 6 } 1 & 299,1 & $291,15 \pm 0,05$ & 10 & 367,6 & 278,8 \\
2 & 299,1 & $290,45 \pm 0,03$ & 20 & 370,8 & 278,5 \\
3 & 299,1 & $290,35 \pm 0,05$ & 30 & 369,0 & 279,2 \\
4 & 299,1 & $293,55 \pm 0,03$ & 40 & 366,4 & 278,6 \\
5 & 299,1 & $293,95 \pm 0,04$ & 50 & 366,1 & 278,6 \\
6 & 299,1 & $294,25 \pm 0,03$ & 10 & 374,7 & 278,0 \\
7 & 299,1 & $294,75 \pm 0,04$ & 20 & 371,5 & 278,4 \\
8 & 299,1 & $294,65 \pm 0,04$ & 30 & 373,9 & 278,8 \\
9 & 299,1 & $294,75 \pm 0,03$ & 40 & 373,5 & 279,3 \\
10 & 299,1 & $294,85 \pm 0,04$ & 50 & 373,0 & 279,0 \\
\hline
\end{tabular}

A Tabela 6.13 e a Tabela 6.14 mostram os valores das temperaturas experimentais da mistura glicerina/água $80 \%$ e da solução de CMC 1\%, ao longo do pasteurizador (vide Figura 4.2). 
Tabela 6.13 - Valores das temperaturas experimentais para a mistura glicerina/água $80 \%$

\begin{tabular}{cccccc}
\hline & \multicolumn{4}{c}{ Experimentos } \\
\cline { 2 - 6 } T1 & 1 & 2 & 3 & 4 & 5 \\
nyyyyy T2 & $351,40 \pm 0,03$ & $302,39 \pm 0,04$ & $303,56 \pm 0,02$ & $303,29 \pm 0,04$ & $301,08 \pm 0,05$ \\
T3 & $360,23 \pm 0,15$ & $360,11 \pm 0,13$ & $353,97 \pm 0,05$ & $349,79 \pm 0,14$ & $342,08 \pm 0,11$ \\
T5 & $368,88 \pm 0,06$ & $368,42 \pm 0,12$ & $360,60 \pm 0,12$ & $358,16 \pm 0,07$ & $352,37 \pm 0,09$ \\
T6 & $371,12 \pm 0,13$ & $372,19 \pm 0,10$ & $364,54 \pm 0,06$ & $361,09 \pm 0,07$ & $355,11 \pm 0,12$ \\
T7 & $360,03 \pm 0,11$ & $362,62 \pm 0,08$ & $357,89 \pm 0,06$ & $355,73 \pm 0,08$ & $350,34 \pm 0,09$ \\
Tsp & $353,25 \pm 0,05$ & $359,25 \pm 0,04$ & $356,05 \pm 0,03$ & $355,85 \pm 0,04$ & $350,85 \pm 0,03$ \\
T9 & $298,49 \pm 0,10$ & $314,84 \pm 0,08$ & $330,62 \pm 0,06$ & $333,83 \pm 0,12$ & $329,77 \pm 0,11$ \\
T10 & $290,26 \pm 0,04$ & $310,16 \pm 0,04$ & $322,14 \pm 0,03$ & $330,18 \pm 0,11$ & $329,14 \pm 0,08$ \\
T11 & $285,02 \pm 0,17$ & $293,06 \pm 0,17$ & $297,25 \pm 0,20$ & $301,69 \pm 0,03$ & $304,77 \pm 0,14$ \\
T12 & $284,76 \pm 0,19$ & $287,78 \pm 0,29$ & $289,78 \pm 0,14$ & $293,83 \pm 0,36$ & $298,55 \pm 0,25$ \\
\cline { 2 - 6 } & & & & & \\
T1 & $299,56 \pm 0,02$ & $298,36 \pm 0,04$ & $298,56 \pm 0,05$ & $299,28 \pm 0,04$ & $301,10 \pm 0,02$ \\
T2 & $339,73 \pm 0,14$ & $327,71 \pm 0,09$ & $322,97 \pm 0,14$ & $325,99 \pm 0,11$ & $326,39 \pm 0,12$ \\
T3 & $349,09 \pm 0,17$ & $351,44 \pm 0,12$ & $345,74 \pm 0,15$ & $344,97 \pm 0,05$ & $341,47 \pm 0,08$ \\
T5 & $354,56 \pm 0,11$ & $357,81 \pm 0,10$ & $347,05 \pm 0,11$ & $347,73 \pm 0,10$ & $342,11 \pm 0,12$ \\
T6 & $356,05 \pm 0,06$ & $362,16 \pm 0,07$ & $351,98 \pm 0,11$ & $352,09 \pm 0,05$ & $346,60 \pm 0,10$ \\
T7 & $348,66 \pm 0,07$ & $353,13 \pm 0,06$ & $346,25 \pm 0,11$ & $347,63 \pm 0,05$ & $343,90 \pm 0,08$ \\
Tsp & $343,05 \pm 0,03$ & $349,75 \pm 0,04$ & $343,75 \pm 0,04$ & $346,15 \pm 0,05$ & $342,95 \pm 0,05$ \\
T9 & $295,45 \pm 0,08$ & $304,75 \pm 0,08$ & $313,37 \pm 0,11$ & $327,59 \pm 0,09$ & $326,36 \pm 0,12$ \\
T10 & $289,34 \pm 0,03$ & $308,30 \pm 0,09$ & $320,42 \pm 0,09$ & $325,13 \pm 0,08$ & $325,89 \pm 0,08$ \\
T11 & $284,68 \pm 0,03$ & $292,94 \pm 0,17$ & $296,26 \pm 0,08$ & $299,81 \pm 0,13$ & $301,86 \pm 0,23$ \\
T12 & $284,63 \pm 0,06$ & $287,82 \pm 0,18$ & $289,59 \pm 0,08$ & $292,31 \pm 0,20$ & $296,50 \pm 0,06$ \\
\hline & & & & & \\
\hline
\end{tabular}


Tabela 6.14 - Valores das temperaturas experimentais para a solução de CMC 1\%

\begin{tabular}{crrrrc}
\hline & \multicolumn{5}{c}{ Experimentos } \\
\cline { 2 - 6 } T1 & $291,15 \pm 0,05$ & $290,45 \pm 0,03$ & $290,35 \pm 0,05$ & $293,55 \pm 0,03$ & $293,95 \pm 0,04$ \\
T2 & $350,05 \pm 0,09$ & $343,95 \pm 0,11$ & $337,85 \pm 0,10$ & $333,85 \pm 0,12$ & $331,75 \pm 0,10$ \\
T3 & $356,45 \pm 0,07$ & $355,05 \pm 0,12$ & $351,75 \pm 0,12$ & $347,35 \pm 0,12$ & $346,25 \pm 0,09$ \\
T5 & $362,35 \pm 0,07$ & $358,25 \pm 0,08$ & $348,05 \pm 0,08$ & $339,55 \pm 0,09$ & $333,55 \pm 0,07$ \\
T6 & $363,25 \pm 0,10$ & $363,75 \pm 0,11$ & $357,95 \pm 0,05$ & $353,15 \pm 0,05$ & $348,15 \pm 0,12$ \\
T7 & $355,95 \pm 0,10$ & $357,55 \pm 0,05$ & $352,95 \pm 0,05$ & $347,05 \pm 0,06$ & $344,45 \pm 0,10$ \\
Tsp & $350,45 \pm 0,04$ & $352,45 \pm 0,03$ & $348,55 \pm 0,04$ & $342,85 \pm 0,04$ & $341,15 \pm 0,03$ \\
T9 & $294,25 \pm 0,10$ & $306,05 \pm 0,07$ & $314,55 \pm 0,11$ & $318,35 \pm 0,10$ & $313,95 \pm 0,06$ \\
T10 & $285,65 \pm 0,04$ & $299,15 \pm 0,04$ & $303,45 \pm 0,08$ & $311,85 \pm 0,07$ & $316,25 \pm 0,12$ \\
T11 & $282,65 \pm 0,07$ & $287,25 \pm 0,21$ & $289,85 \pm 0,19$ & $291,35 \pm 0,17$ & $304,15 \pm 0,07$ \\
T12 & $283,35 \pm 0,31$ & $284,95 \pm 0,17$ & $287,15 \pm 0,11$ & $290,95 \pm 0,11$ & $292,15 \pm 0,25$ \\
& & & 8 & & \\
T1 & $294,25 \pm 0,03$ & $294,75 \pm 0,04$ & $294,65 \pm 0,04$ & $294,75 \pm 0,03$ & $294,85 \pm 0,04$ \\
T2 & $355,15 \pm 0,12$ & $346,35 \pm 0,10$ & $342,75 \pm 0,11$ & $339,25 \pm 0,14$ & $334,85 \pm 0,14$ \\
T3 & $360,65 \pm 0,08$ & $357,35 \pm 0,13$ & $355,55 \pm 0,06$ & $354,45 \pm 0,10$ & $352,05 \pm 0,09$ \\
T5 & $368,65 \pm 0,09$ & $359,95 \pm 0,09$ & $353,75 \pm 0,11$ & $344,85 \pm 0,08$ & $337,95 \pm 0,07$ \\
T6 & $368,75 \pm 0,12$ & $364,15 \pm 0,10$ & $363,85 \pm 0,12$ & $358,25 \pm 0,12$ & $351,85 \pm 0,09$ \\
T7 & $361,40 \pm 0,09$ & $359,95 \pm 0,11$ & $357,05 \pm 0,08$ & $353,45 \pm 0,08$ & $349,85 \pm 0,06$ \\
Tsp & $354,65 \pm 0,03$ & $354,90 \pm 0,03$ & $352,05 \pm 0,05$ & $349,65 \pm 0,04$ & $347,15 \pm 0,04$ \\
T9 & $296,65 \pm 0,11$ & $308,25 \pm 0,10$ & $321,25 \pm 0,08$ & $321,55 \pm 0,12$ & $315,05 \pm 0,11$ \\
T10 & $285,85 \pm 0,11$ & $299,35 \pm 0,04$ & $308,05 \pm 0,12$ & $316,25 \pm 0,06$ & $319,25 \pm 0,05$ \\
T11 & $282,35 \pm 0,15$ & $286,85 \pm 0,12$ & $295,65 \pm 0,10$ & $301,15 \pm 0,05$ & $306,35 \pm 0,23$ \\
T12 & $283,35 \pm 0,14$ & $285,05 \pm 0,15$ & $287,65 \pm 0,12$ & $291,45 \pm 0,33$ & $293,55 \pm 0,22$ \\
\hline
\end{tabular}

\subsubsection{Ajuste do parâmetro do modelo térmico}

Com objetivo de validar as respostas do modelo proposto, realizaram-se simulações para o modelo térmico do processamento térmico contínuo, ajustando a condutividade térmica efetiva na direção radial. Compararam-se os resultados simulados com dados experimentais obtidos com a mistura glicerina/água $80 \%$ e solução de CMC $1 \%$.

A Tabela 6.15 mostra os valores dos parâmetros que foram considerados na validação do modelo térmico. Os parâmetros que possuem a descrição "Exp." São parâmetros que variaram para cada experimento. 
Tabela 6.15 - Parâmetros do pasteurizador e de suas seções

\begin{tabular}{|c|c|c|c|c|c|c|}
\hline & \multirow[b]{2}{*}{ Símbolo } & \multirow[b]{2}{*}{ Unidade } & \multicolumn{3}{|c|}{ PASTEURIZADOR } \\
\hline & & & & Aquec. & Reten. & Resfr. \\
\hline \multirow{8}{*}{ 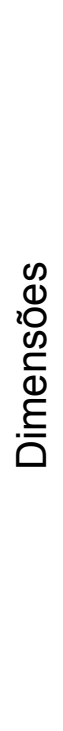 } & Número de módulos & $n$ & adm & 4 & 1 & 4 \\
\hline & $\begin{array}{l}\text { Comprimento efetivo do } \\
\text { módulo }\end{array}$ & $L$ & $\mathrm{~m}$ & 1,675 & 5 & 1,675 \\
\hline & $\begin{array}{l}\text { Comprimento total } \\
\text { efetivo da seção }\end{array}$ & & $\mathrm{m}$ & 6,70 & 5 & 6,70 \\
\hline & $\begin{array}{l}\text { Raio interno do tubo } \\
\text { interno }\end{array}$ & $R_{t i}$ & $\mathrm{~m}$ & $2,25 \times 10^{-3}$ & $2,25 \times 10^{-3}$ & $2,25 \times 10^{-3}$ \\
\hline & $\begin{array}{l}\text { Espessura do tubo } \\
\text { interno }\end{array}$ & $e_{t i}$ & $\mathrm{~m}$ & $1,5 \times 10^{-3}$ & $1,5 \times 10^{-3}$ & $1,5 \times 10^{-3}$ \\
\hline & $\begin{array}{c}\text { Raio interno do tubo } \\
\text { externo }\end{array}$ & $R_{t e}$ & $\mathrm{~m}$ & $1,27 \times 10^{-2}$ & & $1,27 \times 10^{-2}$ \\
\hline & $\begin{array}{l}\text { Espessura do tubo } \\
\text { externo }\end{array}$ & $e_{t e}$ & $\mathrm{~m}$ & $2,20 \times 10^{-3}$ & & $2,20 \times 10^{-3}$ \\
\hline & $\begin{array}{l}\text { Espessura do } \\
\text { isolamento }\end{array}$ & $e_{i s o}$ & $\mathrm{~m}$ & & $9,00 \times 10^{-3}$ & \\
\hline \multirow{8}{*}{ 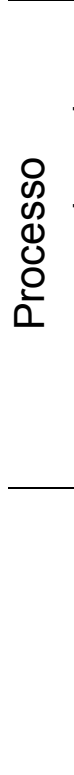 } & Temperatura ambiente & $T_{a m b}$ & $\mathrm{~K}\left({ }^{\circ} \mathrm{C}\right)$ & $\begin{array}{l}299,1 \\
(25,9)\end{array}$ & $\begin{array}{l}299,1 \\
(25,9)\end{array}$ & $\begin{array}{l}299,1 \\
(25,9)\end{array}$ \\
\hline & $\begin{array}{l}\text { Temperatura de entrada } \\
\text { do produto alimentício }\end{array}$ & $T_{1 \text { in }}$ & $\mathrm{K}\left({ }^{\circ} \mathrm{C}\right)$ & Exp. & & \\
\hline & $\begin{array}{l}\text { Temperatura de entrada } \\
\text { do fluido utilidade }\end{array}$ & $T_{2 i n}$ & $\mathrm{~K}\left({ }^{\circ} \mathrm{C}\right)$ & Exp. & & Exp. \\
\hline & $\begin{array}{l}\text { Vazão volumétrica do } \\
\text { produto alimentício }\end{array}$ & $q_{1}$ & $\begin{array}{l}\mathrm{m}^{3} \cdot \mathrm{s}^{-1} \\
(\mathrm{~L} / \mathrm{h})\end{array}$ & Exp. & Exp. & Exp. \\
\hline & $\begin{array}{c}\text { Vazão volumétrica do } \\
\text { fluido utilidade }\end{array}$ & $q_{2}$ & $\begin{array}{l}\mathrm{m}^{3} \cdot \mathrm{s}^{-1} \\
(\mathrm{~L} / \mathrm{h})\end{array}$ & $\begin{array}{c}4,17 \times 10^{-4} \\
(1500)\end{array}$ & & $\begin{array}{c}2,22 \times 10^{-4} \\
(1500)\end{array}$ \\
\hline & $\begin{array}{c}\text { Condutividade térmica } \\
\text { do tubo }\end{array}$ & $k_{t i}$ & $\mathrm{~W} \cdot \mathrm{m}^{-1} \cdot \mathrm{K}^{-1}$ & 14,9 & 14,9 & 14,9 \\
\hline & $\begin{array}{c}\text { Condutividade térmica } \\
\text { do isolamento }\end{array}$ & $k_{\text {iso }}$ & $\mathrm{W} \cdot \mathrm{m}^{-1} \cdot \mathrm{K}^{-1}$ & & 0,039 & \\
\hline & $\begin{array}{c}\text { Coeficiente convectivo } \\
\text { do ar ambiente }\end{array}$ & $h_{e f}$ & $\mathrm{~W} \cdot \mathrm{m}^{-2} \cdot \mathrm{K}^{-1}$ & 17,79 & 17,79 & 28,47 \\
\hline
\end{tabular}

As propriedades termofísicas e reológicas foram calculadas através da temperatura média de cada módulo.

Para a mistura glicerina/água $80 \%$, têm-se as seguintes relações:

- Massa específica:

$$
\begin{gathered}
\rho_{1}{ }^{(k)}=\rho_{\text {glic }}{ }^{(k)} \cdot \% m_{\text {glic }}+\rho_{W}{ }^{(k)} \cdot\left(1-\% m_{\text {glic }}\right) \\
\rho_{W}{ }^{(k)}=1000 \cdot\left(1-\left(\frac{\left(\overline{T_{1}^{(k)}}-273,15\right)-4}{622}\right)^{1,7}\right) \\
\rho_{\text {glic }}{ }^{(k)}=1277-0,654 \cdot\left(\overline{T_{1}^{(k)}}{ }_{m}-273,15\right)
\end{gathered}
$$


em que $\rho_{\text {glic }}$ é a massa específica da glicerina pura $\left(\mathrm{kg}^{-3} \mathrm{~m}^{-3}\right)$, $\rho_{\text {água }}$ é a massa específica da água pura $\left(\mathrm{kg} \cdot \mathrm{m}^{-3}\right)$ e $\% m_{\text {glic }}$ é a fração mássica de glicerina pura e seu valor é igual a 0,80 . As relações foram obtidas por Cheng (2008) e a faixa de temperatura aplicável está entre 273,15 e 373,15 K.

- Calor específico:

$$
\begin{gathered}
C_{p 1}{ }^{(k)}=C_{\text {pglic }}{ }^{(k)} \cdot \% m_{\text {glic }}+C_{p W}{ }^{(k)} \cdot\left(1-\% m_{\text {glic }}\right) \\
C_{p g l i c}{ }^{(k)}=\left(132,145+0,86007 \cdot\left(\overline{T_{1}{ }^{(k)}}{ }_{m}\right)-0,0019745 \cdot\left(\overline{T_{1}{ }^{(k)}}\right)_{m}^{2}+1,807\right. \\
\left.\cdot 10^{-6} \cdot\left(\overline{T_{1}^{(k)}}{ }_{m}\right)^{3}\right) \cdot \frac{1000}{92,09} \\
C_{p W}{ }^{(k)}=4227,1-2,6171 \cdot\left(\overline{T_{1}{ }^{(k)}}{ }_{m}-273,15\right) \\
+\left(4,1758 \cdot 10^{-2} \cdot\left(\overline{T_{1}{ }^{(k)}}{ }_{m}-273,15\right)^{2}\right) \\
-\left(2,1528 \cdot 10^{-4} \cdot\left({\overline{T_{1}{ }^{(k)}}}_{m}-273,15\right)^{3}\right) \\
+\left(5,2013 \cdot 10^{-7} \cdot\left({\overline{T_{1}{ }^{(k)}}}_{m}-273,15\right)^{4}\right)
\end{gathered}
$$

em que $C_{p g l i c}$ é o calor específico da glicerina pura $\left(\mathrm{J} . \mathrm{kg}^{-1} \cdot \mathrm{K}^{-1}\right), C_{p W}$ é o calor específico da água pura $\left(\mathrm{J}_{\mathrm{kg}} \mathrm{kg}^{-1} \cdot \mathrm{K}^{-1}\right)$. As relações (6.15), (6.16) e (6.17) foram obtidas, respectivamente, por Lemauguer e Jelen (1986), Yaws (1999) e Gut e Pinto (2003), sendo esta última com faixa de temperatura aplicável entre 273,15 e 533,15 K.

- Condutividade térmica:

$$
\begin{array}{r}
k_{1}{ }^{(k)}=\left(k_{\text {glic }}{ }^{(k)} \cdot \frac{\% m_{\text {glic }} / \rho_{\text {glic }}{ }^{(k)}}{\% m_{\text {glic }} / \rho_{\text {glic }}{ }^{(k)}+\% m_{W} / \rho_{W}{ }^{(k)}}\right) \\
+\left(k_{W}{ }^{(k)} \cdot \frac{\% m_{W} / \rho_{W}{ }^{(k)}}{\% m_{\text {glic }} / \rho_{\text {glic }}{ }^{(k)}+\% m_{W} / \rho_{W}{ }^{(k)}}\right) \\
\log _{10} k_{\text {glic }}{ }^{(k)}=\left(-0,355-0,2097 \cdot\left(\frac{1-\overline{T_{1}{ }^{(k)}}}{723}\right)^{\frac{2}{7}}\right)^{23} \\
k_{W}{ }^{(k)}=0,570+1,80 \cdot 10^{-3} \cdot\left(\overline{T_{1}{ }^{(k)}}{ }_{m}\right)-6,88 \cdot 10^{-6} \cdot\left(\overline{T_{1}{ }^{(k)}}{ }_{m}\right)^{2}
\end{array}
$$

em que $k_{\text {glic }}$ é a condutividade térmica da glicerina pura $\left(W \cdot \mathrm{m}^{-1} \cdot \mathrm{K}^{-1}\right), k_{W}$ é a condutividade térmica da água pura $\left(W \cdot m^{-1} \cdot K^{-1}\right)$. As relações (6.18) e (6.19) foram 
obtidas de Yaws (1999), enquanto a equação (6.20) foi obtida a partir dos dados de Incropera et al. (2008).

- Condutividade térmica efetiva:

$$
k_{\text {ef } 1}{ }^{(k)}=F_{\text {incr } 1} \cdot k_{1}{ }^{(k)}
$$

- Viscosidade newtoniana:

$$
\begin{aligned}
& a^{(k)}=0,705-0,0017 \cdot \overline{T_{1}{ }^{(k)}} \\
& b^{(k)}=\left(4,9+0,36 \cdot \overline{T_{1}{ }^{(k)}}\right) \cdot a^{(k)^{2,5}} \\
& \alpha^{(k)}=\left(1-\% m_{\text {glic }}\right)+\frac{a^{(k)} \cdot b^{(k)} \cdot \% m_{\text {glic }} \cdot\left(1-\% m_{\text {glic }}\right)}{a^{(k) \cdot \% m_{\text {glic }}+b^{(k)} \cdot\left(1-\% m_{\text {glic }}\right)}}
\end{aligned}
$$

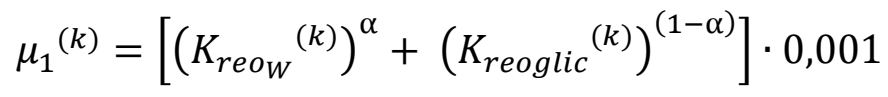

$$
\begin{aligned}
& \mu_{\text {glic }}{ }^{(k)}=12100 \cdot \exp \left(\frac{-\left(1233-\overline{T_{1}{ }^{(k)}}{ }_{m}\right) \cdot \overline{T_{1}{ }^{(k)}}{ }_{m}}{9900+70 \cdot \overline{T_{1}{ }^{(k)}}{ }_{m}}\right) \\
& \mu_{W}{ }^{(k)}=1,79 \cdot \exp \left(\frac{-\left(1230-\overline{T_{1}{ }^{(k)}}{ }_{m}\right) \cdot \overline{T_{1}{ }^{(k)}}{ }_{m}}{36100+360 \cdot \overline{T_{1}{ }^{(k)}}{ }_{m}}\right)
\end{aligned}
$$

em que $\mu_{\text {glic }}$ é a viscosidade newtoniana da glicerina pura (cP), $\mu_{W}$ é a viscosidade newtoniana da água pura (cP). As relações (6.22) a (6.27) foram obtidas por Cheng (2008) e sua aplicação está na faixa de temperatura de 273,15 a 373,15 K.

- Índice de comportamento:

$$
n_{\text {reo }}{ }^{(k)}=1
$$

Para a solução de CMC 1\%, têm-se as seguintes relações:

- Massa específica:

$$
\rho_{1}{ }^{(k)}=\rho_{W}{ }^{(k)}=1000 \cdot\left(1-\left(\frac{\left(\overline{T_{1}^{(k)}}-273,15\right)-4}{622}\right)^{1,7}\right)
$$

Como a quantidade de CMC é muito pequena, considerou-se a massa específica da solução de CMC $1 \%$ igual à massa específica da água (equação (6.13)).

- Calor específico:

$$
C_{p 1}{ }^{(k)}=4173 \mathrm{~J} \cdot \mathrm{kg}^{-1} \cdot \mathrm{K}^{-1}
$$


O calor específico para o a solução de CMC $1 \%$ é considerado constante, pois em seu trabalho Carezzato et al. (2007) estudaram a influência da temperatura na determinação de parâmetros reológicos em soluções de CMC nas concentrações de 0,$5 ; 1,0$ e $1,5 \%$ e o mesmo concluiu que para estas concentrações o calor específico não sofria variação significativa.

- Condutividade térmica:

$$
\begin{aligned}
k_{1}{ }^{(k)}=0,579 & +2,04 \cdot 10^{-3} \cdot\left(\overline{T_{1}^{(k)}}{ }_{m}-273,15\right) \\
& -\left[1,09 \cdot 10^{-5} \cdot\left(\overline{T_{1}^{(k)}}{ }_{m}-273,15\right)^{2}\right]
\end{aligned}
$$

- Condutividade térmica efetiva:

$$
k_{\text {ef } 1}{ }^{(k)}=F_{\text {incr } 1} \cdot k_{1}{ }^{(k)}
$$

- Índice de consistência:

$$
K_{\text {reo }}{ }^{(k)}=2,259 \cdot 10^{-4} \exp \left(\frac{-2,298 \cdot 10^{4}}{8,314 \cdot \overline{T_{1}{ }^{(k)}}}\right)
$$

- Índice de comportamento:

$$
n_{\text {reo }}{ }^{(k)}=7,078 \cdot 10^{-2} \exp \left(5,845 \cdot 10^{-3} \cdot \overline{T_{1}{ }^{(k)}}{ }_{m}\right)
$$

As relações (6.30), (6.32) e (6.33) foram obtidas de Carezzato et at. (2007).

Com os dados experimentais, utilizou-se o módulo de estimação de parâmetros do gPROMS (PSE), para encontrar um único valor para o fator de aumento da condutividade térmica efetiva na direção radial que melhor representasse os dados experimentais. Esse fator como definido nas equações (6.21) e (6.31) é um multiplicador da condutividade térmica do produto em cada módulo que compõe o pasteurizador. Quanto maior $F_{\text {incr } 1}$ maior é o incremento na troca térmica entre as camadas da direção radial.

A Figura 6.9, a Figura 6.10, a Figura 6.11, a Figura 6.12 e a Figura 6.13 mostram as temperaturas experimentais, assim como, as curvas obtidas pelas simulações a partir do ajuste da condutividade térmica efetiva na direção radial (linha preta) para a mistura glicerina/água $80 \%$, e da Figura 6.14 até a Figura 6.18 são mostradas as curvas para a solução de CMC $1 \%$. 

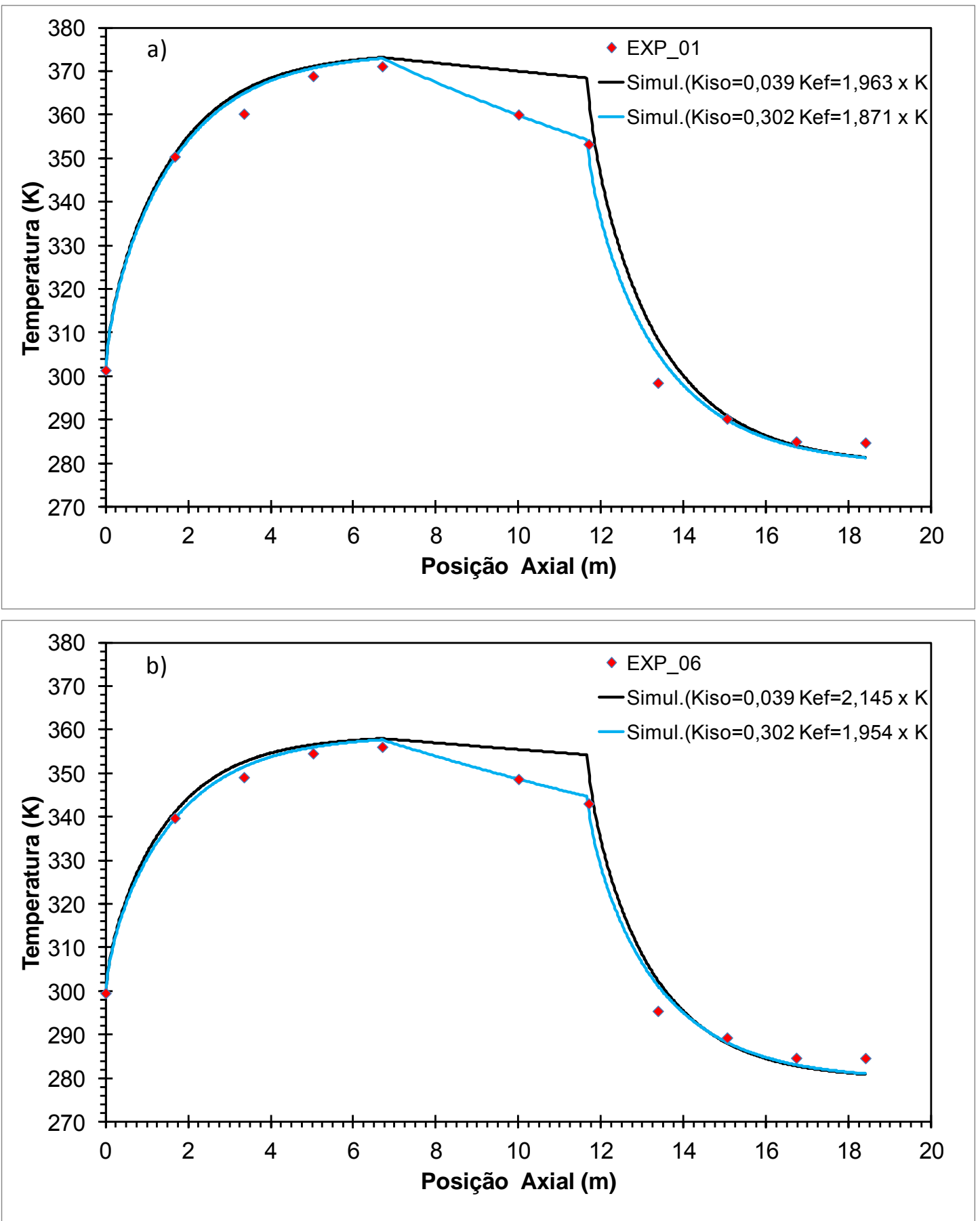

Figura 6.9 - Temperaturas experimentais e perfis de temperatura simulados para os dois ensaios com vazão de $10 \mathrm{~L} / \mathrm{h}$ para a mistura glicerina/água $80 \%$ : a) Experimento 1; b) Experimento 6 

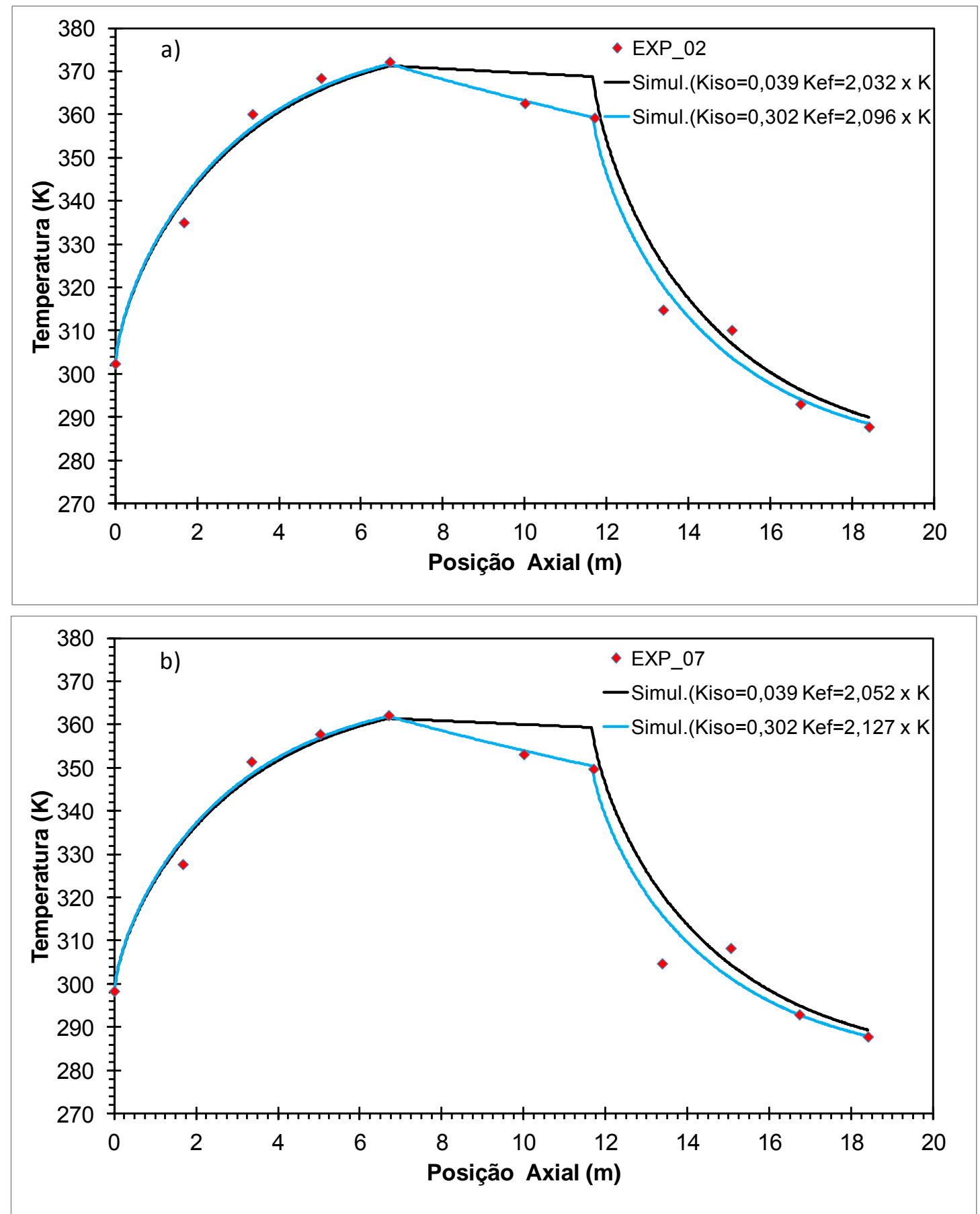

Figura 6.10 - Temperaturas experimentais e perfis de temperatura simulados para os dois ensaios com vazão de $20 \mathrm{~L} / \mathrm{h}$ para a mistura glicerina/água $80 \%$ : a) Experimento 2; b) Experimento 7 

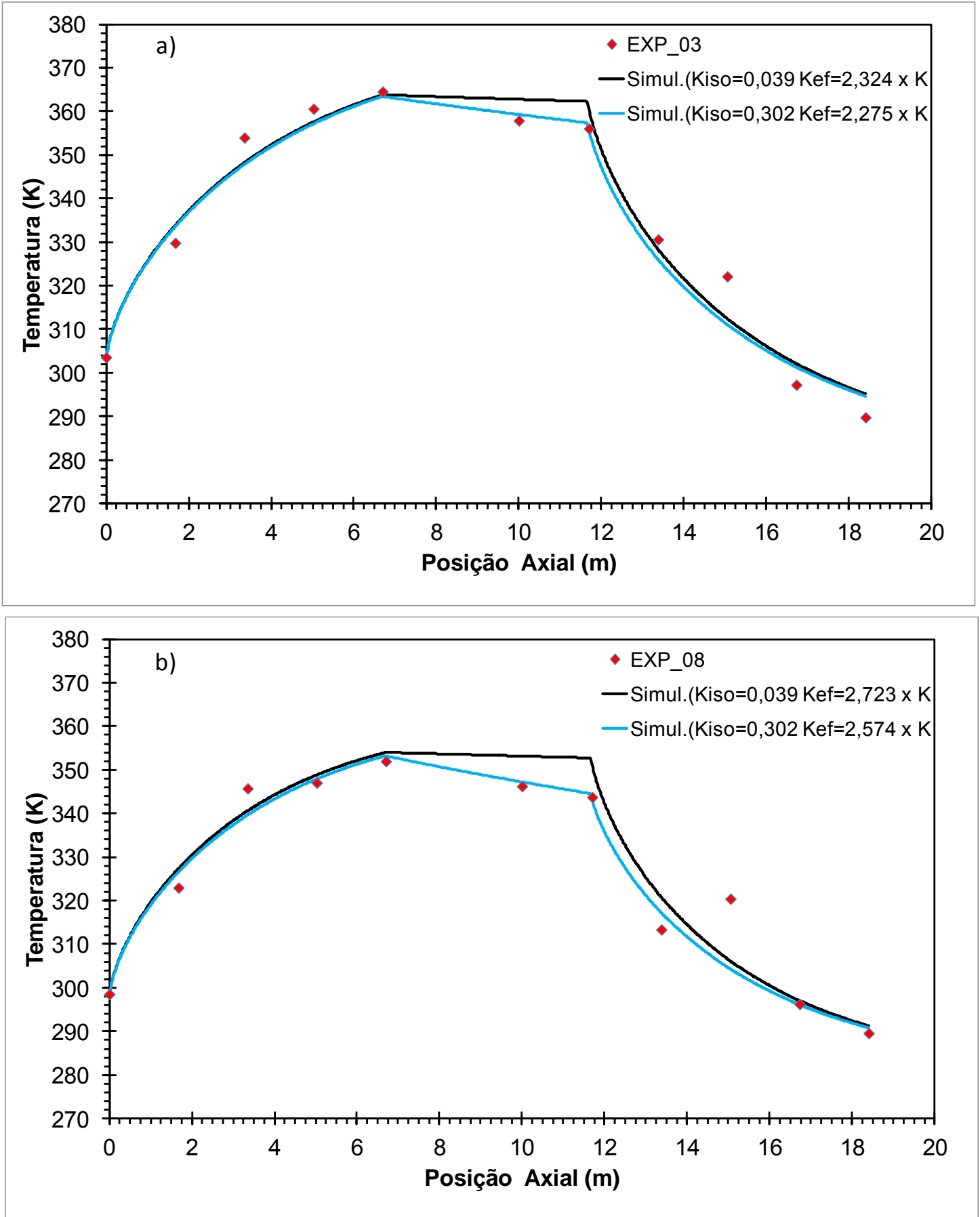

Figura 6.11 - Temperaturas experimentais e perfis de temperatura simulados para os dois ensaios com vazão de $30 \mathrm{~L} / \mathrm{h}$ para a mistura glicerina/água $80 \%$ : a) Experimento 3; b) Experimento 8 

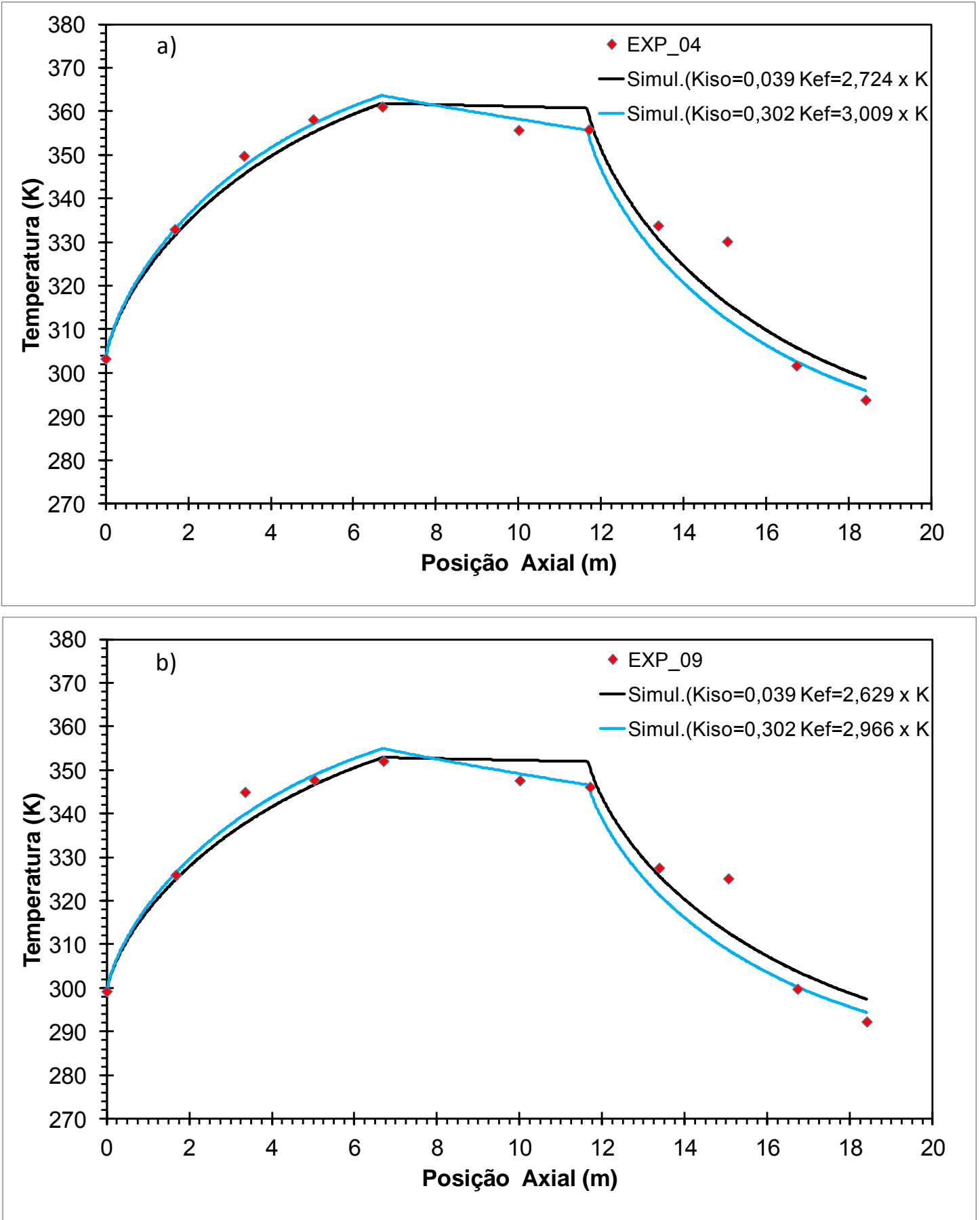

Figura 6.12 - Temperaturas experimentais e perfis de temperatura simulados para os dois ensaios com vazão de $40 \mathrm{~L} / \mathrm{h}$ para a mistura glicerina/água $80 \%$ : a) Experimento 4; b) Experimento 9 

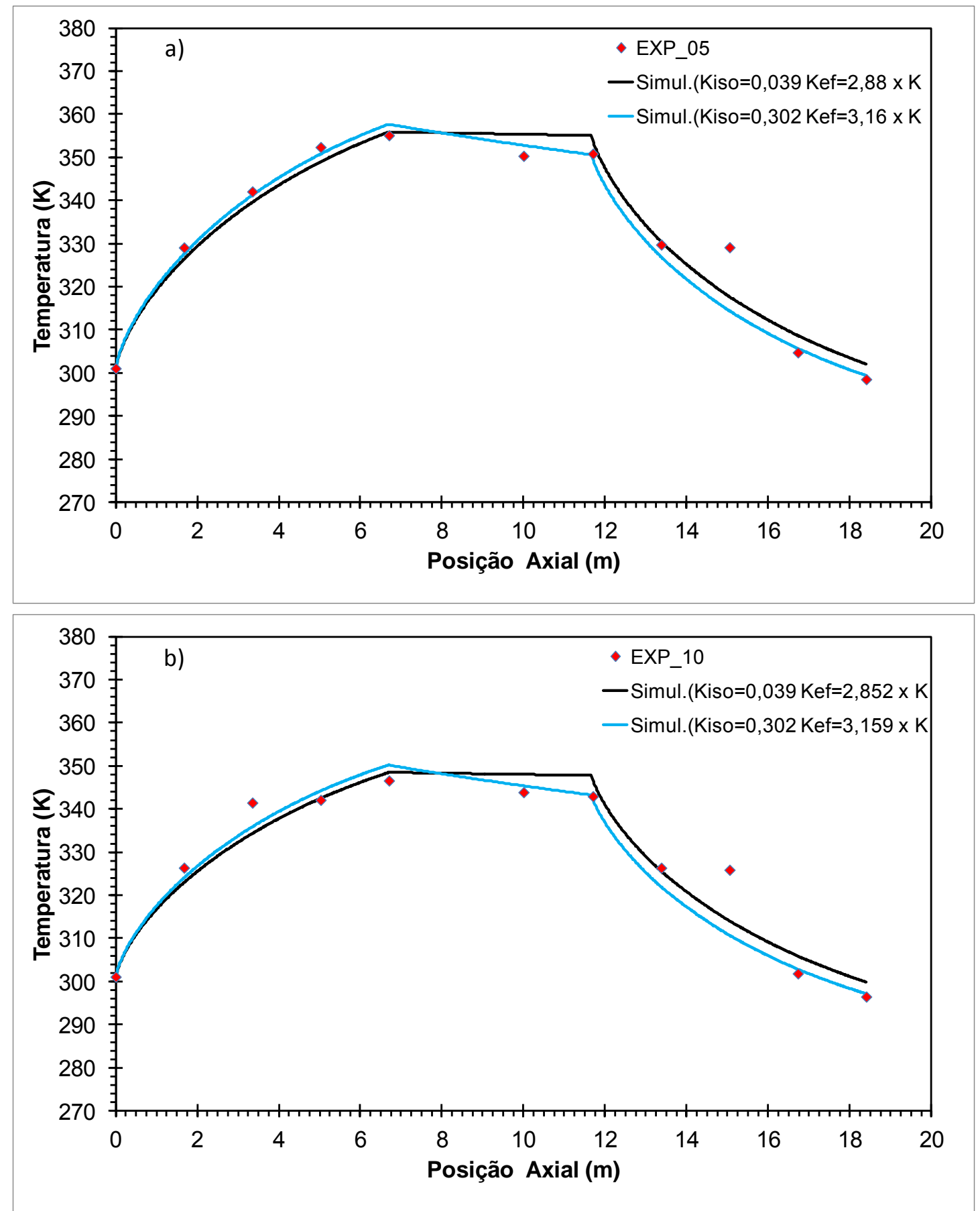

Figura 6.13 - Temperaturas experimentais e perfis de temperatura simulados para os dois ensaios com vazão de $50 \mathrm{~L} / \mathrm{h}$ para a mistura glicerina/água $80 \%$ : a) Experimento 5; b) Experimento 10 

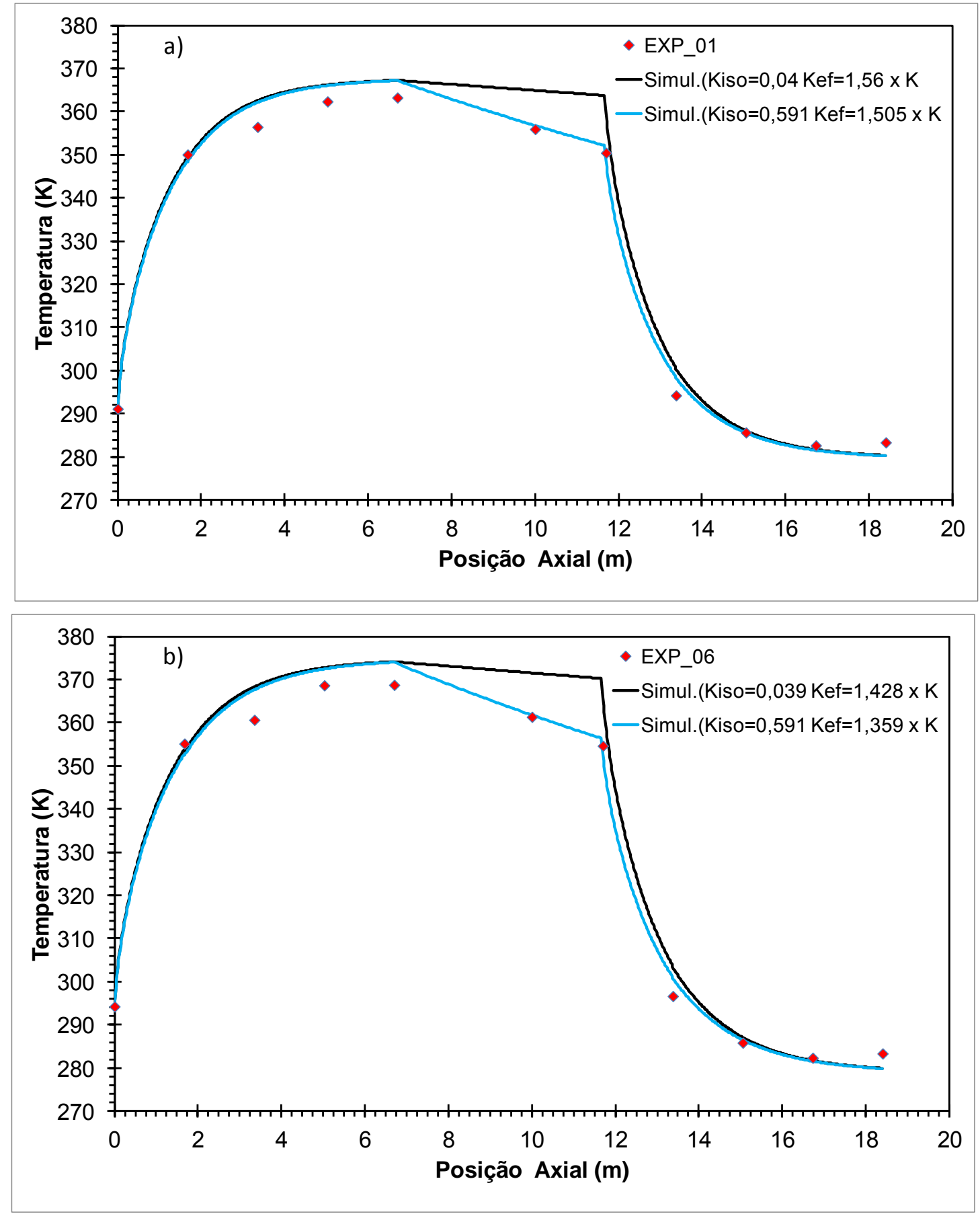

Figura 6.14 - Temperaturas experimentais e perfis de temperatura simulados para os dois ensaios com vazão de $10 \mathrm{~L} / \mathrm{h}$ para a solução de CMC 1\%: a) Experimento 1; b) Experimento 6 

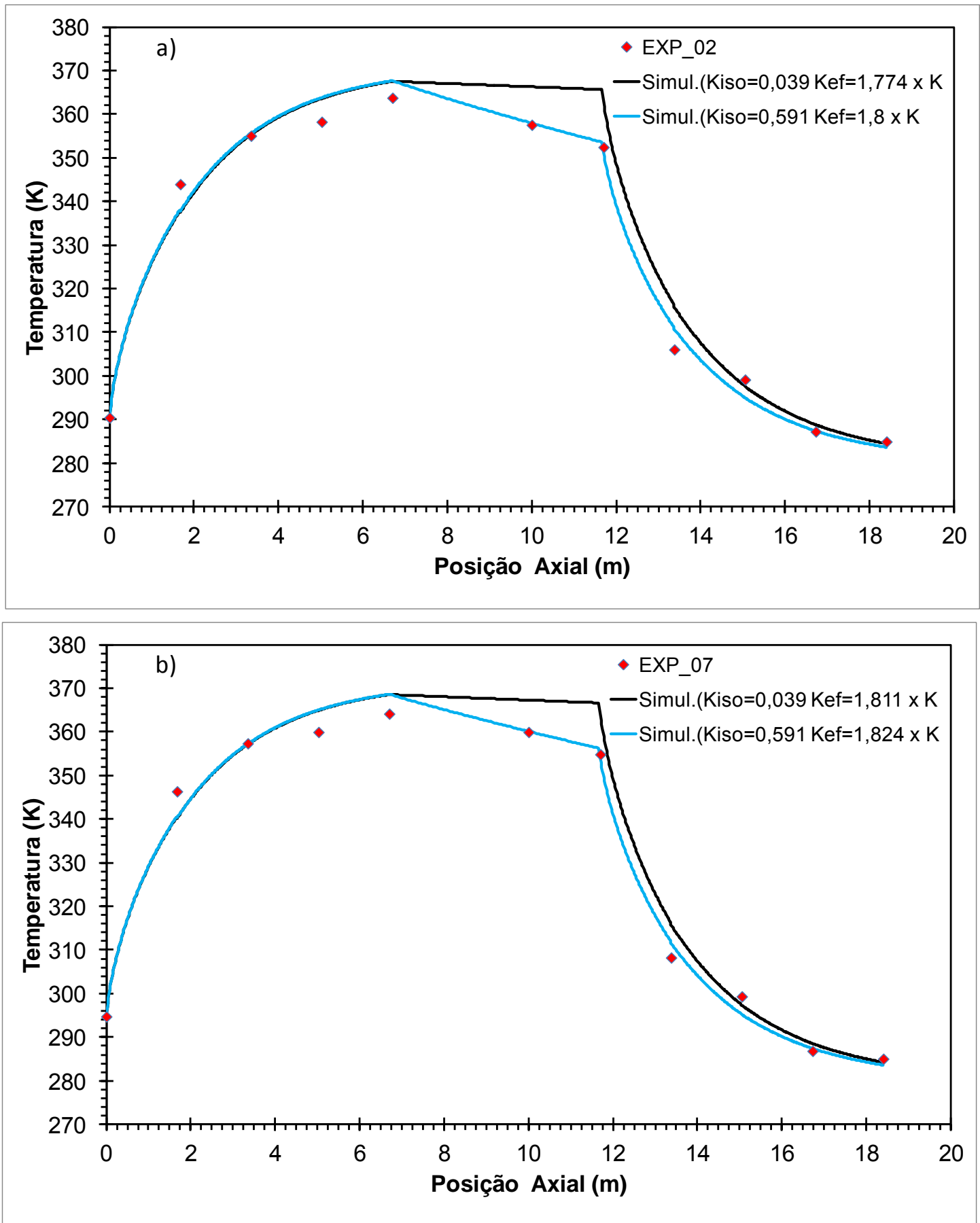

Figura 6.15 - Temperaturas experimentais e perfis de temperatura simulados para os dois ensaios com vazão de $20 \mathrm{~L} / \mathrm{h}$ para a solução de CMC 1\%: a) Experimento 2; b) Experimento 7 

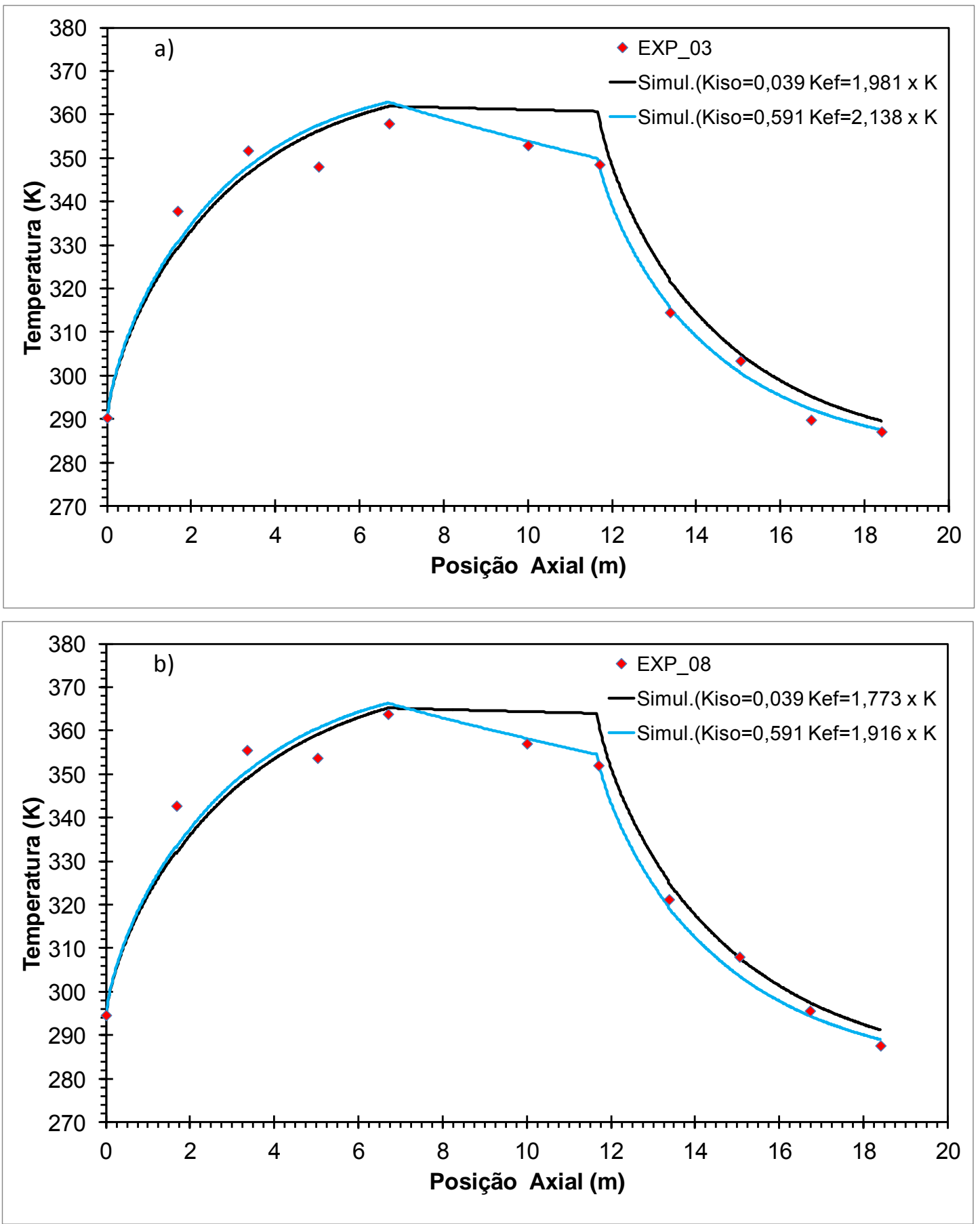

Figura 6.16 - Temperaturas experimentais e perfis de temperatura simulados para os dois ensaios com vazão de $30 \mathrm{~L} / \mathrm{h}$ para a solução de CMC 1\%: a) Experimento 3; b) Experimento 8 

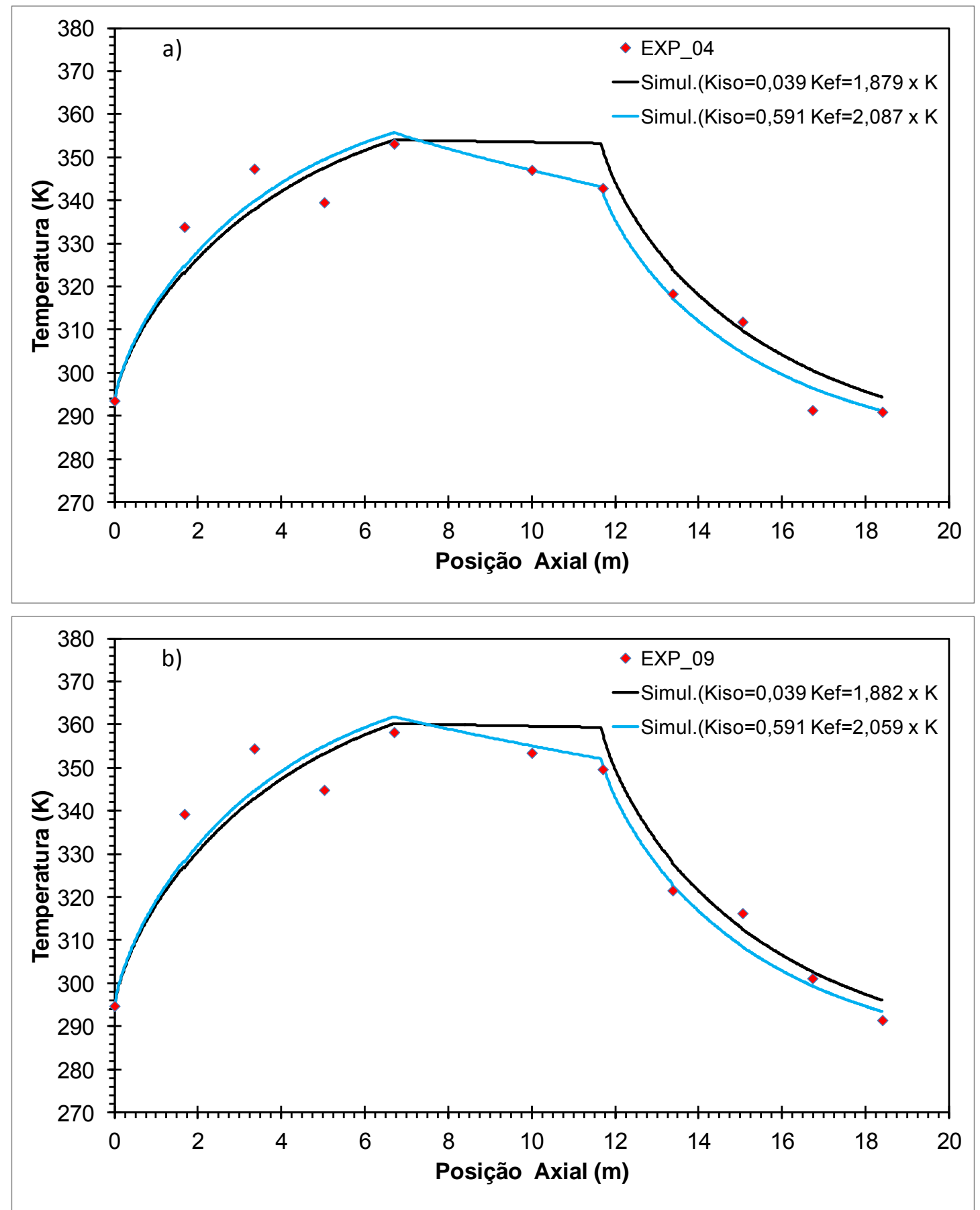

Figura 6.17 - Temperaturas experimentais e perfis de temperatura simulados para os dois ensaios com vazão de $40 \mathrm{~L} / \mathrm{h}$ para a solução de CMC $1 \%$ : a) Experimento 4; b) Experimento 9 

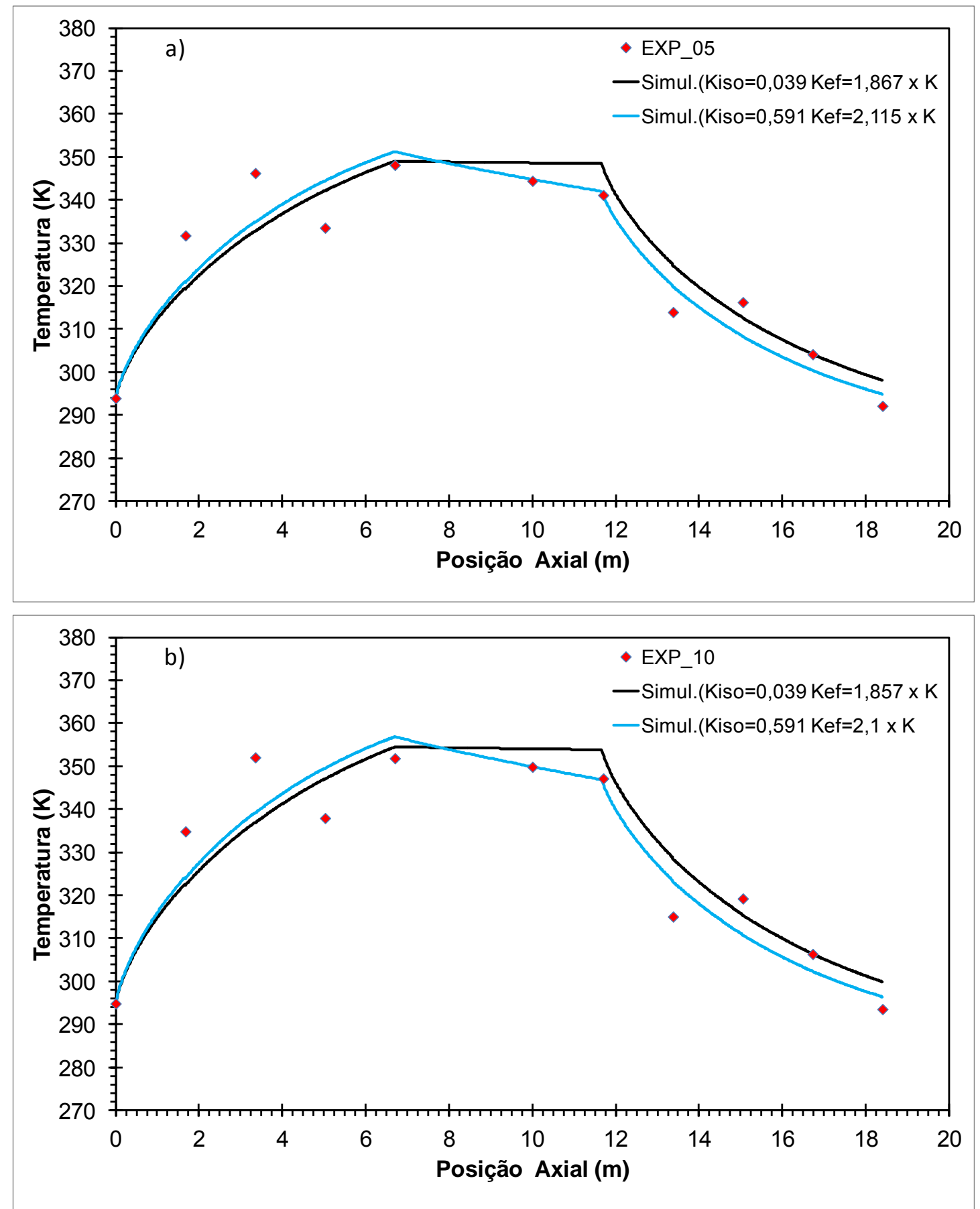

Figura 6.18 - Temperaturas experimentais e perfis de temperatura simulados para os dois ensaios com vazão de $50 \mathrm{~L} / \mathrm{h}$ para a solução de CMC $1 \%$ : a) Experimento 5; b) Experimento 10

Analisando inicialmente as figuras 6.9 à 6.18 , as temperaturas experimentais apresentam variações inesperadas de temperatura ao longo do processo térmico. Isso pode ser explicado pelo pequeno diâmetro da tubulação e, consequentemente, a pequena quantidade de fluido escoando o que pode influenciar nos valores medidos pelos termopares. Além disto, tem-se que os termopares possuem suportes 
metálicos que conduzem calor e podem interferir na leitura da temperatura real (efeito aleta).

$\mathrm{Na}$ seção de aquecimento a temperatura sobe gradativamente, no entanto, percebe-se que no início da seção a temperatura sobe mais rapidamente que nas demais seções. Nota-se também, que no tubo de retenção, existe uma perda de calor significativa especialmente para vazões mais baixas, na qual o tempo de residência no tubo é maior. Esse fato pode ser explicado, devido ao isolamento térmico não estar adequadamente aderido ao tubo de retenção, permitindo as perdas para o ambiente.

Para os perfis de temperaturas simulados, analisando primeiramente as curvas em preto, tem-se que as mesmas foram obtidas através do ajuste do fator de aumento da condutividade térmica do produto. No entanto, verifica-se nas figuras que a perda de energia no tubo de retenção é superior à esperada. Esta diferença pode estar associada a falhas no acabamento da camada de isolante ou à condução de calor através dos suportes metálicos do tubo. Devido a isto novas simulações foram realizadas corrigindo a condutividade térmica do isolamento térmico.

Para a correção da condutividade térmica do isolante térmico utilizou-se o coeficiente de troca térmica de perda $\left(U_{\text {perda }}\right)$ e o coeficiente convectivo efetivo do ar ambiente sobre o tubo externo $\left(h_{e f}\right)$ obtidos de Ferrão (2012).

O valor corrigido da condutividade térmica do isolante térmico para a mistura glicerina/água $80 \%$ e solução de CMC $1 \%$ são dados respectivamente pelas equações (6.34) e (6.35) (Unidades SI):

$$
\begin{gathered}
U_{\text {perda }}=h_{\text {ef }}+\frac{k_{\text {iso }}}{e_{\text {iso }}} \rightarrow 51,32=17,79+\frac{k_{\text {iso }}}{0,009} \rightarrow k_{\text {iso }}=0,302 \\
U_{\text {perda }}=h_{\text {ef }}+\frac{k_{\text {iso }}}{e_{\text {iso }}} \rightarrow 83,5=17,79+\frac{k_{\text {iso }}}{0,009} \rightarrow k_{\text {iso }}=0,591
\end{gathered}
$$

Com os valores das condutividades térmicas corrigidas para o isolante térmico, realizaram-se novas simulações, estimando o parâmetro de aumento da condutividade térmica efetiva do produto (curva azul).

Para as situações, de condutividade térmica do isolante, descritas acima, na Tabela 6.16 e na Tabela 6.17 são mostrados os valores da condutividade térmica e dos valores do fator de aumento da condutividade térmica efetiva na direção radial do fluido produto para a mistura glicerina/água $80 \%$. 
Tabela 6.16 - Condutividade térmica do isolante e fator de aumento da condutividade térmica efetiva radial do produto para os experimentos com a mistura glicerina/água $80 \%$

\begin{tabular}{ccccccc}
\hline & & & \multicolumn{2}{c}{ Curva em preto } & \multicolumn{2}{c}{ Curva em azul } \\
\cline { 4 - 7 } Exp. & $q_{1}(\mathrm{~L} / \mathrm{h})$ & $T_{2 \text { 2in_aque }}$ & $\begin{array}{c}k_{\text {iso }} \\
(\mathrm{K})\end{array}$ & $\begin{array}{c}\left.\mathrm{W}_{\text {. }}^{-1} \cdot \mathrm{K}^{-1}\right) \\
F_{\text {incr } 1}\end{array}$ & $\begin{array}{c}k_{\text {iso }} \\
\left(\mathrm{W} \cdot \mathrm{m}^{-1} \cdot \mathrm{K}^{-1}\right)\end{array}$ & $F_{\text {incr } 1}$ \\
\hline 1 & 10 & 374,3 & 0,039 & 1,963 & 0,302 & 1,871 \\
2 & 20 & 378,7 & 0,039 & 2,032 & 0,302 & 2,096 \\
3 & 30 & 375,6 & 0,039 & 2,324 & 0,302 & 2,275 \\
4 & 40 & 376,9 & 0,039 & 2,724 & 0,302 & 3,009 \\
5 & 50 & 374,9 & 0,039 & 2,880 & 0,302 & 3,160 \\
6 & 10 & 359,7 & 0,039 & 2,145 & 0,302 & 1,954 \\
7 & 20 & 368,2 & 0,039 & 2,052 & 0,302 & 2,127 \\
8 & 30 & 362,4 & 0,039 & 2,723 & 0,302 & 2,574 \\
9 & 40 & 367,6 & 0,039 & 2,629 & 0,302 & 2,966 \\
10 & 50 & 365,3 & 0,039 & 2,852 & 0,302 & 3,159 \\
\hline
\end{tabular}

Tabela 6.17 - Condutividade térmica do isolante e fator de aumento da condutividade térmica efetiva radial do produto para os experimentos com solução de CMC $1 \%$

\begin{tabular}{|c|c|c|c|c|c|c|}
\hline \multirow[b]{2}{*}{ Exp. } & \multirow[b]{2}{*}{$q_{1}(\mathrm{~L} / \mathrm{h})$} & \multirow[b]{2}{*}{$\begin{array}{c}T_{\text {2in_aque }} \\
\text { (K) }\end{array}$} & \multicolumn{2}{|c|}{ Curva em preto } & \multicolumn{2}{|c|}{ Curva em azul } \\
\hline & & & $\begin{array}{c}k_{i s o} \\
\left(\mathrm{~W} \cdot \mathrm{m}^{-1} \cdot \mathrm{K}^{-1}\right)\end{array}$ & $F_{\text {incr } 1}$ & $\begin{array}{c}k_{i s o} \\
\left(\mathrm{~W} \cdot \mathrm{m}^{-1} \cdot \mathrm{K}^{-1}\right)\end{array}$ & $F_{\text {incr } 1}$ \\
\hline 1 & 10 & 367,6 & 0,039 & 1,560 & 0,591 & 1,505 \\
\hline 2 & 20 & 370,8 & 0,039 & 1,774 & 0,591 & 1,800 \\
\hline 3 & 30 & 369,0 & 0,039 & 1,981 & 0,591 & 2,138 \\
\hline 4 & 40 & 366,4 & 0,039 & 1,879 & 0,591 & 2,087 \\
\hline 5 & 50 & 366,1 & 0,039 & 1,867 & 0,591 & 2,115 \\
\hline 6 & 10 & 374,7 & 0,039 & 1,428 & 0,591 & 1,359 \\
\hline 7 & 20 & 371,5 & 0,039 & 1,811 & 0,591 & 1,824 \\
\hline 8 & 30 & 373,9 & 0,039 & 1,773 & 0,591 & 1,916 \\
\hline 9 & 40 & 373,5 & 0,039 & 1,882 & 0,591 & 2,059 \\
\hline 10 & 50 & 373,0 & 0,039 & 1,857 & 0,591 & 2,100 \\
\hline
\end{tabular}

Nota-se pela tabela, que geralmente, com o aumento da vazão e/ou da temperatura aumenta-se o valor do fator de aumento.

Comparando-se os $F_{\text {incr } 1}$ da mistura glicerina/água $80 \%$ e da solução de CMC $1 \%$, observa-se que os fatores deste são menores. Isto se deve ao fato da solução de CMC $1 \%$ ter um grau de mistura menor, que por sua vez, está associado ao regime laminar.

Os valores das Funções Objetivo (erro quadrático) obtidas para os perfis de temperaturas simulados a partir das simulações para o ajuste do parâmetro térmico são mostradas na Tabela 6.18. 
Tabela 6.18 - Valores das Funções Objetivo para os perfis de temperaturas simulados obtidos através do ajuste do fator de aumento da condutividade térmica da mistura glicerina/água $80 \%$ e solução de CMC $1 \%$

\begin{tabular}{|c|c|c|c|c|}
\hline \multirow[b]{2}{*}{ Exp. } & \multicolumn{2}{|c|}{ Mistura Glicerina $80 \%$} & \multicolumn{2}{|c|}{ Solução CMC 1\% } \\
\hline & $\begin{array}{c}k_{\text {iso }}\left(\mathrm{W} \cdot \mathrm{m}^{-1} \cdot \mathrm{K}^{-1}\right)= \\
0,039\end{array}$ & $\begin{array}{c}k_{\text {iso }}\left(\mathrm{W} \cdot \mathrm{m}^{-1} \cdot \mathrm{K}^{-1}\right)= \\
0,302\end{array}$ & $\begin{array}{c}k_{\text {iso }}\left(\mathrm{W} \cdot \mathrm{m}^{-1} \cdot \mathrm{K}^{-1}\right)= \\
0,039\end{array}$ & $\begin{array}{c}k_{\text {iso }}\left(\mathrm{W} \cdot \mathrm{m}^{-1} \cdot \mathrm{K}^{-1}\right)= \\
0,591\end{array}$ \\
\hline 1 & 35,40 & 27,16 & 33,52 & 27,52 \\
\hline 2 & 33,49 & 28,93 & 35,33 & 28,97 \\
\hline 3 & 32,91 & 31,21 & 36,81 & 31,43 \\
\hline 4 & 34,33 & 33,41 & 38,25 & 34,24 \\
\hline 5 & 32,11 & 27,37 & 40,38 & 37,62 \\
\hline 6 & 31,46 & 24,81 & 35,85 & 29,29 \\
\hline 7 & 36,25 & 30,47 & 33,51 & 28,32 \\
\hline 8 & 36,16 & 31,80 & 35,23 & 31,22 \\
\hline 9 & 33,77 & 30,47 & 38,62 & 35,80 \\
\hline 10 & 33,16 & 32,20 & 42,89 & 39,83 \\
\hline
\end{tabular}

Como se tem uma diversidade de valores para as temperaturas de entrada da água quente realizou-se uma regressão dos dados experimentais com o objetivo de verificar qual é a influência da vazão do produto e da temperatura de entrada da água quente. Os valores do fator utilizados foram os valores considerando a perda para o ambiente efetiva no tubo de retenção (curvas azuis). A Tabela 6.19 mostra os efeitos das variáveis nas respostas, quantificando qual é a mais significativa. Utilizou-se para a regressão o software Statistica 7.0 (StatSoft, EUA)

Tabela 6.19 - Efeitos da temperatura de entrada da água quente e da vazão do produto no fator de aumento da condutividade térmica efetiva do produto

\begin{tabular}{ccccccc}
\hline & \multicolumn{3}{c}{ Mistura Glicerina $80 \%$} & \multicolumn{3}{c}{ Solução CMC 1\% } \\
\cline { 2 - 7 } Variável & Coef. & Erro Padrão & Valor $p$ & Coef. & Erro Padrão & Valor $p$ \\
\hline$q_{1}$ & 0,0337 & 0,0031 & 0,000004 & 0,0163 & 0,0031 & 0,000753 \\
$T_{\text {2in_aque }}$ & 0,00407 & 0,00028 & 0,000000 & 0,00378 & 0,00028 & 0,000001 \\
\hline
\end{tabular}

Pela Tabela 6.19, observa-se que para ambas as soluções o efeito da temperatura de entrada da água quente é maior que o da vazão do produto. Ou seja, pela análise estatística feita, o aumento da temperatura afeta mais positivamente no aumento da condutividade térmica do que a vazão. Esta observação se encontra de acordo com o fenômeno observado, pois o fator de aumento está relacionado com a agitação molecular/atômica, que por sua vez, é uma função de temperatura.

As equações da regressão para a mistura glicerina/água $80 \%$ e CMC 1\%, juntamente com os coeficientes de correlação, estão mostradas, respectivamente, nas equações (6.36) e (6.37): 


$$
\begin{array}{ll}
F_{\text {incr } 1}=0,0337 \cdot q_{1}+0,00407 \cdot T_{2 i n \_a q u e} & \left(R^{2}=0,9971\right) \\
F_{\text {incr } 1}=0,0163 \cdot q_{1}+0,00378 \cdot T_{2 i n \_a q u e} & \left(R^{2}=0,9947\right)
\end{array}
$$

Como observado nas Figuras 6.9 a 6.18 o modelo térmico proposto representou satisfatoriamente o tratamento térmico da mistura glicerina/água $80 \%$ e solução de CMC $1 \%$.

\subsection{Validação do modelo mássico}

\subsubsection{Experimentos}

De acordo com o procedimento experimental descrito na seção 4.2, foram realizados ensaios com o objetivo de obter as DTR's, os tempos médios de residência e da curva $E_{\Phi}(\Phi)$ do pasteurizador em estudo. Posteriormente utilizaramse os dados experimentais na validação do modelo mássico proposto pelo ajuste do parâmetro mássico.

Foram utilizados como fluido produto mistura glicerina/água $80 \%$ e solução de CMC 1\% nas vazões de 10, 20, 30, 40 e $50 \mathrm{~L} / \mathrm{h}$.

A partir dos dados experimentais foi obtido numericamente o tempo médio de residência e então a curva $E_{\Phi}(\Phi)$. Para tanto, utilizou-se, na seguinte sequência, as equações (3.3), (3.4), (3.5), (3.7) e (3.8). Os valores das curvas $E_{\Phi}(\Phi)$ foram posteriormente comparados com os valores de DTR numérica (simulação da equação (4.8)), conforme descrito na seção 4.2 .3

\subsubsection{Ajuste do parâmetro do modelo mássico}

O tempo computacional para cada simulação de DTR numérica foi de cerca de 15 minutos por simulação.

A Figura 6.19 apresenta as curvas de DTR numéricas obtidas considerando $n_{\text {reo }}=1,0$ (fluido Newtoniano) onde é evidente a transição do comportamento 
puramente laminar (baixa difusão radial, alto valor de Peclet) e o comportamento turbulento (alta difusão radial, baixo valor de Peclet).
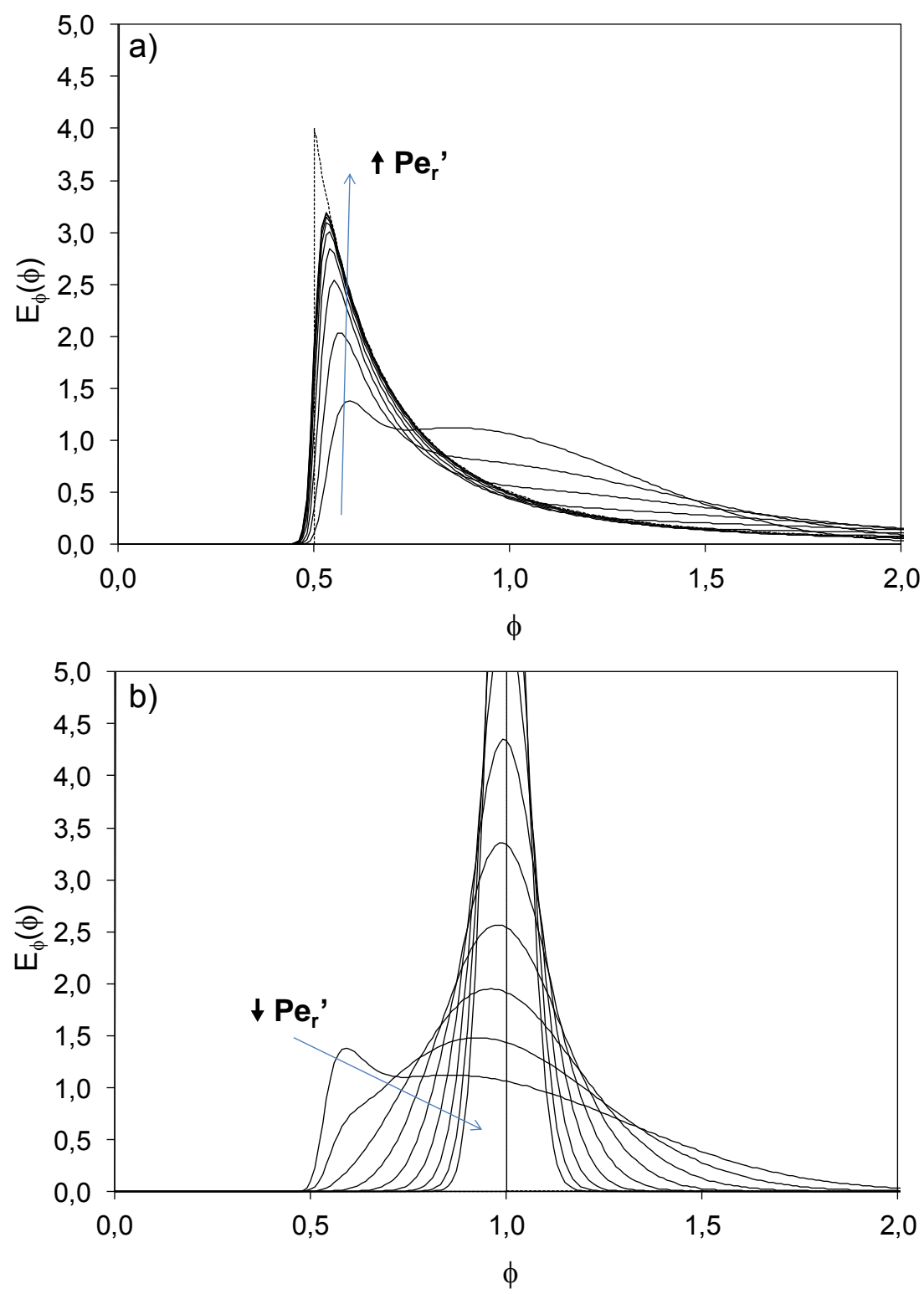

Figura 6.19 - Curvas adimensionais de DTR obtidas pela simulação do modelo, considerando fluido Newtoniano $\left(n_{\text {reo }}=1,0\right)$ e número de Peclet modificado variável: a) Curvas obtidas para baixa difusividades $\left(\log \left(P e_{r}{ }^{\prime}\right) \geq 0,5\right)$; b) Curvas obtidas para alta difusividade $\left(\log \left(P e_{r}{ }^{\prime}\right) \leq 0,5\right)$

É curioso observar que para $\log \left(P e_{r}{ }^{\prime}\right)=0,5$, a curva de DTR apresenta dois picos. O primeiro referente à maior velocidade no centro do tubo, próximo de $\Phi=0,5$ e o segundo referente ao efeito da difusão mássica, próximo de $\Phi=1,0$.

A Figura 6.20 apresenta resultados simulados, mas considerando $n_{\text {reo }}=0,4$ (fluido pseudoplástico). Este valor foi escolhido, pois corresponde ao índice de fluxo da solução de CMC $1 \%$ na temperatura média dos ensaios de DTR realizados. 
Novamente se observa a transição entre os comportamentos puramente laminar e turbulento. Para baixa difusão, o pico em $\Phi=0.5$ é mais pronunciado, pois o perfil de velocidade de um fluido pseudoplástico é mais achatado, reduzindo a variância da curva (dispersão).
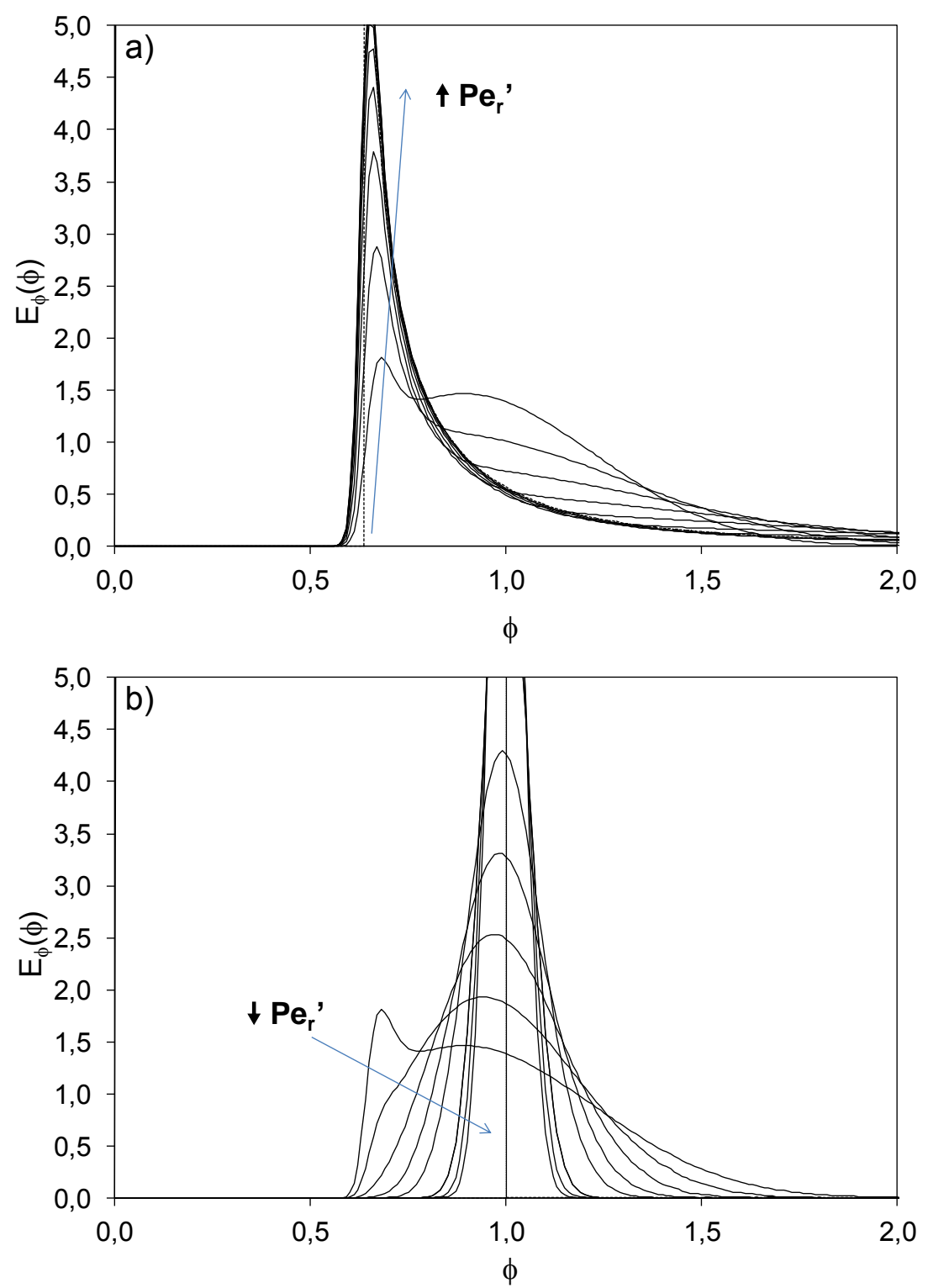

Figura 6.20 - Curvas adimensionais de DTR obtidas pela simulação do modelo, considerando fluido pseudoplástico $\left(n_{\text {reo }}=0,4\right)$ e número de Peclet modificado variável: a) Curvas obtidas para baixa difusividades $\left(\log \left(P e_{r}{ }^{\prime}\right) \geq 0,5\right)$; b) Curvas obtidas para alta difusividade $\left(\log \left(P e_{r}{ }^{\prime}\right) \leq 0,5\right)$

Cada curva experimental obtida foi comparada com as curvas de DTR numérica (curvas da Figura 6.19 ou Figura 6.20) para ajuste do número de Peclet do reator modificado. Para cada comparação gerou-se um valor de erro quadrático. Este erro foi usado para identificar, por interpolação polinomial, em qual valor de 
$\log \left(P e_{r}{ }^{\prime}\right)$ encontrava-se o mínimo erro. Utilizou-se para este procedimento a ferramenta Solver do software Excel (Microsoft, EUA). A Figura 6.21 apresenta um exemplo de comparação entre as DTR's numéricas e a experimental. A partir desta comparação, gerou-se um valor de erro quadrático. Este erro em conjunto com os encontrados nas demais comparações, é visualizado na Figura 6.22.

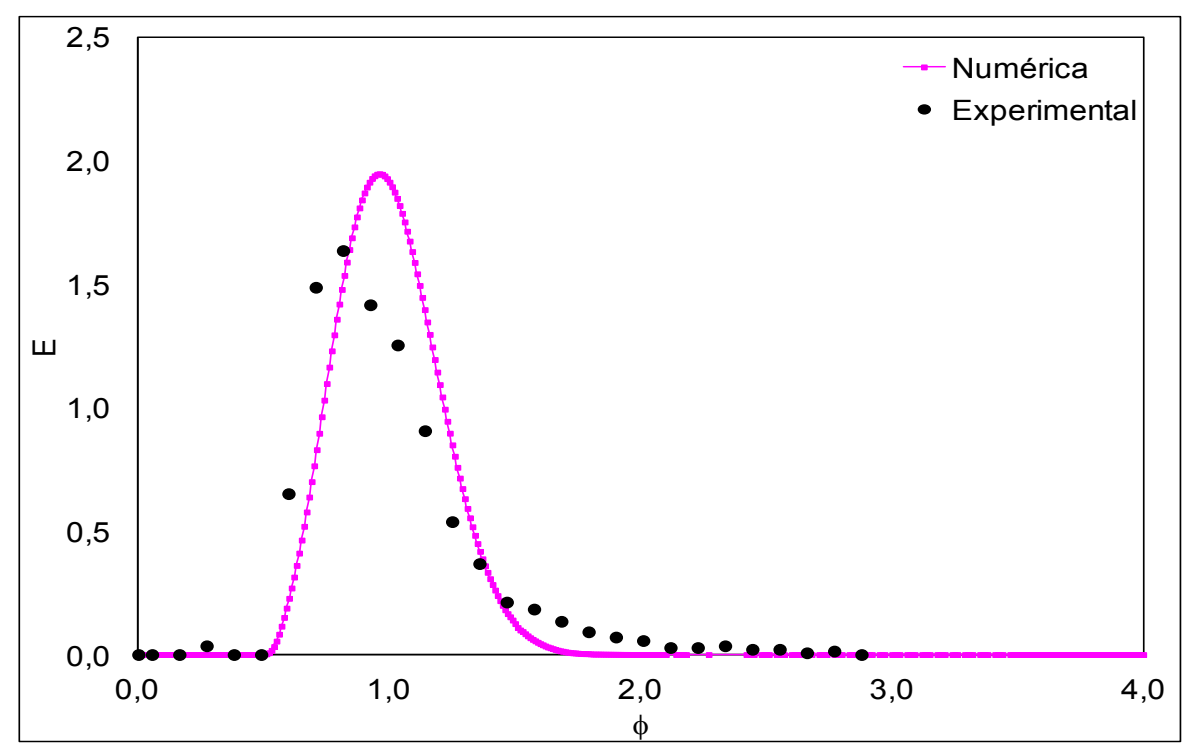

Figura 6.21 - Exemplo de comparação entre uma DTR numérica e a DTR experimental de um ensaio

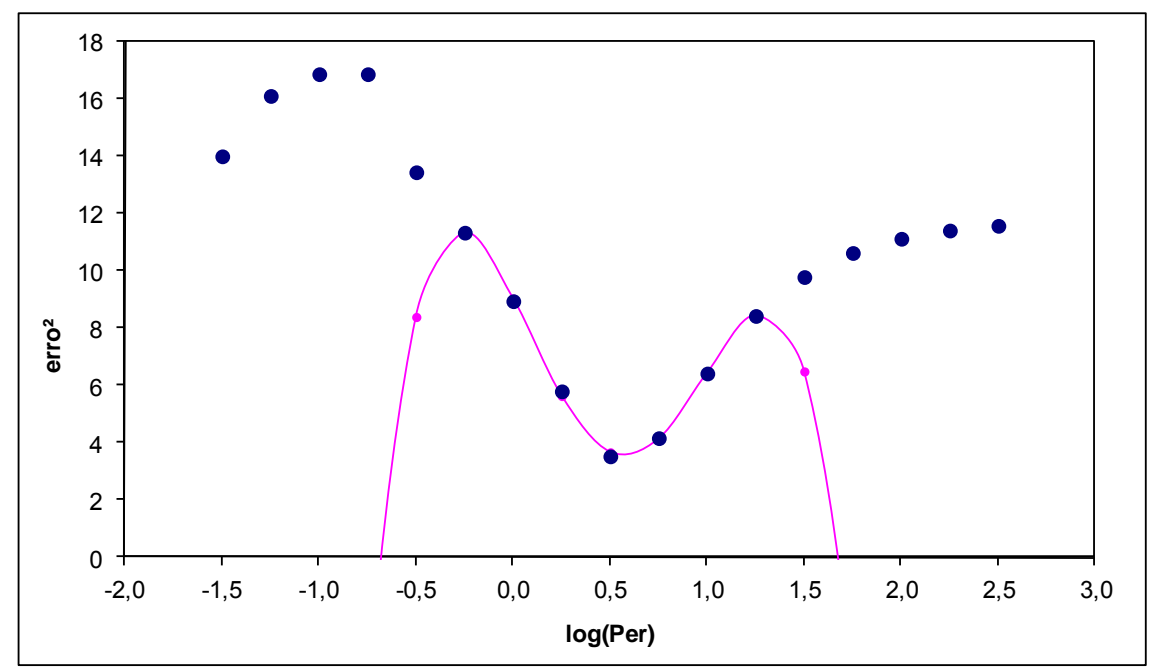

Figura 6.22 - Erros quadráticos obtidos pela comparação entre as DTR numéricas e a DTR experimental em função do $\log \left(P e_{r}{ }^{\prime}\right)$

A partir dos erros quadráticos obtidos das comparações entre as DTR's numéricas e a DTR experimental, observou-se uma região onde poderia se encontrar um valor de mínimo erro quadrático. Para valores próximos a esta região, ajustou-se um polinômio de no máximo grau 6 (curva rosa da Figura 6.22). A esta curva de erro quadrático em função do $\log \left(P e_{r}{ }^{\prime}\right)$ calcula e identifica-se o ponto de 
mínimo erro através da ferramenta Solver do software Excel (Microsoft, EUA), e consequentemente o número de Peclet do reator modificado que se ajusta melhor aos dados experimentais.

Os resultados de Peclet modificado para a mistura glicerina/água $80 \%$ e solução de CMC 1\%, em função da vazão, estão mostrados na Tabela 6.20 , juntamente com a média do Peclet para cada vazão, o desvio padrão e o Peclet médio para a cada tipo de solução.

Tabela 6.20 - Valores do número de Peclet modificado para a mistura glicerina/água $80 \%$ e solução de CMC $1 \%$ nas vazões de estudo

\begin{tabular}{|c|c|c|c|c|c|c|c|c|c|c|}
\hline \multirow[b]{3}{*}{ Ensaio } & \multicolumn{10}{|c|}{ Vazão (L/h) } \\
\hline & \multicolumn{5}{|c|}{ Solução de CMC 1\% } & \multicolumn{5}{|c|}{ Mistura glicerina/água 80\% } \\
\hline & 10 & 20 & 30 & 40 & 50 & 10 & 20 & 30 & 40 & 50 \\
\hline 1 & 2,6 & 2,4 & 5,9 & 12,7 & 1,3 & 1,2 & 1,4 & 3.9 & 8,2 & 2,5 \\
\hline 2 & 2,1 & 2,4 & 3,5 & 6,3 & 2,5 & 1,2 & 4,4 & 0,9 & 7,6 & 0,9 \\
\hline 3 & 3,4 & 7,5 & 2,4 & 2,9 & 15,0 & 2,8 & 2,2 & 0,8 & 0,7 & 180 \\
\hline 4 & 1,8 & 2,4 & 3,8 & 2,5 & 3,0 & 7,9 & 1,9 & 0,9 & 1,7 & 0,8 \\
\hline 5 & 2,4 & 2,1 & 22,7 & 2,5 & 6,1 & 1,6 & 2,5 & 2,0 & 2,5 & 3,0 \\
\hline Média & 2,5 & 3,4 & 3,9 & 3,6 & 3,2 & 2,9 & 2,5 & 1,7 & 4,2 & 1,8 \\
\hline $\begin{array}{l}\text { Desvio } \\
\text { padrão }\end{array}$ & 0,6 & 2,3 & 1,5 & 1,8 & 2,0 & 2,8 & 1,2 & 1,3 & 3,5 & 1,1 \\
\hline $\begin{array}{l}\text { Média } \\
\text { geral }\end{array}$ & & & 3,3 & & & & & 2,6 & & \\
\hline
\end{tabular}

Da Tabela 6.20 tem-se que os dados em vermelho foram excluídos das análises, pois seus valores foram muito discrepantes em relação aos dados de mesma vazão. Os resultados são mostrados na Figura 6.23 e Figura 6.24.

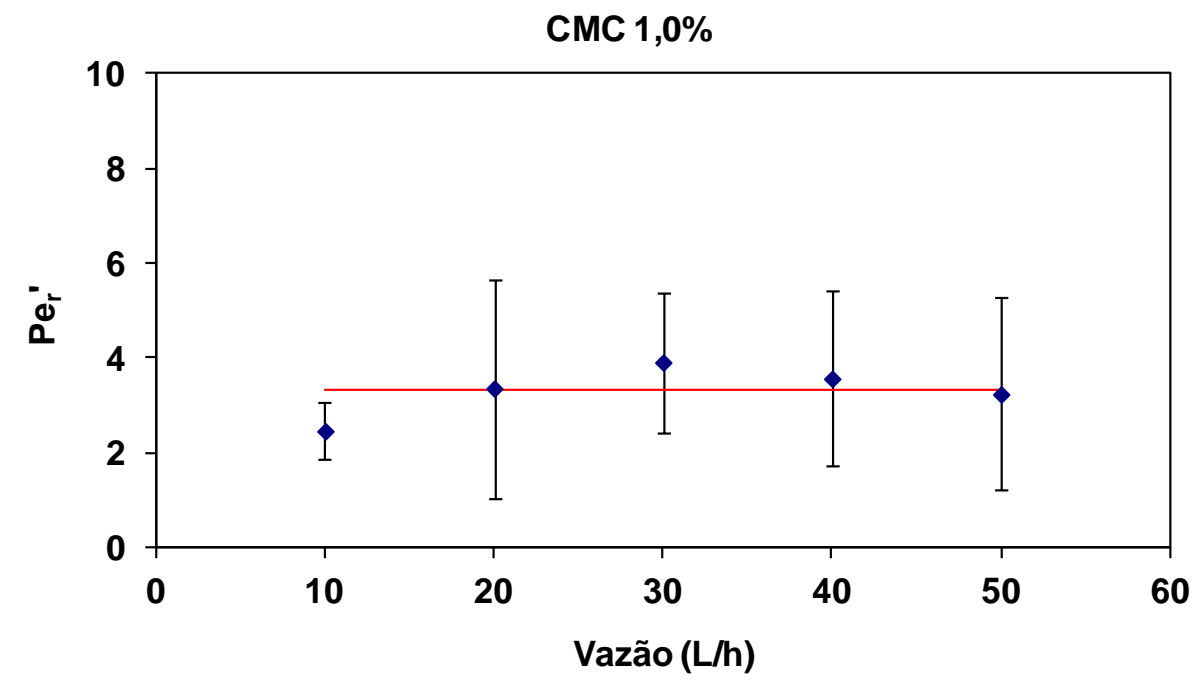


Figura 6.23 - Valores de número de Peclet modificado para solução de CMC $1 \%$ ajustados para os ensaios experimentais

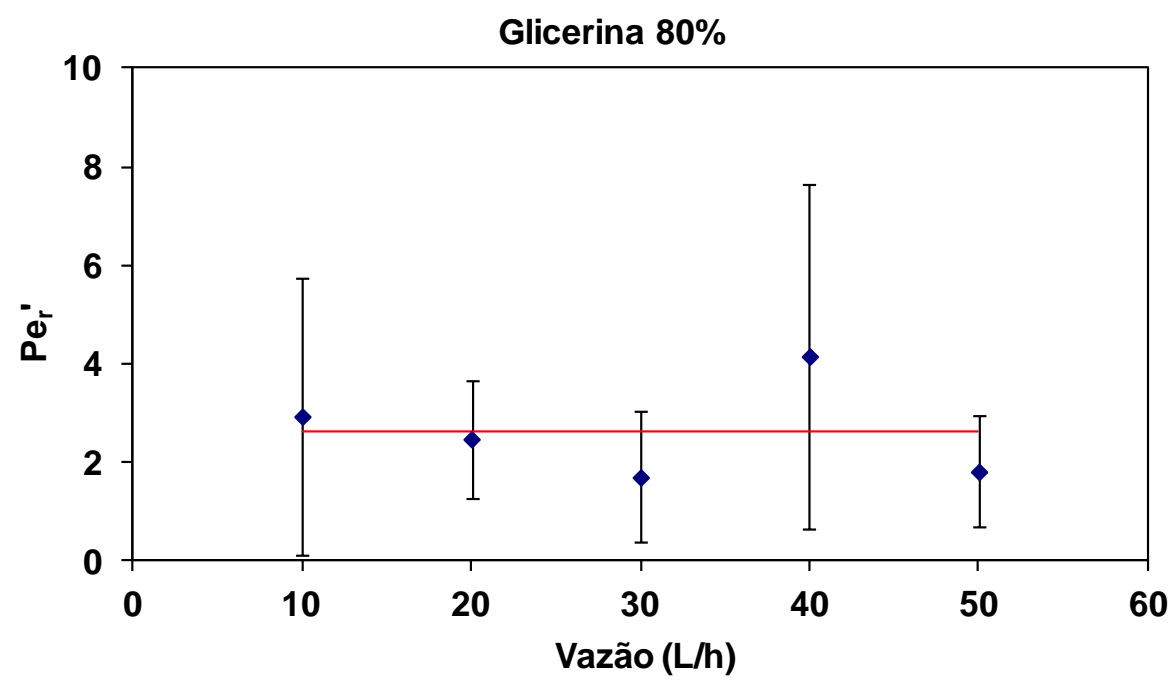

Figura 6.24 - Valores de número de Peclet modificado para mistura glicerina/água $80 \%$ ajustados para os ensaios experimentais

Pela Figura 6.23 e Figura 6.24 não foi possível observar dependência da vazão volumétrica sobre o parâmetro $P e_{r}{ }^{\prime}$, de forma que os valores médios são considerados. Isto indica que a difusividade radial efetiva aumenta com a vazão (equação (4.7)). (Ver Figura 6.25 e Figura 6.26).

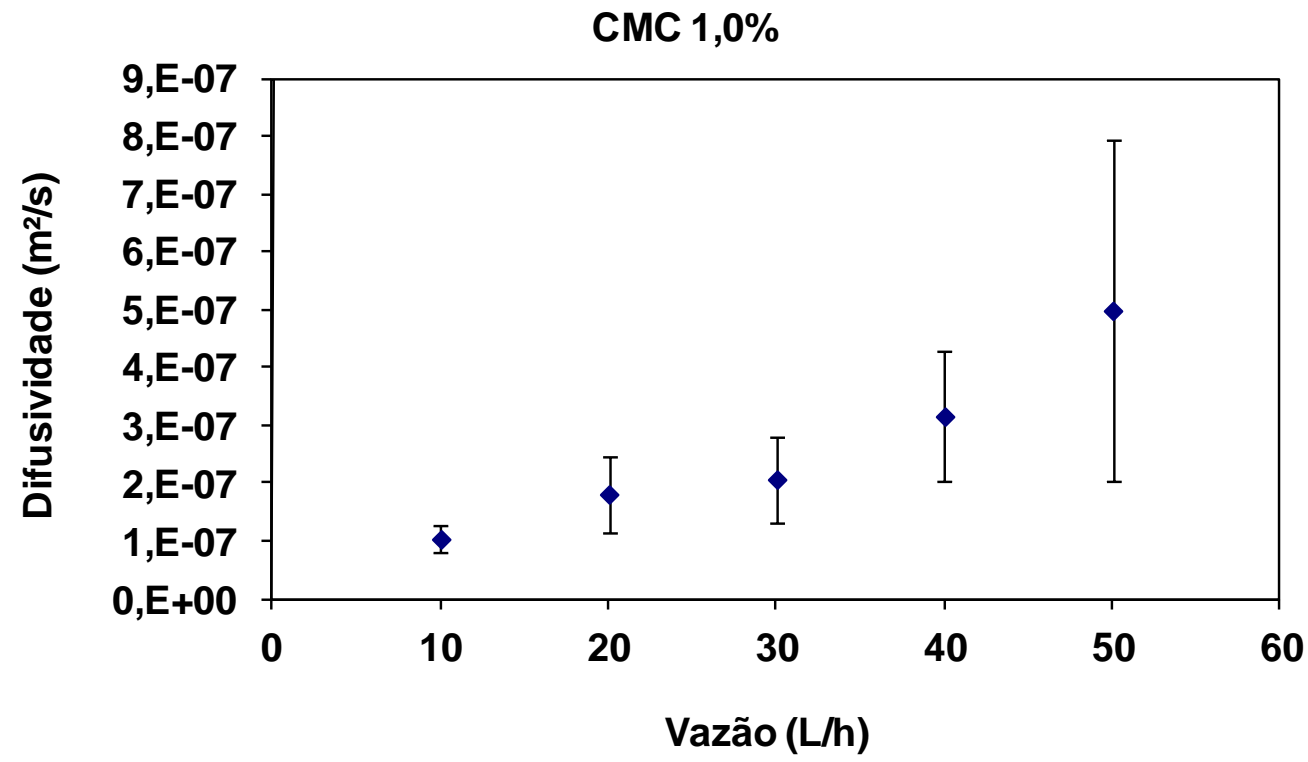

Figura 6.25 - Valores da difusividade mássica efetiva da solução de CMC 1\% em função da vazão 


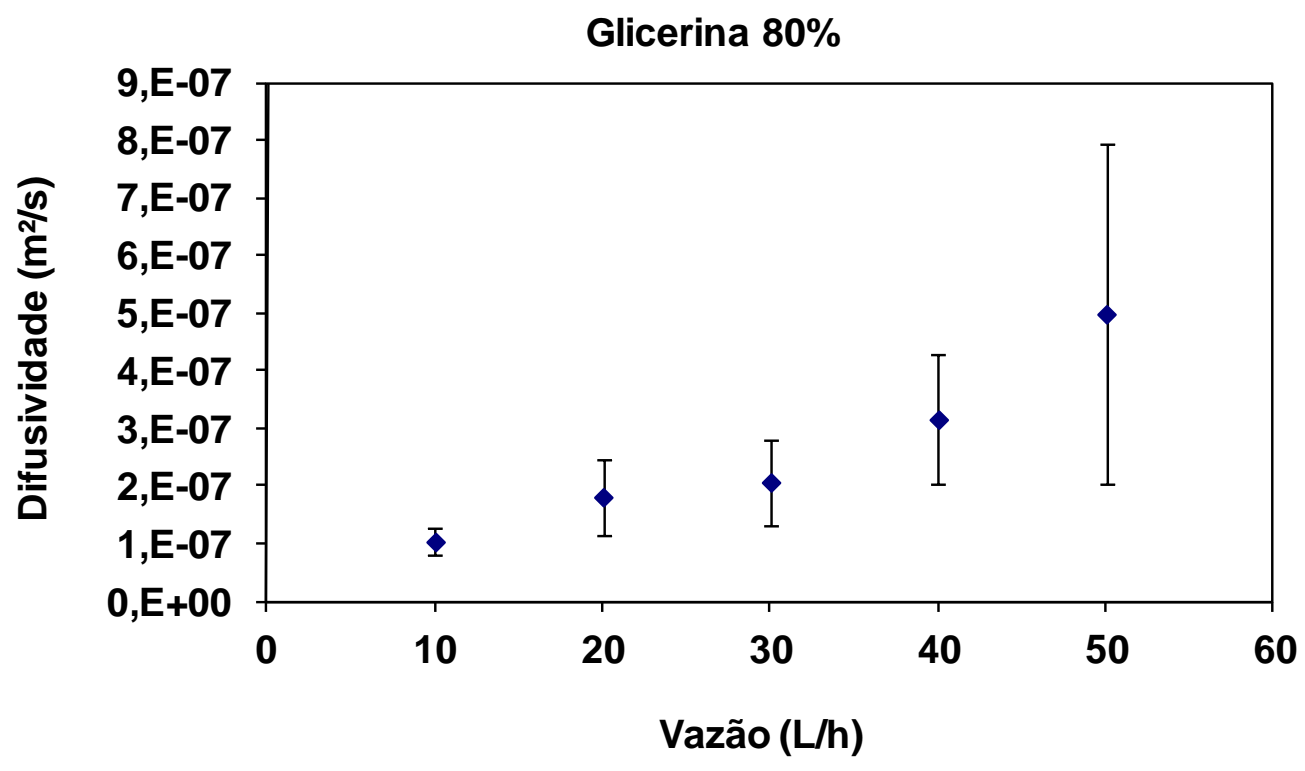

Figura 6.26 - Valores da difusividade mássica efetiva da mistura glicerina/água $80 \%$ em função da vazão

Aplicando-se o logaritmo dos valores médios do Peclet modificado para as soluções tem-se:

$$
\begin{aligned}
& \log \left(P e_{r}{ }^{\prime}\right)=\log (2,6)=0,42 \text { (Mistura glicerina/água 80\%) } \\
& \log \left(P e_{r}{ }^{\prime}\right)=\log (3,3)=0,52 \text { (Solução de CMC 1\%) }
\end{aligned}
$$

Como discutido anteriormente, para os valores de $\log \left(P e_{r}{ }^{\prime}\right)$ próximos de 0,5, observa-se um comportamento de escoamento entre o puramente laminar e o turbulento para ambos os fluidos. Esta fuga do comportamento laminar pode ser atribuída principalmente à curva presente no tubo de retenção (Figura 4.3) e à elevada rugosidade relativa da tubulação. 


\section{CONCLUSÕES}

O modelo desenvolvido para o tratamento térmico contínuo de alimentos viscosos consta de uma seção de aquecimento, um tubo de retenção e uma seção de resfriamento. Sendo as seções de aquecimento e resfriamento compostas por módulos de troca térmica (trocadores de calor bitubulares). Os volumes de controle estudados foram: fluidos alimentício e de utilidade, tubos interno e externo e ar ambiente. $O$ modelo foi formulado a partir de equações diferenciais de conservação e resolvido pelo método de diferenças finitas.

Os resultados obtidos no estudo de caso indicam que o modelo proposto representou de maneira satisfatória o comportamento da temperatura, concentração e esterilidade do processo, com reduzida complexidade computacional em comparação com a abordagem CFD. Os resultados obtidos foram coerentes com os esperados.

O estudo de caso permitiu concluir que as seções de aquecimento e resfriamento possuem papel importante no tratamento térmico. Para as condições de processo propostas no estudo de caso, a contribuição de ambas as seções foi de $44 \%$ no valor da esterilização ao final do processo.

Os valores da difusividade efetiva (térmica e mássica) radial possuem grande influência no perfil de temperatura, concentração e letalidade do processo. O aumento desses parâmetros contribui com uma maior letalidade de processo, pois os efeitos de mistura se tornam mais acentuados.

Os valores de esterilização, tanto de atributos de qualidade microbiológica quanto para os de qualidade nutricional também foram influenciados pela vazão volumétrica do fluido alimentício e a temperatura de entrada do fluido utilidade (água quente). Relações dos valores de esterilização do atributo de qualidade microbiológica e do atributo de qualidade nutricional em função da temperatura e vazão foram obtidas e serviram para encontrar os valores ótimos destas variáveis de processo minimizando as perdas de qualidade nutricional para determinado nível de qualidade microbiológica.

O modelo térmico proposto mostrou-se adequado para descrever a troca térmica em pasteurizador bitubular. Os efeitos de mistura e difusão na direção radial 
foram quantificados através do ajuste da condutividade térmica efetiva, que por sua vez, é influenciada pela vazão e tipo de fluido. A previsão da distribuição de temperatura possibilita a avaliação da letalidade distribuída em alimentos líquidos e a determinação das melhores condições operacionais. Na validação foi possível ajustar o parâmetro térmico de forma que o modelo representasse bem o comportamento experimental. Desta forma considera-se válida a modelagem térmica para representar 0 tratamento térmico que o produto sofre ao passar pelo pasteurizador bitubular.

A simulação do modelo transiente permitiu obter as curvas de DTR numéricas em formato adimensional tendo como parâmetros o número de Peclet modificado e o índice de fluxo da lei de potência. A comparação entre resultados experimentais e numéricos permitiu o ajuste do número de Peclet modificado, como era desejado. A introdução deste parâmetro previsto no modelo do pasteurizador tubular permite uma avaliação mais rigorosa da DTR, em vez de usar a hipótese de escoamento puramente laminar. Na validação mássica foi possível ajustar o Peclet do reator modificado de forma que o parâmetro representasse bem o comportamento do fluido no pasteurizador. Desta forma pode-se considerar válida a modelagem da dispersão mássica para representar o escoamento do produto em um pasteurizador bitubular.

\subsection{Contribuições deste trabalho}

As principais contribuições deste trabalho foram:

- Adequação da modelagem matemática propostas por Kechichian (2011) às características dos trocadores de calor bitubulares (arranjo em grampos/módulos) que propiciou a correta representação do escoamento do fluido utilidade no resfriamento.

- Consideração na modelagem matemática proposta da variação das propriedades termofísicas e reológicas dos fluidos com a temperatura ao longo do processamento térmico.

- Desenvolvimento da metodologia para validação dos modelos térmico e mássico de um trocador bitubular. 
- Avaliação do atributo de qualidade nutricional no processamento térmico contínuo.

- Metodologia de otimização dos atributos de qualidade nutricional utilizando parâmetros de processo.

\subsection{Perspectivas para trabalhos futuros}

Sugere-se para aperfeiçoamento do modelo e métodos propostos:

- Adequar a modelagem considerando a presença de curvas.

- Realização de ensaios de DTR não isotérmicos com o objetivo de verificar a influência da temperatura na distribuição do tempo de residência, comparando os resultados obtidos com os resultados isotérmicos.

- Utilizar um integrador de tempo temperatura enzimático para quantificar a letalidade real do equipamento e comparar com a letalidade prevista pelo modelo.

- Estudar a dependência entre as difusividades mássica e térmica e consequentemente este efeito na letalidade do processamento térmico.

- Validar os modelos térmico e mássico a partir de dados experimentais utilizando fluido alimentício.

- Validar a modelagem utilizando um trocador em escala industrial com fluido alimentício. 


\section{REFERÊNCIAS BIBLIOGRÁFICAS}

AGUIAR, H. F. Modelagem matemática e validação experimental da pasteurização de leite pela avaliação do histórico de temperatura e letalidade em trocador a placas. 2009. 64p. Dissertação (Mestrado em Engenharia Química) Escola Politécnica, Universidade de São Paulo, São Paulo, 2009.

ALFA LAVAL. Viscoline Monotube Unit. Disponível em: $<$ http://www.alfalaval.com/solution-

finder/products/viscoline/Documents/Viscoline\%20Monotube\%20unit.pdf>. Acesso em: 2011-08-18.

ARMAFLEX Armacell. Disponível em:

<http://armaflex.com.br/novo/catalogos/armaflex_af1.pdf>. Acesso em: 2011-08-18.

BERTO, M. I.; GRATÃO, A. C. A.; VITALI, A. A.; SILVEIRA JR.; V. Rheology of sucrose-CMC model solution. Journal of Texture Studies, v. 34, n. 4, p. 391-400, 2003.

BIRD, R. B.; STEWART, W. E.; LIGHTFOOT, E. N. Transport phenomena. 2nd ed. Nova York: John Wiley \& Sons, 2002. 895p.

CABRAL, R. A. F.; ORREGO-ALZATE, C. E.; GABAS, A. L.; TELIS-ROMERO, J. Propriedades reológicas e termofísicas de suco de amora. Ciência e Tecnologia de Alimentos, Campinas, v. 27, n. 3, p. 589-596. 2007.

CAREZZATO, A.; ALCANTARA, M. R.; TELIS-ROMERO, J.; TADINI, C. C.; GUT, J. A. W. Non-Newtonian heat transfer on a plate heat exchanger with generalized configurations. Chemical Engineering and Technology, v. 30, p. 21-26. 2007.

CHENG, N. S. Formula for the Viscosity of a Glycerol-Water Mixture. Industrial and Engineering Chemistry Research, v. 47, p. 3285-3288. 2008.

CHOI, Y.; OKOS, M. R. Thermal Properties of Fluid Foods - Review. In: OKOS, M.R. Physical and Chemical Properties of Food. Michigan: American Society of Agricultural Engineers, 1986. p. 35-77.

CRIVELLARI, G. P. Modelagem e simulação dinâmica de pasteurizador tubular para processamento contínuo de fluido não-newtoniano. 2010. 150p. Trabalho 
de conclusão de curso (Graduação em Engenharia Química). Escola Politécnica, Universidade de São Paulo, São Paulo. 2010.

DITCHFIELD, C. Estudo do processamento contínuo do purê de banana (Musa cavendishii Lamb.). 2004. 268p. Tese (Doutorado em Engenharia Química) Escola Politécnica, Universidade de São Paulo, São Paulo, 2004.

FELLOWS, P. J. Food processing technology: principles and practice. 2nd ed. Cambrigde: Woodhead Publishing; Boca Raton: CRC Press, 2000. 575p.

FERRÃO, E.S.P.; FUNCIA, E.S.; GUT, J.A.W. Determinação dos coeficientes de transferência de calor envolvidos no processamento térmico contínuo em trocador duplo-tubo. In: Simpósio Latino Americano de Ciências de Alimentos, 9, 2011, Campinas/Brasil.

FERRÃO, E. S. P. Modelagem e validação da transferência de calor e da distribuição de temperatura no processamento térmico contínuo de alimentos líquidos em trocadores bitubulares. 2012. Dissertação (Mestrado em Engenharia Química) - Escola Politécnica, Universidade de São Paulo, São Paulo, 2012.

FOGLER, H. S. Elements of chemical reaction engineering. 4th ed. Upper Saddle River, NJ: Prentice Hall PTR, 2006. 1080p.

FOSTER, D. L.; CUSSLER, E. L. Diffusion in liquids. In: CHEREMISINOFF, N. P. Encyclopedia of Fluid Mechanics. Houston: Gulf P. C., 1986. cap. 4, p. 83-85.

GUERRERO, S. N.; ALZAMORA, S. M. Effect of pH, temperature and glucose addition on flow behaviour of fruit purees: II. Peach, papaya and mango purées. Journal of Food Engineering, v. 37, p. 77-101.1998.

GRATÃO, A. C. A., SILVEIRA JR, V., TELIS-ROMERO, J. Laminar forced convection to a pseudoplastic fluid food in circular and annular ducts. International Communications in Heat and Mass Transfer, v. 33, n. 4, p. 451-457. 2006.

GRATÃO, A. C. A., SILVEIRA JR, V., TELIS-ROMERO, J. Laminar flow of soursop juice through concentric annuli: friction factors and rheology. Journal of Food Engineering, v. 78, n. 4, p. 1343-1354. 2007. 
GRIJSPEERDT, K.; HAZARIKA, B.; VUCINIC, D. Application of Computational Fluid Dynamics to Model the Hydrodynamics of Plate Heat Exchangers for Milk Processing. Journal of Food Engineering, v. 57, n. 3, p. 237-242. 2003.

GROVIER, G. W.; AZIZ, K. The Flow of Complex Mixtures in Pipes. Nova York: Van Nostrand Reinhold Co., 1972. 792p.

GUT, J. A. W.; PINTO, J. M. Modeling of Plate Heat Exchangers with Generalized Configuration. International Journal of Heat and Mass Transfer, v. 46, n. 14, p. 2571-2585. 2003.

GUT, J. A. W.; PINTO, J. M. Optimal design of continuous sterilization processes with plate heat exchangers. Computer Aided Chemical Engineering, v. 20, 2005. p. 919-924. Abstract 15th. European Symposium on Computer Aided Process Engineering. 2005.

IBARZ, A.; BARBOSA-CÁNOVAS, G. V. Unit operations in food engineering. Boca Raton: CRC Press, 2002. 865p.

INCROPERA, F. P.; DEWITT, D. P.; BERGMAN, T. L.; LAVINE, A. S. Fundamentos de transferência de calor e massa. $6^{\text {a }}$ Ed. Rio de Janeiro: LTC, 2008. 643p.

JUNG, A.; FRYER, P. J. Optimising the quality of safe food: Computational modeling of a continuous sterilisation process. Chemical Engineering Science, v. 54, n. 6, p. 717-730. 1999.

KECHICHIAN, V. Modelagem do processo térmico contínuo de fluidos alimentícios não-newtonianos em trocador bitubular. 2011. 103p. Tese (Doutorado em Engenharia Química) - Escola Politécnica, Universidade de São Paulo, São Paulo, 2011.

KIZILTAS, S.; ERDOGDU, F.; PALAZOGLU, T. K. Simulation of heat transfer for solid-liquid food mixtures in cans and model validation under pasteurization conditions. Journal of Food Engineering, v. 97, n. 4, p. 449-456. 2010.

LAPIDUS, L.; PINDER, G. F. Numerical Solution of Partial Differential Equations in Science and Engineering. New York: Wiley, 1982. 677p.

LAVARDA, L.; MERCALI, G. D.; SARKIS, J. R.; CASSINI, A. S. Determinação da cinética de degradação térmica da vitamina c em polpa de acerola via 
aquecimento ôhmico. In: Simpósio Latino Americano de Ciências de Alimentos, 9, 2011, Campinas/Brasil.

LEMAUGUER, M.; JELEN, M. Food engineering and process applications: transport phenomena. London: Elsevier Applied Science, 1986.

LEVENSPIEL, O. Chemical reaction engineering. 3rd ed. Nova York: John Wiley \& Sons, 1999. 668p.

MIN, T.; CHOI, H. G.; YOO, J. Y. Laminar convective heat transfer of a Bingham plastic in a circular pipe - II. Numerical approach hydrodynamically developing flow and simultaneously developing flow. International Journal of Heat and Mass Transfer, v. 40, n. 15, p. 3689-3701. 1997.

PEGORARO, P. R. Distribuição do tempo de residência e letalidade no processamento térmico contínuo de líquidos com escoamento laminar não ideal em trocadores bitubulares. 2012. 138p. Dissertação (Mestrado em Engenharia Química) - Escola Politécnica, Universidade de São Paulo, São Paulo, 2012.

PERONA, P. An experimental investigation of laminar-turbulent transition in complex fluids. Journal of Food Engineering, v. 60, n. 2, p. 137-145. 2003.

RAMASWAMY, H. S.; AWUAH, G. B.; ECONOMIDES, A. Thermal processing and quality: principles and overview. Chemical Engineering and Processing, v. 46, n. 6, p. 584-602. 2007.

SARKIS, J. R.; JAESCHKE, D. P.; MARCZAK, L. D. F.; TESSARO, I. C. Kinetics of anthocyanin degradation during conventional and ohmic heating. In: Simpósio Latino Americano de Ciências de Alimentos, 9, 2011, Campinas/Brasil.

SILVA, N. M. C. Propriedades termofísicas e comportamento reológico da polpa de jenipapo (Genipa americana L.). 2008. 56p. Dissertação (Mestrado em Engenharia de Alimentos) - Universidade Estadual do Sudoeste da Bahia, Itapetinga/BA. 2008.

SLONGO, A. P.; ARAGÃO, G. M. F. Behaviour of Neosartorya fischeri Ascospores in pineapple juice. Boletim do Centro de Pesquisa e Processamento de Alimentos, v. 26, n. 1, p. 51-60. 2008. 
STEFFE, J. F. Rheological methods in food process engineering. 2nd ed. East Lansing: Freeman Press, 1996. 418p.

STEFFE, J. F.; SINGH, R. P. Pipeline Design Calculations for Newtonian and Non-Newtonian Fluids. In: VALENTAS, K. J.; SINGH, R. P.; ROTSTEIN, E. Handbook of Food Engineering Practice. Boca Raton: CRC Press, 1997. cap. 1.

SUGAI, A. Y. Processamento descontínuo de purê de manga (Mangífera indica Linn.), variedade Haden: estudo da viabilidade do produto para pronto consumo. 2002. 82p. Dissertação (Mestrado em Engenharia Química) - Escola Politécnica, Universidade de São Paulo, São Paulo, 2002.

TEIXEIRA, A. Thermal Processing of Canned Foods. In: HELDMAN, D. R.; LUND, D. B. Handbook of food engineering. 2nd ed. Boca Raton: CRC Press, 2007. cap. 11. p. $746-797$.

TOLEDO, R. T. Fundamentals of food process engineering. 3rd ed. Nova York: Springer, 2007. 579p.

VAN LOEY, A. M.; SMOUT, C.; HENDRICKX, M. E. Kinetic data for biochemical and microbiological processes during thermal processing. In: RAO, M. A; RIZVI, S. S. H; DATTA, A. K. Engineering Properties of Foods. 3rd ed. Boca Raton: CRC Press, 2005. cap. 13.

WELTI-CHANES, J.; VERGARA-BALDERAS, F.; BERMÚDEZ-AGUIRRE, D. Transport phenomena in food engineering: basic concepts and advances. Journal of Food Engineering, v. 67, n. 1-2, p. 113-128. 2005.

YAWS, C. L. Chemical Properties Handbook. McGraw-Hill, 1999. 779p. 


\section{APÊNDICE A - PERFIL DE TEMPERATURA EM UMA CASCA CILÍNDRICA}

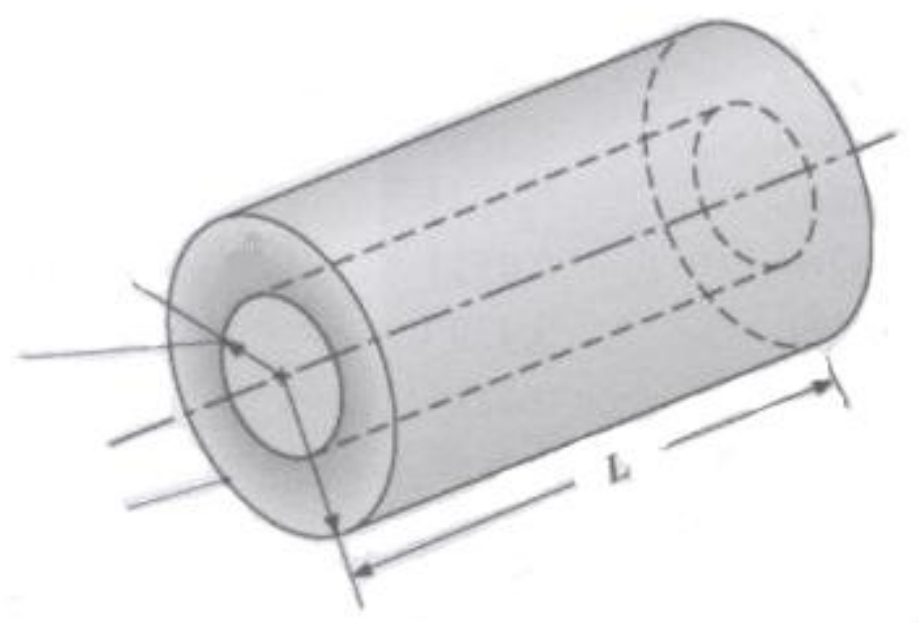

Figura A.0.1 - Casca cilíndrica (Adaptada de Incropera et al. (2008))

Para a casca cilíndrica mostrada na Figura A.0.1, tem-se o seguinte balanço diferencial de energia:

$$
\rho C_{p}\left(\frac{\partial T}{\partial t}+\vec{v} \cdot \nabla T\right)=\nabla(k \cdot \nabla T)+\dot{Q}
$$

Considerando:

I. Estado estacionário;

II. Transferência de calor apenas na direção radial;

III. Sem geração interna de calor;

IV. Sem advecção em material sólido;

V. Tubo cilíndrico e reto com simetria angular;

VI. Propriedades constantes;

VII. Superfícies internas e externas com temperaturas uniformes;

VIII. Temperaturas das superfícies internas e externas conhecidas.

Reescrevendo a equação (A.1), tem-se:

$$
0=k\left[\frac{1}{r} \frac{\partial}{\partial r}\left(r \frac{\partial T}{\partial r}\right)\right]
$$

Integrando-se a equação (A.2) duas vezes, tem-se a seguinte solução geral:

$$
T(r)=C_{1} \cdot \ln (r)+C_{2}
$$


em que as constantes de integração $C_{1}$ e $C_{2}$ são obtidas aplicando as seguintes condições de contorno:

$$
\begin{aligned}
& \text { C.C.1: } r=r_{i} \rightarrow T=T_{i} . \\
& \text { C.C.2: } r=r_{e} \rightarrow T=T_{e} \text {. }
\end{aligned}
$$

em que $r_{i}$ e $r_{e}$ são os raios interno e externo $(\mathrm{m})$, e $T_{i}$ e $T_{e}$ são as temperaturas da superfície interna e externa $(\mathrm{K})$ da casca cilíndrica.

Aplicando as condições de contorno na equação (A.3), obtém-se:

$$
\begin{aligned}
& T_{i}=C_{1} \cdot \ln \left(r_{i}\right)+C_{2} \\
& T_{e}=C_{1} \cdot \ln \left(r_{e}\right)+C_{2}
\end{aligned}
$$

Resolvendo as equações (A.4) e (A.5) em função de $C_{1}$ e $C_{2}$, tem-se:

$$
\begin{gathered}
C_{1}=\frac{T_{i}-T_{e}}{\ln \left({ }^{r_{i}} / r_{e}\right)} \\
C_{2}=T_{e}-\frac{T_{i}-T_{e}}{\ln \left(r_{i} / r_{e}\right)} \ln \left(r_{e}\right)
\end{gathered}
$$

Substituindo $C_{1}$ e $C_{2}$, na solução geral, encontra-se:

$$
T(r)=T_{e}-\frac{T_{i}-T_{e}}{\ln \left(r_{i} / r_{e}\right)} \ln \left(r_{e}\right)+\frac{T_{i}-T_{e}}{\ln \left(r^{r_{i}} / r_{e}\right)} \cdot \ln (r)
$$


APÊNDICE B - ARQUIVO FONTE DO gPROMS 


\begin{tabular}{|l|l|l|l|l|}
\hline Name & Lower bound & Default value & Upper bound & Units \\
\hline CalorEspecifico & $1.0 \mathrm{E}-20$ & 4000.0 & $1.0 \mathrm{E} 10$ & $\mathrm{~J} / \mathrm{kg} . \mathrm{K}$ \\
\hline CalorVolumetrico & $-1.0 \mathrm{E} 20$ & 10000.0 & $1.0 \mathrm{E} 20$ & $\mathrm{~W} / \mathrm{m} 3$ \\
\hline Coef_Troca_Termica & $1.0 \mathrm{E}-20$ & 10000.0 & $1.0 \mathrm{E} 20$ & $\mathrm{~W} / \mathrm{m}^{2} . \mathrm{K}$ \\
\hline Concentracao & $1.0 \mathrm{E}-10$ & $1.0 \mathrm{E} 34$ & $1.0 \mathrm{E} 45$ & $\mathrm{~mol} / \mathrm{m} 3$ \\
\hline CondTermica & $1.0 \mathrm{E}-20$ & 0.57 & 100.0 & $\mathrm{~W} / \mathrm{m} . \mathrm{K}$ \\
\hline Difusividade & $1.0 \mathrm{E}-20$ & $1.0 \mathrm{E}-6$ & 100.0 & $\mathrm{~m} 2 / \mathrm{s}$ \\
\hline IndiceComportamento & $1.0 \mathrm{E}-20$ & 0.55 & 5.0 & $\mathrm{adm}$ \\
\hline MassaEspecifica & $1.0 \mathrm{E}-20$ & 950.0 & $1.0 \mathrm{E} 10$ & $\mathrm{~kg} / \mathrm{m} 3$ \\
\hline NumNusselt_FP & $1.0 \mathrm{E}-20$ & 10.0 & $1.0 \mathrm{E} 10$ & $\mathrm{adm}$ \\
\hline NumNusselt_FU & $1.0 \mathrm{E}-20$ & 50.0 & $1.0 \mathrm{E} 10$ & $\mathrm{adm}$ \\
\hline NumReynolds_FP & $1.0 \mathrm{E}-20$ & 50.0 & $1.0 \mathrm{E} 10$ & $\mathrm{adm}$ \\
\hline NumReynolds_FU & $1.0 \mathrm{E}-20$ & 8000.0 & $1.0 \mathrm{E} 10$ & $\mathrm{adm}$ \\
\hline Svalue & 0.0 & 10.0 & $1.0 \mathrm{E} 10$ & $\mathrm{adm}$ \\
\hline TaxaReacao & $1.0 \mathrm{E}-20$ & $1.0 \mathrm{E} 30$ & $1.0 \mathrm{E} 300$ & $\mathrm{~mol} / \mathrm{m} 3 . \mathrm{s}$ \\
\hline Temperatura & $1.0 \mathrm{E}-20$ & 350.0 & $1.0 \mathrm{E} 10$ & $\mathrm{~K}$ \\
\hline Tempo & $1.0 \mathrm{E}-20$ & 0.5 & $1.0 \mathrm{E} 10$ & $\mathrm{~s}$ \\
\hline Velocidade & 0.0 & 0.5 & $1.0 \mathrm{E} 10$ & $\mathrm{~m} / \mathrm{s}$ \\
\hline ViscosidadeAbsoluta_FP & $1.0 \mathrm{E}-20$ & 0.02 & 1000.0 & $\mathrm{~N} . \mathrm{s} \wedge / \mathrm{m} 2$ \\
\hline ViscosidadeAbsolutA_FU & $1.0 \mathrm{E}-20$ & $1.0 \mathrm{E}-4$ & 1000.0 & $\mathrm{~N} . \mathrm{s} / \mathrm{m} 2$ \\
\hline & & & & \\
\hline
\end{tabular}




\section{MODEL Com_reacao_Pasteurizador (Pasteurizador_Suco de Amora_Revisado1_EstudoCaso_Segurança)}

PARAMETER

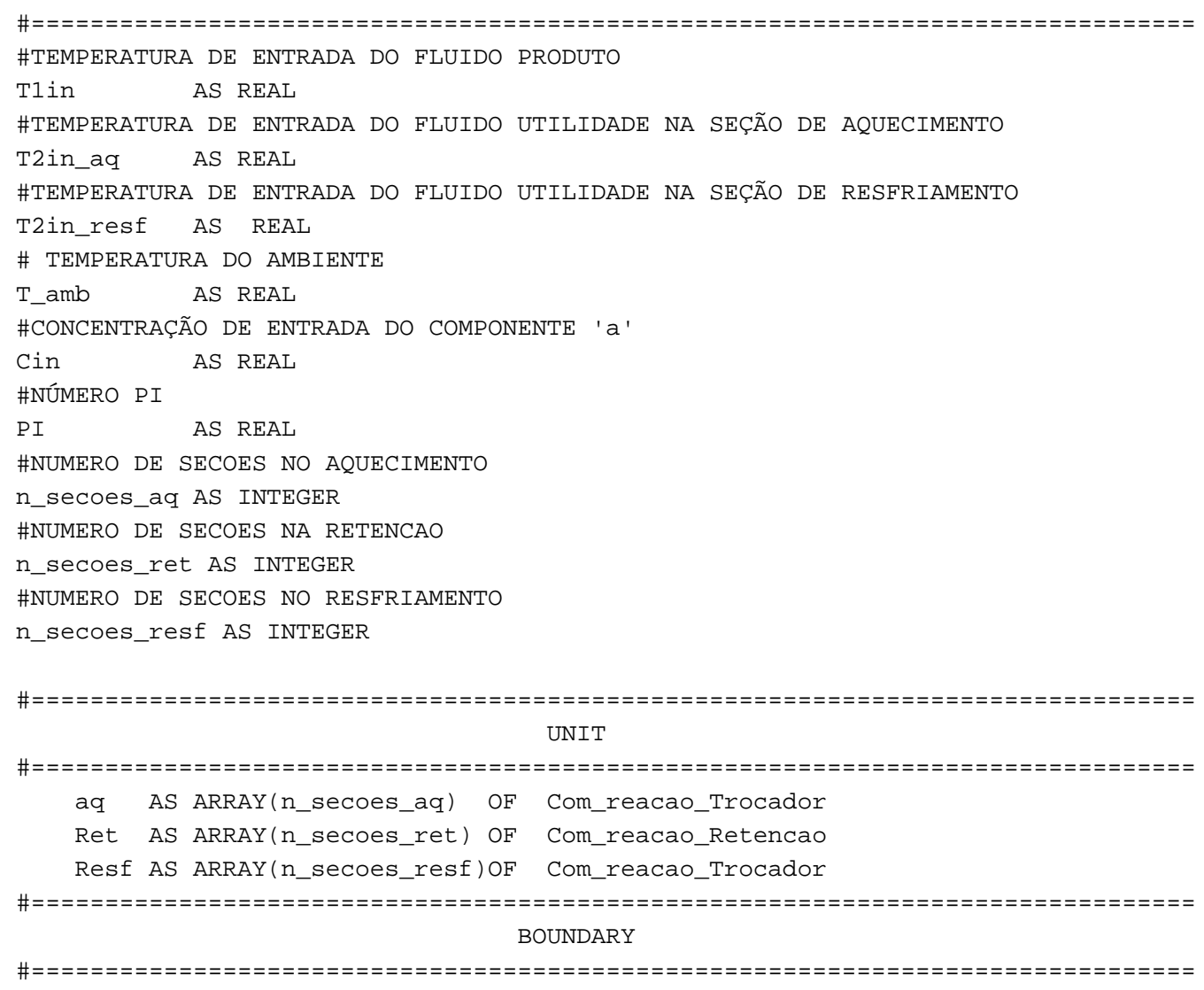

\#-------------CONDIÇÕES DE CONTORNO NA SEÇÃO DE AQUECIMENTO

for sec:=1 to n_secoes_aq do

within aq(sec) do

\#-->PARA O FLUIDO PRODUTO

\#BALANÇO DE ENERGIA

\#NA DIREÇÃO AXIAL

\#EM Z $\mathrm{Z}=\mathrm{A}$

(TEMP. DE ENTRADA CONHECIDA)

if $\sec =1$ then

for $y:=0$ to Raio_int_tubol do

$\mathrm{T} 1(\mathrm{~A}, \mathrm{Y})=\mathrm{T} 1 \mathrm{in}$;

end

else

for $y:=0$ to Raio_int_tubol do

$\mathrm{T} 1(\mathrm{~A}, \mathrm{y})=\mathrm{aq}\left(\mathrm{sec}^{-1}\right) \cdot \mathrm{T} 1\left(\mathrm{aq}\left(\mathrm{sec}^{-1}\right) \cdot \mathrm{B}, \mathrm{y}\right)$;

end

end

\#NA DIREÇÃO RADIAL

\#EM $\mathrm{R}=0$

(SIMETRIA DE EIXO)

for $x:=A \mid+$ to $B$ do

partial $(\mathrm{T} 1(\mathrm{x}, 0), \operatorname{radial} 1)=0$;

end

\#EM R=Raio_int_1

(TRANSF. DE CALOR PELO CONTORNO) 


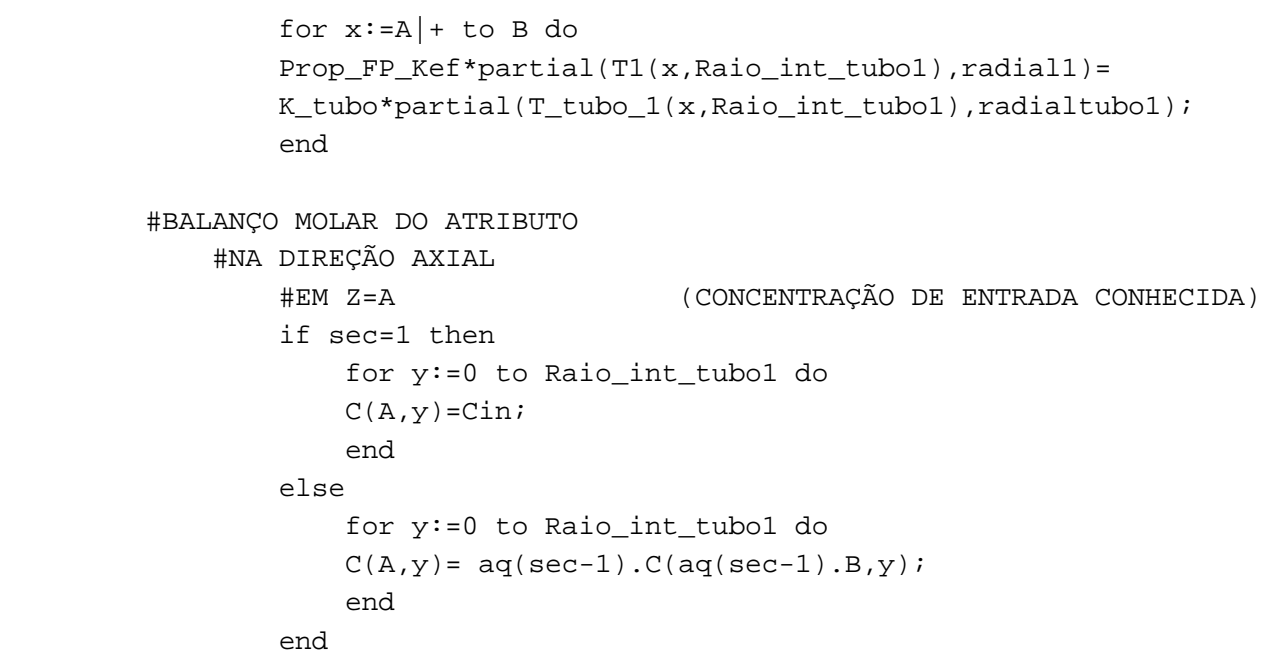

\#NA DIREÇÃO RADIAL

\#EM R=0 (SIMETRIA DE EIXO)

for $x:=A \mid+$ to $B$ do

$($ partial $(C(x, 0), \operatorname{Radial} 1)) *\left(1 /\left(C \_\right.\right.$media $\left.\left.(A) * 1 e 2\right)\right)=0 *\left(1 /\left(C \_\right.\right.$media $\left.\left.(A) * 1 e 2\right)\right)$;

end

\#EM R=Raio_int_1 (IMPERMEABILIDADE)

for $x:=A \mid+$ to $B$ do

$($ partial (C (x,Raio_int_tubo1), Radial1) $) *(1 /($ C_media $(A) * 1 e 2))=0 *\left(1 /\left(C \_m e d i a(A)\right.\right.$

*(e2))；

end

\#-->PARA TUBO INTERNO

\#BALANÇO DE ENERGIA

\#NA DIREÇÃO AXIAL

$\# \mathrm{EM} \quad \mathrm{Z}=\mathrm{A}$

if sec=1 then \#(PAREDE ADIABÁtICA)

for y:=Raio_int_tubol to Raio_ext_tubol do

partial (T_tubo_1 (A, y), axial) $=0$;

end

else \#(CONTINUIDADE DA TEMPERATURA)

for $y:=$ Raio_int_tubol to Raio_ext_tubol do

T_tubo_1 $(\mathrm{A}, \mathrm{y})=\mathrm{aq}(\mathrm{sec}-1) \cdot$ T_tubo_1 $(\mathrm{aq}(\mathrm{sec}-1) \cdot \mathrm{B}, \mathrm{y})$;

end

end

\#EM $\mathrm{Z}=\mathrm{B}$

if sec=n_secoes_aq then\# (TEMP. NO AQUEC. IGUAL A TEMP. NA RETENÇÃO)

for $y:=$ Raio_int_tubo1 to Raio_ext_tubo1 do

T_tubo_1 (B,y)=ret (1).T_tubo_1 (ret (1).A, y) ;

end

else \#(TAXA DE CALOR NO AQUEC. IGUAL A TAXA DE CALOR NA

RETENÇ̃̃̃)

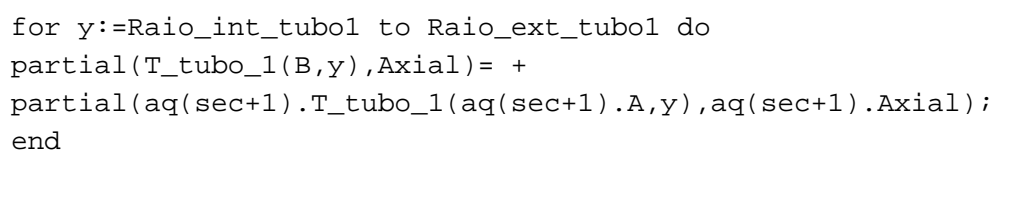

\#NA DIREÇÃO RADIAL

\#EM R=Raio_int_1 (TEMP.FLUIDO PRODUTO IGUAL A TEMP. PAREDE DO TUBO

INTERNO)

for $\mathrm{x}:=\mathrm{A} \mid+$ to $\mathrm{B} \mid-$ do 


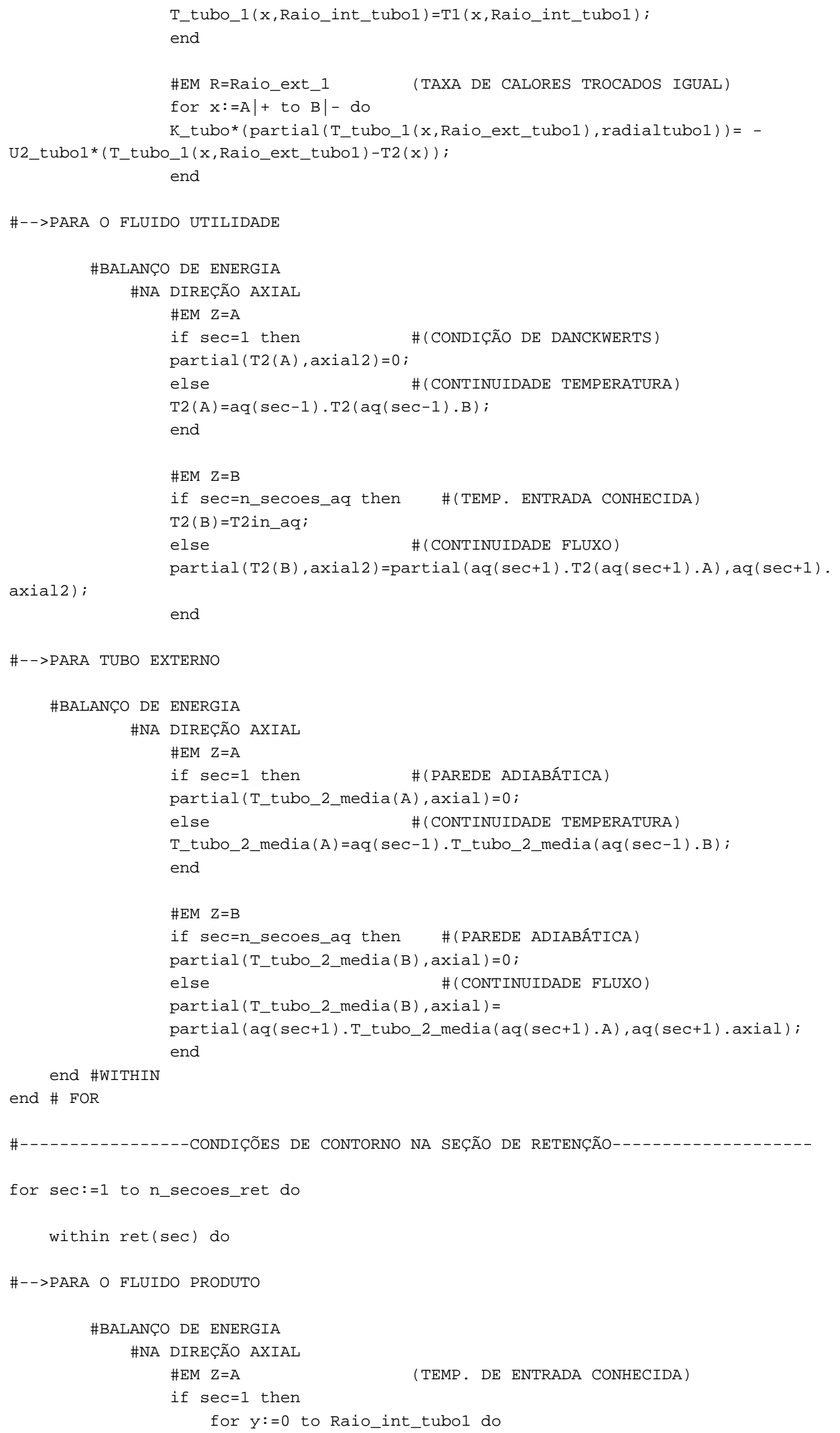




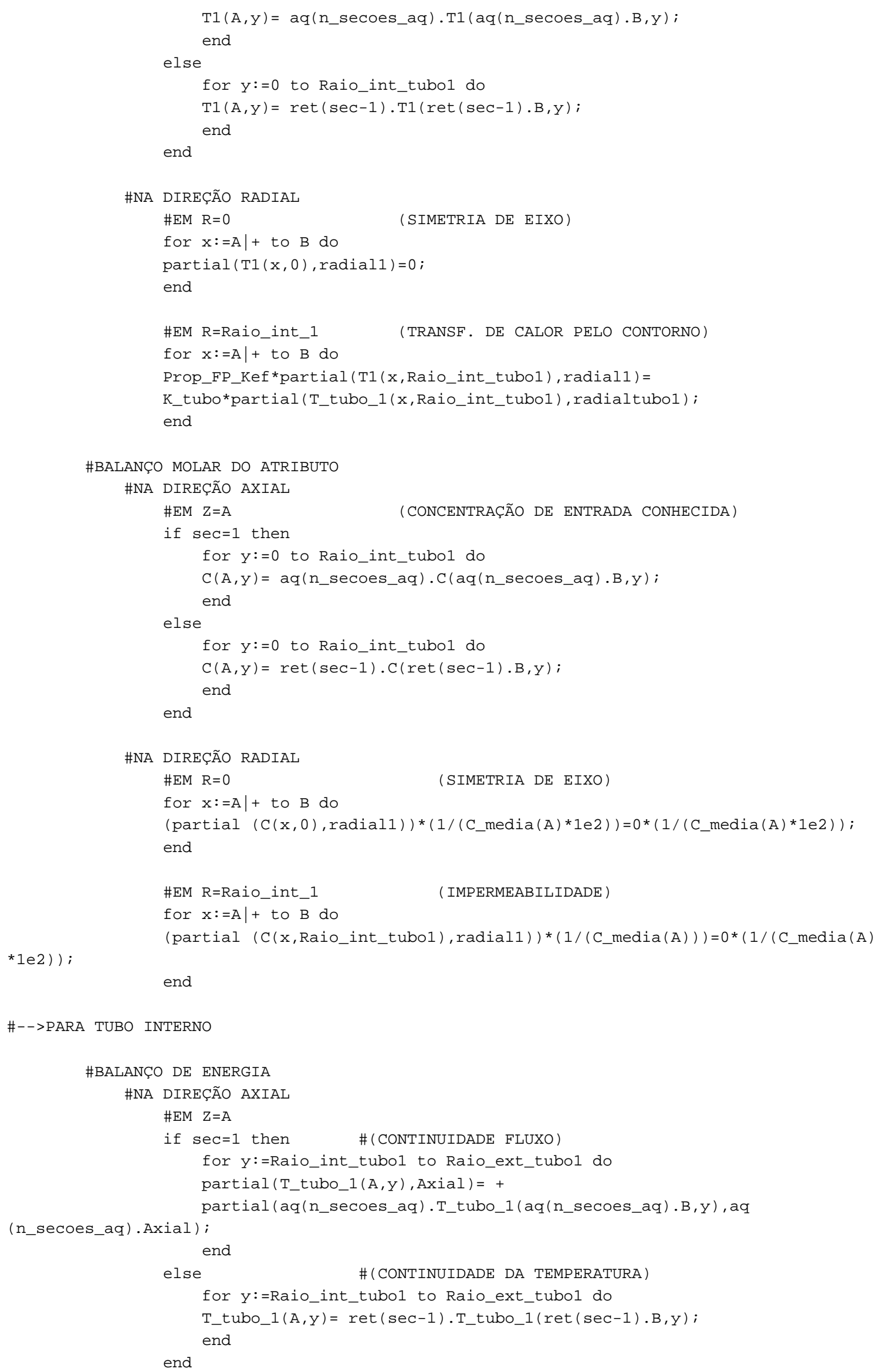




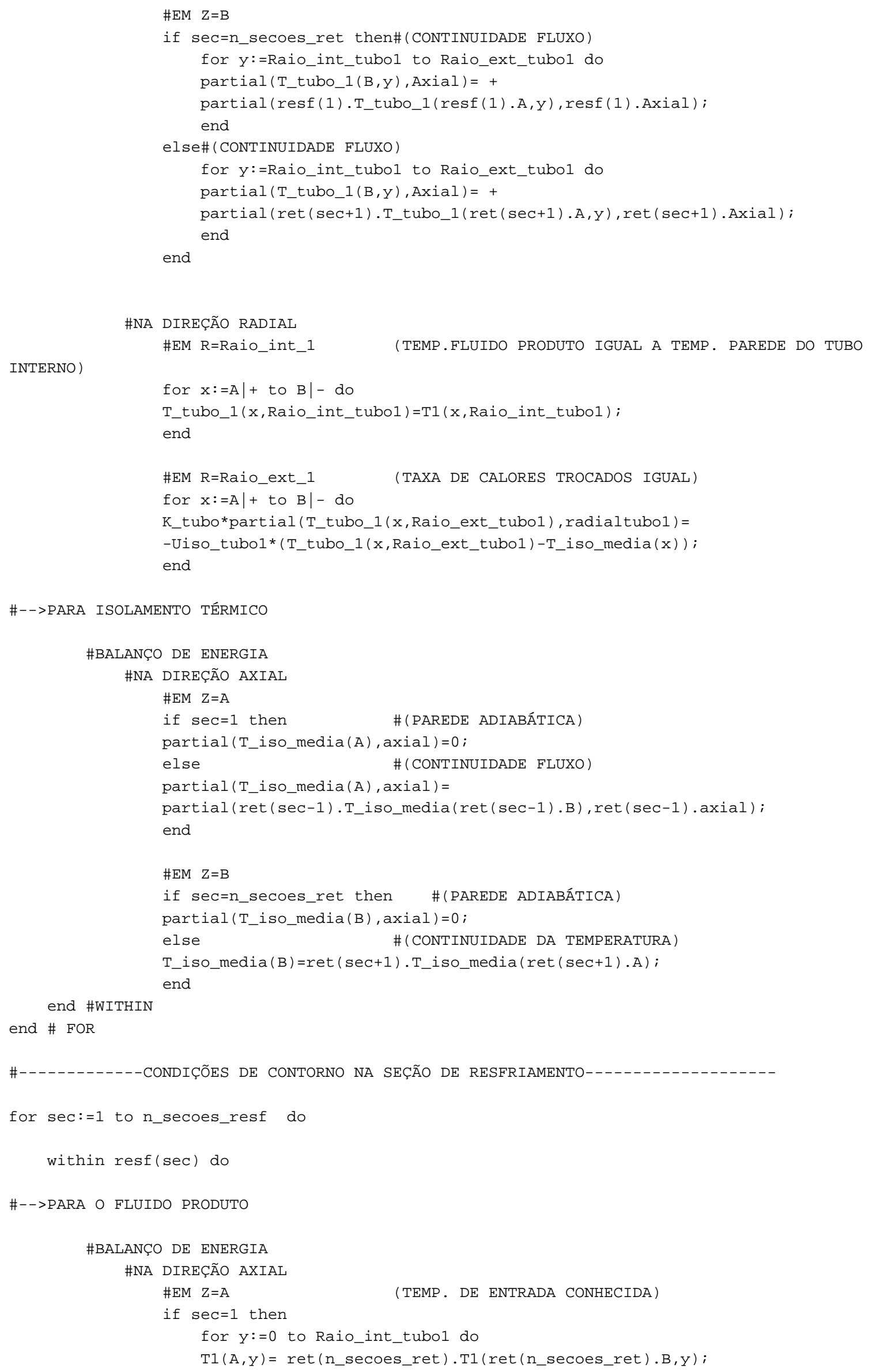




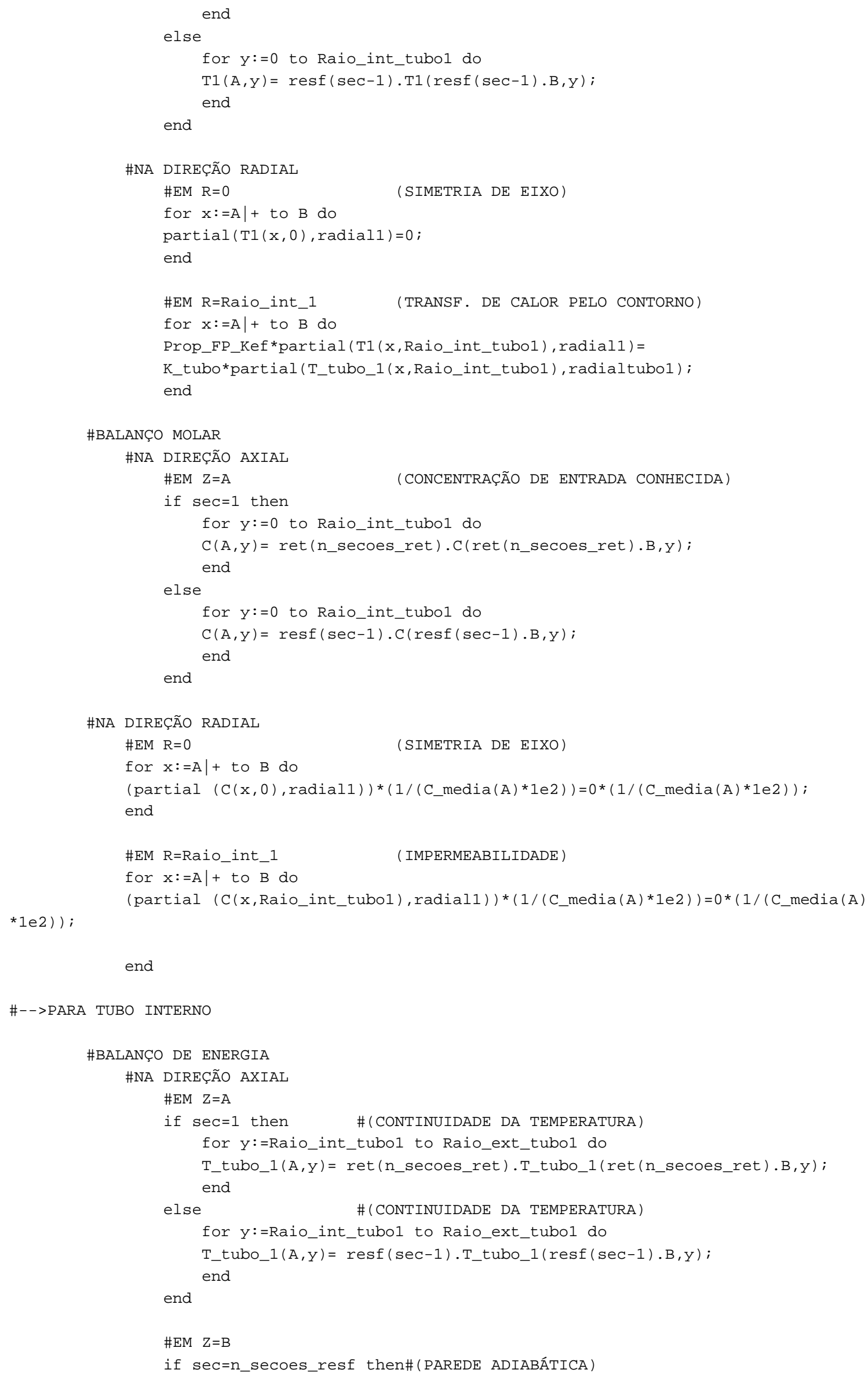




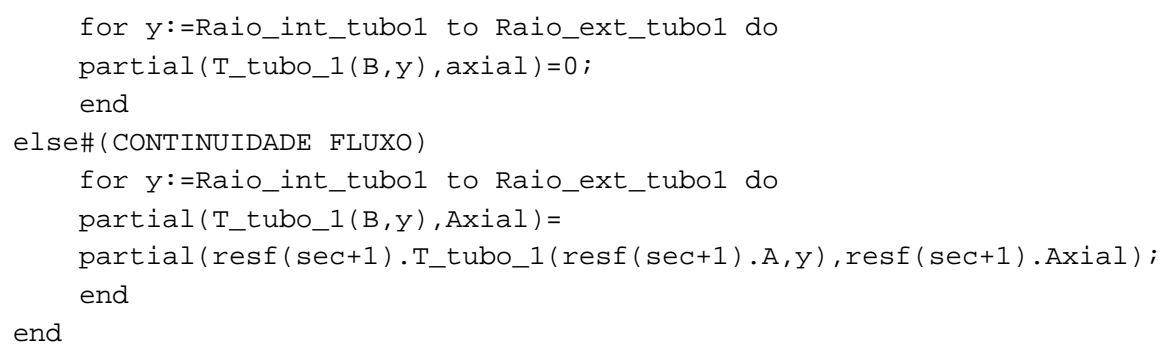


end \# FOR

Preset

for sec:=1 to (n_secoes_aq-1) do within aq (sec) do

$\mathrm{C}:=1 \mathrm{e} 38$;

C_media:=1e38;

$\mathrm{T} 1:=350$;

T1_media: $=350$;

T1_media_secao: $=350$;

T_tubo_1:=350;

T2 $:=350$

T2_media_secao: $=350$;

end

end

within aq(n_secoes_aq) do

$C:=1 e 38 ;$

C_media: $=1$ e38;

$\mathrm{T} 1:=350$;

T1_media: $=350$;

T1_media_secao: $=350$;

T_tubo_1:=350;

$\mathrm{T} 2:=350$;

T2_media_secao: $=350$;

end

for sec:=1 to n_secoes_resf do within resf (sec) do

$\mathrm{C}:=1 \mathrm{e} 37$;

C_media: $=1$ e 37 ;

$\mathrm{T} 1:=350$;

T1_media: $=350$;

T1_media_secao: $=350$;

T_tubo_1:=350;

$\mathrm{T} 2:=350$;

T2_media_secao: $=350$;

end

end

MODEL Com_reacao_Retencao (Pasteurizador_Suco de

Amora_Revisado1_EstudoCaso_Segurança)

PARAMETER

\# TEMPERATURA DO AMBIENTE

(K)

T_amb AS REAL

\#CONCENTRAÇÃO DE ENTRADA DO ATRIBUTO

$\left(\mathrm{mol} / \mathrm{m}^{3}\right)$

Cin AS REAL

\#---------------FRACAO MASSICA DAS SUBSTANCIAS QUE COMPOEM O ALIMENTO---------\#CONCENTRACAO DE SOLIDOS SOLUVEIS ('BRIX)

Conc_SS

AS REAI 


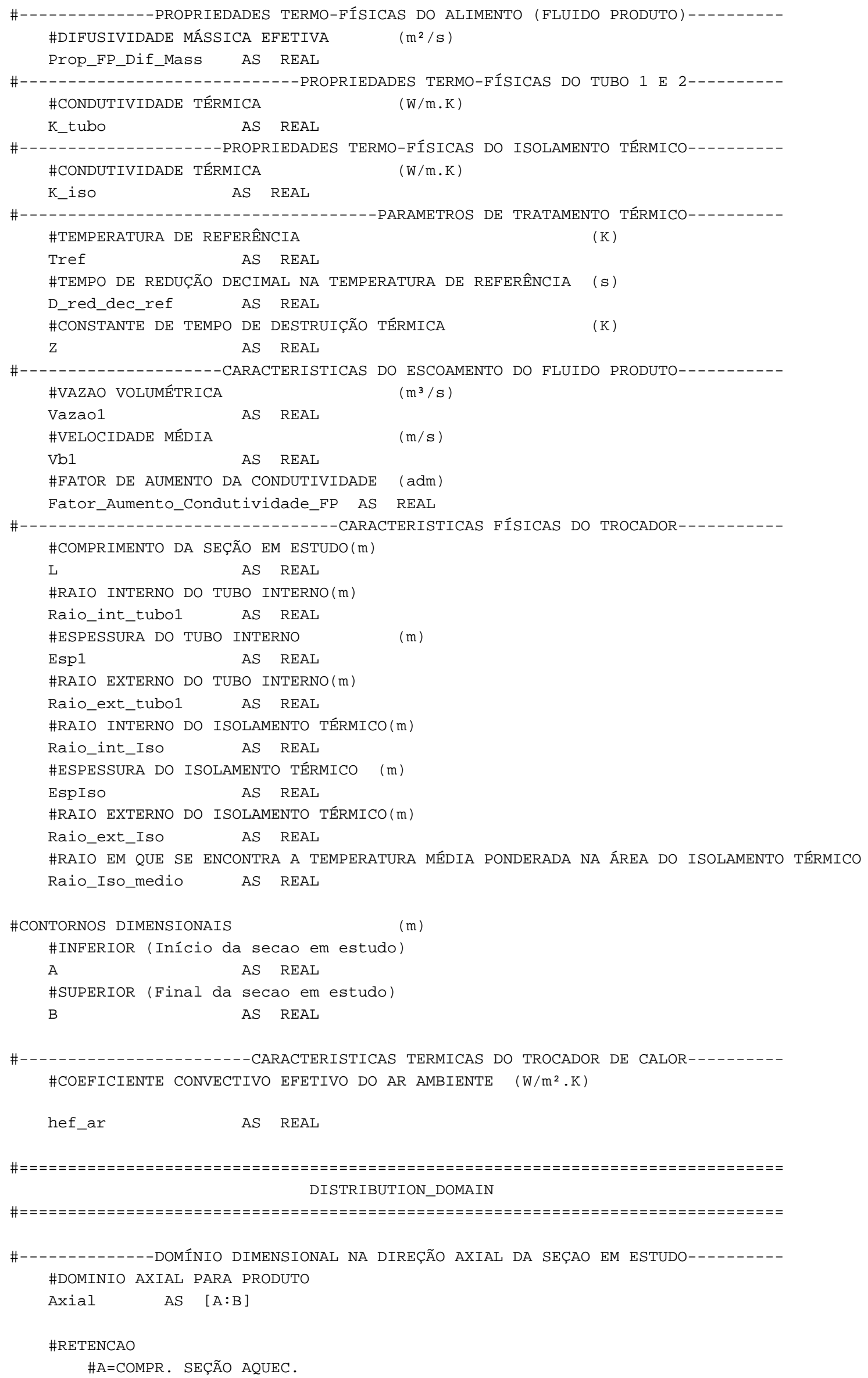


\#B=COMPR. SEÇAO AQUEC. + COMPR. SEÇÃO RETENÇÃO

\#-------------DOMÍNIO DIMENSIONAL NA DIREÇÃO RADIAL DO FLUIDO PRODUTO---------Radial1 AS [0:Raio_int_tubo1]

\#-----DOMÍNIO DIMENSIONAL NA DIREÇÃO RADIAL DA PAREDE DO TUBO INTERNO---------Radialtubo1 AS [Raio_int_tubo1:Raio_ext_tubo1]

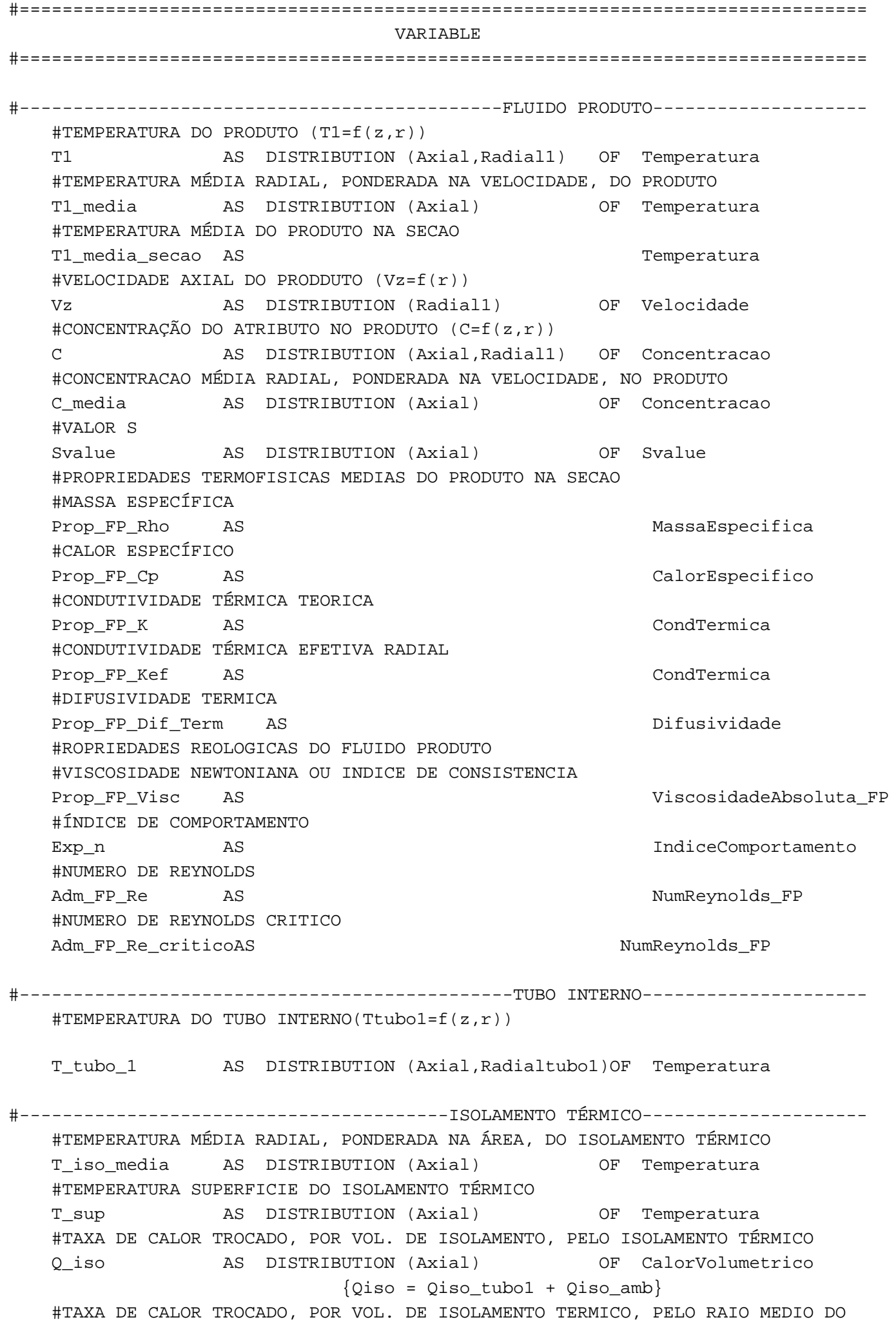


\#ISOLAMENTO TÉRMICO COM A PAREDE EXTERNA DO TUBO INTERNO

Qiso_tubo1 AS DISTRIBUTION (Axial) OF CalorVolumetrico \#TAXA DE CALOR TROCADO, POR VOL. DE ISOLAMENTO TÉRMICO, PELO RAIO MEDIO DO \#ISOLAMENTO E O AMBIENTE

Qiso_amb AS DISTRIBUTION (Axial) OF CalorVolumetrico \#COEF. GLOBAL DE TRANSFERÊNCIA DE CALOR ENTRE O RAIO MEDIO DO ISOLAMENTO \#TÉRMICO COM A PAREDE EXTERNA DO TUBO INTERNO

Uiso_tubo1 AS Coef_Troca_Termica \#COEF. GLOBAL DE TRANSFERÊNCIA DE CALOR ENTRE O RAIO MEDIO DO ISOLAMENTO \#TÉRMCIO E A PAREDE EXTERNA DO ISOLAMENTO TÉRMICO

Uiso_sup AS Coef_Troca_Termica \#COEF. GLOBAL DE TRANSFERÊNCIA DE CALOR ENTRE A PAREDE EXTERNA DO ISOLAMENTO \#TÉRMICO E O AMBIENTE

Usup_amb AS Coef_Troca_Termica

\section{EQUATION}

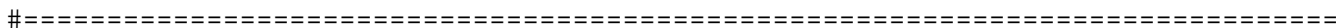

\#Dica de programação: Não colocar as variáveis como denominadores. Deixar todas $\#$ no numerador

\# $\mathrm{x}=$ direção Axial $\quad \mathrm{y}=$ direção radial

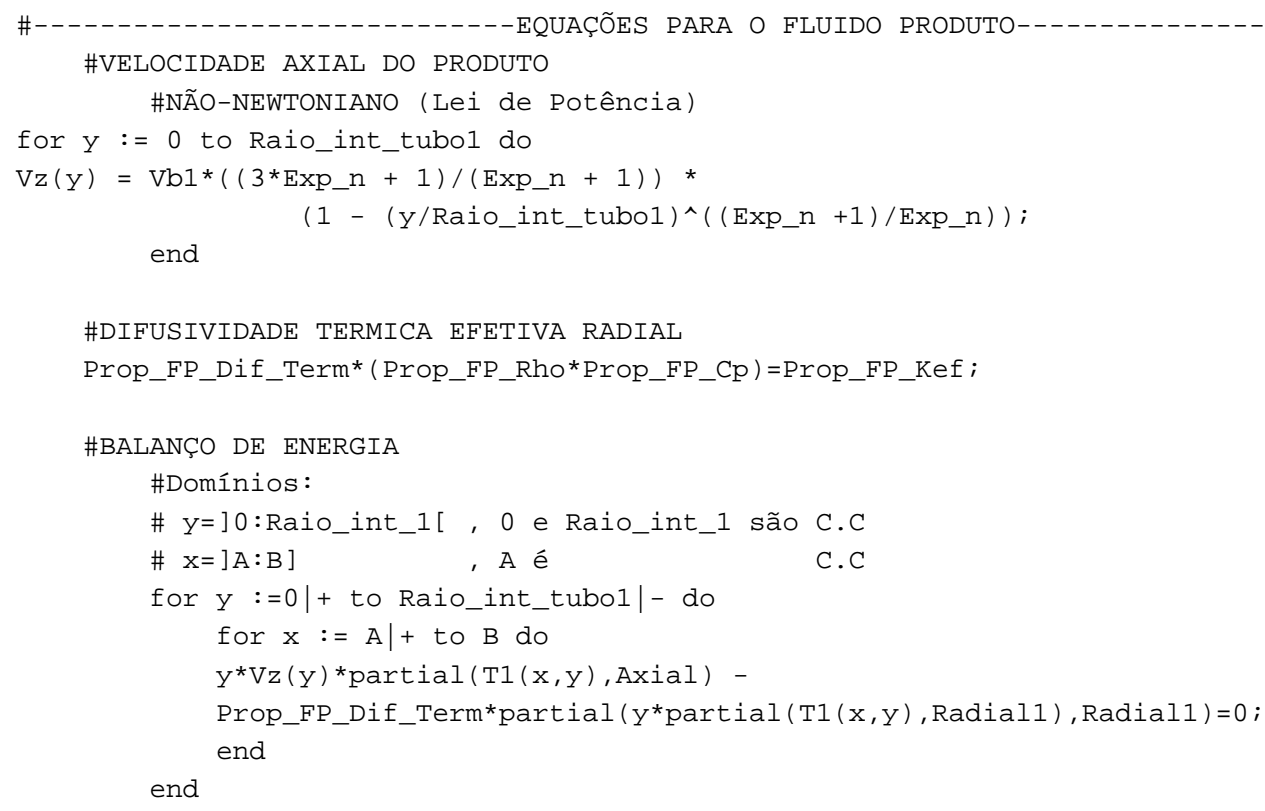

\#TEMPERATURA MEDIA RADIAL DO PRODUTO, PONDERADA NA VELOCIDADE for $x:=A$ to $B$ do $\mathrm{T} 1 \_$media $(\mathrm{x})=$ integral $\left(\mathrm{y}:=0\right.$ :Raio_int_tubo1; $\left.\mathrm{Vz}(\mathrm{y}){ }^{*} \mathrm{~T} 1(\mathrm{x}, \mathrm{y}){ }^{*} 2{ }^{*} \mathrm{y}\right) /$

(Vb1*Raio_int_tubo1^2);

end \#FOR

\#TEMPERATURA MEDIA DO PRODUTO NA SECAO

T1_media_secao $=\left(\mathrm{T} 1 \_\operatorname{media}(\mathrm{A})+\mathrm{T} 1 \_\right.$media $\left.(\mathrm{B})\right) / 2$;

\#BALANÇO MOLAR DO ATRIBUTO

\#Domínios:

\# $y=$ ] 0:Raio_int_1 [ 0 e Raio_int_1 são C.C

\# $\mathrm{x}=] \mathrm{A}: \mathrm{B}] \quad, \mathrm{A}$ é C.C

for $y:=0 \mid+$ to Raio_int_tubol $\mid-$ do

for $x:=A \mid+$ to $B$ do 


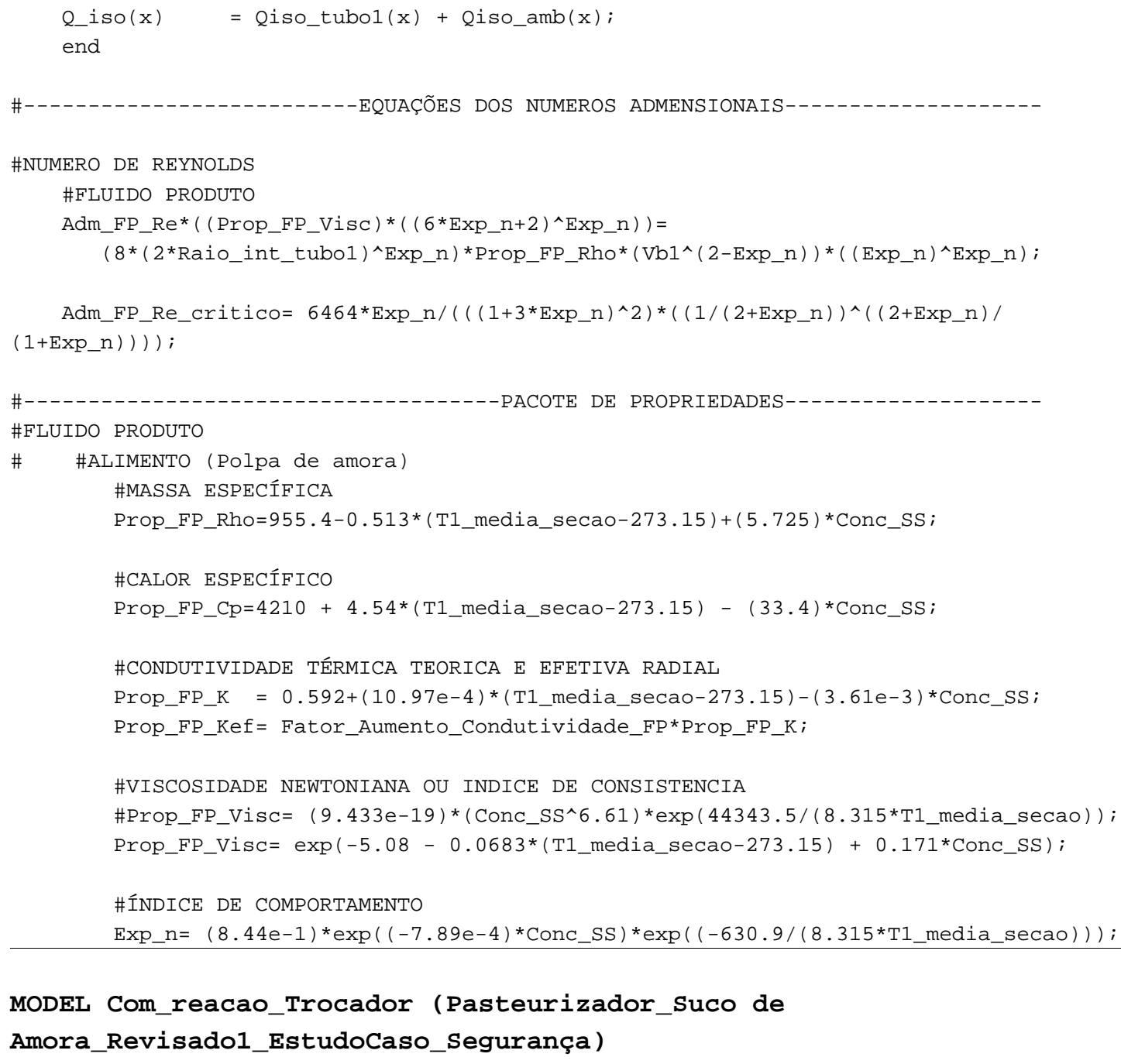




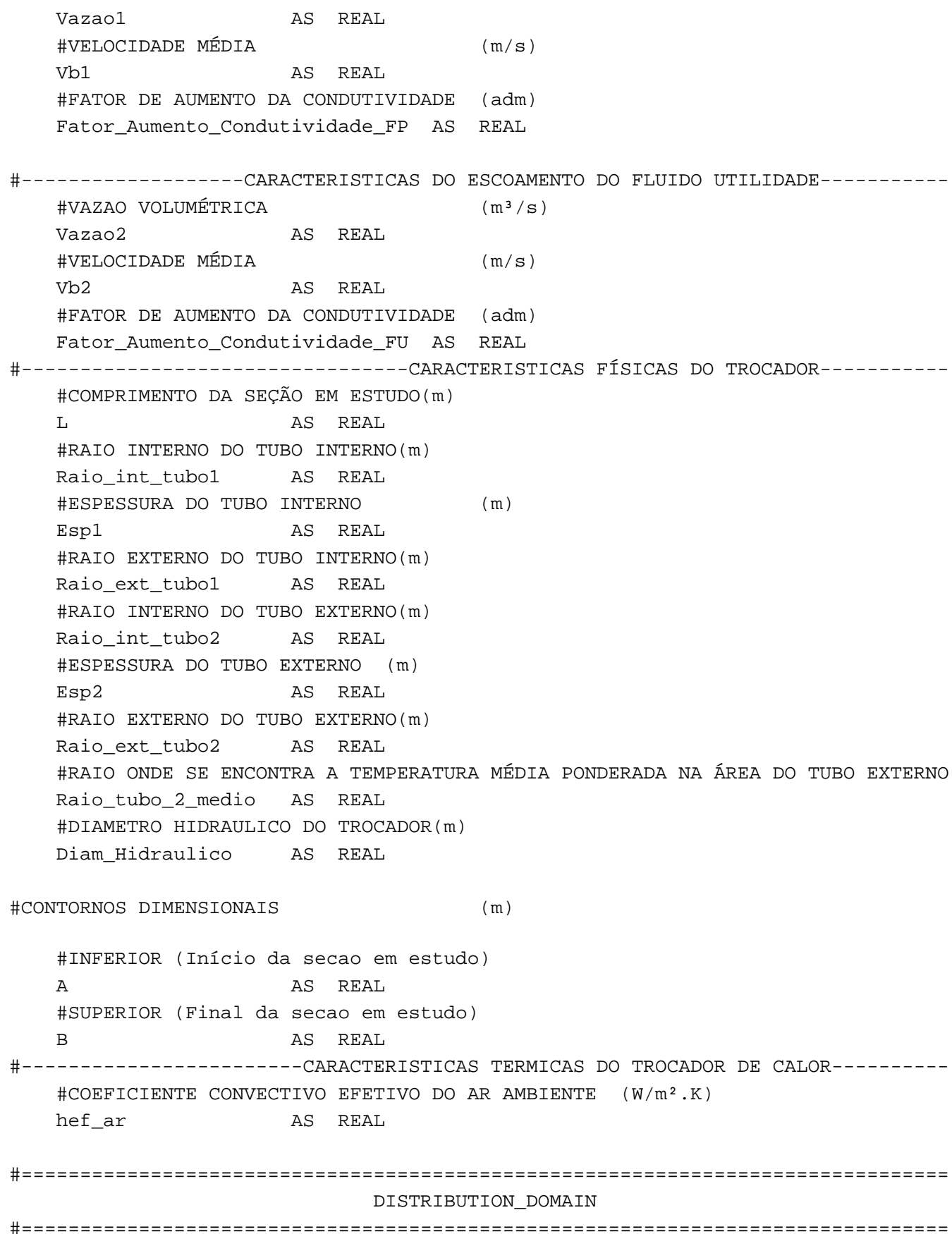

\#------------DOMÍNIO DIMENSIONAL NA DIREÇÃO AXIAL DA SEÇAO EM ESTUDO---------\#DOMINIO AXIAL PARA PRODUTO

Axial AS $[\mathrm{A}: \mathrm{B}]$

\#DOMINIO AXIAL PARA UTILIDADE

Axial2 AS $[\mathrm{A}: \mathrm{B}]$

\#AQUECIMENTO

$\# \mathrm{~A}=0$

\#B=COMPR. SEÇÃO AQUEC.

\#RESFRIAMENTO

\#A=COMPR. SEÇAO AQUEC. + COMPR. SEÇÃO RETENÇÃO

\#B=COMPR. SEÇAO AQUEC. + COMPR. SEÇÃO RETENÇÃO + COMPR. SEÇAO RESFR. 
Radial1 AS [0:Raio_int_tubo1]

\#------DOMÍNIO DIMENSIONAL NA DIREÇÃO RADIAL DA PAREDE DO TUBO INTERNO----------

Radialtubo1 AS [Raio_int_tubo1:Raio_ext_tubo1]

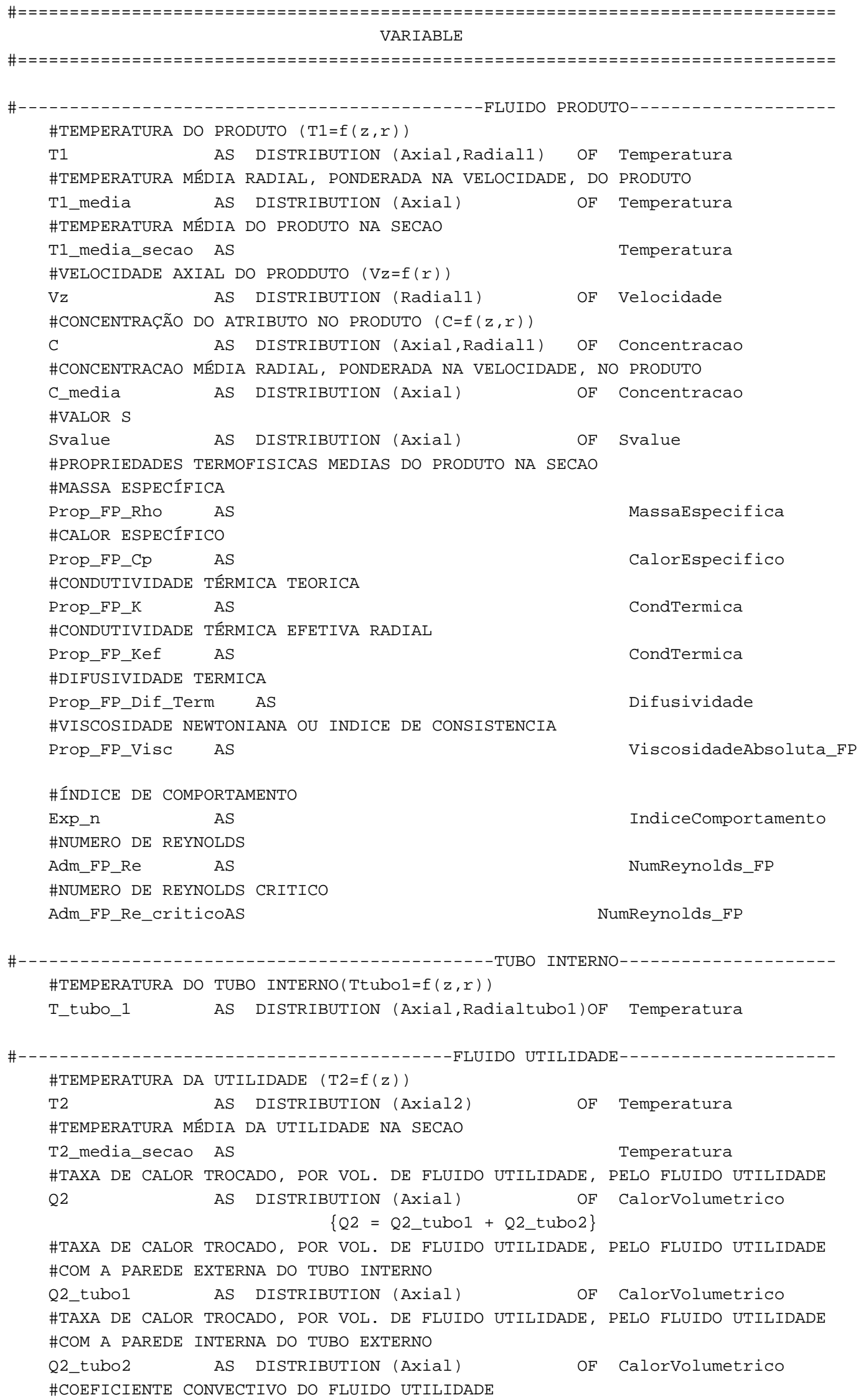


h2 AS

Coef_Troca_Termica

\#COEF. GLOBAL DE TRANSFERÊNCIA DE CALOR ENTRE O FLUIDO UtILIDADE E A \#PAREDE EXTERNA DO TUBO INTERNO
U2_tubo1
AS
Coef_Troca_Termica

\#COEF. GLOBAL DE tRANSFERÊNCIA DE CALOR ENTRE O FLUIDO UtilidAdE E O

\#RAIO MÉDIO DO TUBO EXTERNO

U2_tubo2 AS Coef_Troca_Termica

\#PROPRIEDADES TERMO-FÍSICAS

\#MASSA ESPECÍFICA

Prop_FU_Rho AS MassaEspecifica

\#CALOR ESPECÍFICO

Prop_FU_CP AS CalorEspecifico

\#CONDUTIVIDADE TÉRMICA TEORICA

PrOp_FU_K AS CondTermica

$\begin{array}{llll}\text { \#CONDUTIVIDADE } & \text { TÉRMICA EFETIVA AXIAL } & \\ \text { Prop_FU_Kef } & \text { AS } & \text { CondTermica }\end{array}$

\#VISCOSIDADE

Prop_FU_Visc AS ViscosidadeAbsoluta_FU

\#DIFUSIVIDADE TERMICA EFETIVA

Prop_FU_Dif_Term AS

\#NUMERO DE REYNOLDS

Adm_FU_Re AS

\#NUMERO DE NUSSELT

Adm_FU_Nu AS

Difusividade

NumReynolds_FU

NumNusselt_FU

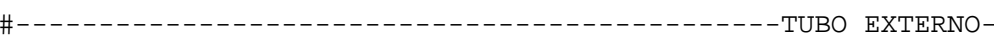

\#TEMPERATURA MÉDIA RADIAL, PONDERADA NA ÁREA, DA PAREDE DO TUBO EXTERNO

T_tubo_2_media AS DISTRIBUTION (Axial) OF Temperatura

\#TEMPERATURA SUPERFICIE DA PAREDE (Tsup=f $(z)$ )

T_sup AS DISTRIBUTION (Axial) OF Temperatura

\#TAXA DE CALOR TROCADO, POR VOL. DE TUBO EXTERNO, PELO TUBO EXTERNO

Qtubo2 AS DISTRIBUTION (Axial) OF CalorVolumetrico

$\{$ Qtubo2 = Qtubo2_2 + Qtubo2_amb $\}$

\#TAXA DE CALOR TROCADO, POR VOL. DE TUBO EXTERNO, PELO RAIO MEDIO DO TUBO \# EXTERNO COM O FLUIDO UTILIDADE

Qtubo2_2 AS DISTRIBUtion (Axial) OF CalorVolumetrico

\#TAXA DE CALOR TROCADO, POR VOL. DE TUBO EXTERNO, PELA PAREDE INTERNA DO \#TUBO EXTERNO COM O AMBIENTE

Qtubo2_amb AS DISTRIBUTION (Axial) OF CalorVolumetrico \#COEF. GLOBAL DE TRANSFERÊNCIA DE CALOR ENTRE O RAIO MEDIO DO TUBO EXTERNO E \#O FLUIDO UTILIDADE

Utubo2_2 AS

Coef_Troca_Termica

\#COEF. GLOBAL DE TRANSFERÊNCIA DE CALOR ENTRE O RAIO MEDIO DO TUBO EXTERNO E \#A SUPERFÍCIE DO TUBO EXTERNO

Utubo2_sup AS Coef_Troca_Termica

\#COEF. GLOBAL DE tRANSFERÊNCIA DE CALOR ENTRE A SUPERFICIE DO tUBO EXTERNO E \#O AMBIENTE

Usup_amb AS Coef_Troca_Termica

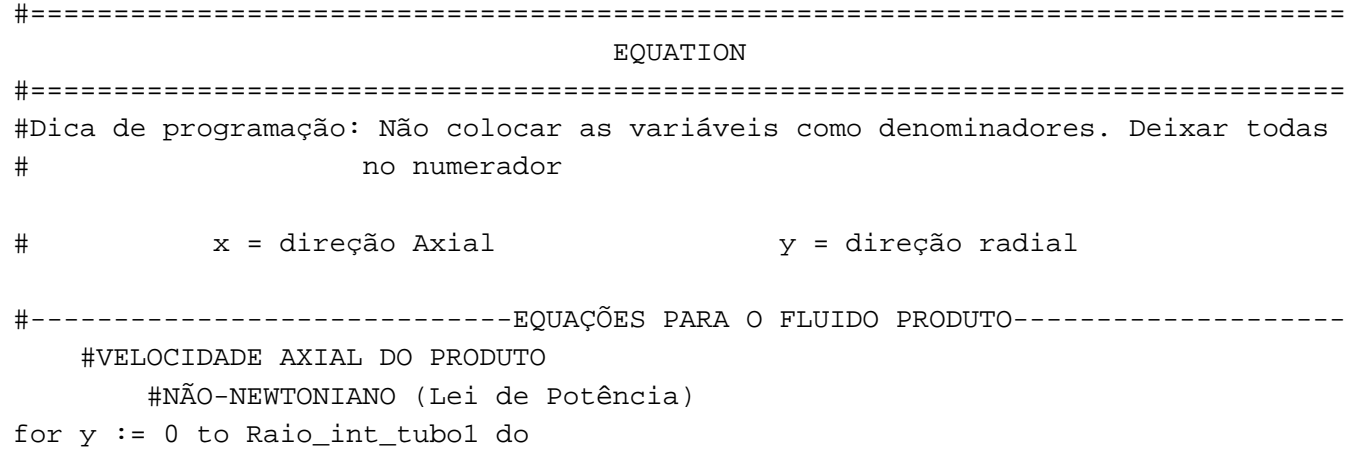




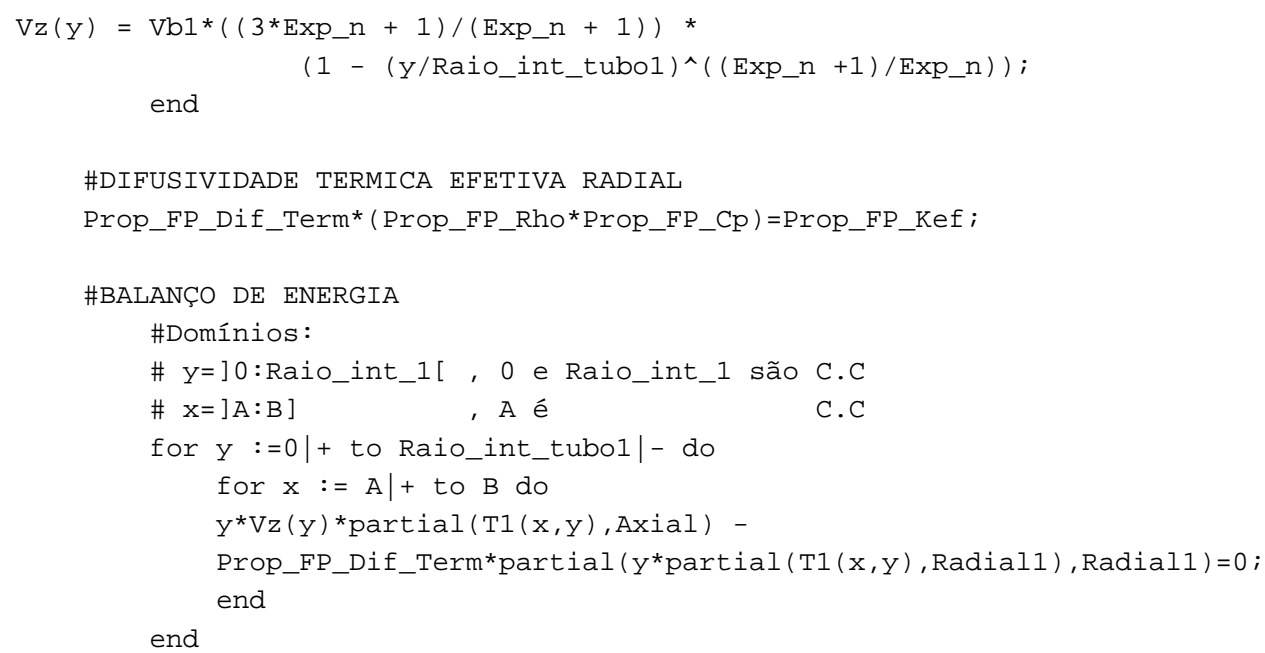

\#TEMPERATURA MEDIA RADIAL DO PRODUTO, PONDERADA NA VELOCIDADE for $x:=A$ to $B$ do

T1_media $(\mathrm{x})=$ integral $(\mathrm{y}:=0$ : Raio_int_tubo1; $\mathrm{Vz}(\mathrm{y}) * \mathrm{~T} 1(\mathrm{x}, \mathrm{y}) * 2 * \mathrm{y}) /$ (Vb1*Raio int_tubo1^2);

end \#FOR

\#TEMPERATURA MEDIA DO PRODUTO NA SECAO

T1_media_secao $=\left(\mathrm{T} 1 \_\right.$media $(\mathrm{A})+\mathrm{T} 1 \_$media $\left.(\mathrm{B})\right) / 2$;

\#BALANÇO MOLAR DO ATRIBUTO

\#Domínios:

\# y=]0:Raio_int_1[ , 0 e Raio_int_1 são C.C

$\# \mathrm{x}=\mathrm{A}: \mathrm{B}] \quad$ A é C.C

for $y:=0 \mid+$ to Raio_int_tubol $\mid$ - do

for $x:=A \mid+$ to $B$ do

$((\mathrm{y} * \mathrm{Vz}(\mathrm{y}) * \operatorname{partial}(\mathrm{C}(\mathrm{x}, \mathrm{y}), \operatorname{Axial}))) *\left(1 /\left(\mathrm{C} \_\right.\right.$media $\left.\left.(\mathrm{A}) * 1 \mathrm{e} 2\right)\right)-$

(Prop_FP_Dif_Mass*partial (y*partial (C (x,y), Radial1), Radial1))*(1/ (C_media (A)

$\star(e 2))+$

$\left(\mathrm{y} * \operatorname{LOG}(10) *(\mathrm{C}(\mathrm{x}, \mathrm{y})) /\left(\left(\mathrm{D} \_\right.\right.\right.$red_dec_ref $\left.\left.) * 10^{\wedge}((\operatorname{Tref}-\mathrm{T} 1(\mathrm{x}, \mathrm{y})) / \mathrm{Z})\right)\right) *\left(1 /\left(\mathrm{C} \_\right.\right.$media $(\mathrm{A})$

$\star(e 2))=0$;

end

end

\#VALOR $S$

for $x:=A$ to $B$ do

\#Svalue $(x)=\log 10\left(\mathrm{Cin} / \mathrm{C} \_\right.$media $\left.(\mathrm{x})\right)$;

$10^{\wedge}(\operatorname{Svalue}(\mathrm{x}) / 10)=10^{\wedge}(($ LOG10 (Cin/ (C_media $\left.\left.(\mathrm{x})))\right) / 10\right)$;

end

\#CONCENTRAÇÃO MEDIA RADIAL DO ATRIBUTO, PONDERADA NA VELOCIDADE, DO FLUIDO

for $x:=A$ to $B$ do

C_media $(\mathrm{x}) \quad=$ integral $\left(\mathrm{y}:=0\right.$ :Raio_int_tubol; $\left.\mathrm{Vz}(\mathrm{y}){ }^{*} \mathrm{C}(\mathrm{x}, \mathrm{y}){ }^{*} 2{ }^{*} \mathrm{y}\right) /$

$(\mathrm{Vb} 1 *$ Raio_int_tubo1^2);

end \#FOR

\#BALANÇO DE ENERGIA

\#Domínios:

\# y=]Raio_int_1:Raio_ext_1[ , Raio_int_1 e Raio_ext_1 são C.C

$\# \mathrm{x}=\mathrm{A}: \mathrm{B}[\mathrm{A}$ e $\mathrm{B}$ são $\mathrm{C} . \mathrm{C}$

for y :=Raio_int_tubol|+ to Raio_ext_tubol $\mid$ - do

for $x:=A \mid+$ to $B \mid-$ do

K_tubo*( (partial (y*partial (T_tubo_1 (x,y), Radialtubo1), Radialtubo1)) + 


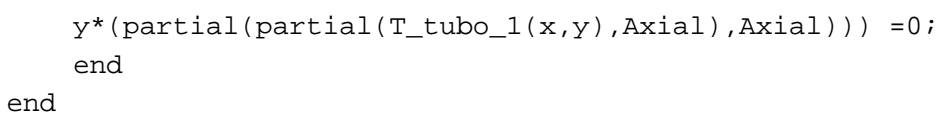




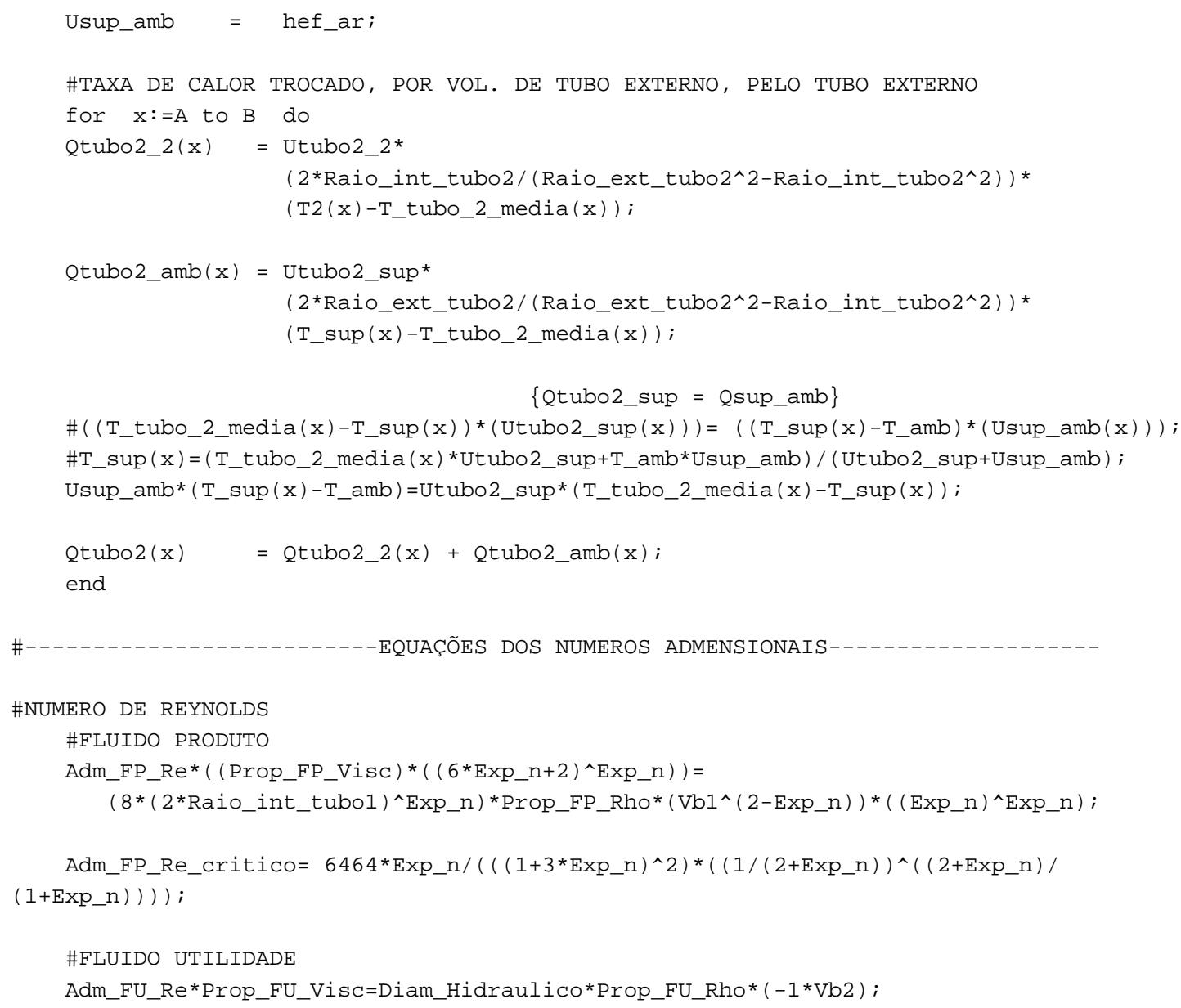

\#NUMERO DE NUSSELT (EQ. DE COLBURN)

\#FLUIDO UTILIDADE

Adm_FU_Nu* $($ Prop_FU_Visc^(4/5)) * (Prop_FU_K^ $(1 / 3))=$

$0.023 *\left((\text { Diam_Hidraulico*Prop_FU_Rho* }(\operatorname{abs}(\mathrm{Vb} 2)))^{\wedge}(4 / 5)\right) *\left((\text { Prop_FU_Cp*Prop_FU_Visc })^{\wedge}\right.$

$(1 / 3)) ;$

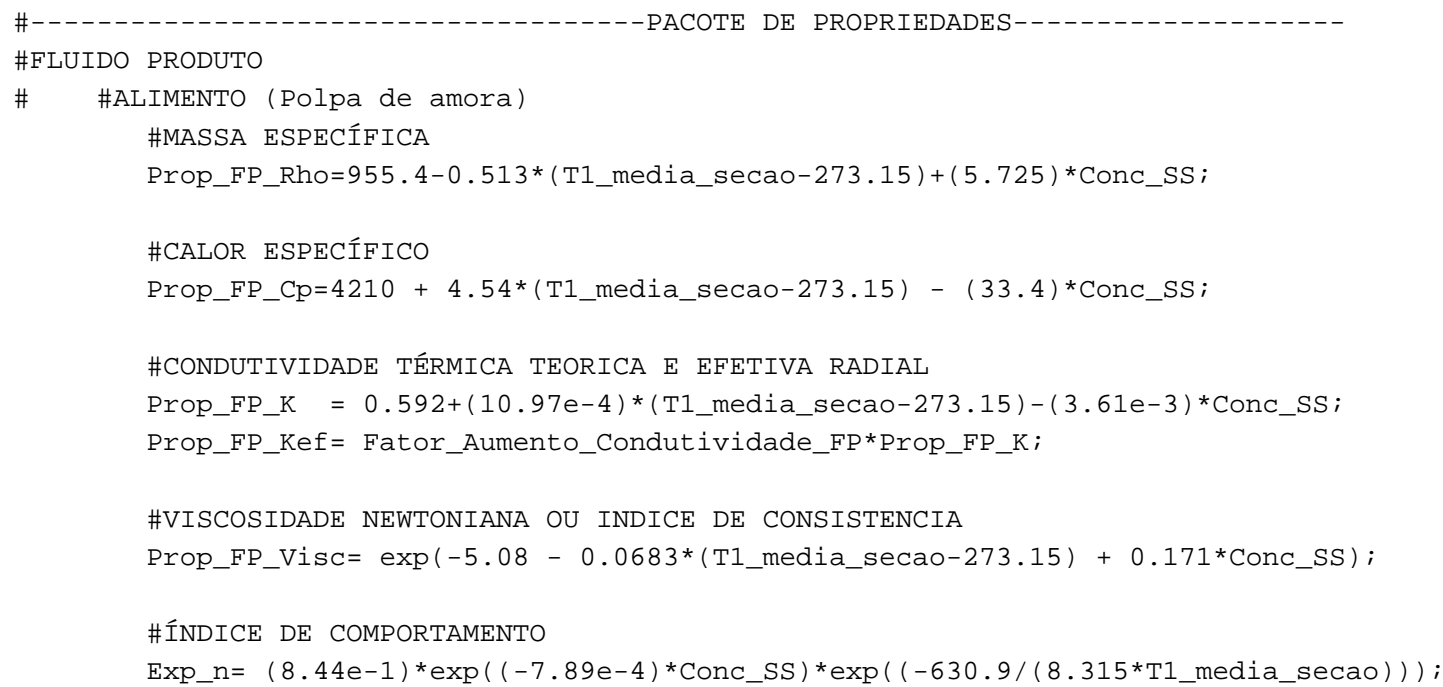


\#MASSA ESPECÍFICA

Prop_FU_Rho $=9.9718 \mathrm{e} 2+(3.1439 \mathrm{e}-3) *($ T2_media_secao-273.15) $-(3.7574 \mathrm{e}-3)$ * ( (T2_media_secao-273.15)^2);

\#CALOR ESPECÍFICO

Prop_FU_Cp $=4176.2-9.0864 \mathrm{e}-2 *\left(\mathrm{~T} 2 \_\right.$media_secao-273.15) + 5.4731e-3* ( T2_media_secao$273.15)^{\wedge} 2$ );

\#CONDUTIVIDADE TÉRMICA TEORICA E EFETIVA AXIAL

Prop_FU_K=5.71e-1 $+1.76 \mathrm{e}-3 *\left(\mathrm{~T} 2 \_\right.$media_secao-273.15) - 6.70e-6*((T2_media_secao$273.15)^{\wedge} 2$ );

Prop_FU_Kef=Fator_Aumento_Condutividade_FU*Prop_FU_K;

\#VISCOSIDADE ABSOLUTA

Prop_FU_Visc $=1 /((21.482 *((($ T2_media_secao-273.15) -8.435$)+((8078.4+$ $(($ T2_media_secao-273.15) -8.435$) \wedge 2) \wedge 0.5)))-1200)$;

PROCESS Simul_EstudoCaso_Real (Pasteurizador_Suco de Amora_Revisado1_EstudoCaso_Segurança)

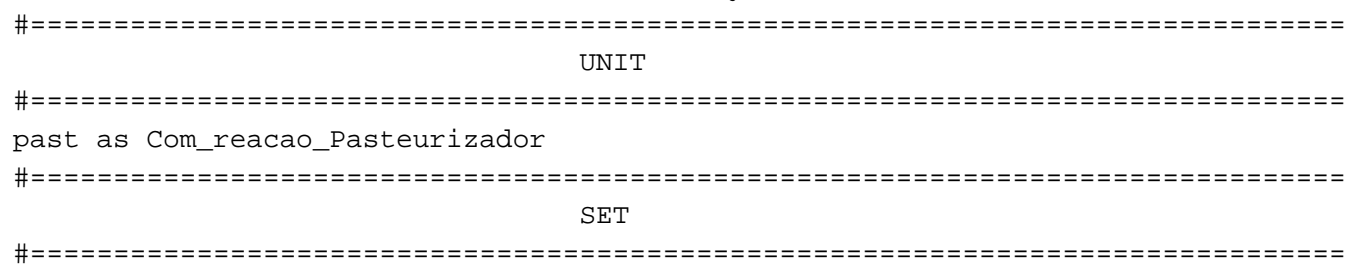$$
\#-
$$
VALORES DOS PARAMETROS GERAIS DO PASTEURIZADOR-

within past do

\#TEMPERATURA DE ENTRADA DO FLUIDO PRODUTO

Tin $\quad\{\mathrm{K}\} \quad:=273.15+18$;

\#TEMPERATURA DE ENTRADA DO FLUIDO UTILIDADE NA SEÇÃO DE AQUECIMENTO

T2in_aq $\quad\{\mathrm{K}\} \quad:=273.15+88$;

\#TEMPERATURA DE ENTRADA DO FLUIDO UTILIDADE NA SEÇÃO DE RESFRIAMENTO

T2in_resf $\{\mathrm{K}\} \quad:=273.15+8$;

\# temperatura do AMBiente

T_amb $\quad:=273.15+18$;

\#CONCENTRAÇÃO DE ENTRADA DO COMPONENTE 'a'

Cin := 1e38;

\#NÚMERO PI

PI $\quad:=3.141592654$;

\#NUMERO DE SECOES NO AQUECIMENTO

n_secoes_aq : =6;

\#NUMERO DE SECOES NA RETENCAO

n_secoes_ret $:=3$;

\#NUMERO DE SECOES NO RESFRIAMENTO

n_secoes_resf: $=5$;

end \#WITHIN

\#------------VALORES DOS PARAMETROS DA SECAO DE AQUEC. DO PASTEURIZADOR--------

for sec:=1 to past.n_secoes_aq do

within past.aq (sec) do

\# temperatura do AMBIEnte

T_amb $\{\mathrm{K}\} \quad:=$ past.T_amb;

\#CONCENTRAÇÃO DE ENTRADA DO ATRIBUTO

Cin := past.Cin;

\#--->CONCENTRACAO DE SOLIDOS SOLUVEIS

CONC_SS $\quad:=40.2$;

\#DIFUSIVIDADE MÁSSICA EFETIVA

Prop_FP_Dif_Mass := 1e-5;

\#--->PROPRIEDADES TERMO-FÍSICAS DO TUBO 1 E 2 (AçO 304-18/8)

\#CONDUTIVIDADE TÉRMICA 


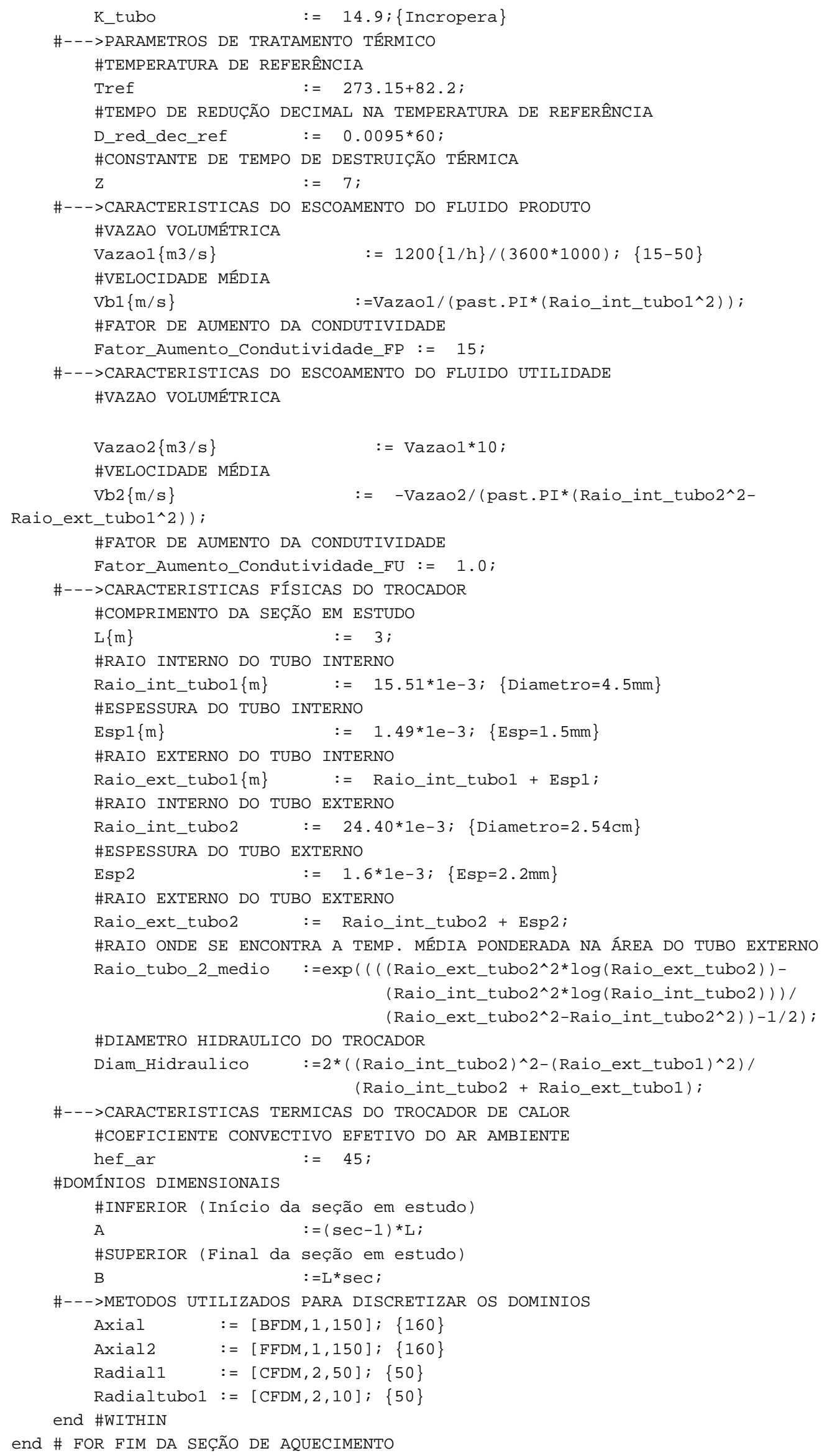




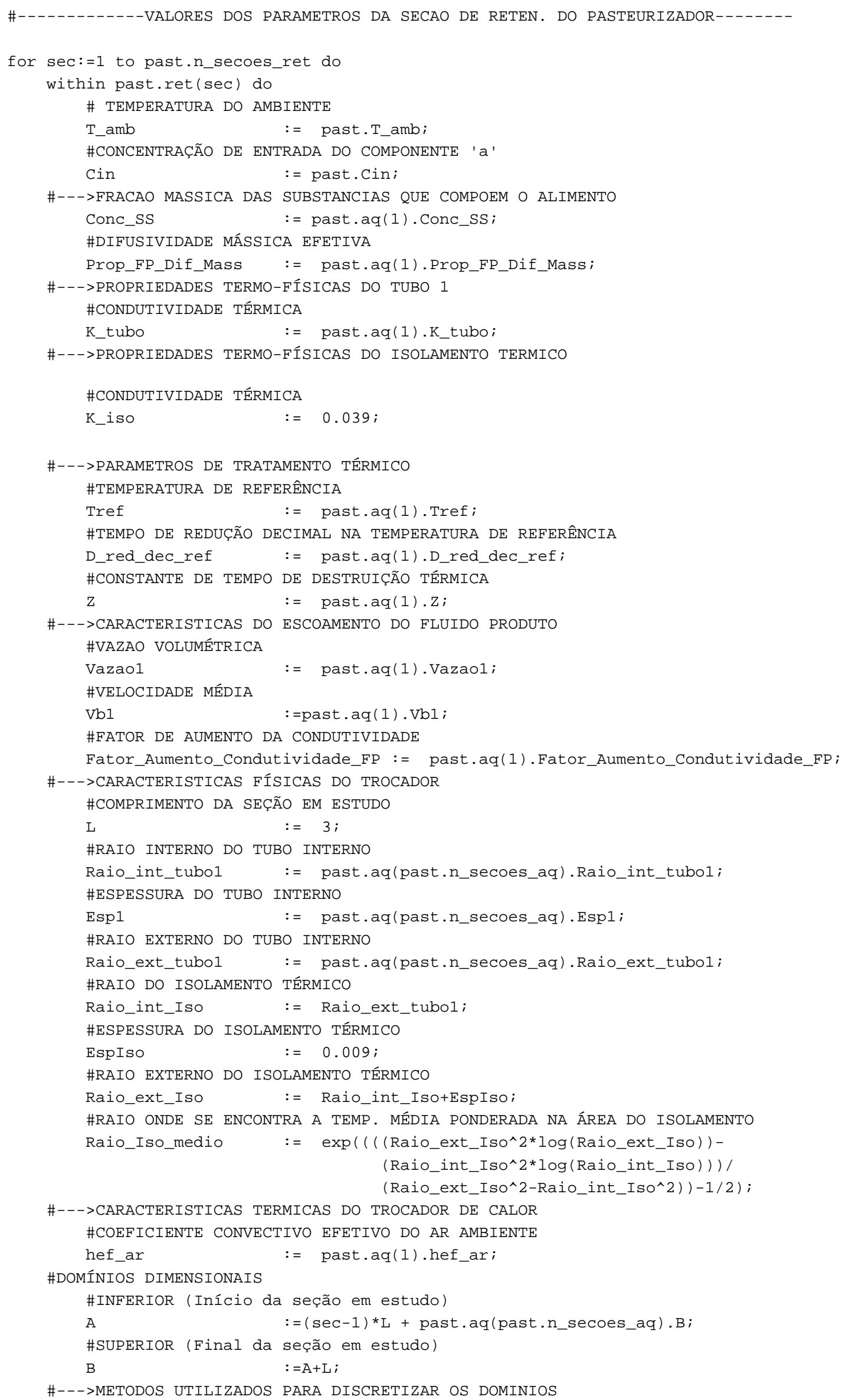



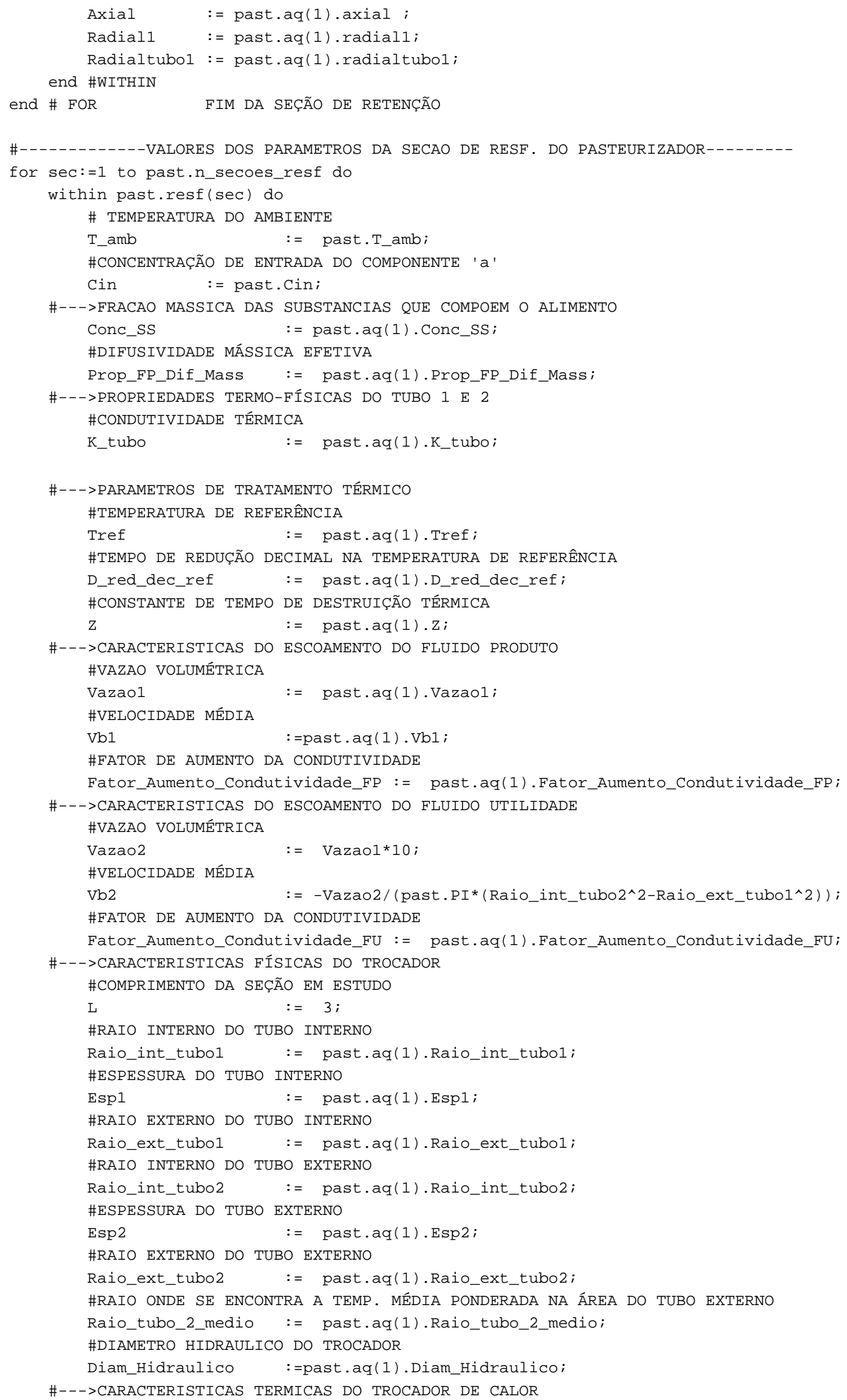
\#COEFICIENTE CONVECTIVO EFETIVO DO AR AMBIENTE (Levando-se em conta a radiação e conveç̧ão natural)

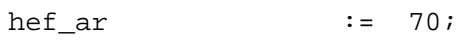

\#DOMÍNIOS DIMENSIONAIS

\#INFERIOR (Início da seção em estudo)

A $\quad:=(\sec -1) \star L+$ past.ret (past.n_secoes_ret).B;

\#SUPERIOR (Final da seção em estudo)

$\mathrm{B} \quad:=\mathrm{A}+\mathrm{L}$;

\#--->METODOS UTILIZADOS PARA DISCRETIZAR OS DOMINIOS

Axial := past.aq (1).axial ;

Axial2 := past.aq(1).axial2 ;

Radial1 := past.aq(1).radial1;

Radialtubo1 := past.aq(1).radialtubo1;

end \#WITHIN

end \# FOR FIM DA SEÇÃO DE RESFRIAMENTO

INITIAL

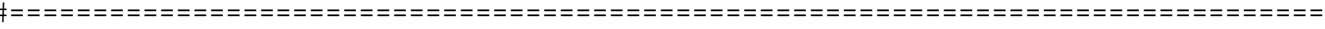

STEADY_STATE 